\title{
ÉTICA Y CALIDAD EN LA EDUCACIÓN VIRTUAL
}
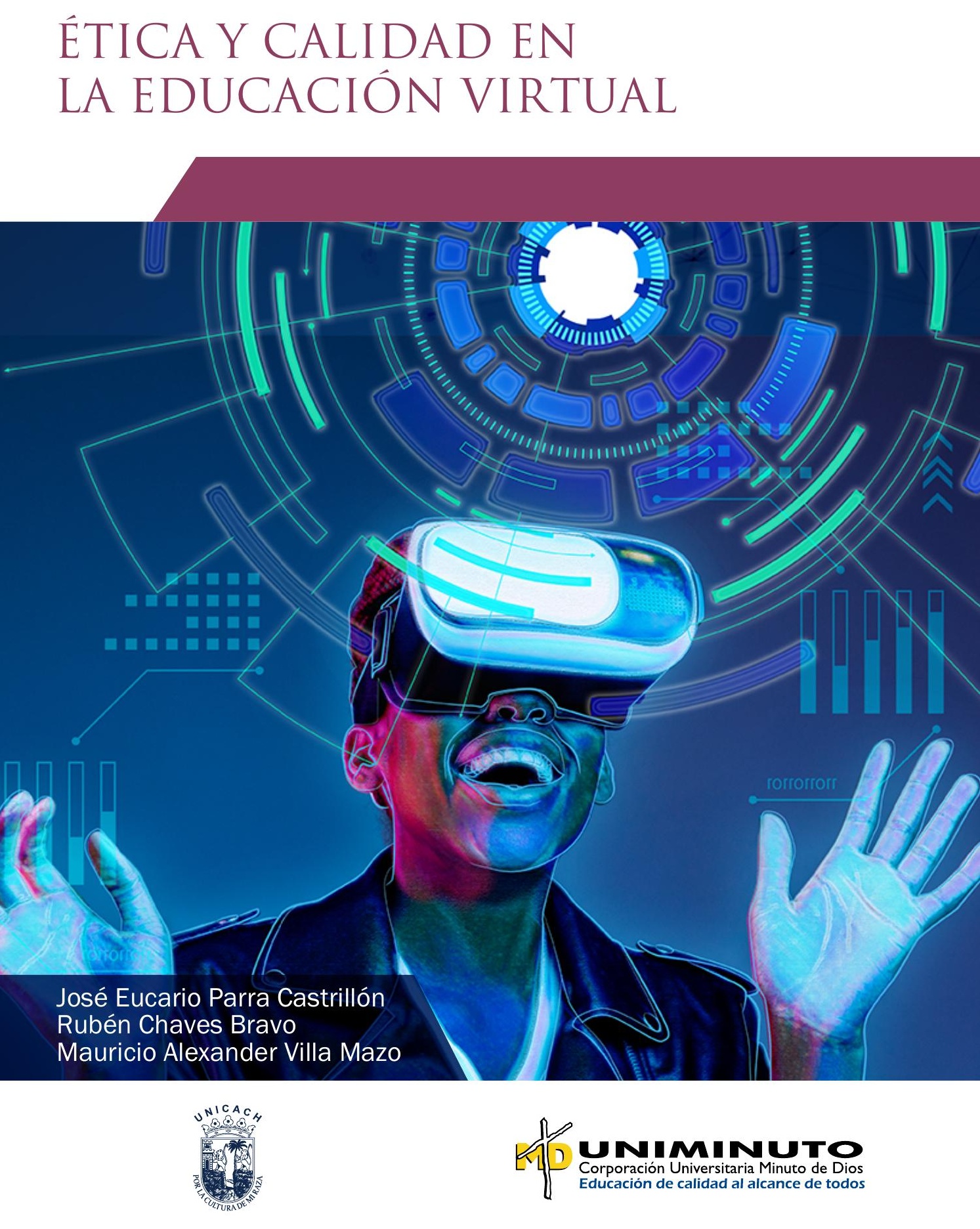



\section{ÉTICA Y CALIDAD EN LA EDUCACIÓN VIRTUAL}




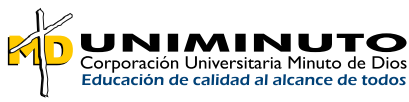

Corporación Universitaria Minuto de Dios UNIMINUTO

Presidente Consejo de Fundadores

P. Diego Jaramillo Cuartas, CJM

Rector General Corporación Universitaria

Minuto de Dios - UNIMINUTO

P. Harold Castilla Devoz, CJM

\section{Vicerrectora General Académica}

Stéphanie Lavaux

Rector Seccional Antioquia - Chocó

P. Huberto Obando Gil, CJM

Vicerrector Académico Seccional Antioquia - Chocó Jorge Arbey Toro Ocampo

Director General de Investigaciones

Julio Mario Rodríguez Devis

Subdirectora del Centro Editorial

Rocío del Pilar Montoya Chacón

Directora de Investigación Seccional Antioquia - Chocó

Elizabeth Meneses Ospina

Decano de la Facultad de Ciencias Económicas y

Administrativas Seccional Antioquia - Chocó

Francisco Javier Echeverry Correa

Líder de Investigación de la Facultad de

Ciencias Económicas y Administrativas

Seccional Antioquia - Chocó

Laura Altamiranda Echeverri

Analista de Publicaciones y Divulgación Científica Seccional Antioquia - Chocó

Diana Sofía Villa Múnera

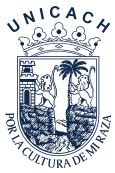

Universidad de Ciencias y Artes de Chiapas

Rector

Dr. José Rodolfo Calvo Fonseca

Secretario General

Mtro. Rafael Domínguez Salazar

Secretario Académico

Dr. Ricardo David Estrada Soto

Abogada General

Lic. Belén Alejandra Palacios Cabrera

Director General de Extensión Universitaria

Lic. Jesús Adrián Toledo Vázquez 


\section{ÉTICA Y CALIDAD EN LA EDUCACIÓN VIRTUAL}


Parra Castrillón, José Eucario

Ética y calidad en la educación virtual / José Eucario Parra Castrillón, Rubén Chaves Bravo, Mauricio Alexander Villa Mazo. Bogotá: Corporación Universitaria Minuto de Dios. UNIMINUTO; México: Universidad de Ciencias y Artes de Chiapas, 2020.

ISBN: 978-958-763-440-2 (Colombia)

ISBN: 978-607-543-123-9 (México)

190p.: il; Colección de investigación

1.Enseñanza con ayuda de computadores -- Investigaciones 2.Pedagogía -- Estudios de casos 3.Conducta(Ética) 4. Tecnología educativa 5.Educación virtual 6.Calidad en la educación i.Chaves Bravo, Rubén ii.Villa Mazo, Mauricio Alexander

CDD: 371.334 P17e BRGH

Registro Catálogo Uniminuto Nº. 100394

Archivo descargable en MARC a través del link: https://tinyurl.com/bib100394

Título:

\section{ÉTICA Y CALIDAD EN LA EDUCACIÓN VIRTUAL}

\section{Autores:}

José Eucario Parra Castrillón

Rubén Chaves Bravo

Mauricio Alexander Villa Mazo

\section{Diseño y diagramación:}

Andrea Sarmiento B.

\section{Corrección de estilo:}

Karen Grisales Velosa

\section{Primera edición:}

noviembre de 2020

Libro digital

ISBN: 978-958-763-440-2 (Colombia)

ISBN: 978-607-543-123-9 (México)

(C) Corporación Universitaria Minuto de Dios - UNIMINUTO

Calle 90 NN$^{\circ} .87-69$

Bogotá D.C. - Colombia

2020

(C) Universidad de Ciencias y Artes de Chiapas

1a Avenida Sur Poniente $N^{\circ} .1460$

Tuxtla Gutiérrez, Chiapas, México

2020

Esta publicación es resultado del proyecto de investigación "Percepciones sobre la ética y la calidad de la educación virtual”, financiado por la VII Convocatoria General de Fortalecimiento a Grupos de Investigación de la Corporación Universitaria Minuto de Dios - UNIMINUTO, con código C117-20-201.

Este libro está protegido por el Registro de Propiedad Intelectual. Se autoriza su reproducción parcial en cualquier formato, incluido el electrónico, con la condición de que se cite la fuente de forma clara y completa, siempre y cuando las copias no sean usadas para fines comerciales. Los textos son responsabilidad del autor y no comprometen la opinión de UNIMINUTO. 


\section{CONTENIDO}

$\begin{array}{ll}\text { AUTORES } & 9\end{array}$

PRÓLOGO 11

$\begin{array}{lr}\text { PRESENTACIÓN } & 17\end{array}$

CAPÍTULO I.

ANTECEDENTES Y TENDENCIAS TECNOPEDAGÓGICAS

DE LA EDUCACIÓN VIRTUAL

$\begin{array}{ll}\text { Desarrollo de la educación virtual } & 19\end{array}$

Entornos y participación en la educación virtual 26

Entornos virtuales de aprendizaje $\quad 26$

Ambientes personales de aprendizaje (PLE) 29

Aprendizaje en redes sociales y en dispositivos móviles $\quad 32$

$\begin{array}{ll}\text { Cursos virtuales masivos } & 34\end{array}$

Pedagogía para la educación virtual 36

Calidad de la educación virtual 46

\section{CAPÍTULO II.}

CALIDAD Y ÉTICA EN LA MODALIDAD DE EDUCACIÓN VIRTUAL 59

Ética y ética digital $\quad 59$

$\begin{array}{ll}\text { Escepticismo por la calidad } & 62\end{array}$

Investigación sobre calidad y ética en

$\begin{array}{ll}\text { la educación virtual } & 68\end{array}$

Informantes e instrumentos en el enfoque cualitativo 75

Estratificación y variables en el enfoque cuantitativo 78

Hallazgos en el abordaje cualitativo $\quad 81$

Hallazgos en el abordaje cuantitativo 108

Análisis convergente final del estudio mixto 119 
CAPÍTULO III.

CÓDIGO DE ÉTICA PARA LA EDUCACIÓN VIRTUAL 125

Responsabilidad y libertad $\quad 125$

Referentes sobre códigos de ética 128

Constitución de un código de ética

para la educación virtual

135

Perspectivas de los involucrados $\quad 137$

\section{CAPÍTULO IV.}

EDUCACIÓN VIRTUAL EN LA CRISIS DE LA COVID-19 147

Marco situacional 148

La educación virtual obligada $\quad 154$

Las brechas entre niveles educativos $\quad 154$

Los profesores fueron los héroes $\quad 158$

Dudas sobre ética y calidad de la educación virtual $\quad 161$

Desconexión con la comunidad escolar $\quad 165$

Efectos en la educación superior $\quad 167$

$\begin{array}{ll}\text { Lecciones aprendidas } & 170\end{array}$

REFERENCIAS BIBLIOGRÁFICAS 173 


\section{LISTA DE TABLAS}

Tabla 1. Datos sobre crecimiento de programas virtuales en Colombia

Tabla 2. Modelos y dimensiones de la educación virtual 46

Tabla 3. Dimensiones del estándar 66181

Tabla 4. Indagaciones del componente cuantitativo del proyecto 72

Tabla 5. Estratificación y variables en el enfoque cuantitativo 80

Tabla 6. Percepciones sobre características de calidad 99

Tabla 7. Propuestas para reducir el riesgo de fraude en la educación virtual 102

Tabla 8. Propuestas para reducir el riesgo de fraude (b) 105

Tabla 9. Percepciones sobre perfiles del profesor 106

Tabla 10. Indagaciones y estratos de las encuestas 108

Tabla 11. Datos obtenidos sobre ética y calidad de la educación virtual (a) 110

Tabla 12. Datos obtenidos sobre ética y calidad de la educación virtual (b)

Tabla 13. Datos obtenidos sobre ética y calidad de la educación virtual (c)

Tabla 14. Datos obtenidos sobre ética y calidad de la educación virtual (d)

Tabla 15. Referentes teóricos sobre educación virtual 148

Tabla 16. Impactos en la educación superior 168 


\section{LISTA DE FIGURAS}

Figura 1. Dispersión de los programas virtuales con respecto al total de programas 21

Figura 2. El desarrollo de la educación virtual 34

Figura 3. El modelo MESOVA 53

Figura 4. El diseño mixto convergente 72

Figura 5. Estructura del código de ética

136

Figura 6. Ruta metodológica para el código de ética

144 


\section{AUTORES}

\section{José Eucario Parra Castrillón}

Licenciado en Matemáticas, magíster en Educación.

Ha sido directivo, docente e investigador de la educación superior desde 1992. Experto en temas de educación virtual y tecnologías para la educación.

Actualmente es profesor de posgrados de la Corporación Universitaria Minuto de Dios - UNIMINUTO, seccional Antioquia-Chocó.

Correo electrónico: jparracast3@uniminuto.edu.co

\section{Rubén Chaves Bravo}

Ingeniero Industrial, magíster en Gerencia de Proyectos.

Ha sido directivo, docente e investigador de la educación superior en instituciones de los departamentos de Nariño y Antioquia.

Actualmente es docente de la Corporación Universitaria Minuto de Dios - UNIMINUTO, seccional Antioquia-Chocó.

Correo electrónico: rchavesbrav@uniminuto.edu.co

\section{Mauricio Alexander Villa Mazo}

Economista, magíster en Gobierno.

Tiene amplia experiencia en temas de política pública y asuntos relacionados con proyectos sociales.

Docente de la Corporación Universitaria Minuto de Dios - UNIMINUTO, seccional Antioquia-Chocó.

Correo electrónico: mvillama@uniminuto.edu.co 



\section{PRÓLOGO}

El libro intitulado Ética y calidad en la educación virtual, de la autoría de los maestros José Eucario Parra Castrillón, Rubén Chaves Bravo y Mauricio Alexander Villa Mazo, se inscribe en el marco de reflexión de los estudios sobre educación virtual y ética en la educación. Se trata de una línea de indagación que hoy en día, ante la pandemia de la COVID-19, cobra particular interés entre diversos sectores académicos del continente.

El volumen es producto de una investigación cualitativa y cuantitativa, que ha tenido como propósito el estudio de las características y formas de expresión de la calidad y los comportamientos éticos en la educación virtual en los niveles de educación superior y posgrado.

En su escrito, los autores enfatizan en los desafíos e innovaciones que presenta la educación virtual actual, a partir de las posibilidades que las nuevas pedagogías ofrecen para entender y desarrollar el aprendizaje ubicuo. En ello la calidad, la eficiencia y la eficacia de la educación virtual o a distancia son una pieza clave para promover la apertura, la inclusión y el aprendizaje activo. Para el caso de Colombia y otros países del continente con economías deprimidas y alta dependencia tecnológica, la promoción de servicios de educación virtual abre una enorme posibilidad para incentivar el crecimiento de las naciones y los niveles de escolarización de las poblaciones, muchas de ellas, sumidas en la pobreza.

Pensamos que muchas de las brechas educativas podrán ser superadas, a través de los sistemas de educación a distancia y la democratización del internet, esto será posible con el acceso masivo a los dispositivos móviles (smartphone) y con la ampliación del acceso al internet, lo que incluye su acceso gratuito e igualitario. En la medida en la que los estados nacionales se comprometan con un acceso equitativo a los dispositivos y al internet, las economías emergentes del mundo podrán encontrar causes para su desarrollo y crecimiento sostenible.

En este libro se plantea también, una profunda reflexión respecto a los desafíos y los retos formativos en la educación virtual, se proponen líneas de 
discusión asociadas a su calidad, lo que implica no solo la valoración de los objetos y medios de aprendizaje virtual, sino también el análisis profundo de los contextos educativos actuales de nuestros países iberoamericanos.

En este línea, el volumen abona también a la discusión sobre la ética digital en la educación virtual, los autores señalan que: "la ética digital es una habilidad del siglo XXI, junto con la meta cognición, la adaptabilidad, la contemplación creadora y la capacidad de resolver problemas complejos y emprender acciones no rutinarias". Los autores apuntan que si bien, las instituciones de educación superior (IES), tienen la ineludible responsabilidad de fomentar el desarrollo de habilidades digitales y la apropiación tecnológica de los estudiantes, también es cierto que las IES están obligadas a desarrollar un pensamiento crítico y ético ante los enormes desafíos que enfrenta la humanidad en la actualidad.

Por ello, en el desarrollo de un ambicioso proyecto de investigación de corte cuali-cuantitativo los autores se propusieron responder ¿cuáles son las percepciones de actores internos y exógenos a la educación virtual sobre los conceptos de calidad y ética en lo relacionado con los procesos formativos en la modalidad de educación virtual?, para ello recurrieron a diversas técnicas como entrevistas, cuestionarios, exploración documental y grupos focales con estudiantes, profesores, expertos en educación, egresados de la educación virtual y padres de familia. Uno de los resultados más importantes de este proyecto ha sido una propuesta de lineamientos para un código de ética para la educación virtual, el cual es un instrumento muy necesario en todas las instituciones de educación superior.

En su indagación, los autores encuentran la existencia de una amplia heterogeneidad entrelas percepciones de egresados, estudiantes, profesores y expertos respecto a la educación virtual, sin embargo, se distinguen como principales virtudes de la educación virtual: su ubicuidad y la posibilidad de cursarla en diferentes circunstancias y tiempos. Así mismo, los encuestados consideran que la educación virtual abona a la autorregulación, el compromiso, la autodisciplina, es decir, conduce a competencias complejas mucho más favorables que las que ofrece la educación presencial en algunos de los casos. Los expertos consideran a la modalidad bimodal como un área de oportunidad que las instituciones pueden explorar.

Respecto a la calidad de la modalidad virtual no existe un consenso sobre su definición y formas de evaluación, sin embargo, coinciden con algunos aspectos que deben de ser contemplados como: el compromiso de los estudiantes, las mediaciones pedagógicas, las estructuras de 
aprendizaje, la existencia de métricas para su análisis, los diseños curriculares, la construcción de procesos pedagógicos, la idoneidad de profesorados, las plataformas tecnológicas, las trayectorias exitosas de sus egresados, la flexibilidad, la conectividad en el acceso al internet, entre otros. En este sentido, los autores proponen que la calidad educativa se constituye como una trama compleja interconectada que debe de ser abordada de manera integral.

Respecto a los comportamientos éticos, todos los actores entrevistados coinciden en el riesgo de fraude en la educación virtual, ya que no siempre los controles son efectivos, por ello coinciden en la necesidad de desarrollar una conciencia ética entre los estudiantes. Apuntan también sobre la necesidad de que los directivos y profesores reflexionen sobre actos poco éticos como el no comprometerse con los aprendizajes de los estudiantes y su desarrollo integral.

Por ello, el desarrollo de una conciencia ética implica un alto sentido de responsabilidad institucional, que priorice trabajar continuamente en la concientización del estudiante, la implementación de sistemas de validación confiables, la formación integral de los estudiantes, fomentar una formación humanística y motivar al estudiantado para asumir una actitud crítica y responsable ante sus actividades formativas.

Un aspecto más que distingue las opiniones de los encuestados y entrevistados es que el aprendizaje en la educación virtual es significativamente más dinámico, pues al partir de distintas fuentes de información y recursos tecnológicos, los estudiantes tienden a ser más proactivos y proclives al desarrollo del trabajo colaborativo, las metodologías los hacen desarrollar mayores aptitudes para la investigación y el autoestudio. Los encuestados apuntan a la necesidad de mejorar los foros y rúbricas y a generar plataformas más dinámicas (LMS), así como la estructura de las aulas virtuales a partir de la incorporación de elementos como la inteligencia artificial y las tecnologías disruptivas para el desarrollo de contenidos. Todos apuntan sobre la necesidad de fortalecer el acompañamiento permanente de los profesores y la formación-actualización de éstos.

En lo que refiere a la encuesta aplicada a estudiantes, los resultados revelan percepciones importantes respecto a la educación virtual. En su mayoría, los encuestados consideran que la calidad de la educación presencial es mayor que la virtual, 6 de cada 10 afirman que la calidad de la educación virtual es buena, sin embargo, entre el $68 \%$ y el $90 \%$ dicen que es 
mejor la enseñanza en el aula física. Una alta percepción de los encuestados 7 de cada 10, piensa que en la educación virtual hay riesgos de fraude y suplantación. Sin embargo, la gran mayoría considera que el buen actuar de los estudiantes es independiente de la modalidad de estudios. La encuesta muestra también que los egresados de la educación virtual consiguen empleos al igual que los que egresan de modalidades presenciales, sin embargo, los empleadores si bien confían en la educación virtual, no dejan de considerar que el riesgo de fraude en su formación es alto.

En el tercer capítulo de libro se desarrolla la propuesta de código de ética, que tiene como principal propósito fortalecer los procesos de formación de los estudiantes, "se concibe al código de ética no como reglas de conducta sino marco para la reflexión y la autodeterminación de los distintos actores". En este sentido, el propósito del código de ética para la educación virtual busca integrar un marco conceptual que sirva de fundamento para las actuaciones y decisiones con criterios de responsabilidad, corresponsabilidad y libertad de estudiantes, profesores, empleados y directivos de la educación virtual.

Este código de ética contempla aspectos como: el proyecto de vida, la responsabilidad, la libertad, la corresponsabilidad, la autenticidad, la validación y la verificación, todos estos aspectos directamente vinculados con la autodeterminación de alumnos, profesores, empleados.

El volumen cierra con un capítulo que reflexiona sobre el papel de la educación virtual frente a la crisis por COVID-19, en este capítulo disímil papel de los sistemas escolares en la formación de estudiantes para la modalidad virtual, ya que mientras en algunos países se observa la incapacidad de los alumnos para autorregular su aprendizaje, en Europa y Asia profesores y alumnos han sido capaces de administrar horarios y aprender por cuenta propia. Los autores reflexionan sobre las implicaciones de una educación virtual obligada a raíz de la pandemia, así como la existencia de brechas de conectividad, acceso a la tecnologías y pedagogías para la educación a distancia en todos los niveles, instituciones y regiones de Colombia.

Los autores concluyen sobre la necesidad de abrir espacios para la reflexión de las experiencias educativas que han derivado de la educación en línea a causa de la COVID-19, proponen aprovechar estos conocimientos y experiencias para impulsar rediseños curriculares y pedagógicos, así como fomentar procesos efectivos de innovación tecnopedagógica para ampliar las competencias digitales entre alumnos y profesores. 
A manera de cierre, vale la pena destacar la calidad de este volumen en términos de sus contenidos, así como la profunda reflexión que plantea sobre los enormes desafíos que la educación a distancia presenta en la época actual, no solamente en términos de los retos pedagógicos y el uso de las plataformas educativos, sino también sobre los sentidos formativos de la educación universitaria a distancia, la apropiación y usos de la tecnología digital y su efecto en los proyectos de vida y rutas de destino de estudiantes, profesores y autoridades universitarias.

Por tanto, considero como un grato acierto para la comunidad académica de la Corporación Universitaria Minuto de Dios- UNIMINUTO el haber impulsado una publicación sobre ética y calidad de la educación virtual con los aportes y trascendencia como la que distinguen a este volumen.

José Rodolfo Calvo Fonseca Rector de la Universidad de Ciencias y Artes de Chiapas Doctor en Derecho Público Diciembre de 2020 



\section{PRESENTACIÓN}

Los asuntos que encierran la problemática de la educación virtual difícilmente pueden agotarse, a pesar de que su auge viene desde la última década del siglo XX. La variedad de proyectos sobre pedagogía para la virtualidad, mediaciones pedagógicas, tecnología, evaluación o diseño instruccional es amplia, siendo notable el continuo movimiento en la educación global y la aparición de tecnologías y pedagogías disruptivas. Esto a su vez, lleva a problemáticas nuevas que merecen investigarse.

Dentro de ese dinamismo investigativo y formativo, el sentido humano de la educación virtual estará siempre vigente, ya que frente a la pantalla de un computador, interactuando con aulas virtuales, habrá personas ávidas de aprendizaje y beneficios. Aunque un grupo de estudiantes esté conectado en redes tecnológicas comunes y motivado por intereses comunes de formación profesional, sus integrantes están dispersos en lugares geográficos distintos y cada uno está inmerso en sus tensiones, intereses, pasiones, problemas, es decir, en sus propias realidades.

Este asunto humano es el que ha motivado el proyecto de investigación, enfocándose específicamente en dos temas: ética y calidad de la educación virtual. Como se había estimado desde el diseño de la investigación, se confirmó que estos dos conceptos no son disjuntos. La calidad no es una opción, es un compromiso ético e integral de directivos, empleados y profesores de la institución virtual. Asimismo, la autenticidad y la honestidad de todos son requisitos para que efectivamente se perfilen procesos verdaderamente educativos para la sociedad.

Esta relación entre ética y calidad en los ambientes virtuales llevó a que el análisis e interpretación obligaran a la indagación por temas adjuntos como aprendizaje, perfiles de estudiantes y docentes, mediaciones y diferencias entre programas presenciales y virtuales.

Como resultado de la interpretación de hallazgos en los abordajes cualitativos y cuantitativos, se propone un código de ética para la educación virtual. Se entiende este no como un compilado de normas 
para obligar al buen actuar, sino como un marco conceptual que le dé piso a la evaluación de las decisiones que libremente tomen los diferentes actores.

Con respecto a su ámbito, se aclara que la investigación desarrollada tuvo como objeto de estudio a características y formas de expresión de la calidad y comportamientos éticos en la educación virtual en los niveles de formación tecnológica, profesional y de posgrado. 


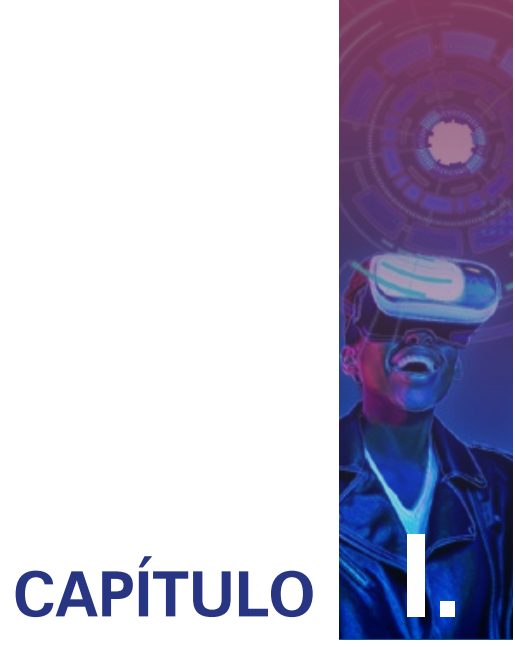

\section{ANTECEDENTES Y TENDENCIAS TECNOPEDAGÓGICAS DE LA EDUCACIÓN VIRTUAL}

La educación virtual, desde que empezó a fundarse, ha sido atractiva para la sociedad por dos razones: su forma de realización rompe con paradigmas históricos, pues flexibiliza conceptos como ambiente estudianteprofesor en intramuros para actividades de enseñanza-aprendizaje, con todas las implicaciones que esto ha derivado, y segundo, ha evidenciado cómo el advenimiento del ciberespacio y de la sociedad de la información han creado nuevas posibilidades, antes inimaginables por la humanidad. No obstante, aún persiste el prototipo de educación presencial como el enfoque socialmente predominante, aunque en los inicios las expectativas sobre la educación virtual hacían pensar en transformaciones avasallantes.

\section{Desarrollo de la educación virtual}

Terminando el siglo XX, empezaron a surgir en Colombia iniciativas de educación virtual, aunque ya había experiencias de varias décadas anteriores con la educación a distancia, la educación por correspondencia o la educación por radio. En 1997, el 10 \% de la matrícula académica de educación superior era de modalidad a distancia y de ellos el 96,7\% eran de posgrado (Facundo, 2003).

Las primeras experiencias en Colombia se conocieron en 1992 cuando el Instituto Tecnológico de Estudios Superiores de Monterrey, en convenio con algunas universidades colombianas, ofreció estudios de maestría mediante clases a través de comunicaciones satelitales originadas en México. Otras experiencias de clases en Colombia con metodología distancia/virtual fueron las de Nova Southeastern University (Estados 
Unidos) y desde España las de la Universidad de Salamanca, la Universitat Oberta de Catalunya y la Universidad Nacional de Educación a Distancia. Además, se conocía ya la oferta de la Universidad Virtual de Quilmes (Argentina). Es de anotar que en esos momentos aún en el país era muy incipiente la comunicación a través de internet y las conexiones con el extranjero eran tecnológicamente vetustas.

Según Facundo (2003), en 1998 aparecieron las primeras iniciativas propiamente colombianas de educación virtual: un sistema interactivo de la Universidad de los Andes para cursos en línea y cursos virtuales de la Red Mutis conformada por la Universidad Nacional, la Universidad Autónoma de Bucaramanga, la Universidad Autónoma de Manizales, la Corporación Universitaria del Tolima, Corporación Universitaria Minuto de Dios - UNIMINUTO, la Universidad Tecnológica de Bolívar y la Corporación Autónoma de Occidente. Además, aparecen programas académicos $100 \%$ virtuales, entre los que se destacan uno de la Universidad Militar Nueva Granada y tres de la Fundación Universitaria Católica del Norte. Oficialmente, esta fue la primera institución de educación superior completamente virtual y aunque su centro de operaciones estaba en el municipio de Santa Rosa de Osos (Antioquia), rápidamente extendió su cobertura y en 2005 tenía estudiantes en más de 80 municipios de ese departamento y en todas las regiones de Colombia, especialmente en Medellín, Bogotá, el Eje Cafetero y en la Costa Atlántica.

En 2001 había 25 instituciones reportando 130 programas en modalidad distancia/virtual diferenciados así: 28 profesionales, 18 de posgrado (especializaciones) y 84 diplomados (cursos de extensión). En ese año en los registros de Instituto Colombiano para el Fomento de la Educación Superior (Icfes) había 446 programas a distancia y en total eran 6.530 (Facundo, 2003). Es decir, el 6,83\% de la oferta era de modalidad a distancia, en tanto que cerca del 1,99 \% eran programas de distancia/ virtual. En 2016, de 11.213 programas con registro calificado activo, 539 de ellos eran virtuales $(4,80 \%$ ) (Sistema Nacional de Información de la Educación Superior [SNIES], 2016). En 2018, de 13.949 programas, también con registro calificado y activos, $715(5,12 \%)$ eran de modalidad virtual y 549 de modalidad a distancia (3,93 \%) (Sistema Nacional de Información de la Educación Superior, 2018). Las cifras muestran un incremento que es moderado en comparación con las expectativas agitadas en círculos académicos hacia el 2000, cuando se pronosticaba que en el futuro cercano la educación en aulas físicas ya no sería viable (Loaiza, 2003). Aunque hay casos que muestran el desarrollo de estructuras institucionales sólidas que le han dado continuidad creciente a la virtualidad, como la Fundación 
Universitaria Católica del Norte y el Politécnico Gran Colombiano. Sus ofertas académicas tienen matriculados en todos los departamentos de Colombia y han creado sistemas tecnopedagógicos garantes de calidad formativa. La figura 1 muestra un resumen estadístico sobre el crecimiento de la educación virtual en Colombia.

Tabla 1. Datos sobre crecimiento de programas virtuales en Colombia

\begin{tabular}{rrrr} 
Año & Total de programas & Programas virtuales & \multicolumn{1}{c}{ Porcentaje } \\
\hline 2001 & 6.530 & 130 & $1,99 \%$ \\
\hline 2016 & 11.213 & 539 & $4,8 \%$ \\
\hline 2018 & 13.949 & 715 & $5,12 \%$ \\
\hline 2020 & 13.594 & 762 & $5,6 \%$ \\
\hline
\end{tabular}

Figura 1. Dispersión de los programas virtuales con respecto al total de programas

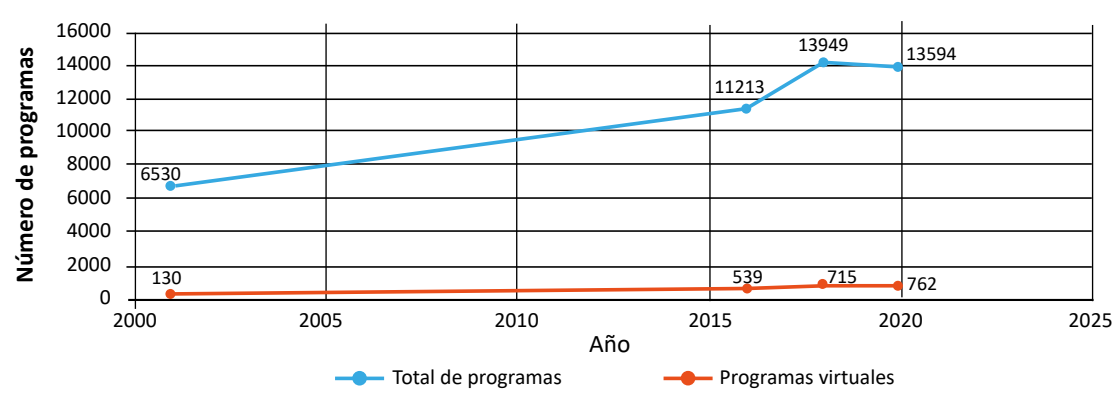

Se entendía implícitamente que los programas de modalidad a distancia eran aquellos desarrollados a partir de módulos de autoaprendizaje y con tutorías periódicas (semanales, quincenales, mensuales, por ejemplo) en unos ambientes educativos físicos, donde el profesor y los estudiantes aclaraban dudas. La modalidad a distancia/virtual se diferenciaba porque las actividades de aprendizaje estaban apoyadas por multimedia distribuida en CD (compact disc), transmisiones satelitales, canales de televisión educativa, videoconferencias, software educativo o por las nacientes plataformas LMS (learning management system) hospedadas en internet. En realidad, las diferencias entre programas a distancia propiamente dicha y programas virtuales no estaban reglamentadas. En 2010 hubo ya una normativa precisa (Decreto 1295 del Ministerio de Educación Nacional) y se precisaron las condiciones y alcances de programas académicos virtuales y a distancia. En el Decreto 2566 de 2003 se expusieron condiciones para 
la modalidad a distancia y, por eso, hasta antes de 2010 los programas virtuales que se ofrecían en las instituciones de educación superior tenían el rótulo legal de programas a distancia. Aunque en Colombia la educación no presencial se fue desarrollando con formas como las siguientes: virtualidad $100 \%$, presencial con apoyo virtual, virtual con apoyo presencial, distancia $100 \%$ o distancia con apoyo virtual, oficialmente en el SNIES (Sistema Nacional de Información de la Educación Superior) aparecen solo las opciones de metodología a distancia, presencial o virtual. Pero la variedad de modalidades metodológicas de los programas que realmente se conoce en la oferta de programas académicos fue reconocida por el Decreto 1330 de 2019, en el cual se definió que un programa académico puede ser modalidad virtual, presencial, a distancia, dual u otro que combine esas modalidades.

Un asunto pendiente es el de otras modalidades que aparecen en la oferta y conceptualización de las instituciones de educación superior y que no están incorporadas en los conceptos del Decreto 1330 de 2019, ni algún otro documento oficial del Ministerio de Educación, tales como universidad electrónica, universidad digital o programas en línea o digitales, todo con el ánimo de eludir la denominación de modalidad virtual. No obstante, hasta ese año, es la reconocida por el ministerio de manera formal.

Iniciando el siglo XXI fue surgiendo la modalidad de educación virtual en el mundo, llegándose a pensar incluso, que las universidades presenciales tendrían que transformarse irremediablemente para no desaparecer. Con el desarrollo de internet, la educación virtual ha ampliado sus horizontes en la segunda década del siglo XXI. No obstante, surgen interrogantes: ¿por qué en los imaginarios sociales y académicos pareciera que las dudas sobre sus fortalezas persisten y aun dentro de las comunidades se advierte un sentir que valora la educación virtual más por su capacidad de cobertura e inclusión que por su calidad? Lo cierto es que esta es una modalidad por sí misma atractiva, pues sin tener que ir a las tradicionales aulas físicas, se posibilita la obtención de las titulaciones académicas en consideración a que la organización basada en la tecnología permite la mediación formativa. Póngase el caso del estudiante tipo millennial: hipotéticamente la opción de estudiar virtualmente desde su casa sería muy atractiva, pues no tendría que desplazarse y podría jugar con los horarios y, además, estaría en aprendizaje formal dentro de unos ambientes armonizados con su mundo cotidiano digital, móvil, minimalista, entrecruzado por redes y lleno de dispositivos multiusos e inteligentes y como requisito para aprender no tendría el mínimo interés por tener que estar en intramuros con horarios fijos y sometido a jerarquías directas. La educación 
virtual está mucho más cercana que la educación presencial a las dinámicas y dimensiones de la sociedad red (Day, 2018), al entorno social basado en la ubicuidad, a las ambiciones por la autonomía para optar y a los procederes y servicios que se generan en el ciberespacio (Páez, 2019). Es decir, la opción de estudiar virtualmente está alineada con el entorno y las intersubjetividades de las personas del siglo XXI y entonces las aulas virtuales serían ya el patrón generalizado en las instituciones. No obstante, ni los millennials prefieren altamente a la educación virtual ni el paradigma del aula física ha desaparecido. En el segundo capítulo de este libro se exponen los resultados de una investigación cuantitativa y los datos muestran que los estudiantes de bachillerato en un 94,3\% saben que es educación virtual, pero solo el 5,7 \% la prefieren para sus estudios universitarios.

¿Llegará el momento del derribamiento de las aulas físicas, en favor de la educación total en el ciberespacio, debido a la incompatibilidad con las formas como viven y sienten los nacientes estudiantes del siglo XXI? Para intentar responder, antes habría que mirar retrospectivamente y comparar desde 1998 en los inicios de la educación virtual en Colombia. Desde allá hasta el 2020 habría en las universidades menos construcciones físicas y muchos ambientes virtuales se habrían fundado. La segunda premisa es cierta y prácticamente en todas las instituciones existen proyectos o iniciativas sobre educación virtual (digital o en línea o electrónica) e igualmente, sería difícil encontrar alguna donde no se hayan hecho ampliaciones físicas. Por supuesto, hace falta la medición científica, pero son evidencias demostrables. Lo cierto es que las instituciones que son referentes en Colombia por su calidad, impacto y tradición, como la Universidad Nacional, la Universidad de los Andes, la Universidad del Valle o la Universidad de Antioquia, tienen sus fortalezas mayúsculas en modalidad presencial, a pesar de iniciativas y desarrollos académicos de educación virtual y regionalización, especialmente en las dos últimas.

Téngase en cuenta que iniciando el siglo XXI las expectativas con respecto a la educación virtual eran grandes, y propulsores de esa modalidad en Colombia como Guillermo Cardona Ossa (rector en esa época del Colegio Virtual Siglo XXI) y Roger Loaiza Álvarez (director del Centro Internacional de Marketing Territorial para la Educación y el Desarrollo CIMTED) presentaban en sus conferencias y divulgaciones premonitorias:

En los próximos diez años [desde 1997], el 40 por ciento de las instituciones educativas desaparecerían desplazadas por aquellas que utilizarán nuevas tecnologías para impartir educación a distancia. (Loaiza, 2003, p. 7). 
Las instituciones educativas van a laborar 24 horas diarias y los fines de semana. La jornada de trabajo de los adultos se reducirá a 32 horas semanales, para dedicar el resto a preparación del próximo curso. En los siguientes 10 años [próximas 500 semanas] desaparecerían las aulas físicas. (Loaiza, 2003, p. 8).

A tono con tales presentimientos en los albores de la educación virtual en Colombia, se exhibían también otros conceptos como los siguientes, que están vigentes en el mundo educativo de 2020:

Las universidades famosas, siguiendo el ejemplo de Harvard, ofrecerán programas no solo para las élites, sino para espectros más amplios de la población. No se otorgarán en estos cursos de divulgación masiva diplomas rimbombantes, tan solo se recibe un certificado por cada curso aprobado y cada cual estudiará lo que necesite o desee. (Loaiza, 2003, p. 8).

Ante toda esta dinámica, el sistema educativo tiene un reto muy importante. Debe cuestionarse a sí mismo, repensar sus principios y objetivos, reinventar sus metodologías docentes y sus sistemas organizacionales. Tiene que replantear el concepto de la relación alumno-profesor y el proceso mismo del aprendizaje, los contenidos curriculares, además, revisar críticamente los modelos mentales que han inspirado el desarrollo de los sistemas educativos. Por lo anterior, la necesidad de repetir una y otra vez, hasta la saciedad, algunas de las ideas innovadoras sobre las que se ha logrado un cierto consenso a lo largo de los años, aunque con muy escasos resultados aún en el sistema educativo, desde la educación infantil hasta la educación para la tercera edad. (Cardona, 2002, p. 4).

La verdad es que los futuristas argumentos de Loaiza y Cardona son representativos de las expectativas que en esa época se respiraba en las universidades. En el centro del debate académico estaban las TIC comola apuesta ineludible para los próximos años del sistema educativo y las expectativas apuntaban a una transformación radical. La evaluación dos décadas después demuestra que ni las universidades ni las escuelas tumbaron sus paredes, pero si se incrementaron mediaciones tecnopedagógicas, iniciativas globales de aprendizaje en línea, transformaciones en la relación estudiante-profesor y potencialidades de las fuentes de aprendizaje.

En otro aspecto, una discusión que se ha levantado por años en las universidades es sobre la denominación de educación virtual. La motivación para los debates se ha engendrado en una idea, según la cual, la virtualidad es oposición de la realidad tangible, y por esto, la educación no puede ser virtual. Al respecto, Parra (2005) opina: 
Lo anterior porque la educación implica contactos reales, y porque lo virtual es apariencia, sin piso, dicen; entonces, como tal, es atrevido hablar de educación virtual. Se escucha también que la educación es un proceso para el desarrollo humano, que tiene que ser real, no imaginado. Los escenarios educativos no se pueden imaginar, ni imitar. Negar su existencia tangible sería negar la posibilidad de la verdadera trascendencia educativa.

Puede deducirse que el término virtual sí crea barreras, aunque, claro está, los especialistas en el tema saben que la evolución de la educación virtual implica el tratamiento de otros indicadores, dentro de los cuales la denominación pasa a un segundo plano. De todas formas, esa falta de identidad social de alguna manera obstaculiza los procesos. (p. 4).

Como consecuencia del debate, se han conocido otras denominaciones como educación electrónica, educación distribuida, educación basada en escenarios múltiples, educación infovirtual, educación mediada por TIC, virtualidad en la educación, educación digital, entre otras. Pero el ímpetu de las críticas de la denominación se ha venido diluyendo, la trascendencia no ha sido impactante probablemente por dos razones: la penetración de las redes sociales en los dispositivos móviles de la gente ha demostrado que virtualidad no es sinónimo de irrealidad, y la popularización de servicios cotidianos que ofrecen plataformas de internet inducen que la educación tiene posibilidades en ese mundo virtual.

Un asunto que es crítico es ¿hasta dónde una comunidad académica virtual es educadora en sentido estricto? ¿Hasta dónde hay posibilidades para transformar personas? ¿Las transformaciones de aprendices son exclusivas de entornos físicos porque allí hay conexiones directas $y$ socializaciones naturales y espontaneas? El énfasis iniciando el siglo XXI, cuando se presentaban los proyectos o iniciativas de cursos o programas de educación virtual, se concentraba en poder de la plataforma tecnológica o en implementación de simuladores o de software educativo. Con el tiempo se afinó la conceptualización y esa modalidad educativa se consideró como un ambiente de aprendizaje basado en la mediación tecnológica. Los siguientes dos conceptos así lo expresan:

Educación virtual significa que se genere un proceso educativo, una acción comunicativa con intenciones de formación, en un lugar distinto al salón de clases: en el ciberespacio; en una temporalidad que puede ser sincrónica o asincrónica y sin necesidad de que los cuerpos de maestros y alumnos estén presentes. (Unigarro, 2004). 
La educación virtual o virtualidad en la educación se define como la apropiación pedagógica-didáctica de tecnologías de información y comunicación que apoyan y facilitan la formación integral y el proyecto de vida de seres humanos, en aquellos conocimientos y aprendizajes significativos para la vida y a lo largo de la vida. Por tanto, las tecnologías se conciben en la institución como medios para educar y formar. (Fundación Universitaria Católica del Norte [FUCN], 2015, p. 36).

En términos generales, un curso virtual es una composición de los siguientes elementos:

a). Una plataforma tecnológica tipo LMS (learning management system) para la gestión de contenidos, comunicaciones, actividades, evaluaciones, estudiantes, calendarios o avisos (García et al., 2015).

b). Un enfoque pedagógico que sirva de marco para los procesos de aprendizaje (Rúgeles et al., 2015).

c). Un profesor que cumple funciones de planeador y orientador de los aprendizajes es quien lidera los procesos formativos y motiva las interacciones con sus estudiantes (Rúgeles et al., 2015).

d). Unos estudiantes proactivos y abiertos para interactuar entre ellos y con el profesor (Durán et al., 2015).

e). Un asesor para acompañamiento a los estudiantes en aspectos relacionados con gestión técnica de la plataforma, comunicaciones institucionales o de desarrollo de los cursos (Durán et al., 2015).

f). Unos contenidos con características de calidad como usabilidad, visibilidad, funcionalidad y accesibilidad, adecuadas para las necesidades de los estudiantes (Jaramillo, 2005).

g). Un diseño instruccional que plasme mediaciones pedagógicas para facilitar la formación (Jaramillo, 2005).

\section{Entornos y participación en la educación virtual}

\section{Entornos virtuales de aprendizaje}

En la medida en que ha penetrado la educación virtual en la sociedad, distintos conceptos han venido surgiendo sobre los ambientes de aprendizaje. Es así como han surgido denominaciones como aulas virtuales, entornos virtuales de enseñanza y aprendizaje (EVEA), entornos virtuales de aprendizaje (EVA) y ambientes virtuales de aprendizaje 
(AVA), con diferencias que son exiguas, en cuanto a las funciones y las características del ambiente educativo que determinan.

Subrepticiamente podría pensarse que las últimas dos definiciones implican una intencionalidad pedagógica más enfocada en la autonomía del estudiante, en el sentido que es él quien aprende. La primera, en cambio, involucra directamente al profesor (es quien enseña) y por esto determinaría unos procesos donde la comunicación directa con sus estudiantes sería esencial para el aprendizaje. No obstante, estas son conjeturas que se justifican únicamente desde las denominaciones. Lo que sí es claro es que, independiente de su denominación, constituyen la esencia de un programa educativo virtual.

Según Guaña-Moya y LImiquinga-Quispe (2015), en un EVEA el estudiante busca con su propia iniciativa el conocimiento y por esto demuestra competencias investigativas, es colaborativo y utiliza los artefactos tecnológicos para el intercambio y la comunicación. Se asume que los estudiantes son los gestores de sus conocimientos, pero con una interacción frecuente con sus profesores. Se acepta que la educación virtual tiene su esencia en la actividad de los estudiantes y que estos tienen la suficiente capacidad y actitud para gestionar su aprendizaje (no son inertes consumidores de informática e información). No obstante, en su investigación, los citados encontraron carencias de calidad demostradas en la baja aplicación de los contenidos por parte de los estudiantes, deficiencias en la comunicación e interactividad, limitaciones en los análisis grupales de contenidos, limitación de actividades para fomento de la colaboración formativa, prevalencia de métodos de enseñanza característicos de la educación presencial tradicional y debilidades en la construcción epistemológica y praxeológica ${ }^{1}$ de la formación.

A su vez, Silva y Romero (2014) plantean indistintamente que tanto los EVA como los AVA integran herramientas informáticas para la comunicación, la gestión de objetos de aprendizaje y de monitoreo y evaluación de la actividad del estudiante. Además, brindan soporte tecnológico para el desarrollo curricular. Proponen un modelo para entornos virtuales de aprendizaje (EVA) sustentado por procesos de formación del profesorado; gestión de procesos institucionales para la dotación y mantenibilidad de los recursos tecnológicos y humanos;

1 La praxeología la define así el Proyecto Educativo Institucional de UNIMINUTO (2014): “Establece y construye lazos entre el saber y la acción, es fundamental para las prácticas de interacción social: invitando al profesional a adoptar una postura reflexiva (ese va y viene entre lo que hace en su práctica y lo que la práctica le hace a él), le evita asumir una visión dualista (mundo científico/mundo vivido), y lo invita a considerar siempre la creciente complejidad del mundo social" (p. 40). 
contratación de profesionales expertos en pedagogía, informática y comunicación gráfica; desarrollo de comunidades de prácticas para la implementación y administración de los entornos virtuales y desarrollo de propuestas pedagógicas basadas en activismo del estudiante. Aunque no hay una alusión directa, sí se desprende que desde estas concepciones se perfilan otros indicadores o matices para la evaluación de la calidad.

Por otra parte, Cando et al. (2017) afirman que los entornos virtuales de aprendizaje (EVA) tienen elementos que permiten funciones como las siguientes: distribución de la información, intercambio de conocimientos, aplicación de aprendizajes, evaluación de aprendizajes y confiabilidad del sistema. Se resalta esta última, ya que expresa preocupación por asuntos como la autenticidad y la transparencia de los actores.

Como un elemento de calidad puede considerarse el cúmulo de competencias que debe demostrar el profesor en el desempeño de funciones en la modalidad virtual en los siguientes aspectos: pedagógico, social (dinamización de las comunicaciones de los estudiantes), de liderazgo (para la gestión de los aprendizajes), técnico (para el manejo de la información en el aula virtual) y de orientación (sobre aspectos técnicos, filosóficos, sociales y evaluativos) (Llorente, 2005, citado por Cando et al., 2017).

La educación virtual tiene como presupuesto que la dinámica de aprendizaje está centrada en los estudiantes. En Sancho y Borges (2011) se exhiben al respecto las siguientes características:

1). Son los estudiantes quienes aprenden, sin que tengan que esperar a que el profesor decida por ellos.

2). El estudiante decide libremente los elementos significativos de su aprendizaje.

3). El aprendizaje es colaborativo.

4). Los estudiantes tienen oportunidades y espacios para su autonomía.

5). Se privilegian las competencias sobre gestión de la información, procesos y orientación al resultado, en vez de la memorización y la replicación temática de ideas o de contenidos.

6). Énfasis en la educación a lo largo de la vida.

El rol de los profesores en los entornos virtuales es fundamental, lo que aparentemente contradice los planteamientos anteriores sobre el 
estudiante virtual. El profesor de la educación virtual debe tener ciertas especificaciones distintas a los de la educación presencial. En Bautista (2011) se plantean las siguientes características que deben distinguir a los profesores cuando asumen el reto de la educación virtual:

1). Entusiasmo expreso y decisión por ayudar a aprender.

2). Conocimiento acerca de cómo aprenden sus estudiantes.

3). Manejo de recursos y formas para promover el aprendizaje.

4). Competencia para organizar actividades.

5). Competencia para el diseño de actividades y espacios de aprendizaje.

6). Planeación y desarrollo de metodologías para enriquecer los aprendizajes.

7). Organización para definir y supervisar el logro de objetivos en los entornos de aprendizaje.

8). Orientación al diseño de espacios de aprendizaje, en vez de la transmisión de contenidos.

9). Rol concentrado en el acompañamiento, supervisión y evaluación de la actividad del estudiante.

\section{Ambientes personales de aprendizaje (PLE)}

Un concepto que explica la actividad de los estudiantes en la educación virtual es el de entorno personal de aprendizaje o personal learning enviroment (PLE). Se trata de prácticas de aprendizaje individuales que aplican tecnologías Web 2.0 para el intercambio de saberes y el aprendizaje colaborativo. Más exactamente, un PLE lo constituyen artefactos tecnológicos, software, recursos físicos, repositorios, buscadores, vínculos o actividades que cada estudiante utiliza de forma frecuente en función de aprender (Cabezas et al., 2016). Un objeto virtual de aprendizaje (OVA) o una aplicación móvil (app) pueden hacer parte del PLE de una persona. Resaltan Cabezas et al. (2016) dos puntos de vista sobre la concepción de PLE: como entorno tecnológico es una plataforma de software de usabilidad flexible y con capacidad para gestionar e integrar distintos recursos como multimedia, bases de datos, redes sociales, por ejemplo, de acuerdo con el interés y criterio individual de cada estudiante; como entorno pedagógico, se concibe como las prácticas de los estudiantes para aprender interactuando con otros compañeros y para construir comunicaciones que faciliten apoyo mutuo, reflexión sobre el conocimiento, transferencia de experiencias, soluciones colectivas. Es decir, los PLE pedagógicamente crean ambiente para el aprendizaje colaborativo. 
Pero estos dos ángulos no son mutuamente excluyentes, por el contrario, se yuxtaponen y estratégicamente los constituye el estudiante para aprender.

Es de anotar que el anterior concepto sobre PLE pone en evidencia la necesidad de metadatos estructurados de los OVA, ya que deben estar hospedados para su acceso, filtración, recuperación, organización, almacenamiento y transferencia, cuando los elija el estudiante. Además, debe tenerse en cuenta que estas funciones son posibles en internet si se dispone de suficientes herramientas de acceso público.

Ahondando en su concepción, Leiva et al. (2018) afirman que un PLE es un grupo de herramientas tecnológicas que los estudiantes aplican en sus actividades de aprendizaje (visión instrumental del PLE). Desde una visión pedagógica, el conjunto lo constituye aquellas herramientas que el estudiante utilice para gestionar esas actividades. Esta segunda visión supone la activa participación del estudiante para adaptar tecnologías y procesos a sus estilos de aprendizaje y sus capacidades para autorregulación de sus actividades.

Las características básicas de un PLE son según Leiva et al. (2018) son:

1). Unicidad: cada ambiente de aprendizaje es único, pues es una construcción que obedece a las necesidades propias de su creador.

2). Individualidad: su construcción es producto de criterios y gustos personales de cada estudiante.

3). Movilidad: el estudiante los modifica constantemente sus propios ambientes de aprendizaje de acuerdo con las oportunidades que vaya encontrando, pues surgen en el proceso de aprendizaje necesidades, problemas, conocimientos e intereses nuevos.

Para Chaves-Barboza y Sola-Martínez (2018), un PLE lo constituyen recursos tecnológicos seleccionados, integrados y aplicados por los estudiantes para obtener conocimiento e información de su interés particular.

Esencialmente, un PLE se concibe como una aplicación teóricopedagógica de tecnologías Web 2.0 que son seleccionadas e integradas por los individuos para aprender y acceder a variadas fuentes de conocimiento. En el sentido pedagógico, es primordial la actividad de los estudiantes, ya que sin la intervención del profesor ellos van construyendo sus aprendizajes por medio del uso de tecnologías Web 2.0. Las expectativas de un PLE superan las de las plataformas LMS, que corrientemente están centradas en los contenidos y en la gestión del profesor (Vera et al., 2017). 
En una investigación de Gallego-Arrufat y Chaves-Barboza (2014), se encontraron las siguientes especificidades de los PLE:

a). Dentro de la hiperconectividad del mundo permiten que las personas mantengan actualizada su información.

b). Disposición individual de amplio abanico de recursos para la comunicación seleccionados de acuerdo con criterios propios.

c). Fortalecimiento de la competencia profesional para aprender a través de la Web 2.0.

d). Las personas son los protagonistas básicos de sus aprendizajes, ya que ellos son quienes deciden sobre la organización, actualización, acceso y modelos de aprendizaje.

e). Los estudiantes crean estrategias de control sobre lo que aprenden y las metodologías que utilizan.

f). Su construcción obedece a factores como necesidades, intereses, complacencias, problemas específicos o circunstancias personales. Además, influyen las recomendaciones y ejemplos que reciben de sus profesores y sus círculos sociales y familiares.

g). Facilitan el acceso colectivo a la inteligencia colectiva a través de la Web 2.0, incluidas las redes sociales.

h). Ayudan a elevar la motivación de los estudiantes, la gestión grupal, la promoción de la responsabilidad o la gestión con autonomía.

i). Permiten que el individuo flexiblemente adapte contenidos, recursos, métodos o fuentes de información a sus circunstancias personales, necesidades específicas o preferencias.

j). Surgen natural y espontáneamente como soluciones pragmáticas de los estudiantes debido a su continua interacción con herramientas tecnológicas.

k). Pueden ser conjuntos de unidades o artefactos físicos (libros, cuadernos u objetos), virtuales (aplicaciones móviles, sitios web, simuladores, bancos de imágenes).

I). Pueden ser grupos sociales o entornos específicos (económicos, políticos o deportivos, entre otros), ya que son sistemas que puede utilizar el estudiante para aprender. 


\section{Aprendizaje en redes sociales y en dispositivos móviles}

En consideración de los anteriores puntos de vista sobre los PLE, merece analizarse la posibilidad pedagógica de dos ámbitos tecnológicos ampliamente utilizados por la gente: las redes sociales y los dispositivos móviles. Fundamentalmente, estos han estado en boga debido a sus funciones de entretenimiento, comunicación, socialización, divulgación, entre otras. No es difícil reconocer que, en la vida cotidiana, las personas están inmersas en redes y dispositivos de bolsillo y que los estudiantes (niños, jóvenes, adultos) no están al margen, estando allí la fuente de muchos de sus aprendizajes. A propósito de esto, un estudio de Romero y Garay (2018) ha encontrado cómo a través de Facebook los estudiantes expresaron actitud colaborativa entre ellos, se proporcionó la comunicación entre los estudiantes y el profesor y se logró profundizar en los contenidos que resultaban más motivantes. Además, concluyen que el uso de las redes sociales permite desarrollar competencias digitales y la interacción con contenidos de aprendizaje. Según esto, las redes sociales públicas, que como se sabe hacen parte de la vida cotidiana de las personas, se han convertido también en un PLE.

Las redes sociales son representativas de la Web 2.0 y por eso en ellas es significativo el rol de los usuarios construyendo información. Se pueden aprovechar como estrategia de aprendizaje, ya que su arraigo y atracción están dentro de la vivencia de los estudiantes. Dentro de las ventajas se tienen el potencial para el trabajo colaborativo y la instantaneidad de las comunicaciones (Islas y Carranza, 2011).

Asimismo, Barrón et al. (2015) lograron el desarrollo e implementación de la Red Social de Aprendizaje Colaborativo (RSAC), para el compartimiento y construcción de conocimiento utilizando dispositivos móviles, aprovechando la capacidad de estos artefactos para la interacción entre usuarios en tiempo real y la facilidad para que potencialmente cualquier espacio sea escenario para aprendizaje colaborativo. Llama la atención que en esta iniciativa se consideraron como actores a estudiantes, profesores y padres de familia. Obsérvese que, en este caso, se implementó una red social privada como alternativa de un PLE.

Se conocen aplicaciones específicas para dispositivos móviles para apoyar procesos de aprendizaje. Organista-Sandoval et al. (2019) desarrollaron un sistema de contenidos educativos digitales (CED) para aprender estadística desde teléfonos inteligentes. Los contenidos se organizaron de 
acuerdo con la siguiente estructura: presentación general e introductoria del tema, despliegue de conceptos básicos, exposición de problemas resueltos y ventana de resultados y conclusiones. El aplicativo se validó con un grupo de 40 estudiantes y en los resultados de la evaluación de aprendizajes se obtuvo una calificación de 89,4, sobre 100.

A su vez, Cantú et al. (2019) proponen un modelo de reforzamiento de aprendizajes en dispositivos móviles. Se toma como referencia la tecnología de smartphones (teléfonos inteligentes), los cuales integran abanicos de posibilidades con herramientas interactivas, dispositivos computacionales, comunicaciones instantáneas y almacenamiento de contenidos. Este modelo se fundamenta en tres elementos básicos: los dispositivos móviles de los actores (profesores y estudiantes); la ubicuidad que facilitan los dispositivos (capacidad para manipular información entrante y saliente y para la interacción social); el enfoque pedagógico que se complementa con escenarios constructivistas y conductistas (incluye elementos de interacción, retroalimentación, evaluación diagnóstica y evaluación formativa).

Según Villalonga y Marta-Lazo (2015), el aprendizaje móvil (mobile learning) es una evolución del e-learning en contextos en los que los estudiantes aprovechan las ventajas de las tecnologías móviles para apoyar sus procesos de aprendizaje. Plantean que algunas ventajas de esta modalidad de educación virtual son las siguientes:

a). Potencialidades para el aprendizaje ubicuo, la interactividad en tiempo real, el trabajo colaborativo, el acceso diversificado al conocimiento, la exploración para el aprendizaje y la integración curricular. La ubicuidad se logra porque se puede acceder al ambiente de aprendizaje desde distintos contextos y circunstancias.

b). Facilidad para procesos de comunicación horizontales y bidireccionales, el aprendizaje en red (formación de redes para el aprendizaje), creatividad y aprendizaje personalizado.

c). Adaptación de los dispositivos a las necesidades personales de aprendizaje. Esto es, vinculación del sistema de comunicación móvil al ambiente personal de aprendizaje (PLE).

Añádase a lo anterior que es común que los teléfonos inteligentes de las personas estén vinculados con internet, redes sociales como Facebook o WhatsApp, aplicaciones tipo app como programas de estadística o calculadoras financieras y en general, a los recursos disponibles en el 
ciberespacio como los servicios de cloud (gestión de información en la nube). Es así como las personas en su dispositivo móvil instantáneamente están en conversaciones con distintos grupos, tienen acceso a su correo electrónico, pueden navegar por sus redes sociales, comparten archivos, pueden crear información en foros y tienen acceso a bancos de imágenes, listas de música o diversidad de recursos propios para sus condiciones. Si se aprovecha este abanico de recursos con fines pedagógicos, se pueden integrar comunidades o ambientes virtuales de aprendizaje alineados con la cotidianidad de los estudiantes y con su manera de relacionarse.

En la evolución de la educación virtual se ha definido la siguiente línea de tiempo, siendo caracterizada cada etapa por las características de las mediaciones pedagógicas y las actuaciones de profesores y estudiantes (Báez y Clunie, 2019):

Figura 2. El desarrollo de la educación virtual

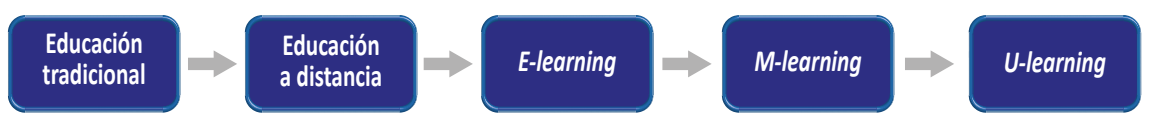

\section{Cursos virtuales masivos}

El desarrollo de cursos de tipo MOOC (Massive Online Open Courses) viene marcando tendencia en la educación, por sus ventajas de ser masivos, abiertos y en línea a través de internet. Para su desarrollo se conocen plataformas como Miriada X, Coursera, EdX, FutureLearn o UNED abierta. En cuanto a las certificaciones, hay cursos que las otorgan luego de superar un examen, otros con el único requisito de verificar las interacciones con los contenidos y en otras veces las certificaciones están ligados a un pago por derechos de matrícula. Asimismo, se conocen MOOCS que otorgan certificaciones de competencias laborales. Esta variedad de alternativas y el potencial de su concepción de cursos online de amplia cobertura han hecho muy atractivas las iniciativas sobre esta opción formativa.

Pero los MOOC, junto con sus bondades, exhiben también dificultades. Así lo plantea Bernal (2015), destacando las siguientes: escaza retroalimentación para los participantes, falta de interacción, insuficiencia en la verificación de los resultados de aprendizaje y énfasis en contenidos específicos, pero sin organización curricular. En la argumentación cita un estudio de la Universidad de Pennsylvania donde se concluye que la tasa de terminación de los cursos por parte de los estudiantes fue del $4 \%$ (población de un millón de usuarios de 16 cursos de la plataforma Coursera). 
Según Fernández-Ferrer (2019), los MOOC presentan las siguientes limitaciones:

a). Con respecto a la evaluación: falta de seguimiento, retroalimentación y autorregulación de los aprendizajes.

b). Con respecto a la masificación: falta de atención personalizada a las necesidades individuales de los estudiantes.

c). Con respecto a la participación: la alta participación puede determinar ofertas educativas engañosas ya que se dificulta un enfoque pedagógico sólido.

Sobre la calidad de los cursos de tipo MOOC, Baldomero y Salmerón (2015) hicieron una investigación y evaluaron 20 cursos de las plataformas Udacity, EdX, MiríadaX y Coursera con indicadores de tres factores: certificación para el empleo (expedición y naturaleza de certificados o diplomas), metodología de aprendizaje y accesibilidad. De este estudio se concluyó que los $\mathrm{MOOC}$ exhiben en sus formatos un fundamento pedagógico consistente, pero hay diferencias significativas entre las plataformas. Además, no se evidencian discrepancias relevantes con la formación online tradicional del e-learning. Con base en esto, se plantean preocupaciones en el sentido de la necesidad de certificación y acreditación de las plataformas para evitar oferta de formación con debilidades en la metodología de enseñanza. De esta forma, los cursos de tipo MOOC serían elementos para la democratización de educación, pero con intereses pedagógicos que estén por encima de otros asuntos coyunturales.

Como los referentes anteriores, se pueden encontrar más en bases de datos y no es difícil hallar casos en internet sobre éxitos o fracasos, pudiéndose verificar que los $\mathrm{MOOC}$ son atractivos por su carácter democrático, masivo, abierto y actualizado en cuanto a sus contenidos. Además, porque están enfocados en la precisión de los objetivos de formación. Pero en el otro lado hay asuntos críticos que merecen considerarse como lo son los intentos por la estandarización del conocimiento, las dificultades para atender diferencias individuales de los estudiantes (debido a la masificación) y la configuración de procesos comunicativos unidireccionales centrados en el docente y encajados en el contenido.

En percepciones sobre su naturaleza, pareciera que los MOOC se conciben enfocados en los contenidos y sin intencionalidad pedagógica. Es más, la interpretación formativa en los cursos MOOC pareciera no estar alineada totalmente con la concepción pedagógica de la educación virtual, 
entendida como: A) generación de procesos educativos y comunicativos en el ciberespacio, con una temporalidad que puede ser sincrónica o asincrónica, sin que sea necesario el encuentro físico de profesores y estudiantes (Unigarro, 2004); B) ambiente educativo integrado por TIC, donde profesores, asesores y estudiantes se comunican y participan en actividades de aprendizaje aun estando distanciados geográficamente (Fundación Universitaria Católica del Norte, 2015).

Según Roig et al. (2014), a pesar de la vigencia de los MOOC en internet, pedagógicamente aún no se ha dado un salto cualitativo significativo, y en su entorno tecnosocial -bastidores conformados por experiencias individuales y grupales en eventos de interacción con tecnologías de la información y la comunicación-, según Rueda (2011), aún no se perciben rupturas significativas con los modelos formativos basados únicamente en los contenidos. Esta crítica podría sustentarse con la presencia en internet de cursos que se hospedan en repositorios sin rutas metodológicas o evaluativas y que consisten esencialmente en organizaciones de contenidos en distintos formatos para la autogestión de los usuarios. Por ejemplo, en la plataforma Merlot https://www.merlot. org/ es usual encontrar este tipo de cursos.

\section{Pedagogía para la educación virtual}

La aplicación de las tecnologías de la información y la comunicación (TIC) en la educación no implica desplazamiento del profesor, sino que modifica sus roles en los procesos de aprendizaje y comunicación. Por esto, la utilización de las herramientas tecnológicas debe ir de la mano de cambios para el aprendizaje colaborativo, descentralizado y pluralista (Santaella, 2018).

De acuerdo con Martínez et al. (2018), lo virtual en la educación debe comprenderse como utilización de aplicaciones tecnológicas dentro de un marco pedagógico para la construcción de aprendizaje significativo, considerándose que el centro y el fin es el aprendizaje, no la modalidad misma y, además, que lo vital es la formación de competencias en los estudiantes. Por esto, dicen, en la educación virtual deben hacerse renovaciones para evitar que se sigan aplicando prácticas de educación tradicional presencial que se enfocan en la transmisión de información. En relación con esto, se sugiere que el profesor en el ambiente virtual debe utilizar las TIC para el desarrollo de actividades que exciten en los estudiantes capacidades para funciones como asimilación, entendimiento y procesamiento de la información. 
Una teoría de aprendizaje que está en correspondencia con estos preceptos sobre los roles de los profesores debido al uso de la tecnología, es el conectivismo. Sus argumentos se basan en los siguientes principios:

a). El aprendizaje y el conocimiento están en la diversidad de juicios.

b). El aprendizaje consiste en la conexión de fuentes diversas de información.

c). El aprendizaje no es de la exclusividad de los seres humanos.

d). La competencia para ampliar el conocimiento es más importante que el conocimiento ya adquirido.

e). Es indispensable proporcionar las interrelaciones entre áreas o campos, ideas y conceptos.

f). La intencionalidad de todas las actividades debe apuntar a la información actualizada y precisa (Martínez et al., 2018).

De estos principios es llamativo el tercero: no solo las personas aprenden. Lo hacen también las redes, el software, los dispositivos inteligentes.

Se afirma que el conectivismo es un paradigma de aprendizaje en la era digital. Dentro de este se establece que el conocimiento es "voluble, inestable, incontrolable y en continua expansión, lo que supone que escape del control total de la persona, pudiendo residir en sus redes externas (comunidades, dispositivos digitales, etc.) y estar en permanente cambio" (Sánchez et al., 2019, p. 123). Visto así, el aprendizaje es un proceso de construcción de redes entre distintos nodos, y el conocimiento habita en estas. Se concibe que el estudiante es un actor dinámico y creativo, porque el entorno cambiante le impone la necesidad de actualización continua. En su dinamismo debe permanentemente estar realizando nuevas conexiones, reconociendo patrones, aprendiendo de experiencias propias y ajenas e interactuando con situaciones repentinas.

Acorde con lo anterior, el conectivismo explica cómo en el mundo actual (globalizado, interconectado, cruzado por informaciones masivas y múltiples tramas) el estudiante aprende de las redes sociales, los portales de información, los desarrollos tecnológicos, los dispositivos móviles o los artefactos de software. Es decir, a los contenidos y currículos de sus instituciones educativas virtuales o presenciales y a la formación que adquiere en sus familias y en sus círculos sociales, hay que sumarle la variedad de nodos inmersos en su contexto. 
Según García (2017), la calidad, eficacia y eficiencia de la educación a distancia y virtual demuestran su auge social y menciona características como apertura, inclusión, democratización, interactividad y aprendizaje activo. Igualmente, en dicho trabajo se exponen realidades y tendencias alrededor de conceptos como aprendizaje digital, que supone cambios educativos radicales y pedagogías disruptivas; el aprendizaje personalizado, que va de la mano con las versiones renovadas de plataformas LMS (learning management system), que incluyen funciones adaptativas para el diseño individualizado de cursos virtuales; el aprendizaje móvil, soportado por teléfonos inteligentes conectados con redes inalámbricas que garantizan diversidad de contenidos, participación en grupos y comunicación en tiempo real e interrelaciones permanentes. Además, se hace alusión al aprendizaje ubicuo, definido como aquel que se genera cuando el estudiante lo necesite, en cualquier lugar, a través de diversidad de medios digitales y en distintos formatos.

Dentro de las tendencias de la educación virtual se encuentran las tecnologías y pedagogías disruptivas. Este concepto es aclarado de la siguiente manera:

Se habla de disrupción al referirnos a las tecnologías o innovaciones que son disruptivas cuando un producto o servicio nace y pasado un tiempo se convierte en líder sustituyendo a otro anterior (Christensen, 1997 y 2012). Al menos, podríamos hablar de disrupción cuando ese producto o servicio sobrepasa en aceptación a los que estaban asentados en la sociedad y mercado. En estos casos se llega a generar un brusco cambio que rompe drásticamente y ocupa el espacio del producto o servicio anterior. Solo por enumerar algunas tecnologías disruptivas en el sentido señalado, serían: el correo electrónico, la fotografía digital, la música en $\mathrm{CD}$, en $\mathrm{mp3}$, por internet, el teléfono móvil, los teléfonos inteligentes, la telefonía por IP, etc. Estas innovaciones llegaron a sustituir a las anteriores que venían ofreciendo servicios similares, pero de menor calidad y eficiencia que las nuevas. En algunos casos podrá discutirse si esas rupturas no son tales al tratarse de meras evoluciones. (García, 2017, p. 15).

En Molano (2018), se afirma que la educación disruptiva busca reformar métodos de enseñanza y contenidos para la transformación de paradigmas educativos clásicos en categorías como estas: aplicación intensa de tecnologías de información y comunicación en procesos de aprendizaje; enfoques en la formación personalizada; flexibilidad de los contenidos; reasignación del rol del docente para que no sea el eje 
de los procesos de aprendizaje; reconocimiento del aprendizaje de los estudiantes por fuera de las aulas de clase; priorización de ambientes de aprendizaje basados en las prácticas en contexto; configuración para la inclusión diferencial en los ambientes de aprendizaje y valoración especial a lo artístico.

\section{Dimensiones formativas de la educación virtual}

Aun con las capacidades de las TIC, la educación virtual no es indistintamente adecuada para cualquier nivel formativo, objeto de conocimiento o individuo. Esto porque en cada caso hay consideraciones sobre la subjetividad de los actores, desde donde se teje relaciones de convivencia y comunicación.

En cuanto a los niveles formativos, las necesidades en cada uno determinan dinámicas distintas en los ambientes de aprendizaje. Según el Ministerio de Educación Nacional (2020), "los niveles son etapas del proceso de formación en la educación formal, con los fines y objetivos definidos por la ley". La educación formal referida en la Ley 115 de 1994, se organiza en tres niveles: el preescolar, la educación básica y la educación media. A su vez, los niveles de formación de la educación superior especifican unos objetivos y tipo de estudios que las caracterizan. Estos son: universitario, tecnológico, técnico profesional, especialización universitaria, especialización técnico profesional, especialización tecnológica, especialización médica, maestría, doctorado y posdoctorado, según el SNIES (2020). Cuando se comparan estos distintos niveles educativos, desde la experiencia docente se evidencia que la educación virtual implica enfoques diferentes, especialmente si se analizan las necesidades de encuentros presenciales o de intensidad de las interacciones virtuales. Pero esto no es ajeno a la educación presencial, donde también los ambientes formativos son disímiles según el nivel. En cada nivel es posible desarrollar distintos estilos de aprendizaje que, según Honey y Mumford (1992), pueden ser: activista, reflexivo y pragmático.

Los ambientes con estilos activistas le plantean a las TIC la necesidad de recursos para la exploración de nuevas experiencias y el trabajo colaborativo, mientras que los reflexivos reclaman ambientes para el análisis de la información y su sistematización. A su vez, las TIC deben proveer alternativas para al análisis y síntesis de enunciados teóricos y posibilidades para el estilo de aprendizaje pragmático, cuya esencia es la aplicación práctica de los conceptos para revolver problemas. 
Por otra parte, Durán y Costaguta (2008) plantean otros estilos de aprendizaje, de acuerdo con la forma como los estudiantes reciben y procesan la información. Pueden ser sensorial/intuitivo (forma de percepción), visual/verbal (entrada de información), activo/reflexivo (procesamiento), secuencial/global (dimensión de la percepción). Lo anterior quiere decir que mientras a los sensitivos les gustan los hechos y los datos, los intuitivos prefieren principios y teoría; los estudiantes visuales tienden a recordar mejor lo que ven, mientras que los auditivos recuerdan más lo que escuchan y dicen. Asimismo, mientras que la experimentación es fundamental en el estudiante activo, la teorización es fundamental para el estudiante reflexivo; y en cuanto a los procesos de comprensión, el aprendizaje secuencial dispone los contenidos y momentos en un orden de progresión lógico, mientras que el global prefiere enfocarse en la naturaleza de los problemas y los conceptos. Como puede deducirse, cada estilo de aprendizaje implica aulas virtuales adecuadas y procesos formativos específicos.

\section{Dimensiones instruccional y educativa}

La educación virtual puede presentar dimensiones formativas distintas y considerar distintos modelos instruccionales, intenciones pedagógicas, ambientes de aulas virtuales, de acuerdo con el nivel, el objeto de estudio y el tipo de estudiante. Estas dimensiones pueden ser instruccional o educativa propiamente dicha. Antes de plantear las diferencias entre la una y la otra, conviene recordar la concepción general sobre educación: es el conjunto de acciones e influencias proporcionadas para la adaptación del individuo a un determinado entorno, de acuerdo a sus marcos conceptuales e históricos de identidad social. Las sociedades en el curso de la humanidad han educado a las personas para defender y perpetuar las relaciones que las definen (Heredia, 2020). Es decir, se educa de acuerdo con cierta ideología. Pero también se puede educar para actuar antagónicamente, con la intencionalidad de romper la continuidad del poder subyacente, representado por acciones políticas, culturales, económicas, en todo caso, públicas.

En uno y otro caso es indiscutible que educar implica interacciones sociales entre los individuos, ya que los mundos individuales absolutos no son de humanos. Sobre esto, Gimeno (2002) escribió:

El ser humano es un ser inclinado por naturaleza, inexorablemente, a establecer vínculos con los otros y a relacionarse con los demás, ya que encuentra en estos una referencia inevitable para apoyar su "incompletud" originaria. Gracias a estos contactos en nuestra existencia llegamos a ser lo que somos. (p. 24). 
Según esto, es incongruente el intento de educar en soledad en sentido estricto, sin que la persona tenga vínculos con otros. Unas preguntas que irrumpe a respecto es: ¿ puede hablarse de educación en escenarios donde no haya profesores ni otros estudiantes?, ¿cuál es el contexto y cómo es la adaptabilidad en esas condiciones? Es posible que surjan iniciativas para aprender a vivir en carencia voluntaria o involuntaria de compañía alguna, dígase en una cueva, en un monasterio, en una casucha en la playa o en una celda oscura en la cárcel, pero serían eventos momentáneos, artificiales, controlados para sobrevivir y no procesos educativos propiamente dichos. Esto es, serían aprendizajes de algoritmos o procedimientos para adaptarse el medio, pero no transformadores de la persona.

Distinta es la instrucción, pues es un proceso menos complejo. Instruir es lo mismo que enseñar técnicas precisas, informar, comunicar ideas, transmitir doctrinas. Se puede instruir por ejemplo para la convivencia comunicando protocolos previamente construidos. El éxito de la instrucción, no como en la educación, es posible sin que las personas se relacionen con otras personas, o sea que no es condición necesaria el que la persona esté inmersa dentro de alguna comunidad. En este sentido, puede decirse que un maestro puede instruir a su alumno para que conviva con la soledad y es igualmente posible que la persona aun estando en comunidad, reciba instrucciones estando en soledades momentáneas. En estos casos, el progreso depende de las mediaciones utilizadas y los ambientes de aprendizaje. (Parra, 2010, p. 30).

Esta disyunción entre educación e instrucción la describe muy bien el siguiente texto. Es contundente el planteamiento, pues la biblioteca puede albergar enseñanzas sobre contenidos de disciplinas concretas, pero no educación en sentido estricto.

En su choza de la playa, Tarzán quizá puede aprender por sí solo y ponerse al día en la historia, geografía o matemáticas utilizando la biblioteca de sus padres muertos, pero sigue sin haber recibido una educación humana que no obtendrá hasta conocer muchos después a Jane, a los watuzi y demás humanos que se acercarán. (Savater, 2008, p. 15).

El planteamiento sobre tales diferencias entre educar e instruir sitúa un referente dentro del análisis de potencialidades para la socioafectividad, ya que estas se fundamentan en la relación educación-convivencia y, entonces, como problema central surge la duda acerca de las capacidades de la educación online para tales potencialidades, si se tiene en cuenta que el encuentro entre las personas es virtual, pero no presencial. 
De acuerdo con lo anterior, puede establecerse la diferencia entre la dimensión instruccional y la dimensión educativa propiamente dicha de la educación virtual. La instrucción es un proceso menos complejo que la educación. Instruir es lo mismo que enseñar técnicas precisas, informar, comunicar ideas, transmitir doctrinas. El éxito de la instrucción es posible sin que las personas se relacionen con otras personas y sin que estén inmersas dentro de alguna comunidad. Un enfoque instruccional de la modalidad online debe proveer repositorios de contenidos con la suficiente capacidad ilustrativa, guías de estudio efectivamente diseñadas para orientar aprendizajes, posibilidades de retroalimentación sin necesidad de comunicación con el tutor y alta calidad en los objetos de aprendizaje. La instrucción es un proceso menos complejo que la educación. Instruir es lo mismo que enseñar técnicas precisas, informar, comunicar ideas, transmitir doctrinas. La dimensión educativa, por su parte, es la interpretación de modelos, valores, reglas, problemas y relaciones socioculturales del entorno (Heredia, 2020).

La esencia de la dimensión propiamente educativa de la educación virtual está en la intensidad de las interacciones entre facilitador y estudiantes y entre ellos mismos. No es posible que se lleve a cabo en aislamiento, sin que haya comunicativas multidimensionales.

No todo proceso de educación virtual (e-learning) es educativo, pues es posible que tengan propósitos solo instruccionales. Es diferente educación a instrucción. Desde el enfoque cultura y desarrollo, "La educación es el vehículo principal e insustituible para la transmisión de cultura" (PNUD, 1999). En esos términos se plantea la educación como desarrollo de las personas, en relación con el crecimiento interior; desarrollo por las personas, en el sentido social, pues la educación permite "darse al otro e influir sobre el otro; desarrollo para las personas, ya que el fin último de la educación es contribuir para que el educando ponga en escena todas sus potencialidades al servicio de los demás. Debe tenerse en cuenta que lo cultural está relacionado con el conjunto de identidades colectivas, de posturas unánimes frente a la vida. La cultura, puede decirse, es un conjunto de manifestaciones que identifican la tradición de una comunidad. (Parra, 2010, p. 30).

Usualmente, para medir el impacto de la educación virtual, a veces se compara esta con la educación presencial, ya que la concentración en las aulas para aprender ha sido el paradigma de la educación en la historia. A su vez, el conocimiento tiene también anclas con estas concepciones cuando se afirma que es el resultado de procedimientos, pautas, sistematizaciones colectivas en los centros de interés (Hernández, 2001). Dicho esto, se entienden las preocupaciones en la sociedad sobre las iniciativas disruptivas como la 
educación virtual, que conciben la posibilidad de ambientes de aprendizaje sin la necesidad de implementaciones en aulas físicas. El debate es aún más intenso cuando se sabe que el currículo no es únicamente contenidos y técnicas, pues se aprende también de las experiencias de los otros y de la convivencia con ellos.

Un ambiente de aprendizaje rico, desde la perspectiva psicosocial, es aquel que posibilita el encuentro inter e intrageneracional con sus concebidas oportunidades de crear y recrear significados personales y colectivos, el encuentro de experiencias pasadas y presentes nutridas por relaciones de apoyo y solidaridad, el encuentro de grupos etéreos con intereses y expectativas comunes y disimiles (Roldán e Hincapié, 1999, p. 45)

El currículo se construye desde las vivencias y experiencias significativas para grupos de estudiantes. Es una configuración de hechos y memorias que va determinando colectivamente formación de competencias y habilidades (Sánchez, 2019).

Desde otro punto de vista, dice Unigarro (2004), se pueden generar procesos educativos y comunicativos en la virtualidad, mediante relaciones sincrónicas o asincrónicas, sin que sea ineludible la concentración física de profesores y estudiantes. Es decir, los ambientes educativos pueden lograrse en el ciberespacio. No obstante, antes que discrepancias, hay coincidencias, cuando en ambos enfoques de ambiente educativos (en el aula física o en la virtualidad), se reconoce el pilar de la comunicación como un requisito básico para la educación. En un caso la comunicación es directa, en el otro hace presencia la mediación de las TIC. De todas formas, no puede ignorarse que la educación se configura desde interacciones sociales entre las personas, pues todos aprenden cuando conviven en comunidad, cuando se reconocen mutuamente (Delors, 1996).

Según lo anterior, puede ser inapropiado poner en la misma balanza la metodología de educación virtual y la presencial. Intentar equipararlas puede conllevar críticas acerca de la dimensión educativa, en el sentido de los juicios que posiblemente surjan alrededor de la capacidad tecnológica para crear calor humano o para reemplazar las relaciones humanas que naturalmente brotan en las aulas de clase tradicionales. Esto es, en esas aulas hay sensaciones intrínsecas que no se sabe si se podrán construir en el aula virtual. Es probable que, por ejemplo, los videos o las fotografías aproximen realidades remotas o que en las redes sociales se establezcan comunicaciones sinceras, pero queda pendiente el atractivo de la subjetividad, la identidad, la realidad del ser humano que se encuentra cuando se siente al otro. 
Considerado lo anterior, se comprenderá que el aula virtual y el aula presencial deben observarse con lupas distintas, reconociendo sus delimitaciones conceptuales y funcionales, y a partir de estas, crear armazones distintos sobre sus procesose indicadores de evaluación. El asunto crítico no está en que independiente del contexto un ambiente presencial o virtual sea de mejor calidad que el otro, por sí mismo. El verdadero fondo es que el ambiente en el aula del ciberespacio o en el aula física responda efectivamente al proyecto educativo de estudiante, pero reconociéndose brechas y limitaciones. Es decir, asumiendo responsabilidades que lleven a "indicar caminos que permitan aproximarse a la comprensión de la realidad y de las distintas situaciones del contexto" (Díaz, 2007, p. 54). Estos argumentos anteriores ponen en escena el compromiso humano de la educación virtual, o sea, su dimensión educativa. ¿Cómo hacerlo? ¿Cómo entender estos retos para que en las aulas virtuales haya realmente formación y transformación de las personas?

\section{El reto formativo de la educación virtual}

¿Cómo crear dinámicas educativas sabiendo que hay conexiones humanas que difícilmente los sistemas tecnológicos pueden sustituir? ¿Cómo crear mecanismos de autoevaluación y metaevaluación para que los estudiantes puedan construir sus proyectos de vida? ¿Cuáles son las alternativas para fomentarse el aprendizaje en contextos significativos y la formación de valores axiológicos, aun con las limitaciones educativas y comunicativas? Son preguntas constantes en la planeación de los ambientes virtuales. Estas preguntas deben enfocarse comprendiendo que en la comunidad virtual la convivencia no está en la territorialidad, sino en el ciberespacio. Además, pueden los interrogantes pueden ser puntos de partida para la determinación de rutas metodológicas de aprendizaje.

La opción más factible para la educación virtual es asegurar la convivencia para la humanización desde los mecanismos de comunicación potencializados. En este caso, las formas de comunicación que se puedan sostener deben ser motivos de permanente creatividad, pues el reto es que pueda suplir los beneficios de la ausencia física. Sobre esto ya hay evidencias en un proyecto de investigación en el que se logró concluir que desde la comunicación escrita dentro de la virtualidad se construyen marcos de afectos, emociones, tensiones, relaciones interpersonales, gratitudes y convicciones colaborativas (Parra et al., 2007). Pero en esta investigación tales conclusiones no se plantearon con el afán dogmático de considerarlas en comparación con las fortalezas de la educación presencial, lo que se concluyó de manera objetiva es que, en el escenario virtual, sí se registran sentimientos, afectividades y reconocimientos personales (Parra, 2010). 
Según Gómez (2006), lastecnologías de la información yla comunicación han transformado formas y prioridades de aprendizaje e incluso visiones sobre los ambientes educativos. Además, han llevado a modificaciones en los procedimientos de acceso a las disciplinas y cambios metodológicos de sus estudios (Machado y Ramos, 2005). Es el caso de la estadística, el acceso a su objeto de estudio y las metodologías para su aprendizaje han cambiado sustancialmente debido al advenimiento de las TIC. Esto confirma la prominencia tecnológica en la configuración de ambientes de aprendizaje disruptivos y, ciertamente, sitúa a los ambientes virtuales de aprendizaje en posiciones tan reconocidas que parecen ya inexorables.

Así entonces, la educación virtual configura factores humanos, sistemas tecnológicos, contenidos, nuevas formas de acercamiento a las disciplinas y propósitos educativos amplios. Según esto, lo fundamental está en las redes de seres, de personas participantes, pero sin desconocimiento de las redes teleinformáticas y de las estructuras de las comunicaciones. Por esto tienen que considerarse asuntos relacionados con autenticidad e identidad de los profesores y estudiantes, y con las formas como se establecen los vínculos entre ellos. Aunque las redes acercan a las personas, es inocultable que en la educación virtual hay alejamiento de la comunidad física escolar, pero en una sociedad caracterizada por la movilidad, la flexibilidad, la cultura global, la inmediatez de la comunicación y avalancha informacional de internet, son múltiples las oportunidades para los encuentros no presenciales. Los actos pedagógicos en la educación surgen desde el interés por el otro. Ello determina las intensidades y formas de los mensajes y los medios, es decir, la preocupación pedagógica implica construir comunicación pensada de acuerdo con las condiciones de los actores. Al respecto, en Correa (2009) se afirma que "si todo lo que el hombre hace está mediado; si no hay ser humano posible sin mediaciones; reconozcamos entonces como un espacio amplio de reflexión y de trabajo la mediación educativa" (p. 19).

En el caso de la virtualidad total, los actos pedagógicos adquieren ciertos matices distintos a los que plantean la educación presencial y a distancia. Por lo siguiente: la presencia física debe ser reemplazada por las tecnologías para la mediación, con el reto de reemplazar el vínculo corporal. Esto es, la integración de TIC debe responder a las necesidades de comunicación de los actos pedagógicos, observándose que proporcionalmente la exigencia de efectividad es mayor, cuando la virtualidad es más absoluta. Por supuesto, cuando hay oportunidades para reuniones presenciales en los casos en que la virtualidad es apoyada con tutorías físicas, entonces, disminuyen las obligaciones para los 
procesos y dispositivos tecnológicos. Se observa también que en el caso de la tipología de e-learning educativo, las necesidades tecnológicas para la comunicación son aún más apremiantes que en el caso del e-learning instruccional, pues en el primero deben crearse condiciones suficientes para potenciar intensidad en los diálogos de facilitadores y estudiantes.

\section{Calidad de la educación virtual}

\section{Sistemas de calidad de la educación virtual}

Usualmente, para medir la calidad en la educación superior se crean sistemas que comprenden: los atributos objeto de medición, los instrumentos que se aplicarán en las mediciones y las escalas de valores para el análisis e interpretación de los datos logrados. A continuación, se presentan varios de estos sistemas, con el ánimo de un marco de referencia para entender las condiciones de calidad de la educación virtual.

En una investigación se encontró que la evaluación de la calidad educativa de modalidad virtual requiere de parámetros distintos a los de la modalidad presencial, debido a especificaciones de la primera sobre modelo pedagógico, caracterización de los estudiantes y objetivos formativos (Marciniak y Gairin, 2018). Con tal supuesto los investigadores compararon 25 modelos y 42 dimensiones que se han utilizado para determinar calidad de la educación virtual. Los resultados se resumen en la tabla 2.

Tabla 2. Modelos y dimensiones de la educación virtual

\begin{tabular}{clc} 
Dimensión & \multicolumn{1}{c}{ Descripción } & $\begin{array}{c}\text { Modelos } \\
\text { que } \\
\text { la incluyen }\end{array}$ \\
\hline Pedagogía & $\begin{array}{l}\text { Presentación de objetivos, contenidos, objetos de } \\
\text { aprendizaje, actividades y estrategias de evaluación. }\end{array}$ & 16 \\
\hline & $\begin{array}{l}\text { Enfoque 1: centrado en evaluar características de los } \\
\text { estudiantes como habilidades tecnológicas, acceso a la } \\
\text { tecnología, manejo del computador y autogestión del }\end{array}$ & \\
& $\begin{array}{l}\text { aprendizaje y del tiempo. } \\
\text { Estudiantes }\end{array}$ & 9 \\
& $\begin{array}{l}\text { Enfoque 2: centrado en evaluar la satisfacción y } \\
\text { percepción de los estudiantes sobre los profesores, los } \\
\text { recursos, los contenidos, el acceso a los cursos virtuales, }\end{array}$ & \\
& $\begin{array}{l}\text { la infraestructura tecnológica, los servicios académicos } \\
\text { y los servicios de apoyo que brinda la institución. }\end{array}$ & \\
\hline
\end{tabular}




\begin{tabular}{|c|c|c|}
\hline Dimensión & Descripción & $\begin{array}{l}\text { Modelos } \\
\text { que } \\
\text { la incluyen }\end{array}$ \\
\hline $\begin{array}{c}\text { Contexto } \\
\text { institucional }\end{array}$ & $\begin{array}{l}\text { Evaluación de la capacidad de la institución para } \\
\text { asuntos académicos, administrativos y relacionados } \\
\text { con el e-learning; suficiencia en cuanto a recursos } \\
\text { económicos y tecnológicos; fortalezas de la estrategia } \\
\text { organizacional, el compromiso con la innovación y la } \\
\text { apertura a la sociedad. }\end{array}$ & 8 \\
\hline Infraestructura & $\begin{array}{l}\text { Evaluación de la capacidad de la infraestructura } \\
\text { tecnológica para que estudiantes y profesores participen } \\
\text { eficientemente en el curso virtual. }\end{array}$ & 8 \\
\hline Docentes & $\begin{array}{l}\text { Evaluación de competencias de los docentes, proyección } \\
\text { a través del medio tecnológico, comunicación en el } \\
\text { entorno virtual, utilización adecuada de las TIC y gestión } \\
\text { del desarrollo del curso virtual. }\end{array}$ & 6 \\
\hline Desarrollo & $\begin{array}{l}\text { Evaluación desde dos enfoques. El primero, relacionado } \\
\text { con los procesos desde la planificación de las actividades } \\
\text { hasta la evaluación final del curso, y el segundo, } \\
\text { relacionado con la cualificación y preparación de los } \\
\text { profesores, sus estrategias para la comunicación e } \\
\text { interacción y las funciones pedagógicas y motivacionales } \\
\text { que ellos exhiben. }\end{array}$ & 7 \\
\hline $\begin{array}{c}\text { Materiales y } \\
\text { recursos }\end{array}$ & $\begin{array}{l}\text { Evaluación de la capacidad y suficiencia de los objetos } \\
\text { virtuales y de la forma como los estudiantes los } \\
\text { incorporan a sus ambientes personales de aprendizaje } \\
\text { (PLE). }\end{array}$ & 7 \\
\hline Impactos & $\begin{array}{l}\text { Evaluación de los resultados del curso virtual. Considera } \\
\text { indicadores para aspectos como consecución de } \\
\text { los objetivos institucionales y del curso, nivel de } \\
\text { transferencia de los aprendizajes de los estudiantes a su } \\
\text { ámbito profesional y cambios observados en individuos, } \\
\text { grupos, comunidades u organizaciones. }\end{array}$ & 7 \\
\hline Diseño & $\begin{array}{l}\text { Evaluación del diseño didáctico (objetivos del curso, } \\
\text { estrategias de enseñanza y aprendizaje, actividades, } \\
\text { objetos didácticos, estrategias de evaluación de los } \\
\text { estudiantes, contenidos y estructura general del curso); } \\
\text { y del diseño tecnológico (organización de la plataforma } \\
\text { virtual, funcionalidad del aula virtual y medios } \\
\text { tecnológicos de comunicación e interacción. }\end{array}$ & 6 \\
\hline
\end{tabular}

Fuente: elaboración propia a partir de Marciniak y Gairin (2018).

Para los estudiantes, la calidad de la educación virtual está relacionada directamente con la actuación formativa y con la docencia. Para ellos la calidad se expresa en acciones como las siguientes: respuesta oportuna de los profesores, gestión de la plataforma para cargar actividades en el menor 
tiempo posible, retroalimentación ágil de las actividades de evaluación y compromiso de los actores (estudiantes y profesores) con el desarrollo del curso (Arras et al., 2018). Agregan que el proyecto de educación virtual requiere de un armazón o ambiente institucional favorable a cambios cualitativos e innovaciones educativas. Igualmente, consideran esencial el diseño de escenarios creativos en los cuales los estudiantes logren desarrollar su potencial y puedan llevar a cabo sus propios proyectos, para el logro no solo de competencias profesionales y técnicas, sino, además, de niveles de motivación personal. Marciniak (2015) hizo un estudio donde se aplicó benchmarking para la evaluación de calidad de organizaciones de educación virtual. En el ámbito empresarial, esta es una técnica que se utiliza para la comparación sistemática de prácticas internas de una organización con las de otras consideradas referentes por su impacto o tradición. El propósito es aprender lo mejor que hacen las organizaciones referentes y aplicar lo aprendido, haciendo adaptaciones acordes con el ámbito propio.

El resultado del estudio fue la propuesta de una metodología para aplicar benchmarking internacional en universidades que tengan la modalidad de educación virtual, como una opción para la evaluación de su calidad. Como un punto de partida que es fundamental, se concibe que los criterios de calidad de la educación virtual no son comparables con los definidos para la educación presencial, infiriéndose que se requieren metodologías y modelos de calidad especializados y contextualizados con el ámbito formativo virtual. El modelo incluye las siguientes fases:

a). Planteamiento del sistema: definición de objetos de medición o análisis, variables, indicadores, procesos, fuentes y técnicas para acceso a la información.

b). Selección de la institución de educación virtual que será el par o referente del benchmarking.

c). Análisis de información: aplicación de las técnicas de indagación y procesos de medición en ambas instituciones; comparación de resultados, establecimiento de paralelos y establecimiento de distancias y semejanzas.

d). Formulación y desarrollo de planes de mejora: elaboración y puesta en marcha de planes de acción con base en la información analizada.

La tendencia de los cursos tipo $\mathrm{MOOC}$, cursos on line masivos y abiertos, ha surgido como otra alternativa para la educación virtual. Con respecto 
a su calidad, se han expuesto preocupaciones por los intentos para estandarización del conocimiento, dificultades para atender diferencias individuales de los estudiantes (debido a la masificación) y procesos comunicativos unidireccionales centrados en el docente e hincados en el contenido. Con esto en mente, Baldomero y Salmerón (2015) aplicaron el instrumento EduTool para la evaluación de este tipo de cursos en las plataformas, enmarcado por la Norma UNE66181 de Gestión de la Calidad de la Formación Virtual (Norma de AENOR - Asociación Española de Normalización y Certificación). Las selecciones de los cursos evaluados se obtuvieron de las siguientes plataformas de internet especializadas en cursos MOOC: Udacity, EdX, MiríadaX y Coursera. Las dimensiones del estándar 66181 utilizado en la evaluación tienen tres niveles de calidad, como se muestra en la tabla 3.

Tabla 3. Dimensiones del estándar 66181

\begin{tabular}{lccc}
\multicolumn{1}{c}{ Niveles de calidad } & $\begin{array}{l}\text { Número } \\
\text { de ítems }\end{array}$ & $\begin{array}{l}\text { Número de } \\
\text { subfactores }\end{array}$ & Ponderaciones \\
$\begin{array}{l}\text { Nivel de calidad del factor de } \\
\text { reconocimiento de la formación para }\end{array}$ & 6 & 1 & $8,85 \%$ \\
la empleabilidad & 43 & 4 & $47,43 \%$ \\
\hline $\begin{array}{l}\text { Nivel de calidad del factor de metodología } \\
\text { de aprendizaje }\end{array}$ & 21 & 3 & $43,72 \%$ \\
\hline Nivel de calidad del factor de accesibilidad & & & \\
\hline
\end{tabular}

El factor de reconocimiento de la formación para la empleabilidad tiene indicadores como expedición o no de certificados o diplomas, obtención de estos solamente por asistencia, obtención luego de superar un examen y reconocimiento internacional del título alcanzado. En el estudio se evaluaron 20 cursos.

Se concluyó que los $\mathrm{MOOC}$ exhiben en sus formatos un fundamento pedagógico consistente, pero hay diferencias significativas entre las plataformas. Igualmente, no se evidencian diferencias significativas con la formación tradicional en línea. Con base en esto, se plantean preocupaciones en el sentido de la necesidad de certificación y acreditación de las plataformas para evitar oferta de formación con debilidades en la metodología de enseñanza. Así pues, los MOOC serían elementos para la democratización de educación, pero con intereses pedagógicos que estén por encima de otros coyunturales. 


\section{Calidad de los objetos virtuales de aprendizaje}

Un objeto virtual de aprendizaje (OVA) es un dispositivo en formato digital para funciones mediadoras en procesos formativos. Por ejemplo, en el sitio web de Merlot, se encuentran objetos para negocios, educación, humanidades, ciencia y tecnología y ciencias sociales. El ciclo de vida de un OVA lo constituyen las fases de análisis, diseño, producción y evaluación y su encadenamiento lo determina el propósito básico que es impactar en los aprendizajes de los estudiantes positivamente.

De acuerdo con Massa y Rodríguez (2014), un OVA debe tener una estructura conformada por un contenido de aprendizaje, una metodología, unos objetivos y un módulo de evaluación. Según Astudillo et al. (2016) deben tener tres atributos: reusabilidad (la posibilidad de ser reutilizado con distintos temas), dotación de metadatos (variables que identifican la estructura y funcionalidad del OVA) y tener de guías de aprendizaje.

La reusabilidad es una característica esencial porque posibilita que el OVA pueda adaptarse a distintas secuencias formativas y diversos contextos de aprendizaje; los metadatos son descripciones técnicas estructuradas sobre las características del OVA; los itinerarios de aprendizaje deben estar definidos en sistemas de ensamblaje.

La siguiente es una propuesta de caracterización de un OVA:

a). Intencionalidad: el OVA debe estar enfocado como mediador pedagógico.

b). Granularidad: su diseño debe ser específico en cuanto a su alcance, pudiendo ser un tema o un módulo compuesto por varios temas o un curso compuesto por varios módulos.

c). Modularidad: el OVA debe tener los atributos técnicos que lo doten de independencia para poderlo hospedar en distintos repositorios o ambientes virtuales.

d). Interoperabilidad: técnicamente, el OVA debe tener las características mínimas que le permitan hospedarse en distintos entornos o plataformas. Por ejemplo, en distintas versiones de sistemas operativos, en servidores web o en dispositivos móviles (Suárez, 2016).

Suárez (2016) enfatiza en que los OVA son recursos para la mediación pedagógica, es decir, deben estar vinculados con una intencionalidad formativa precisa y estar alineados con unos aprendizajes esperados de 
los estudiantes. Además, su función puede desplegarse en aulas virtuales, aulas físicas o en procesos bimodales.

Las funciones de un OVA son: proveer métodos de aprendizaje; fomentar el aprendizaje activo; implicar aprendizaje centrado en el estudiante y facilitar la construcción, la exploración e indagación (Rosanigo et al., 2016). Estas funciones son posibles si su desarrollo se ha planeado hacia allí, si tanto los diseñadores como los profesores son conscientes de su intencionalidad pedagógica. De lo contrario, su utilización podría ocasionar retrocesos en las actividades formativas.

Otro concepto conocido es el relativo a los medios educativos digitales (MED). Según Astudillo et al. (2016), deben estar hospedados en repositorios públicos o privados y deben informar a los potenciales usuarios sobre tres aspectos: cuál es su ámbito de uso o alcance, cuál ha sido la valoración de especialistas en mediaciones y cuál es su formato técnico (video, audio, página web, libro digital, por ejemplo). Estos metadatos agregados a los contenidos proveen la información suficiente para que los estudiantes conozcan su utilidad y beneficio, antes de decidir su aplicación. Los metadatos permiten la implementación en los hospedajes de procesos llamados ensambladores (guías que definen rutas de aprendizaje) y recomendadores (guías que permiten la elección de un MED de acuerdo con el perfil del estudiante).

Un recurso OVA es un medio educativo digital (MED). Esto se explica desde el concepto de mediación pedagógica. Básicamente un OVA es un medio digital que cumple con la función pedagógica de apropiación y construcción de conocimiento. El reto para los diseñadores de estos objetos es que sean medios efectivos para lograr estudiantes activos, descubridores y comunicados (Gallar et al., 2015).

Con respecto a su estructura, un MED debe tener tres capas o abstracciones:

a). El perfil del contenido: es decir su alcance en cuanto a complejidad y extensión.

b). El perfil del estudiante: cuál es el nivel o característica del estudiante que usará el MED.

c). El perfil del profesor: determinación del modelo de aprendizaje intrínseco en el MED (Astudillo et al., 2016). 
Estos perfiles determinan unos criterios de calidad, que se clasifican en tres categorías:

a). Características básicas del MED: propuesta pedagógica, estructura de los metadatos, capacidad de reutilización, motivación y sistemas de ensamblaje y recomendador. El módulo recomendador exhibe sugerencias al usuario sobre contenidos, de acuerdo con su perfil y características.

b). Contexto del MED: especificidad de los usuarios potenciales, nivel de proactividad de los usuarios, especificidad didáctica, especificidad de los mecanismos de evaluación.

c). Software: especificaciones técnicas de la plataforma de software requerida, criterios de estandarización y aspectos relacionados con empaquetamiento y la accesibilidad del MED.

Otro concepto es el de recursos educativos abiertos (REA). Son materiales en formato digital con las mismas configuraciones de los OVA o los MED. El agregado es que son de acceso libre, gratuito y disponible en internet para quien elija utilizarlos (Méndez et al., 2018). Son recursos de dominio público o tienen licencias de uso libre y pueden ser rediseñados o mejorados para ambientes específicos. Pueden ser libros, cursos, simuladores o mediadores en formato de audiovisuales (Mercado et al., 2018). Las licencias de software libre exigen que cualquier mejora que se haga sea también divulgada y puesta al servicio de otros usuarios.

\section{Evaluación de objetos virtuales de aprendizaje}

En Parra (2011) se propone la metodología de desarrollo de software para objetos virtuales de aprendizaje (MESOVA) con las siguientes fases: concepción del objeto, diseño y desarrollo modular evolutivo, integración y despliegue, pruebas de aprendizaje, consolidación. En la figura 3 se expone el modelo. 
Figura 3. El modelo MESOVA

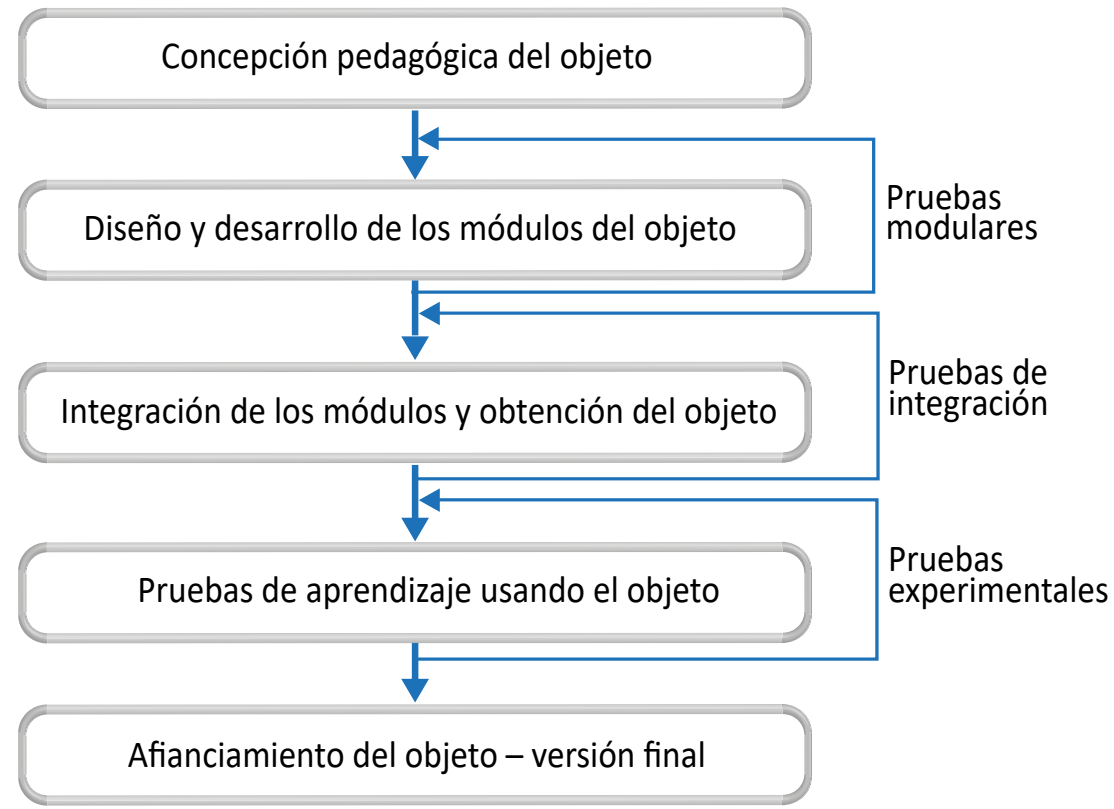

Fuente: elaboración propia a partir de Parra (2011).

Las fases de concepción del OVA y de pruebas de aprendizaje son las fundamentales en el modelo MESOVA, ya que la primera recoge las necesidades e intereses de mediación pedagógica que motivan y justifican su creación, y la segunda se constituye en la evaluación del objeto ya terminado para su validación, antes de implementarse en el ambiente virtual. La fase de concepción del OVA considera las siguientes actividades:

- Caracterización de temática, el nivel educativo y el tipo de contenido.

- Especificidades tecnopedagógicas de alto nivel.

- Especificidad de requisitos funcionales y no funcionales.

- Diseño modular global y de casos de uso.

- Modelado transición de estados y de flujos de información.

- Caracterización del entorno tecnológico del OVA y del usuario.

- Construcción de un prototipo de cada módulo.

- Evaluación del prototipo. 
Las pruebas de aprendizaje usando el objeto comprenden las siguientes actividades:

- Definición de variables dependientes, independientes y extrañas.

- Condiciones e integración de grupos experimentales y de control.

- Caracterizaciones de las pruebas y del ambiente de los experimentos.

- Experimentaciones, mediciones, análisis e interpretación de resultados.

- Evaluación de los OVA teniendo en cuanta la experimentación.

Otra propuesta sobre evaluación de calidad de objetos de aprendizaje es la que hacen Méndez et al. (2018). Utilizaron un LORI (Learning Object Review Instrument) con los siguientes criterios:

- Calidad de los contenidos.

- Alineación de los contenidos con los objetivos de aprendizaje.

- Mecanismos de retroalimentación.

- Capacidad para motivación de los estudiantes.

- Visibilidad y diseño de la presentación.

- Calidad de las interfaces en cuanto a usabilidad e interacción.

- Nivel de accesibilidad.

- Nivel reusabilidad.

- Nivel de estandarización.

Tabares et al. (2017) diseñaron un modelo de evaluación por capas con una estructura que comprende dimensión educativa, de contenidos, estética, funcional, de metadatos y contextual (el contexto es el repositorio donde esta hospedado el OVA).

Massa y Rodríguez (2014) propusieron otro modelo de evaluación con los siguientes niveles:

a). Nivel I: actividades de evaluación realizadas por expertos externos al proyecto.

b). Nivel II: verificación de indicadores de la calidad interna antes del hospedaje en un repositorio público para uso de los estudiantes. Esta evaluación la hacen los técnicos del proyecto.

c). Nivel III: evaluación por parte de los usuarios acerca de la funcionalidad del objeto de aprendizaje. 
Insuasty et al. (2014) compararon tres metodologías para evaluar los OVA. Estas metodologías tenían las siguientes rutas:

Primera metodología. Constitutiva con los siguientes aspectos: cohesión (especificidad temática y de los objetivos de aprendizaje); dimensión (cantidad de subtemas que aborda); reusabilidad tecnológica (capacidad para instalarse en distintos ambientes y plataformas y reusabilidad didáctica (capacidad para adecuarse a temas distintos de los contenidos).

Segunda metodología. Constitutiva con los siguientes aspectos: intencionalidad pedagógica; caracterización psicopedagógica (capacidad para despertar la motivación y atención del estudiante); capacidad didácticocurricular (especificación de tiempos de aprendizaje y de retroalimentación); y usabilidad (diseño de interfaz y navegabilidad).

Tercera metodología. Competencias a desarrollar. Consideró las siguientes categorías: pertinencia del contenido; diseño estético y funcional del contenido; diseño instruccional para aseguramiento de adquisición de las competencias.

Sánchez (2011) propuso un modelo de ciclo de vida para creación y evaluación de OVA con las siguientes etapas:

a). Análisis y determinación requerimientos didácticos.

b). Diseño estructural y funcional.

c). Desarrollo técnico e implementación de acuerdo con el análisis y el diseño definidos.

d). Evaluación: aplicación de criterios sobre la calidad antes de presentarse a los estudiantes.

e). Implantación en los repositorios. Hospedaje para el servicio de los estudiantes.

Massa y Rodríguez (2014) propusieron un modelo diferente para la evaluación de OVA:

a). Planificación de la evaluación: son los procesos de elección y preparación de los evaluadores, diseño de guías de evaluación y definición de los escenarios de evaluación.

b). Desarrollo de la evaluación: comprende procesos de aplicación de las guías de evaluación según los escenarios establecidos y de consolidación de los informes sobre los resultados obtenidos. 


\section{Evaluación experimental de objetos de aprendizaje}

En la experimentación se consideran hipótesis, variables independientes que serán controladas o manipuladas, variables dependientes que serán las que se medirán y que dependen de las independientes, variables extrañas que deben ser eliminadas de los experimentos para evitar resultados influenciados o sesgados, objetos de la experimentación que los procesos, eventos o individuos sobre los cuales se medirán las variables y los escenarios de experimentación (Montoya et al., 2011; Riestra, 2013).

En las evaluaciones experimentales, los grupos de control y experimental se utilizan para confirmar las hipótesis de los experimentoso para rechazarlas. En el primer grupo se miden los efectos en el ambiente debidos a las variables no controladas, $y$, a su vez, en el segundo grupo se miden los efectos de las variables manipuladas. La diferencia entre estas dos mediciones demuestra la incidencia o intensidad de la variable experimental o controlada. A manera de ejemplo, si el objetivo fuera evaluar la capacidad de un software educativo para mejorar resultados de aprendizaje de movimiento parabólico en un curso de física, se aplicaría en ambientes de clase en un grupo experimental y luego se compararían los resultados con los obtenidos en un grupo de control, donde se desarrolló la misma clase (igual contenido, metodología y ambiente) pero sin aplicación del software. Podría asumirse que la calidad del software es fiable y que, por tanto, se puede aplicar en las clases como mediación pedagógica, si los resultados del grupo experimental superan a los del grupo de control. La garantía de validez interna del experimento se alcanza con la homogeneidad de los dos grupos (deben ser similares en cuanto a características cognitivas, sociales, culturales y físicas de los estudiantes) (Montoya et al., 2011; Ramos, 2015; Riestra, 2013).

En los experimentos, las variables se manipulan de acuerdo con su presencia, ausencia, nivel de intensidad o de acuerdo a su modalidad; las variables dependientes se miden en función de las independientes y deben medirse cuando se evidencia la relación causa-efecto (Acevedo et al., 2013; Reidl, 2012; Marañón et al., 2017). Es decir, se espera que las variables independientes ocasionen reacciones o alteraciones en las variables dependientes.

Ponce et al. (2007) hicieron un experimento para medir la capacidad de un software de entrenamiento en lectura significativa (e-PELS). Romero (2016) evaluó un software matemático para aprendizaje de los temas de límites y derivadas en cálculo diferencial. Para esto creó grupos experimentales y de control para medir las variables dependientes e independientes. En ambos 
casos, un grupo experimental utilizó los programas de software y otro de control no los utilizó.

Narváez-Romo et al. (2017) hicieron una evaluación de software educativo con un diseño experimental. Se utilizó el software Mundo Agroforestal y se realizaron pruebas en dos momentos: evaluación diagnóstica (Ed) y evaluación posterior (Ep), con tres repeticiones R1 (al terminar las capacitaciones); R2 (al segundo mes de terminadas las capacitaciones) y R3 (al cuarto mes de terminadas las capacitaciones).

Raposo-Rivas y Salgado-Rodríguez (2017) evaluaron un software llamado MeMotiva, para comparar su capacidad en el apoyo de procesos de aprendizaje enfocados en la memoria operativa, la atención, la planificación y del control inhibitorio de los estudiantes. Guedez (2005) aplicó pruebas pretest y postest sobre grupos experimentales y de control para evaluar un software educativo del área de matemáticas para el aprendizaje del tema de funciones reales.

Villalobos et al. (2017) evaluaron experimentalmente un software llamado GeoGebra. La hipótesis que se validó fue que aplicando GeoGebra como mediación tecnológica en las clases de apoyo, se obtiene una mejora en el aprendizaje en la asignatura de cálculo diferencial. Orozco et al. (2017) desarrollaron un estudio sobre perfiles de distintas experimentaciones para evaluación de software educativo y contenidos digitales de aprendizaje.

Ramírez et al. (2015) evaluaron experimentalmente un recurso multimedia denominado ABCLandia, diseñado para apoyar procesos educativos sobre las habilidades comunicativas básicas de hablar, escuchar, leer y escribir en niños con síndrome de Down. Para la experimentación se seleccionaron niños con edades entre 8 y 12 años y de los resultados obtenidos experimentales y de control se logró establecer el impacto del recurso, antes de ser expuesto para su aplicación real. 



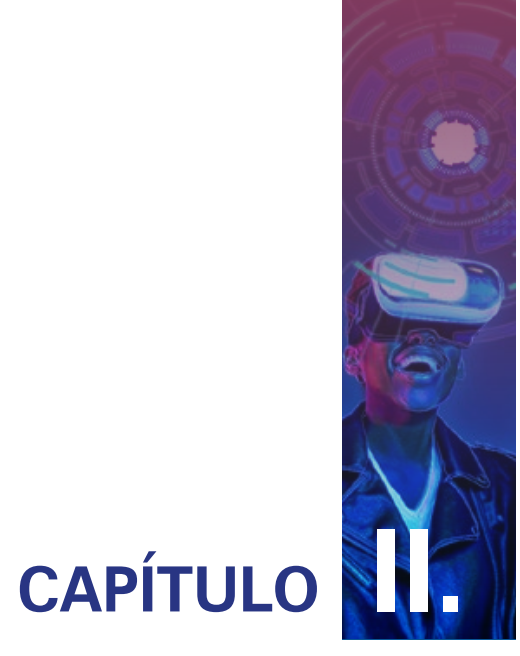

\section{CALIDAD Y ÉTICA EN LA MODALIDAD DE EDUCACIÓN VIRTUAL}

Usualmente, se relaciona el avance de la educación virtual con la aplicación de las tecnologías de la información y la comunicación para crear escenarios educativos distintos a los que se despliegan en los ambientes físicos de las instituciones. Pero investigaciones, vivencias, lecciones aprendidas y debates académicos han trascendido hasta determinar enfoques más amplios y complejos sobre tal modalidad educativa, infiriéndose que el sistema tecnológico es insuficiente si no se acondiciona de acuerdo con propuestas pedagógicas interactivas y descentralizadas. Además, el progreso en sí mismo de la educación virtual ha desentrañado que su conceptualización y funcionalidad se complejizan aún más, si se reconoce que en sus sistemas tecnopedagógicos el objetivo esencial está en los intereses de grupos de humanos que buscan incrementar aprendizajes. Esos grupos, como es natural, están expuestos a subjetividades e intersubjetividades y por eso los análisis sobre comportamientos éticos y sobre calidad merecen estudios y deliberaciones que conduzcan a planeaciones y prácticas con menos eventualidades y con mayores impactos educativos.

\section{Ética y ética digital}

Un concepto de ética expuesto de una manera simple, pero no superficial, es el de Savater (citado por Camperos, 2002). Antes de entrar en aspectos de ética digital o analizar aspectos sobre la ética en la educación virtual, es menester exponer, a manera de reflexión o de discusión, en fin, lo que es una dimensión de la ética desde la libertad.

Según Savater, en el texto citado por Camperos (2002), vivir bien determina conocer qué es lo que realmente se quiere y, además, conocer por símismo, cuáles son los satisfactores que humanamente traen regocijo. 
Ser ético es cultivar el buen vivir. Ser ético es hacer lo que verdaderamente se quiere, no con satisfactores inmediatos, sino recordando que nuestras decisiones y comportamientos fundamentalmente influenciarán nuestras vidas, aunque se piense que la incidencia será en la vida de los demás (comúnmente así se cree). Es decir, si la persona intenta perjudicar al prójimo, finalmente, el daño es para ella misma. Cuando tratamos de dañar a otro, muchas veces nos causaremos peores daños nosotros. El ser humano debe ser tratado como tal, dignamente, no hacerlo así lleva a que la misma persona consiga ser tratada en las mismas condiciones. Asimismo, hay que evitar hacer a los otros lo que no queremos que nos hagan y no permitir que nos agredan, menoscaben o nos traten indignamente, como nosotros seríamos incapaces de hacerlo con los demás. En conclusión, esto es un asunto de equidad, justifica, juicio y razón (Camperos, 2002).

Las tecnologías de la información brindan opciones para la gestión y transferencia de la información en tiempo real a grupos de usuarios, constituyéndose posiblemente redes con intereses comunes. Pero, aunque la información sea moralmente neutra, puede encerrar intencionalidades, dependiendo del uso que la gente le dé. De acuerdo con Martínez (2015), la conciencia ética de la información puede tomar rumbos diversos, en concordancia con las interpretaciones e intereses. Además, deja interrogantes sobre el sentido de la innovación tecnológica cuando esta se separa de los beneficios y compromisos sociales. De igual manera, sugiere que la educación virtual debe demostrar fundamento ético y construcción de ciudadanía y subraya la reflexión sobre las implicaciones éticas de la apertura de la información, dejando entrever cierta relación que podría relacionarse con la educación virtual. Esto es, advierte sobre los compromisos éticos de la institución que organiza la modalidad virtual.

En otro trabajo, Martínez (2017) indaga sobre la necesidad de una ética digital para la educación a distancia, debido a las continuas innovaciones y al desarrollo de nuevas tecnologías y expone preocupaciones por prácticas como el plagio, la manipulación de información o la falsificación de identidades. Aunque advierte que en la educación escolarizada tradicional también hay riesgos digitales. Señala que la ética digital es una habilidad del siglo XXI, junto con la metacognición, la adaptabilidad, la contemplación creadora y la capacidad para resolver problemas complejos y emprender acciones no rutinarias.

Se expone que un análisis sobre las implicaciones éticas, legales y sociales de las tecnologías sobre la educación a distancia debe considerar tres criterios: la reflexión sobre las transformaciones en el ser y sus 
relaciones; la necesidad de un marco ético que oriente las actuaciones en los entornos virtuales (ética digital); y las habilidades que son reto para la educación del siglo XXI. Concluye que el contexto educativo influenciado por las TIC determina la necesidad de procesos curriculares adaptativos, más libres (entendidos así en términos estrictos), conectados con la realidad y más comprometidos con la creatividad. Agrega que, la necesidad de ciertas habilidades digitales de los estudiantes en la hiperconectividad del mundo, no exime la responsabilidad de las instituciones educativas (sin distinto de modalidad) para el cultivo del pensamiento crítico y la ética como marco para el actuar correctamente mirando hacia el futuro.

Pero concretamente: ¿a qué se refiere la ética digital? El ciberespacio es otro espacio de actuación, tan común como la ciudad, la familia o la escuela. Al mismo tiempo la gente va en el tren metropolitano y está en la red social o está ahí y en su casa, viviendo dos escenarios reales (uno tangible y el otro real). Incluso, es común ver a los millennials viviendo en paralelo y en tiempo real varios mundos, más de dos. En el hogar, en la escuela, en la ciudad, hay marcos de actuación, acuerdos acerca de comportamientos responsables o ciertos conceptos generales para la toma de decisiones o procederes en consideración con la armonía establecida. De esta forma, entonces, la sociedad y el mismo individuo pueden tener criterios para establecer hasta dónde una actuación es o no ética. En el entorno virtual ocurre lo mismo: deben existir marcos sociales o acuerdos que permitan diferenciar las interacciones de los usuarios con los dispositivos tecnológicos y con las comunidades de internet, para la determinación acerca de si son o no éticas o armoniosas con los otros.

Rivera y Minelli (2017) exhiben las relaciones entre ética y educación virtual, de acuerdo al concepto de antropología digital, enfocándose en el estudio del ser humano influenciado por la tecnología y la hiperconectividad. Se plantea una nueva identidad del ser humano manifestada en la exposición de distintos artefactos que definen el "yo" virtual, presente en la Web 2.0, los correos electrónicos, las redes sociales o las comunicaciones online presentes en tiempo real en los dispositivos móviles. Con esto en mente, se plantea un dilema ético entre el "yo analógico o real" y el "yo virtual". En consideración de esto, una persona exhibe dos identidades: la primera, la cual es su impronta o realidad interna, y la segunda, virtual, que se muestra en los entornos digitales. Es decir, las personas saben que hay diferencias entre su yo intrínseco, propio, y el que aparece en el entorno virtual. De esta forma, el "yo" se muestra con cierta máscara virtual que esconde encrucijadas personales y en general, todo lo que encierra a la persona misma. 
Estas autoras exponen es sus análisis dos interrogantes: “¿Tiene la tecnología algún espacio en la ética? [...] ¿la ética puede limitar o determinar el influjo de la acción tecnológica?" (Rivera y Minelli, 2017, p. 51), las respuestas o el debate alrededor de estas debe partir de la presencia de los artefactos tecnológicos como agentes y no como instrumentos pasivos, ya que influyen activamente en las personas, en sus formas de percibir, actuar e interactuar. Con este ámbito conceptual de la relación entre ética y tecnología y los dilemas entre el yo real y el yo virtual, se plantea la exigencia del compromiso de los actores con su autenticidad en los ambientes virtuales. En relación con esto, deben establecerse planteamientos pedagógicos que incorporen la visión de la tecnología como agente con significado para el proceso de aprendizaje.

\section{Escepticismo por la calidad}

En referencia a la universidad virtual, en Esteban y Fuentes (2015) se hace un análisis que parte de una doble interpretación: desde un punto de vista, se afirma que internet está permitiendo reavivar a la educación universitaria que requería ser despertada de su aletargamiento e iniciar procesos de renovación. En coherencia con esto, internet se avisará como una presencia que obliga a las universidades a adaptarse a las realidades y necesidades de la gente. En otro ángulo, dice que la universidad debe calcular esas pretensiones renovadoras, en defensa de su responsabilidad histórica con la educación comprometida con el desarrollo íntegro de la persona. Ante los afanes renovadores, la universidad debe ir con cautela, sin perder su rumbo y su sentido y sin dejarse imponer metamorfosis hacia su modernización. La universidad virtual está en este punto encontrado, en enlace con la primera postura, aparece como una opción del mercado neoliberal, y, de acuerdo con la segunda, está arraigada en las dimensiones ética y humanística que históricamente arrastra. Pero el planteamiento va más allá que una irreconciliable dicotomía. Así lo ilustran estos autores cuando dicen que la educación virtual:

Parece ser adecuada para trabajar una gran cantidad de contenidos, habilidades y competencias típicamente universitarias, parece ser pertinente para tratar todo lo relativo a las relaciones humanas, cuestión también peculiarísimamente universitaria, $y$, por supuesto, parece adecuada para lograr el florecimiento humano en el sentido más profundo de los términos. (Esteban y Fuentes, 2015, p. 107).

La preocupación va encaminada hacia el concepto de estudiante que se presenta en la educación virtual, cuando se hace énfasis en su autonomía y que merece respeto incondicional de sus gustos, criterios, 
posturas, en contraposición al comportamiento virtuoso que es regulado por la comunidad universitaria tradicional (pero estas afirmaciones deben interpretarse concienzudamente, ya que es válido decir que en la universidad tradicional, también hay aspiraciones y manifestaciones de estudiante libre y autónomo. El asunto crítico es la autonomía extrema que a veces se promulga en la educación virtual). El tema de fondo, concluyen, es que la universidad virtual, aunque alineada con la renovación y la innovación, debe mantener la esencia universitaria de cultivar virtudes para la vida personal, familiar, social y profesional de las personas.

Con el advenimiento de internet se empezó a hablar también de una revolución educativa sustentada en la proliferación de recursos digitales interconectados que posibilitan formas descentralizadas de aprendizaje. Pero los interrogantes surgen acerca de las dimensiones de esa revolución y en ese sentido se plantea, por ejemplo, que las instituciones educativas se han enfocado en aplicar software, simuladores, video juegos, medios digitales, pero sin investigaciones y análisis acerca de la mejora de los procesos educativos o de transformaciones originadas por las TIC en aspectos sociales, culturales o cognitivos (Peña, 2010). A tono con estos análisis, es cuando se plantea que "las tecnologías de información y comunicación simplemente sustituyen unos roles, trasladan a las redes la educación presencial sin concebir una reestructuración completa del proceso educativo, que resuelva sus problemas actuales y que aproveche más pedagógicamente el potencial de la tecnología" (Peña, 2010, p. 124).

Otro asunto crítico en la educación virtual es la deserción de los estudiantes. Parece contradictorio, pues esta es una de las premisas más notorias que se exhiben de esta modalidad. Hay estudios que se han enfocado en las causas, como el realizado en la Universidad Nacional Abierta y a Distancia (UNAD), que muestra cómo entre las tres razones del abandono de los estudios universitarios, está el relacionado con la metodología y el acompañamiento tutorial (Peralta y Mora, 2016). El factor de la deserción conduce a exámenes conceptuales tanto sobre calidad, como de ética institucional. En consideración de la calidad, en el mundo empresarial la tendencia es que sean los usuarios quienes la determinen y no los productores. Esto es, son las personas que se benefician de los servicios a quienes les compete decidir sobre su calidad, pues son ellos los que están habilitados de acuerdo con sus intereses y necesidades. Estas ideas, si se transfieren al mundo educativo, sitúan a la calidad en términos de pertinencia y su evaluación determina que sean los estudiantes y no los profesores o la institución los determinadores (Rama, 2011). Así, entonces, dentro de tal marco, el fenómeno de la deserción escolar en la educación virtual deja en entredicho su calidad. 
En cuanto a la relación entre deserción escolar y ética institucional, un elemento esencial para el análisis sobre deserción es el rol del profesor. Pero no es que con esto se ignoren otros causales como los económicos, lo que quiere subrayarse es que el profesor es un actor primordial, ya que es quien representa a la institución en el vínculo cotidiano con el estudiante. Por eso mediante esta relación, se plantea el compromiso de los profesores con el mejoramiento, regeneración y resignificación de su tarea docente como una responsabilidad ética (Gozálvez et al., 2014). Allí se hace énfasis sobre la conveniencia y necesidad del compromiso de los profesores con las competencias para el contexto informacional, tomándose como un asunto ético su permanente actualización formativa. Comprendido esto, se desprende que el asunto de la deserción en la educación virtual implica al equipo de profesores. Es decir, ellos no son agentes que únicamente apoyan los aprendizajes específicos en las distintas asignaturas, si no que en realidad hacen parte de la institucionalidad en la cual están inmersos los estudiantes.

La educación virtual no está exenta de la función transformadora de la educación. Ramírez (2016) se plantea que la educación transformadora significa exploración de aprendizajes para fomentar autonomía e independencia de los individuos, la integración y participación social activa, la capacidad para saber escuchar y comprender integralmente a las personas, los contextos, los problemas, las ideas. Este autor hace hincapié en una educación crítica para que se entienda la responsabilidad social como un habituado protagónico. Desde este punto de vista también se hace un examen de la ética en la virtualidad. Se supone, según el concepto de educación transformadora, que las direcciones y actuaciones en la organización virtual tengan como perspectiva la transformación del individuo y, por consiguiente, la ausencia de intencionalidades pedagógicas reales para el aprendizaje significativo y el enfoque a ultranza en la aplicación de dispositivos, objetos digitales o ambientes de simuladores, por ejemplo, dejarían dudas con respecto a la ética institucional.

Con referencia a la educación virtual, las representaciones sociales entremezclan acepciones que la consideran como una iniciativa para la inclusión, una posibilidad para estudiar fácilmente, una ruptura con la educación escolarizada, un ambiente educativo con restricciones con respecto a la educación tradicional, como una alternativa basada en pedagogías disruptivas o como una opción tecnológica para aprender. El atractivo fundamental es que los ambientes virtuales incluyen en la formación profesional o para el trabajo, a personas que por su condición están excluidas de las instituciones educativas tradicionales, 
por condiciones físicas o porque su prioridad en la vida cotidiana está determinada por situaciones y funciones laborales, sociales o familiares o porque presentan limitaciones de movilidad. Pero en el ámbito social se perciben ciertas dudas con respecto a la calidad y las preferencias de la gente, que parecen inclinarse por las opciones clásicas de la educación.

A pesar de los temores por la calidad (de acuerdo con los resultados mostrados en las tablas 12, 13 y 14), en Colombia la oferta de la educación virtual se ha incrementado y, además, con lineamientos concretos las instituciones han procurado definir compromisos con el desarrollo de esta modalidad responsablemente y se han logrado afinar conceptos y mecanismos relacionados con la tecnología utilizada y las propuestas pedagógicas. El incremento se sustenta en datos del capítulo anterior, que muestran cómo el número de programas académicos en Colombia pasó de 130 en 2001 a 760 en 2020 y además, de 552 instituciones de educación superior, $113(20,47 \%)$ ofrecen programas virtuales (ambas estadísticas son de educación de pregrado y de posgrado y se obtuvieron del Sistema Nacional de Información de la Educación Superior (SNIES, 2020). Con respecto los avances sobre pedagogía y tecnología para la educación virtual, a nivel mundial las investigaciones y experiencias se han multiplicado. Así lo demuestra una consulta de la expresión "educación virtual" en Google Académico: entre 2000 y 2009 se encontraron 4.660 resultados y entre 2010 y 2019 los hallazgos fueron 16.100, en tanto que la búsqueda de la frase "didáctica general" arrojó resultados de 3.630 y 15.400 , respectivamente, en esos intervalos de años.

Pero junto con el incremento de la oferta mostrado con las estadísticas anteriores y las experiencias concretas sobre su expansión, los asuntos que quizá son menos visibles son los de la ética y la calidad, pues, aunque probablemente sea motivo de reflexiones internas individuales, pareciera que este tema no ha sido lo suficientemente investigado ni reflexionado en los escenarios académicos. Es así como el asunto de un código de ética, aunque necesario, parece ser inabordable, al contrario de otros como calidad, tecnología, pedagogía, diseño instruccional o contenidos digitales. Igualmente, en relación con la calidad, aunque se logren superar las condiciones del Ministerio de Educación Nacional y procesos internos de autoevaluación diseñados y aplicados por las instituciones, quedan subrepticiamente en el imaginario social ciertas dudas e incomprensiones acerca de lo que realmente puede ser la calidad de una institución o un curso virtual.

Agregando a lo anterior, el desarrollo de la virtualidad como modalidad educativa supone un perfil del estudiante con características como las 
siguientes: autonomía responsable para gestionar sus aprendizajes; decisión para aprender lo que le han programado en el diseño instruccional; actitud investigadora para explorar e indagar intensamente; capacidad para trabajar colaborativamente. Asimismo, se supone que los profesores son facilitadores de los aprendizajes y que son fieles a los contenidos pertinentes con la formación del estudiante. Incluso, los profesores deben tener claro que el cúmulo de competencias y conocimientos que requiere un egresado no debería variar según la modalidad de estudio.

No obstante, es válido evaluar si tales presupuestos sí están en coherencia con la realidad de las actuaciones en el aula virtual. Las experiencias han demostrado que las tecnologías de la información y la comunicación que se aplican en la modalidad virtual tienen las potencialidades suficientes para la creación de los ambientes educativos que efectivamente requieren los docentes y los estudiantes para llevar a cabo los procesos formativos. Lo que no se ha logrado demostrar es que estas tecnologías pueden crear dotaciones para el aula virtual que la equiparen con el aula presencial y que tengan las capacidades suficientes para suplir el encuentro cara a cara entre los actores (estudiantes, docentes, asesores, coordinadores).

En consideración de lo anterior, surge la siguiente pregunta: ¿cuáles son las percepciones de actores internos y exógenos a la educación virtual sobre calidad y la ética de los procesos formativos en esa modalidad de la educación virtual? Junto con esta pregunta se buscó esclarecer con el proyecto cuyos resultados se exponen en este libro, inquietudes con respecto a los elementos y circunstancias que generan desconfianzas sobre la calidad y la ética de los procesos formativos de la educación virtual; las dudas subrepticias sobre autenticidad y validez de procesos formativos de esta modalidad educativa y cuáles concepciones deberían considerarse en los lineamientos para un código de ética.

En general, puede decirse que las investigaciones sobre educación virtual se han enfocado en la pedagogía, tecnología, mediaciones pedagógicas y diseños instruccionales, entro otros, pero sobre la ética y la calidad la investigación es menos recurrente. Con base en estos conceptos se han propuesto sistemas y modelos con el fin de sistematizar atributos sobre la calidad y lograr mediciones precisas (Domínguez y Rama, 2011).

En una investigación del CINDE (Giraldo y Villa, 2006), se abordaron las percepciones de los docentes universitarios sobre el uso de las nuevas tecnologías de información y comunicación en sus prácticas pedagógicas. 
En este proyecto se hace un análisis sobre la importancia de tratar el tema de la calidad y el buen uso pedagógico de la tecnología, como algo mucho más importante que meramente el uso de artefactos informáticos que se utilizan para apoyar la educación.

En otro proyecto desarrollado por Benítez y Gómez (2015), se hace un análisis complejo y profundo sobre las presiones a las que están sometidos los profesores en el siglo actual, debido al flujo continuo de artefactos y paradigmas tecnológicos, lo que de cierta manera les crea distractores con respecto a sus funciones educativas. Esto es, el profesor ante el afán de la mediación tecnológica, se está desviando del interés por la conceptualización y análisis de la pedagogía. Debido a esto, los autores anteriormente citados hablan de cómo en la educación virtual el profesor se está convirtiendo en un operario de la sociedad de la informática.

Las competencias socioafectivas en la educación virtual ponen de presente la necesidad de la comprensión del aula no como un conjunto de recursos informáticos que sirven para hospedar información, sino como un escenario donde confluyen seres humanos ávidos de comunicación, fraternidad, identidad y conocimientos. Esto implica tener serios compromisos con las competencias socioafectivas y con los valores axiológicos de los profesores y los estudiantes (Parra et al., 2007).

En referencia a la práctica educativa en los ambientes virtuales de aprendizaje (AVA), en su proyecto de investigación, Mora y Bejarano (2013) concluyeron:

Como primer momento para concluir es indispensable hacer mención del concepto de práctica y su carácter de construcción social antes que una categoría conductual. En este sentido la práctica debe comprenderse desde la interpretación de los actores y de sus nuevos roles. De esta manera las prácticas desarrolladas en ámbitos presenciales continúan perviviendo en las generadas en los AVA. Pero este nuevo ámbito no representa una sustitución de los contextos existentes puesto que esta sobreviene a la irrupción de la cibercultura entendida como esa nueva forma de representar, actuar y desarrollar la práctica educativa. En la historia de la humanidad ninguna forma artística de expresión reemplazó a las precedentes, la fotografía no reemplazó a la pintura, los AVA no sustituyen los ambientes presenciales. Construyen las prácticas educativas en un medio tecnológico diferente (ciberespacio) que responde a la dinamización de los avances computacionales y de expansión en red. Si bien, la práctica real en el ciberespacio no tendría sustitución, existe una pérdida que estaría ligada a esa relación dialógica, cara a cara entre 
docente y estudiante. La interpelación cotidiana en la que los significados circulan, se yuxtaponen y negocian en un ambiente presencial no es posible, en intensidad y representación, en los AVA.

La responsabilidad en la creación de cursos o programas virtuales no es de alcance únicamente pedagógico y tecnológico, aunque por supuesto, estos dos elementos se interrelacionan y son preponderantes. De acuerdo con Castañeda et al. (2015), la planeación, diseño y ejecución de un curso o programa virtual encarna una responsabilidad social porque se trata de atender la búsqueda de unos seres humanos que demandan esta modalidad educativa para dar respuesta a necesidades formativas.

Llama también la atención el tema de los dilemas éticos en la educación virtual. Se sabe según las experiencias en esos ambientes, que directivos, profesores y estudiantes de esa modalidad de educación están continuamente enfrentando toma de decisiones en circunstancias antagónicas o paradójicas: ¿qué hacer con quien incurre en fraudes o suplantaciones debido a imperfecciones en el ambiente virtual, sancionarlo o corregir la insuficiencia? ¿Qué es lo fundamental, ampliar cobertura virtual para incluir más personas o preservar la calidad racionalizando la oferta? ¿Qué hacer con quién no demuestra perfiles para convivir en el ámbito virtual, motivar su salida o hacer esfuerzos que no están planeados? ¿Qué es lo crucial, garantizar mediaciones y recursos para atender a más personas con menos profesores o mantener un nutrido plan profesoral? La educación virtual está expuesta a dilemas como estos, definidos por Basso-Musso (2012) en términos de problemas éticos que aparentemente no tienen solución, pero que deben ser resueltos y cuyas soluciones serán producto de la deliberación, del análisis y negociación para llegar a consensos.

\section{Investigación sobre calidad y ética en la educación virtual}

Para conocer la percepción de actores internos y observadores externos acerca de la calidad y ética de la educación virtual, se desarrolló un proyecto de investigación cuyo método y resultados se exponen a continuación.

En una fase inicial se hizo una indagación conceptual sobre la caracterización de la educación virtual considerando variables relacionadas con los actores, los medios, los contenidos, la pedagogía, la comunicación y los alcances. Se buscó obtener una presentación organizada de esos 
componentes para una comprensión de sus dinámicas y su importancia en los procesos formativos. Se consultaron fuentes documentales y experiencias como fuentes de información, con la delimitación de considerar programas en modalidad ciento por ciento virtual.

En una segunda etapa se aplicaron encuestas a estudiantes de educación básica y estudiantes de pregrado y posgrado de universidades presenciales, con el fin de conocer sus expectativas y percepciones sobre la calidad y la ética de la educación virtual. Con los datos obtenidos se construyeron los guiones para la siguiente fase de aplicación de entrevistas y grupos focales.

En la tercera etapa se hicieron entrevistas en profundidad con académicos y expertos en educación presencial y virtual a nivel superior, para conocer sus expectativas y su interpretación del funcionamiento de la modalidad virtual. Se escogieron para las entrevistas expertos académicos con trayectoria en la educación superior con y sin experiencias en la educación virtual.

Además, se hicieron grupos focales con estudiantes, egresados y profesores de programas académicos de la educación virtual para comprender sus apreciaciones y sentimientos sobre sus experiencias con la formación en modalidad virtual. Las unidades de análisis y las triangulaciones tuvieron en consideración conceptos relacionados con calidad de la formación recibida y miradas éticas sobre actuaciones de profesores, directivos y estudiantes. La categorización se fue construyendo en la medida en que avanzaron las indagaciones, ya que, desde la interpretación de factores como los discursos de las fuentes de investigación, la comprensión de posturas de los actores de la educación virtual o las lecturas de las actuaciones en el aula virtual, se entrecruzaron las conceptualizaciones para los análisis respectivos. Las categorías sobre ética y calidad se definieron previamente, antes de la aplicación de los instrumentos cualitativos.

Seguidamente, se construyeron textos interpretativos concernientes a características de la educación virtual, la calidad de los procesos formativos y las formas de actuación de profesores, estudiantes y directivos, con los que se pretendió configurar una conceptualización relacionada con referentes teóricos y categorización de los hallazgos.

En la quinta etapa del proyecto, con la intención de analizar la opinión sobre la educación virtual de personas del común (como padres de familia, empleados del sector empresarial o personas que son actores en escenarios académicos), se aplicaron encuestas con el fin de obtener un panorama estadístico sobre discernimientos relacionados con la 
modalidad educativa virtual. Aclárese que el fin no fue validar el texto interpretativo ya construido, pues son distintos los enfoques cualitativo y cuantitativo. Lo que se quiso fue complementar y obtener otra lectura del fenómeno estudiado, para aportar una perspectiva más general y un abordaje más integral.

En la última etapa se hizo una propuesta de lineamientos sobre un código de ética para la educación virtual, entendido como un marco conceptual para el buen actuar en el entorno virtual educativo y no como una reglamentación para actuaciones éticas o para esclarecer dilemas.

Se desarrolló una investigación con enfoque mixto predominantemente cualitativa, que integra procesos de análisis de información recogida a través de entrevistas, grupos focales, encuestas y exploración documental. Se ha optado por el método así, para lograr un entendimiento más completo del problema de la calidad y la ética en la educación virtual. Según Díaz (2014), en los métodos mixtos los investigadores combinan técnicas, metodologías y conceptos para abordar la realidad. Se caracterizan porque coexisten con los paradigmas cualitativo y cuantitativo, potencia las fortalezas de estos dos enfoques y atenúa sus debilidades y lo más importante: posibilita una comprensión del problema de manera más amplia e integral.

Se entiende que las investigaciones cualitativas "desarrollan un contacto directo y permanente con los actores y escenarios que estudian, porque su interés radica, precisamente, en comprender desde ellos y desde la observación de sus acciones y comportamientos el conocimiento que tienen de su situación" (Galeano, 2004, p. 19). De acuerdo con esto, el acercamiento y la comprensión del discurso de los actores resultan predominantes en este tipo de investigación, en tanto que en el enfoque cuantitativo "busca descubrir leyes o principios generales (generalizar resultados) y para ello acude a sistemas estadísticos de muestreo que cuantitativamente sean representativos de poblaciones más amplias [...] los datos son hechos conocidos y recuperables en el sentido que se pueden medir, contar" (Galeano, 2004, p. 14).

Con relación al componente cuantitativo, se entiende que dentro de sus fines están la medición de variables para generalizar a poblaciones completas resultados obtenidos en otras más reducidas. En este proyecto, se asume esa concepción, pero como complemento, pues el propósito general del análisis está enfatizado en la comprensión. En realidad, el componente estadístico se aplicó para ampliar la información obtenida con los instrumentos de tipo cualitativo. 
Se utilizó un diseño mixto de tipo convergente (Creswell, 2014) para el estudio de la información. Por un lado, se siguió la ruta de recolecciónanálisis-resultados de datos cualitativos, en otros momentos la ruta fue recolección-análisis-resultados de datos cuantitativos. Luego, se construyó una interfaz de interpretación de los hallazgos de las dos rutas definidas. Se tomó como punto de inicio el despliegue de los datos cuantitativos y luego se presentaron los datos cualitativos con la intención de confirmar o rechazar los primeros. La interpretación final de los hallazgos se determinó considerando el enfoque cualitativo de la investigación.

No obstante, debido al carácter cualitativo predominante en el proyecto, la secuencia anterior no es exactamente lineal. Primero, porque las fases de recolección de información cualitativa y cuantitativa se alternaron, e incluso, la primera encuesta sirvió para afinar los guiones de las entrevistas y los grupos focales y segundo, porque el componente cualitativo de las investigaciones compromete la subjetividad de los investigadores, no por temor a sesgos, sino porque en las comprensiones entran en juego sus experiencias y posturas sobre los objetos de estudio.

La ruta cualitativa finalizó con una triangulación de resultados clasificados en seis categorías, comparando lo que dijeron los siguientes informantes: expertos en educación superior, egresados de la educación virtual, profesores de la educación virtual y estudiantes de la educación virtual. Las categorías fueron:

- Encuentros y rupturas entre la educación virtual y la educación presencial.

- Calidad de la educación virtual.

- Comportamientos éticos en la educación virtual.

- El aprendizaje en la educación virtual.

- Tendencias y retos de la educación virtual.

- Perfiles de estudiantes y docentes.

La ruta cuantitativa finalizó con un análisis de variables para la contratación de las indagaciones que se presentan en la tabla 4. 
Tabla 4. Indagaciones del componente cuantitativo del proyecto

\begin{tabular}{|c|c|}
\hline Instrumento & Indagaciones generales \\
\hline \multirow{2}{*}{ Encuesta 1} & $\begin{array}{l}\text { ¿La educación virtual ha logrado presencia y preferencia en la sociedad } \\
\text { en proporción igual a la educación presencial? }\end{array}$ \\
\hline & $\begin{array}{l}\text { ¿La educación virtual genera confianza sobre el actuar ético de los } \\
\text { actores en los ambientes de aprendizaje? }\end{array}$ \\
\hline \multirow{2}{*}{$\begin{array}{c}\text { Encuesta } 2 \\
\text { Parte } 1\end{array}$} & $\begin{array}{l}\text { ¿Los egresados de la educación virtual han logrado presencia en el } \\
\text { sector empresarial en igual proporción que egresados de la educación } \\
\text { presencial? }\end{array}$ \\
\hline & $\begin{array}{l}\text { ¿En el sector empresarial se desconfía en la educación virtual y se } \\
\text { considera que el riesgo de fraude en su formación es alto? }\end{array}$ \\
\hline \multirow{2}{*}{$\begin{array}{l}\text { Encuesta } 2 \\
\text { Parte } 2\end{array}$} & $\begin{array}{l}\text { ¿La educación virtual genera confianza y preferencia en las personas } \\
\text { con vinculación empresarial? }\end{array}$ \\
\hline & $\begin{array}{l}\text { ¿Cuál es el nivel de preferencia en los hogares de modalidad virtual } \\
\text { con respecto a la modalidad presencial? }\end{array}$ \\
\hline
\end{tabular}

En la figura 4 se muestra el diseño mixto convergente que se eligió para el análisis de la información.

Figura 4. El diseño mixto convergente

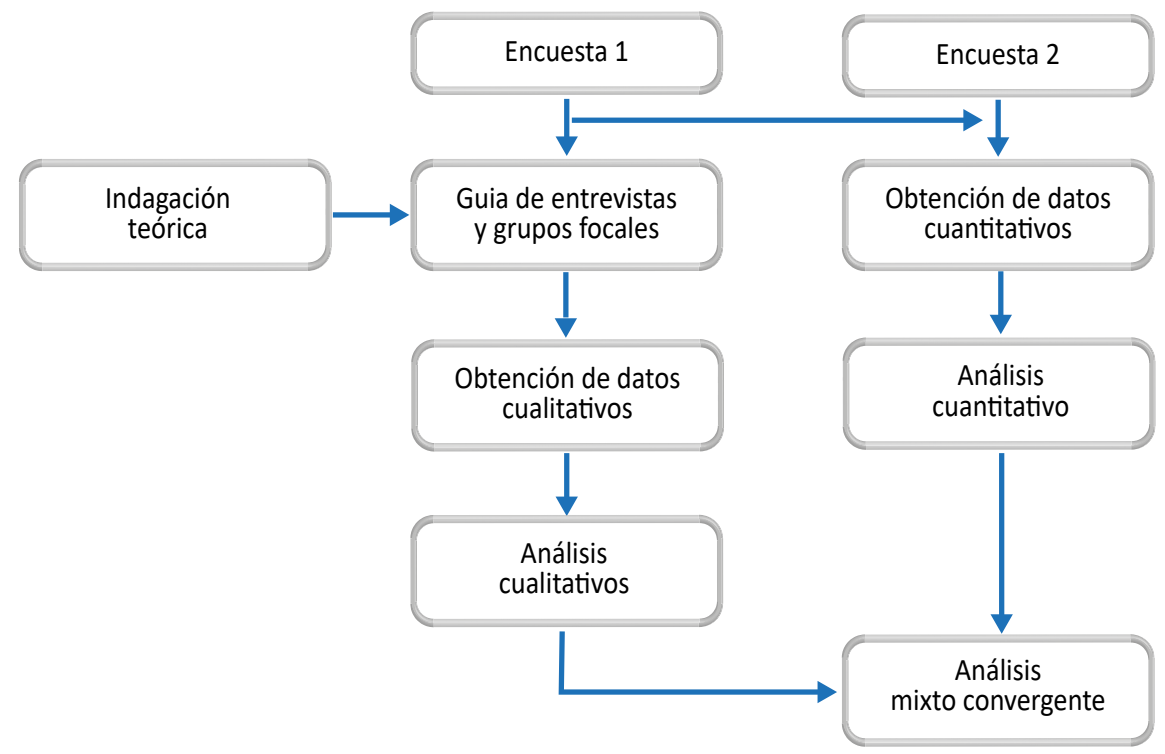


En cuanto al método, dentro del enfoque cualitativo se utilizó un diseño fenomenológico para identificar la esencia de las experiencias de profesores, estudiantes, egresados y expertos en torno a la educación virtual. Según Fuster (2019), "la fenomenología en la educación se ajusta a las experiencias de los agentes de la comunidad educativa, así como en el entendimiento del significado y sentido de estas" (p. 205). Además, "el investigador identifica la esencia de las experiencias humanas en torno a un fenómeno de acuerdo a como lo describen los participantes del estudio" (Creswell, 2003, p. 15). Desde esta mirada fenomenológica, se entiende que el estudio de percepciones sobre ética y calidad de la educación virtual conlleva el análisis de relaciones que establecieron los informantes en torno a estos dos conceptos, con aprendizaje, perfiles de estudiantes y profesores, retos y tendencias de esta modalidad. Esto se confirmó desde los discursos de los informantes, pues cuando hablaban de ética y calidad, directa o indirectamente extendían sus miradas hacia experiencias, sentimientos, propuestas que involucraban actos, actores y conceptos de las dinámicas educativas en la modalidad virtual.

Las unidades de análisis o categorías relacionadas con calidad, ética y diferencias entre educación virtual y presencial, se determinaron antes de la aplicación de las técnicas. Las otras se fueron perfilando cuando se avanzaba en la lectura de los textos. Así que en la medida que avanzaron los discursos, se tejieron unas agrupaciones de ideas comunes hasta llegar a las siguientes categorías:

1) Encuentros y rupturas entre la educación virtual y la educación presencial: de manera recurrente los actores se apoyaron en la concepción de la modalidad presencial para pronunciar ideas sobre la modalidad virtual. Pero no es solo un asunto encajado en los testimonios de los informantes, pues previamente en la investigación se había estimado que para interpretar significaciones de la educación virtual era necesario el referente de la educación presencial, ya que la primera se conoce como una transformación de la segunda. El objetivo de esta categoría fue entender y comparar sentimientos y visiones que sobre encuentros y rupturas entre las modalidades presencial y virtual de educación expresaron expertos en educación, egresados, estudiantes y profesores, pero sin comparar con los sistemas establecidos.

2) Calidad de la educación virtual: es cierto que en la educación superior hay sistemas de calidad que reúnen variables, indicadores, características y factores para evaluar y acreditar la calidad de programas académicos y que, además, son soportes para la legitimidad y para el reconocimiento social. 
No obstante, también es verdad que en la percepción de las personas hay ciertas valoraciones, juicios, interpretaciones o anhelos sobre calidad que no son coincidentes con los sistemas establecidos. Son ciertas representaciones sociales sobre calidad que no son formalmente establecidas y que generan niveles de confianza sobre programas académicos o instituciones. El objetivo con esta categoría fue conocer e interpretar esas visiones sobre calidad de la educación virtual que tienen los informantes.

3) Comportamientos éticos en la educación virtual: cuando se hizo referencia a esta modalidad educativa a veces se escucharon temores, testimonios, casos sobre la facilidad para cometer actos dolosos. Posiblemente porque en el imaginario de la gente está que al estar el estudiante asilado y sin testigos ni controles, puede asumir facilismos para alcanzar logros. Asimismo, porque realmente se exponen situaciones de estudiantes, directivos o profesores que actúan así. Aunque es de reconocerse que el "dedo señalador" casi siempre cae sobre los primeros. Estos asuntos sobre el actuar de las personas en la modalidad virtual condujeron a esta categoría con el objetivo de interpretar los argumentos de los informantes sobre la actuación con ética en la educación virtual y sobre la propuesta posible de un código de ética.

4) El aprendizaje en la educación virtual: hay diferencias entre mediaciones pedagógicas, pedagogía, ambientes de aprendizaje en la educación virtual con respecto a la presencial y hay especificidades en esta última que se evidencian desde la forma como está concebida. Al plantear ideas relacionadas con las primeras tres categorías, los informantes, en buena parte, abordaron el tema del aprendizaje. Esto es entendible porque el engranaje de un curso o un programa virtual es el aprendizaje, este es el motivo primordial de los estudiantes para entrar y es la justificación de los esfuerzos en materia de tecnología y pedagogía. Siendo así, esta categoría se construyó con el objetivo de entender las visiones sobre la forma como se desarrollan los procesos de aprendizaje en la educación virtual.

5) Tendencias y retos de la educación virtual: al tocar los temas de ética, calidad o aprendizaje, recurrentemente los entrevistados hicieron propuestas o críticas. Se fue entonces configurando información sobre situaciones problemáticas de la modalidad virtual que de alguna manera pueden controvertir su credibilidad y calidad o, visto de otra forma, pueden poner en escena elementos para contribuir a su sostenibilidad y reconocimiento social. El objetivo de esta categoría fue interpretar reclamos, críticas o propuestas que hicieron los informantes sobre la educación virtual. 
6) Perfiles de estudiantes y docentes de la educación virtual: en medio de los grupos focales y las entrevistas, de manera repetida, los participantes hicieron alusión a competencias, actitudes y maneras de actuar de los profesores y los estudiantes. En las percepciones encontradas hubo cierta homogeneidad con respecto a características especiales de unos y otros en los procesos de aprendizaje en los ambientes virtuales. Esta categoría se creó con el objetivo de identificar e interpretar las ideas de los informantes sobre los perfiles de estudiantes y profesores en la educación virtual.

\section{Informantes e instrumentos en el enfoque cualitativo}

La investigación con enfoque cualitativo tiene como propósito comprender la realidad desde diversas visiones, perspectivas y lógicas (triada subjetiva) que distintos actores expresan sobre esta. Siendo así, la selección de los sujetos participantes se hace con criterios de diversidad y heterogeneidad. Lo que busca el investigador no es la verdad en esos actores, sino la comprensión detallada de los discursos individuales que dibujan la realidad según esa triada. La realidad es comprendida desde la comparación de los intereses y condiciones de las distintas personas (Galeano, 2004). Con esto en mente, se decidió realizar entrevistas en profundidad a expertos e investigadores de educación superior y grupos focales a egresados, profesores y estudiantes de la educación virtual. Además, se hizo una estratificación entre actores de programas de pregrado y de posgrado.

Las percepciones de los egresados son pertinentes para comprender las dinámicas formativas y sociales de la educación virtual, por cuanto fueron actores directos del acontecer en el desarrollo de las actividades. Como estudiantes que fueron, conocieron de cerca debilidades y fortalezas en el momento de la corresponsabilidad con los compromisos académicos y de estar a tono con su formación profesional. El haber terminado ya el recorrido académico les da una mayor madurez para interpretar los alcances de la educación virtual y les da el piso suficiente para plantear retos y también para exhibir lo que ellos consideran ventajas y desventajas o para el planteamiento abierto de dificultades y logros. Asimismo, tener percepciones de egresados de pregrado y de posgrado les da mayor representatividad a los hallazgos y permite un análisis más completo, ya que en estas dos poblaciones se configuran relaciones distintas entre conocimientos, aprendizajes, metodologías y alcances en el estudio de los problemas. Se pensó, en el diseño metodológico, que el egresado de 
posgrado, por su recorrido, puede hacer planteamientos más sensatos y elaborados sobre la educación virtual, mientras que los de pregrado, al haber estado mayor tiempo en contacto con las aulas virtuales, pueden tener unos conceptos más pormenorizados y puede dar fe de situaciones más específicas de asuntos como la convivencia y la permanencia en la modalidad virtual.

Los profesores constituyen la masa de conocimiento de las universidades ya que, a partir de su experiencia, pedagogía, actitud, investigación y forma de ver el mundo, se erigen los procesos formativos de acuerdo con los currículos establecidos. Incluso, las demás características de calidad de las universidades de alguna manera están en relación con la docencia y desde ahí se justifican los esfuerzos para mantener en alto nivel los propósitos del servicio educativo. En el caso de la educación virtual, aunque en internet están en boga plataformas educativas en cursos masivos y abiertos en los cuales poca importancia se le presta al rol de los profesores, persisten en la conceptualización de esta modalidad los factores preponderantes de la interacción entre estudiantes y docentes como un elemento crucial para el éxito de los primeros.

Considerada, entonces, la importancia primaria de los maestros en los ambientes virtuales, para el proyecto de investigación resultan sumamente trascendentales sus conceptos, aunque obviamente, no son ellos los únicos actores, ni podrían ser los receptores exclusivos de las esperanzas formativas de la gente. Ellos hacen parte de un ambiente en el que se entremezclan variables exógenas y endógenas que configuran los currículos. De los distintos actores del ambiente virtual educativo, quienes mayor autoridad tiene para la evaluación crítica de lo que allí ocurre son los profesores. Son quienes conocen las alteridades de los estudiantes, las incertidumbres pedagógicas cuando la comunidad educativa reflexiona acerca de la metodología más adecuada, las dificultades de las aulas virtuales o las desesperanzas de sus alumnos en momentos de crisis. Por consiguiente, las percepciones expresadas sobre aprendizaje, ética, calidad, tendencias, retos y actuaciones de parte de los actores de la educación virtual dan un piso de sabiduría al análisis e interpretaciones de las dinámicas formativas.

El colectivo de estudiantes se constituye en el motivo primario de los cursos o programas académicos virtuales, puesto que es a ellos a quienes se dirigen las iniciativas institucionales. Por eso, en el momento de un análisis sobre percepciones sobre ética o calidad de la educación virtual, sus conceptos son de especial significado. La relevancia de las opiniones en el ámbito educativo está compartida por directivos, profesores, egresados 
y obviamente por los alumnos. Aunque son los beneficiados directos, naturalmente su visión es menos global que la de los otros actores, porque está encerrada en la inmediatez del aula virtual o presencial, sin reconocer, o haciéndolo muy parcialmente, que sus vivencias directas son producto de determinaciones o posturas institucionales. Sin embargo, el estudiante de la educación virtual, aun con esa visión, adquiere cierto perfil que lo diferencia en cierto modo del de la educación presencial y por esto en sus planteamientos se observan ciertos niveles de madurez y unas argumentaciones que se observan analíticas junto a otras más reflexivas que emotivas. En este grupo focal, esas consideraciones son aún más sentidas ya que se cuenta con estudiantes a nivel de pregrado y de posgrado de especialización o maestría.

En el desarrollo del proyecto se encontró que los conceptos sobre ética y calidad en la educación virtual encierran complejidades que impiden su análisis aisladamente, sin consideración de interrelaciones con otros factores constitutivos y críticos. Es decir, un análisis en torno a la ética y la calidad en un ámbito educativo debe reconocer relaciones con otros conceptos, pues los discursos de los actores introducen vínculos multilaterales y permean distintas áreas. Así quedó demostrado en la recolección de información tanto con las entrevistas en profundidad como con los grupos focales.

Las preguntas detonantes que motivaron las opiniones en los grupos focales y en las entrevistas giraron en torno a las siguientes situaciones:

a). Percepciones sobre las tendencias de la educación virtual en cuanto a pedagogía, mediaciones, comunicación y contenidos en los procesos curriculares.

b). Percepciones sobre los alcances de la educación virtual y como se configuran las diferencias sustanciales con la educación presencial. Que se considera son las limitaciones más sobresalientes. Cuáles se considera son las contribuciones más sobresalientes de la educación virtual.

c). Percepciones sobre las características que determinan calidad en programas académicos y cursos de educación en modalidad virtual.

d). Apreciaciones sobre veracidad, autenticidad, validación, verificación y honestidad en los comportamientos de estudiantes y profesores en la educación virtual. Opiniones sobre la representación social e imaginarios sobre comportamientos éticos de los distintos participantes en los procesos de educación virtual. 
El instrumento que se utilizó en los grupos focales consistió en preguntas cortas ambientadas con comentarios del investigador, con base en un guion con los cuatro interrogantes anteriores. Mientras que en las entrevistas en profundidad se utilizaron comentarios del investigador vinculados con esos interrogantes. Las temáticas, por ser de educación virtual, colateralmente o en forma directa convocan al tratamiento de aspectos educativos, tecnológicos y pedagógicos variados y la experticia de los participantes les da argumentaciones y empoderamiento de manera multidimensional. Esto se tuvo en cuenta tanto en los grupos focales como en las entrevistas en profundidad.

La información recogida de los informantes en los grupos focales y entrevistas se analizó aplicando la técnica del mapeo de relaciones en redes semánticas. Esta perspectiva se centra en las relaciones construidas desde el discurso de los sujetos. A la creación de las redes semánticas precedieron los procesos de codificación y categorización de los textos producto de los discursos de los informantes y a su vez, estos antecedieron la obtención de los hallazgos obtenidos de las entrevistas y los grupos focales. Tal como lo plantean Sabariego-Puig et al. (2014), la reducción de la información envuelve los procesos de selección, focalización y abstracción de los textos brutos en unidades de significado o categorías, con base en unidades temáticas identificadas.

El proceso de análisis se realizó a través de una lógica inductiva consistente en la revisión reiterada de los textos de los discursos, para extraer frases con significado relevantes y clarificarlos en las distintas categorías. Además de palabras y frases sobre ética de la educación virtual, calidad de la educación virtual, educación presencial y educación virtual, se consideraron otras como aprendizaje, actuaciones de los estudiantes, actuaciones de los profesores, recursos para el aprendizaje, medios tecnológicos o técnicas para estudiar en la virtualidad.

\section{Estratificación y variables en el enfoque cuantitativo}

Uno de los objetivos específicos del proyecto fue conocer opiniones que tienen actores externos sobre la calidad y la ética en la educación virtual. Se entiende como actores externos a personas que no están matriculadas en cursos o programas de educación virtual o que no trabajan en gestiones de administración o docencia en el momento de la aplicación de los instrumentos o que su actividad primordial no está en el ámbito de esa modalidad educativa. En este caso, educación virtual hace referencia a la metodología que se desarrolla sin presencialidad alguna. 
Se quiso tener una buena gama de opiniones desde distintos puntos de vista, para tener información diferenciada según posturas y opiniones emanadas a partir de las visiones propias de cada grupo social. Pero tratar de incluira todas las posibles agrupacionesoclases podríallevar a la intratabilidad o imposibilidad no solo de la consecución de la información, sino también de su análisis. Siendo así, para la estrategia de análisis de datos de acuerdo con las indagaciones planteadas, se definieron los siguientes estratos:

a). Estudiantes de pregrado de universidad privada en modalidad presencial: esta clase se caracteriza porque tiende a permanecer menos tiempo en la planta física que los estudiantes de la universidad pública, manifiestan menos apego por el campus universitario y expresan menos intensidad en la pertenencia a la comunidad académica.

b). Estudiantes de posgrado de universidad privada en modalidad presencial: permanecen aún menos tiempo en el campus físico que el estrato 1 . Su interacción con la comunidad académica es muy pasajera y manifiestan muy baja intensidad con la pertenencia a la comunidad académica.

c). Estudiantes de pregrado de universidad pública en modalidad presencial: los estudiantes de este estrato permanecen más en el campus virtual que los de la universidad privada, tejen mayores relaciones de amistad con la comunidad académica y establecen mayores vínculos y sentido de pertenencia con el establecimiento universitario.

d). Estudiantes de educación básica en modalidad presencial: generalmente aún no conocen el campus universitario, no expresan sentido de pertenencia con el campus físico, pues no les pertenece, pero tienen el imaginario del establecimiento físico de la universidad. A diferencia de los estratos a), b) y c), no han tomado decisiones sobre la institución y la modalidad de estudios para alcanzar sus objetivos de profesionalización.

e). Personas vinculadas con el sector empresarial: este estrato es significativo porque aporta perspectivas diferentes de acuerdo con la edad de las personas, en aspectos como las experiencias con las tecnologías de la información y la comunicación, la interpretación sobre el mundo global, la adaptación a movimientos culturales emergentes y las formas como entienden la versatilidad en las interrelaciones sociales. Por consiguiente, la edad puede establecer diferencias en las percepciones sobre la educación virtual. 
f). Hogares: se han configurado con fuentes no académicas y con capacidad de decisión y responsabilidad en los hogares, porque su visión frente a los procesos de la educación es distinta a la que expresan las personas que conviven en el mundo académico. Es decir, se considera que puede haber distancias en la opinión de las personas sobre la educación virtual, según estén o no inmersas en la vida académica.

Teniendo en cuenta la anterior estratificación, se optó por el diseño cuantitativo mostrado en la tabla 5:

Tabla 5. Estratificación y variables en el enfoque cuantitativo

\begin{tabular}{|c|c|c|}
\hline Instrumento & Estratificación & Variables \\
\hline \multirow{4}{*}{ Encuesta $\mathrm{n} .01$} & $\begin{array}{l}\text { Estudiantes de pregrado de } \\
\text { universidad privada en modalidad } \\
\text { presencial. }\end{array}$ & $\begin{array}{l}\text { Educación virtual en comparación con } \\
\text { la educación presencial. }\end{array}$ \\
\hline & $\begin{array}{l}\text { Estudiantes de posgrado de } \\
\text { universidad privada en modalidad } \\
\text { presencial. }\end{array}$ & \\
\hline & $\begin{array}{l}\text { Estudiantes de pregrado de } \\
\text { universidad pública en modalidad } \\
\text { presencial. }\end{array}$ & $\begin{array}{l}\text { Comportamientos éticos en los } \\
\text { ambientes de aprendizaje. }\end{array}$ \\
\hline & $\begin{array}{l}\text { Estudiantes de educación básica en } \\
\text { modalidad presencial. }\end{array}$ & \\
\hline \multirow[b]{2}{*}{ Encuesta $n .02$} & $\begin{array}{l}\text { Personas vinculadas con el sector } \\
\text { empresarial. }\end{array}$ & $\begin{array}{l}\text { Confianza y preferencia por la } \\
\text { educación virtual en el sector } \\
\text { empresarial. }\end{array}$ \\
\hline & $\begin{array}{l}\text { Personas comunes con capacidad } \\
\text { de decisión y responsabilidad en los } \\
\text { hogares. }\end{array}$ & $\begin{array}{l}\text { Confianza y preferencia por la } \\
\text { educación virtual en personas de } \\
\text { hogar. }\end{array}$ \\
\hline
\end{tabular}




\section{Hallazgos en el abordaje cualitativo}

\section{Grupo focal 1: egresados de la educación virtual}

Participaron cuatro egresados de pregrado de Fundación Universitaria del Área Andina y Fundación Universitaria Católica del Norte y cuatro egresados de posgrado de Universidad de Santander y Universitat Oberta de Catalunya.

Categoría 1. Encuentros y rupturas entre la educación virtual y la educación presencial: la visión de los egresados sobre la viabilidad de la educación virtual demuestra, con la versatilidad con que lo expusieron, que conocen de fondo sus ventajas y desventajas. Plantean ciertos asuntos paradójicos, pues mientras dicen que una ventaja de la educación presencial es el contacto directo con el profesor para aclarar dudas, por otro lado, afirman que un privilegio en la educación virtual es que la atención del profesor es personalizada. Esto es entendible, pues difícilmente el profesor en la presencialidad tiene interacciones individuales con los estudiantes.

En el ambiente virtual hay unos mayores dinamismos en los aprendizajes, los estudiantes son muy proactivos, hay mayores plazos para interpretar la información de los profesores. No obstante, llegan momentos en que la institución se vislumbra fría. Por su parte, dicen, la estructura pedagógica de la educación presencial es más sólida, el aprendizaje es más fácil y la atención de los profesores es más natural, pues los estudiantes saben en qué momento tendrán contacto directo. Por su parte en la virtualidad ese contacto tiene más incertidumbre, pues es posible que el profesor acuda al llamado a destiempo o que no acuda.

Un consenso es que la ventaja de la educación presencial está en el contacto físico directo entre los estudiantes, la oportunidad de compartir con los demás compañeros, establecer distintos tipos de vínculos y de tener la relación inmediata con el profesor en el momento programado.

Un aspecto que merece evaluarse es la afirmación acerca de que los estudiantes en la modalidad presencial tienen mayores oportunidades para la formación de competencias comunicativas de oralidad.

Categoría 2. Calidad de la educación virtual: las características para la calidad en la visión de los egresados se pueden agrupar de la siguiente forma: 
a). Tener un equipo pedagógico muy fuerte y objetos virtuales de aprendizaje creados con criterios didácticos.

b). Motivación de los estudiantes con respecto a su decisión para aprender, honestidad en las actuaciones, responsabilidad con el aprendizaje y deseo de hacer bien las cosas.

c). Selección y contratación de los profesores y actuaciones responsables de estos.

d). Infraestructura tecnológica suficiente.

e). Monitoreo sobre la formación profesional que se está impartiendo y validación con las empresas en función de los egresados.

Llama la atención que los egresados relacionan la calidad con la actitud de los estudiantes frente a sus compromisos académicos y con la validación de la formación considerando la interpretación que hacen las empresas.

Categoría 3. Comportamientos éticos en la educación virtual: según los egresados, el riesgo de fraude en la educación virtual sí existe. Se habló de actos engañosos y de la falta de controles para prevención de ese tipo de actuaciones. Unos lo expresaron de manera directa, otros no argumentaron suficientemente lo contrario. Aunque señalan que no es un asunto exclusivo de la educación virtual, pues en otras modalidades también se observan riesgos y conductas de irresponsabilidad. Además, expresaron que la deshonestidad es un asunto de la actitud del estudiante y no de la responsabilidad de la institución.

Como propuestas para la mitigación del riesgo, dijeron que se debe trabajar continuamente en la concientización del estudiante acerca de su responsabilidad consigo mismo en las actividades de evaluación y aprendizaje, avanzar en la implementación de tecnologías y sistemas para validación de identidades y detección de fraudes y procurar actividades que impliquen aplicación de los conocimientos por parte de los estudiantes.

Un planteamiento digno de analizarse profundamente es el que afirma que la confianza en el estudiante es una buena forma para fomentar honestidad en los procesos. $\mathrm{O}$ sea, si al estudiante se le asignan responsabilidades, si en lugar de cohesionar se brinda empatía, se pueden obtener mayor seguridad en cuanto a la trasparencia de los actos.

Los egresados afirmaron que un código de ética sería un reglamento más en la institución, innecesario, ya que los comportamientos surgen desde el interior de las personas. 
Categoría 4. El aprendizaje en la educación virtual: un tema predominante en los discursos de los egresados fue el del trabajo colaborativo. Los equipos de trabajo en la modalidad virtual son más creativos, investigan más, brinda la oportunidad de intercambios con distintas culturas y sirve como mecanismo de autorregulación entre los compañeros. Reconocen los egresados que en varias instituciones planean y exigen el trabajo organizado en equipos. Obviamente, en momentos puede ser no exitoso, pues de todas formas la participación puede estar viciada por subjetividades o determinaciones individuales.

Se plantea, además, que el punto de partida en los procesos de aprendizaje es el estudiante, es muy dinámico, tiene distintas fuentes de información y recursos tecnológicos y abre posibilidades para competencias en materia de investigación y exploración en busca del conocimiento.

Categoría 5. Tendencias y retos de la educación virtual: los argumentos de los egresados se concretaron en los retos, no en las tendencias de la educación virtual. El énfasis lo ponen en la transformación que debe tener el ambiente educativo virtual desde el punto de vista social, para que sea más acogedor y se diezme la sensación de aislamiento que tienen los estudiantes. Interpretando sus sentires, dejan entrever que el aula virtual presentada como una pantalla de computador debe trascender hacia un espacio educativo que haga sentir a sus estudiantes como miembros de una comunidad de aprendizaje.

Otro reto lo plantean en términos del aprendizaje, puesto que indirectamente hacen alusión al constructivismo como elementos para la participación de los estudiantes e igualmente, el método convoca al estudiante a ser responsable con sus procesos educativos. Se añade a lo anterior el protagonismo que le dan a los profesores e inclusive señalan requisitos relacionados con su convencimiento sobre la viabilidad de la educación virtual y el compromiso con los estudiantes.

Categoría 6. Perfiles de estudiantes y docentes: aunque no se quiera, cuando los egresados hablaron de sus profesores cayeron en comparaciones con la educación presencial. Esto parece obvio, pues el paradigma dominante en la educación es del profesor tradicional en sus clases. El asunto de fondo con respecto a los perfiles, es que el profesor debe tener la capacidad y entusiasmo para que sus estudiantes lo sientan, acepten, valoren y comprendan como una persona diáfana, que nada esconde, que está comprometido y cree en la educación virtual. 
Se desprende también que otro perfil de profesor según la visión de los egresados, es su recursividad y creatividad para comunicarse y hacerse entender de los estudiantes y sobre todo, para mantener en ellos altos niveles de motivación.

En relación con los estudiantes, se plantea un perfil que es, por así decirlo, complejo. Debe reconocerse como una persona que está aislada de los campus universitarios físicos, que realmente tienen limitaciones para sus procesos de aprendizaje y que esto le determina mayores sacrificios para obtener logros educativos. Pero esta es una debilidad que se convierte en elemento positivo, pues desde tal reconocimiento se incrementan su disciplina y decisión para formarse profesionalmente.

\section{Grupo focal 2: profesores de la educación virtual}

Participaron ocho profesores de programas virtuales de las siguientes instituciones: un tutor del SENA, dos de la Facultad de Ingeniería de la Fundación Universitaria Católica del Norte, uno del área de Ciencias Sociales de la Fundación Universitaria Católica del Norte, uno de la Facultad de Ingeniería de Universidad de Antioquia (programa U de @), uno del área de Ciencias Administrativas de la Corporación Universitaria Remington, uno de área de Ciencias Sociales de la Corporación Universitaria Minuto de Dios y uno de Ciencias Básicas de la Fundación Universitaria Católica del Norte.

Categoría 1. Encuentros y rupturas entre la educación virtual y la educación presencial: según los profesores, la preferencia por la educación presencial radica en que históricamente ha prevalecido la metodología tradicional y a los padres de familia les es muy difícil aceptar una metodología novedosa y flexible como la virtualidad. Esta aseveración la confirman las decisiones de los estudiantes al terminar la educación básica, ya que deben elegir dónde hacer su carrera profesional. Aparte de esto, debe reconocerse que los jóvenes necesitan ambientes de socialización que pueden encontrar más fácilmente en las universidades presenciales.

Los profesores reconocen que las circunstancias del tiempo y los desplazamientos hacen atractiva a la educación virtual, pero resaltan las ventajas desde el punto de vista pedagógico, enfatizando en que es el estudiante el principal actor de sus aprendizajes. Se afirmó que no son suficientes la democratización tecnológica, la apertura de internet, la generación globalizada de informática, para justificar la viabilidad de iniciativas de educación virtual. En efecto, deben considerarse análisis e interpretación hermenéutica de las necesidades sociales, cognitivas, 
comunicacionales de las personas, antes de decidir sobre oferta de programas virtuales.

Se argumentó también sobre la modalidad bimodal (blended learning) como otra opción para los proyectos educativos. Para concentrar las ventajas que por su lado presentan la educación presencial y la virtual, se pueden hacer programaciones mixtas en las aulas físicas y en las plataformas tecnológicas. En realidad, este esquema es ya común en las universidades tradicionales, donde a los cursos les implementan apoyos con aulas virtuales, páginas web u otros recursos de internet, sea por iniciativa de los profesores o por política institucional. En sentido inverso, la posibilidad de encuentros físicos le daría más vigor a la educación virtual.

Se afirmó también que no es prudente hacer comparaciones entre la educación virtual y la educación presencial, ya que cada persona puede elegir dónde y cómo llevar a cabo su proyecto de vida. En este sentido, las personas que lideran la educación virtual deben trabajar para convencer a los estudiantes, a los profesores, a los administrativos, que la virtualidad es una forma de educación, otra vía para hacerse profesional.

Categoría 2. Calidad de la educación virtual: los profesores consideraron unos factores sobresalientes para evaluar la calidad de la educación virtual que pueden esbozarse así:

a). Los calendarios debieran de ser flexibles, no como en la educación presencial donde son establecidos con rigurosidad, considerando la organización del tiempo en función de las coyunturas de los estudiantes.

b). La dotación de textos digitales debe ser una garantía para los estudiantes, y los profesores deben ser artífices de esas mediaciones. Debe considerarse que los estudiantes hacen parte de una comunidad académica, más que de un ambiente de artefactos tecnológicos.

c). La razón de ser de las aulas virtuales es el conocimiento y desde ahí que la metodología, las mediaciones y los contenidos del proceso de aprendizaje merecen todo el cuidado. Esta característica es altamente significativa porque está relacionando la calidad con el conocimiento, que se constituye en la inspiración trascendental de las universidades.

d). El diseño de los cursos, la dotación tecnológica y la prelación al contacto y las interacciones con los docentes y no únicamente 
el desarrollo de los cursos teniendo como centro los contenidos. Esto determina la capacidad de los profesores para liderar los procesos de aprendizaje.

e). Garantizar que la universidad debe darles a los estudiantes que se matriculen acceso a internet y la conectividad para poder interactuar con el aula virtual.

f). Asegurar a los estudiantes oportunidades para pertenecer a grupos de investigación y semilleros, aplicar para becas internacionales y realizar prácticas profesionales en el contexto.

g). Realizar esfuerzos institucionales por lograr el establecimiento de niveles académicos, pero con niveles de deserción mínimos.

De estos criterios hay dos que merecen debates de fondo en las instituciones. Si se acepta que la educación virtual es una alternativa para personas que por coyunturas especiales de tiempo o desplazamiento no pueden asistir a las universidades y que un factor sobresaliente es que ellos eligieron el estudio virtual por su versatilidad, entonces es de esperarse que los calendarios académicos y la programación de los cursos tengan una lógica distinta a los de las universidades tradicionales. Esto es, deben ser más abiertos y tal vez, más personalizados. La otra situación se relaciona con los procesos de investigación, los semilleros, los espacios de prácticas y las oportunidades artísticas, pues estos también son requisitos de calidad en la visión de los profesores.

Categoría 3. Comportamientos éticos en la educación virtual: es notable que los profesores no se detuvieron en detalles ni en denuncias sobre validación, verificación y autenticidad de actos y actores del aula virtual. No podría decirse que quisieron eludir el tema, mejor es afirmar que, probablemente, se enfocaron en el sentido ético entendido desde la opción de cada persona de ser fiel o no con su integridad. Por eso plantearon que es muy difícil hablar de controles exhaustivos.

Se hizo énfasis en la responsabilidad del profesor con sus estudiantes, no teniendo en la mira la sanción como alternativa inminente, pero desde la formación integral de la persona. El punto de partida no debe ser la mala fe de los estudiantes, ni el desdeño de los profesores. Por el contrario, debe partirse es de del amor propio de ambos, de su honestidad, del cuidado intrínseco de sí mismo, del cuidado de su integridad y la del otro. Cada uno, profesor y estudiante, debe ser consciente de que ha elegido la educación virtual por elección propia y por esto, seriamente debe responsabilizarse con sus entresijos. 
Además, los profesores afirmaron que el control más efectivo debe establecerse desde la planificación de las actividades y el tipo de exámenes que se haga. Si las actividades que se propone al estudiante están centradas en la formación y evaluación de competencias, se merma la posibilidad de copias o actos engañosos. Igualmente, el tipo de preguntas de los cuestionarios, o la utilización de instrumentos como rúbricas o portafolios le dan un mayor dinamismo a la evaluación y en consecuencia la posibilidad del engaño pierde interés para el estudiante. Con franqueza dijeron que la educación virtual no está pensada para evaluar a los estudiantes mediante exámenes.

Dijeron, algunos, que la ética no debe recaer solo en los estudiantes, pues resaltan que los directivos y los profesores desde sus posiciones deben actuar con criterios de honestidad, pensando en la formación de los estudiantes. Es compromiso ético de ellos la pedagogía para la formación humanística e investigativa, pues de manera transversal se inculcan en el estudiante formas complejas de ver el mundo que lo llevan a pensar que hay que disfrutar y cumplir las responsabilidades académicas.

La posición de los profesores sobre la posibilidad de un código de ética para la educación virtual, no es de rechazo franco, pero sí de reflexión. Plantean que la existencia o no para nada incide en el compromiso de la universidad virtual con formar ciudadanos de bien. Con o sin código debe confiarse en la virtualidad como escenario educativo y por esto, directivos, profesores, empleados y los propios estudiantes deben convivir en armonía y, en consecuencia, con respeto y honestidad consigo mismos y con los demás.

Categoría 4. El aprendizaje en la educación virtual: los profesores afirmaron que el aprendizaje en el ambiente virtual es muy activo. Los estudiantes son muy proactivos y crean ambientes personales de aprendizaje con recursos y estrategias que cada uno elige.

Un sentir común es que el aprendizaje contextualizado basado en problemas reales o al menos con significado para el estudiante, es una opción sumamente ventajosa para la educación virtual.

Se hicieron a su vez críticas y halagos a los foros y a las rúbricas. Así se pudo identificar que muchas veces los estudiantes participan en foros únicamente por cumplir con un requisito de evaluación, pero no con el interés sincero de exponer reflexiones o debates. En el caso de las rúbricas, la crítica es que las universidades han optado por implementar formatos digitales que son pesados y difíciles de gestionar por los profesores. Los 
foros se destacan porque permiten la socialización y divulgación en el aula virtual, mientras que las rúbricas están abiertas para la evaluación integral y formativa de los estudiantes.

Categoría 5. Tendencias y retos de la educación virtual: los profesores expusieron su preocupación sobre transformaciones en la educación virtual mencionando tres posibilidades que son llamativas por las innovaciones que traerían: inteligencia artificial, integración de las plataformas de aprendizaje virtual (tipo LMS - Learning Management System) con plataformas Web 2.0 y redes sociales y la introducción currículos disruptivos.

Este último concepto merece atención y análisis: ¿cuál es el significado de un currículo disruptivo? ¿Cuál es el fondo del mensaje que quisieron dar los profesores? No se profundizó en el grupo focal en este concepto, quedó como una opción que puede ser valiosa, pues si la educación virtual es ejemplo de rompimiento de paradigmas educativos, conceptos como estos deben ser objeto de investigaciones en las universidades.

Otros comentarios de los profesores tienen que ver con el reconocimiento de las redes sociales y de la computación móvil como oportunidades para el desarrollo de la educación virtual, que deben pensarse como opciones formativas educativas y no como fuente de ingresos a partir de la oferta desmedida y masificada para la comunidad.

Categoría 6. Perfiles de estudiantes y docentes: en este grupo se destacaron los siguientes argumentos:

a). Dicen los profesores que un docente de educación virtual no es ético cuando no está haciendo de manera adecuada su trabajo, cuando no está haciendo una retroalimentación adecuada a su trabajo, cuando no está señalando de manera adecuada los vacíos que los estudiantes presentan.

b). El profesor virtual tiene que entender que el propósito es la transformación de sus estudiantes, que por ser una modalidad virtual no está exento de ese reto.

c). El profesor debe ser ético y comprender que su trabajo está dirigido a la transformación de sus estudiantes.

d). Los profesores se caracterizan por su creatividad para la aplicación de la tecnología, sus propuestas pedagógicas y sus formas de comunicación. Igualmente, deben ser estratégicos para la 
preparación de los ambientes, el control de las actividades y la retroalimentación de los estudiantes.

e). Tanto los profesores como los estudiantes saben que en la educación virtual el esfuerzo es mayor. En cuanto a los docentes, la preparación de los ambientes, el control de las actividades, la revisión de evaluaciones y la retroalimentación demanda tiempo largo y obliga a estrategias diversas. Por su parte, los estudiantes deben ser artífices de ambientes personales de aprendizaje que les facilite su estadía en el ambiente virtual de una manera muy constructiva.

f). En el caso de los estudiantes, la metodología exige más organización, disciplina, convencimiento, dinamismo y autogestión para aprender. Concretamente los profesores plantean los siguientes perfiles de los estudiantes de la educación virtual: Los estudiantes deben ser muy creativos para construir sus ambientes personales de aprendizaje (Personal Learning Environment -PLE) y ser organizados, disciplinados, convencidos de sus capacidades, dinámicos y con capacidad para auto gestionar sus aprendizajes.

\section{Grupo focal 3: estudiantes de la educación virtual}

Participaron ocho estudiantes de programas académicos virtuales distribuidos así: tres de pregrado de Fundación Universitaria Católica del Norte y de Fundación Universitaria del Área Andina; tres de posgrado de Universidad del Istmo (Panamá), Universidad Iberoamericana de México, CEIPA; uno de tecnología del SENA y uno de academia virtual (Open English).

Categoría 1. Encuentros y rupturas entre la educación virtual y la educación presencial: cuando se pide hablar de características de la educación virtual, los estudiantes entraron en comparaciones con la modalidad presencial. Parece que es inevitable ese marco de referencia, pues permite disertaciones más exactas con respecto a posibilidades, ventajas o dificultades que se viven en el ambiente virtual.

Con respecto a las bondades, las opiniones se enfocaron en las situaciones relacionadas con la flexibilidad del tiempo y la inclusión social que permite la educación virtual. La valoran como una alternativa que les facilita el acceso a la formación profesional sin tener que desplazarse hasta las aulas. Lo que merece evaluarse es que en menor intensidad hacen referencia a las prerrogativas con respecto a la formación. Es decir, 
son menores las referencias a las cualidades formativas o a la capacidad de las mediaciones pedagógicas para hacer viable la metodología virtual. Aunque se afirma que este ambiente de aprendizaje facilita al estudiante investigar, consultar, ir más allá de la información que el profesor le puede proporcionar.

Un asunto que plantearon, y que se convierte en un reto para los líderes de la educación virtual, es que es difícil equiparar las posibilidades que brindan los ambientes presenciales, con respecto los vínculos con el ambiente universitario, actividades de extensión, compartir con distintos grupos de personas, vivir las dinámicas sociales del campus universitario como se conoce tradicionalmente. Este es un asunto de fondo, pues como lo han expuesto los especialistas en currículo, los estudiantes aprenden no únicamente a partir de un plan de estudios o unas actividades planificadas, sino además del contacto con la gente o de las heterogeneidades que confluyen de todos los rincones de la vida universitaria.

Categoría 2. Calidad de la educación virtual: los estudiantes en general son muy positivos con la calidad de la educación virtual. Se notaron más propositivos que críticos, se enfocaron en las ventajas y es claro que la calidad la relacionan con el proceso de aprendizaje y con la docencia.

Sobre sus conceptos con respecto a las características para valorar la calidad, las respuestas se agruparon en el acompañamiento de los profesores, las mediaciones pedagógicas y la responsabilidad institucional.

Un asunto crítico que debe analizarse en los programas virtuales es el relacionado con el trabajo de campo o las experiencias prácticas con los contextos reales. Esta dificultad la plantearon los estudiantes y como otras se convierte en reto para los directivos en las instituciones. Es evidente que, por ejemplo, el trabajo experimental en ingeniería puede ser difícil de realizar.

Categoría 3. Comportamientos éticos en la educación virtual: es preponderante la autocrítica de los estudiantes con respecto a la ética. Los estudiantes entienden que la honradez parte de su actitud en el ambiente virtual y por eso es muy difícil el establecimiento de controles totalmente efectivos que aseguren protección contra el riesgo de fraude. Afirman que no tiene sentido adquirir un título profesional de cualquier forma y por eso se rescata que la responsabilidad de cada uno es el mejor control que se pudiera establecer. Con respecto a la autenticidad, un punto importante es la credibilidad del propio estudiante hacia sí mismo y el respeto que se merece la institución. Esto plantea implícitamente que el amor propio como un valor intrínseco de los estudiantes es la mejor inspiración para 
el buen actuar y, asimismo, el amor por la institución determina que la correcta acción del estudiante parte del principio del respeto hacia ella.

Preocupa su percepción sobre la ausencia de controles institucionales para evitar el fraude, pues no se sintieron voces mayoritariamente explícitas al respecto, y algunos de ellos en varias veces afirmaron que no sienten prevenciones o mecanismos institucionales para diezmar las posibilidades de trampas.

Sin embargo, algunos hicieron alusión a estrategias que tienen los profesores para validar los actos y para asegurar transparencia. Se pone como ejemplo de esto, las sustentaciones de los trabajos que entregan y la fijación de horarios para las videoconferencias. Se afirma también que las instituciones deberían establecer tecnología para control que minimice la posibilidad de actos deshonrosos.

Categoría 4. El aprendizaje en la educación virtual: un asunto interesante es que los estudiantes han tenido oportunidad de estar en ambientes educativos tanto presenciales como virtuales y por eso establecen puntos de encuentro y de divergencia. Además, se resalta la sensatez y sabiduría con las que se refieren a los procesos de aprendizaje en la educación virtual.

Los asistentes al grupo focal coincidieron en que la pedagogía de la educación virtual se presta para aprender y adquirir conocimientos significativos, debido a que el estudiante asume sus compromisos con determinación, mientras que en el aula física el estudiante puede estar pasivo, a veces despreocupado o a veces cansado. El estudiante de virtualidad es constructivo, en el sentido en que es la ausencia del aula física los obliga a investigar, indagar y a ser autodidactas.

El eje central de aprendizaje son las actividades que se proponen en el curso. Es decir, el alumno no entra a estudiar contenidos, sino que toma las actividades que debe entregar y desde ahí inicia sus indagaciones tanto en los recursos disponibles en los cursos como en otros dispuestos en internet, como videos.

Un asunto crítico que plantearon los estudiantes es el de la monotonía de la plataforma tecnológica. Es algo que merece investigarse en profundidad, ya que después de cierto tiempo se torna repetitiva. Esta percepción coincide con lo que puede observarse en los entornos virtuales con las características de las plataformas LMS (Learning Management System) o con las estructuras de las aulas virtuales, que son 
desplegadas con formatos específicos para la funcionalidad, navegabilidad y visibilidad. Esos formatos son únicos para todos los cursos y a veces permanecen indefinidamente, aunque tengan prestaciones de animación técnicamente establecidas y se implementen con criterios de ergonomía computacional, de igual manera, son ambientes digitales expuestos en pantallas de computador.

Categoría 5. Tendencias y retos de la educación virtual: se presentó una interesante propuesta para el avance de la educación virtual, lo que además puede entenderse como una tendencia. Se trata de la relacionada con la obsolescencia de los contenidos, que puede resolverse dotando tecnologías disruptivas basadas en inteligencia artificial e internet. Dadas las condiciones tecnológicas modernas, es factible la incorporación de sistemas en las aulas virtuales que permitan supervisar y actualizar la información consignada en los contenidos, en tiempo real.

Se plantea también a manera de reto, el cambio de paradigma de los profesores para que entiendan que el compromiso en la educación virtual marca distancia con las aulas tradicionales. Esto parece algo trivial y lógico, sin embargo, sentarse a pensar detenidamente lo que significa un cambio de paradigma docente, es plantear transformaciones no solo de tipo instrumental, sino además de puntos de vista frente a la educación en la modernidad del siglo XXI.

Categoría 6. Perfiles de estudiantes y docentes: en cuanto a los perfiles de los estudiantes, se señala que estos se diferencian por sus compromisos laborales o familiares como primer interés, siendo la responsabilidad académica un asunto culminante, pero no el prioritario. Además, comprenden que los profesores no son la única fuente de información y son conscientes de su compromiso y autonomía para abordar sus estudios. Con respecto al profesor, se plantea que se caracteriza especialmente por su interés en la mediación tecnológica de la pedagogía y comprenden las plataformas como centros de aprendizaje.

\section{Entrevistas en profundidad}

Participaron nueve expertos con experiencias en gestión e investigación de la educación superior: el rector de la Fundación Universitaria CEIPA, el vicerrector académico de la Corporación Universitaria Unisabaneta y miembro de la mesa de Comisión Nacional Intersectorial de Aseguramiento de la Calidad de la Educación Superior (Conaces), el vicerrector académico de la Corporación Universitaria Minuto de Dios - UNIMINUTO (sede 
Bello), el vicerrector académico de la Institución Universitaria Escolme, investigadores de la Fundación Universitaria Católica del Norte (2), el vicerrector académico del Politécnico Jaime Isaza Cadavid, el director de Investigaciones del Politécnico Jaime Isaza Cadavid y el coordinador de Educación Virtual de la Corporación Universitaria Remington.

Categoría 1. Encuentros y rupturas entre la educación virtual y la educación presencial: la educación virtual es una alternativa para que la gente la considere de acuerdo con su realidad. No sería oportuno establecer una balanza entre presencialidad y virtualidad para ver hacia dónde se inclina la preferencia de la gente. De acuerdo con el entorno sociocultural, las necesidades particulares, las limitaciones específicas o las expectativas propias de su edad, las personas tienen estas dos posibilidades para estudiar. Ahora bien, hay una cultura universitaria arraigada por siglos cuyos imaginarios conectan la educación con la concentración en aulas físicas, con una única fuente de información que es el profesor. Esa visión histórica de la educación siembra dudas sobre la alternativa virtual, que reemplaza el aula física por un entorno de aprendizaje en una plataforma tecnológica y donde además se acepta que profesor y estudiantes creen escenarios de aprendizaje, estando dispersos.

Podría pensarse, por lo anterior, que la educación presencial tradicional es garante irrefutable para el imaginario de la sociedad y que la modalidad virtual es una opción emergente, sin más que ser una contribución no confiable socialmente- para ciertas personas que la necesitan. No obstante, según expertos entrevistados, la educación virtual supera a la educación presencial en cuanto a los recursos disponibles para los estudiantes y además porque determina autorregulación, compromiso, autodisciplina, es decir, conduce a competencias complejas altamente favorables. Pero indudablemente, el cara a cara, la presencia como tal, el vínculo social que es característico en interior de las aulas físicas entre profesores y estudiantes no puede reemplazarse.

Otro punto a considerar es que, aparte del arraigo histórico de las clases concentradas en aulas, la desconfianza puede surgir debido a que en ocasiones las instituciones no asumen la responsabilidad de la docencia universitaria virtual con criterio educativo, lo que determina percepciones sobre mala calidad. Las dudas entonces no se plasman sobre las herramientas tecnológicas para los procesos virtuales, sino en la planeación de los elementos educativos institucionales que participan en la virtualidad y que llevan, por eso, a problemas e incoherencias. 
Categoría 2. Calidad de la educación virtual: según los entrevistados, las siguientes son características críticas para valorar la educación virtual: mediaciones tecnológicas, impacto de los egresados en el medio, tutoría y contratación de profesores y la medición de los resultados de los aprendizajes. Aunque los discursos develaron que en realidad la calidad está representada en el reconocimiento del impacto educativo en el medio, es decir, en los egresados.

Entre las entrevistas, una conclusión sobresaliente es que la calidad no está determinada según la metodología por sí misma, es decir, un programa académico no puede evaluarse de buena o mala calidad por ser virtual o por ser presencial. Todo depende de la responsabilidad institucional con el compromiso educativo, siendo la cuestión del profesorado la que más se resaltó. La calidad puede evidenciarse cuando los procesos formativos en marcha en las aulas físicas o en los campus tecnológicos, están comprometidos sinceramente con los estudiantes.

Algunos entrevistados afirmaron que no es sensato plantear sistemas de calidad diferentes para la educación presencial y virtual, pues en ambos casos debe demostrarse impacto social, investigación, internacionalización, procesos pedagógicos y construcción de conocimiento. Otros, en proporción menor, admiten que no es apropiado tener los mismos indicadores de calidad para ambas modalidades, ya que las rutinas de aprendizaje, las experiencias de comunicación, las mediaciones pedagógicas y los roles de los actores son distintos en la educación virtual.

La calidad de la educación virtual está relacionada con la actitud de los profesores y con su preparación. Pero no puede perderse de vista que es la institución quien planea, ejecuta y evalúa la contratación y la gestión de su cuerpo docente. En este sentido, las decisiones no deben soportarse en el autodidactismo de los estudiantes, para cargar a los profesores con exagerado número de estudiantes, pensando más en la cobertura masificada que en la calidad formativa.

Categoría 3. Comportamientos éticos en la educación virtual: las voces de los expertos en educación entrevistados entretejen ideas alrededor del buen actuar en el ambiente virtual de aprendizaje que en general no se enfocan en el asunto puntual de la posibilidad del engaño, sino en las circunstancias que pueden conducir hacia allí y en la prevención. Se admitieron posibilidades para el engaño y se citaron casos dolosos específicos posibilitados por la dificultad para el control, pero se advierte también que en la educación presencial se presentan trampas. Esto no debería interpretarse como una justificación, 
sino como un llamado de atención acerca de la ética del estudiante en general, no de una modalidad educativa específica, derivada o influenciada por condiciones previas en sus contextos cotidianos. Es decir, antes de ser estudiante virtual hay una formación previa, una integridad personal, una actitud frente a la manera de afrontar compromisos.

Una coincidencia en las opiniones es que la autenticidad, la validación, la veracidad, la honestidad, son asuntos permeados por los valores de los estudiantes y su compromiso sincero con las responsabilidades y con su determinación de ser un actor en la modalidad virtual. Actuar responsablemente es una actitud comprometida con su amor propio. Pero aun siendo muy trascendente esta circunstancia, no implica que las instituciones no planeen medidas para el control, de manera que se pueda prevenir o mitigar el riesgo de fraude.

En relación con lo anterior, se mencionaron estrategias para la validación de actores y actuaciones y para proteger los procesos contra el fraude. En general, estas se puedan agrupar así: dispositivos y sistemas tecnológicos avanzados, sensibilización continua sobre actuaciones éticas, modelos de didáctica y evaluación que fomenten la creatividad del estudiante y el empeño de los profesores para fomentar en las clases la reflexión sobre la responsabilidad y el compromiso con la libertad y la autonomía.

El problema de la ética no se dejó asignado al estudiante, se abordó de una manera más compleja y en esa dirección se hizo énfasis en la responsabilidad institucional, la postura de los directivos y las actuaciones de los profesores. Indirectamente se dejó entrever que en parte las buenas actuaciones de los estudiantes están determinadas o influenciadas por otras actuaciones en el ambiente virtual. Las actuaciones indecorosas de los directivos se reflejan, por ejemplo, cuando pretenden programar la iniciativa de educación virtual pensando solamente en el mercado, no dimensionar adecuadamente el esfuerzo de los profesores, no asignar los recursos necesarios y no comprometerse con los aspectos pedagógicos de la formación. Con respecto al profesor, se señala que su ética se compromete cuando no es coherente con su compromiso educativo, cuando se despreocupa de cómo están sus estudiantes o cuando no se interesa por la actuación ética de ellos.

En relación con un código de ética para la educación virtual, la apreciación general es que no se requiere, ya que el acto educativo tiene ya establecidos unos principios de buen actuar, unos preceptos. Se expresó el temor sobre un código de ética configurado como un recetario de 
mandatos o de buenos comportamientos fundados en camisas de fuerza y no en la libertad de las personas. Además, se afirmó que estos códigos son empresariales e inapropiados para la educación. Dijeron que la ética es general, no siendo acertado postularla para una metodología educativa en particular. Sea en la modalidad virtual, presencial o a distancia, el valor de la responsabilidad, el compromiso diáfano con la libertad, la reflexión permanente sobre la autonomía controlada de estudiantes y profesores, la convicción verdadera de la institución con la formación académica planeada, le restaría importancia a la creación de un código de ética.

Categoría 4. El aprendizaje en la educación virtual: una conclusión claramente establecida es que no basta con disposición de contenidos y plataforma tecnológica para el desarrollo de los procesos de aprendizaje en la educación virtual. Para evitar la posición inercial de los estudiantes, es preciso planear el acompañamiento permanente de los profesores y la creación de posibilidades para la interacción formativa.

El propósito en el ambiente educativo virtual es que el estudiante sea creador de conocimiento y que disfrute con sus creaciones. Los contenidos, las plataformas, las mediaciones pedagógicas son indispensables para el desarrollo de la clase virtual, pero el papel del profesor es fundamental, porque es él quien diseña la guía, sirve de acompañante, demarca el inicio de la construcción y motiva a sus estudiantes para que construyan sus aprendizajes. Pero esos aprendizajes no deben enfocarse en memorizar contenidos, sino en solucionar problemas. La enseñanza-aprendizaje en la metodología virtual adquiere significado para los estudiantes cuando se plantea en relación con las problemáticas de sus contextos, pues intrínsecamente en ellos se despierta el interés por sus aportes constructivos.

Categoría 5. Tendencias y retos de la educación virtual: cada vez el desarrollo tecnológico ofrece más oportunidades para la educación virtual. Cada vez es más fácil comunicarse y acceder a contenidos. Se deduce de los comentarios de los entrevistados que el audio, las redes sociales y los dispositivos móviles son oportunidades para la mediación pedagógica. Además, se observan avances en la cultura docente que reconoce la tecnología como una opción mediadora para el aprendizaje. Se nota que es creciente el interés de los profesores por la educación virtual y se exhibe que las instituciones han avanzado en la comprensión de la incorporación tecnológica para la función didáctica efectiva, demostrándose mayor preocupación por la innovación educativa. 
El reto es llegar a la comprensión social de la apertura tecnológica para la educación. $O$ sea, que se gane confianza en la gente a partir de las evidencias de la calidad de los programas virtuales y que se propicie un cambio cultural en los aprendizajes con mediaciones pedagógicas. Debe avanzarse para que la gente entienda la educación virtual no como sistemas tecnológicos sino como escenarios pedagógicos.

Categoría 6. Perfiles de estudiantes y docentes: el profesor de la educación virtual debe tener apertura hacia su capacitación permanentemente acerca de objetos virtuales de aprendizaje, ética, didáctica y mecanismos para la comunicación e interacción con los estudiantes. Pero esta intencionalidad no debe ser del gusto del profesor, sino que debe enmarcarse desde las políticas institucionales con respecto a la docencia.

Otros perfiles deducidos de las entrevistas son la capacidad del profesor para transmitir ideas y poder atender acertadamente a sus estudiantes, conocer tendencias globales con respecto al diseño de cursos y tener actitud para la innovación educativa lo que se puede lograr si hay intereses por pedagogías y tecnologías disruptivas. Además, el profesor en modalidad virtual debe ser estratégico sobre la forma como evalúa a sus estudiantes, para evitar actividades que poco aporten al desarrollo de competencias.

En relación con los estudiantes, debe aceptarse que son distintos sus perfiles en la educación virtual y en la presencial. En la segunda modalidad los estudiantes están acostumbrados a la relación directa con el profesor, al devenir en el aula de clase, a la interacción con los compañeros cara a cara. Estas relaciones no las tienen los estudiantes de la virtualidad y en cambio sí se esperan capacidades para interacciones productivas con la información puesta en internet.

\section{Conclusiones de los hallazgos cualitativos}

A continuación, se comparan las percepciones de las distintas categorías de análisis que hicieron los egresados, estudiantes, profesores y expertos. Se enfatiza que, en las investigaciones con enfoque cualitativo, el objetivo no es encontrar verdades absolutas sino interpretar visiones, sentimientos, experiencias, posturas, que, en el caso de este proyecto, se tienen sobre la educación virtual. Se reconoce la heterogeneidad de la información, las distintas miradas sobre los temas y se hacen comparaciones, pero no para el establecimiento de jerarquizaciones con 
respecto a quien está más próximo a la verdad. Para analizar la complejidad de la educación virtual se hace necesario interpretar la lógica de quiénes son actores directos (estudiantes y profesores), quiénes han vivido la experiencia (egresados) y quiénes desde afuera tienen otras perspectivas que son válidas por sus investigaciones y prácticas educativas. Con estas aclaraciones en mente, a continuación, se exponen, a manera de conclusiones y de triangulación de hallazgos, un compendio sobre los textos de los informantes.

\section{Categoría 1: encuentros y rupturas entre la educación virtual y la educación presencial}

Los egresados dijeron que una ventaja de la educación presencial es el contacto directo con el profesor para aclarar dudas. Por otro lado, afirman que un privilegio en la educación virtual es que la atención del profesor es personalizada. Los estudiantes agregaron que la flexibilidad y la inclusión son bondades de la modalidad virtual, ya que facilitan que se puedan compartir responsabilidades académicas con otras de tipo laboral, social o familiar. Según los egresados, la estructura pedagógica de la educación presencial es más sólida, el aprendizaje es más fácil y la atención de los profesores es más natural, mientras que en la virtualidad ese contacto tiene más incertidumbre, pues es posible que el profesor acuda al llamado a destiempo o que no acuda. En el grupo de estudiantes no resaltan las ventajas de la educación virtual por sus aspectos formativos, sino por las circunstancias relativas a tiempos y desplazamientos.

En todos los grupos se coincide en que la ventaja de la educación presencial es el contacto físico directo entre los estudiantes, la oportunidad de compartir con los demás compañeros, establecer distintos tipos de vínculos. Los estudiantes hicieron énfasis en la dificultad de la virtualidad para equiparar las posibilidades que brindan los ambientes presenciales, con respecto los vínculos con el ambiente universitario, las actividades de extensión, el compartir con distintos grupos de personas, el vivir las dinámicas sociales del campus universitario como se conoce tradicionalmente.

En los grupos de profesores, estudiantes y egresados se reconoció que las circunstancias del tiempo y la posibilidad de evitar desplazamientos a las universidades hacen atractiva a la educación virtual, pero los primeros agregan ventajas desde el punto de vista pedagógico. Según profesores y expertos la preferencia por la educación presencial radica en que históricamente ha prevalecido la metodología tradicional y a los padres de familia les queda muy difícil aceptar una metodología novedosa. 
En ambos grupos se afirmó que no es prudente hacer comparaciones entre la educación virtual y la educación presencial, ya que cada persona puede elegir dónde y cómo llevar a cabo su proyecto de vida. Por su parte, varios expertos en educación superior afirmaron que la educación virtual supera a la educación presencial en cuanto a los recursos disponibles para los estudiantes y además porque determina autorregulación, compromiso, autodisciplina, es decir, conduce a competencias complejas altamente favorables. Para el grupo de los profesores una buena opción es la modalidad bimodal (blended learning) para los proyectos educativos. Con esta modalidad se logra concentrar las ventajas que por su lado presentan la educación presencial y la virtual y se pueden hacer programaciones mixtas en las aulas físicas y en los ambientes virtuales.

\section{Categoría 2: calidad de la educación virtual}

En las entrevistas con los expertos se concluyen dos tendencias. Unas fuentes dijeron que para evaluar la calidad de un programa virtual hay que compararlo con otro de modalidad presencial con un mismo sistema de calidad; por otro lado se afirmó que los programas virtuales deben evaluar su calidad por separado, con su propio sistema. Algunos expertos expusieron que la modalidad virtual debe estar a tono con las mediciones para la educación superior a nivel internacional. Según ellos, la calidad de un programa no está asociada a su metodología por sí mismo, o sea, programas virtuales o presenciales pueden ser de buena calidad o pueden tener carencias evidentes. En la tabla 6 se resumen las características sobre calidad según las percepciones de todos los grupos de informantes.

Tabla 6. Percepciones sobre características de calidad

\begin{tabular}{llll}
\multicolumn{1}{c}{ Característica de calidad } & $\begin{array}{c}\text { Expertos en } \\
\text { educación } \\
\text { superior }\end{array}$ & Egresados Profesores Estudiantes \\
\hline $\begin{array}{l}\text { Compromiso de los estudiantes } \\
\text { con sus funciones académicas, } \\
\text { motivación, y responsabilidad } \\
\text { en el ambiente virtual. }\end{array}$ & $\mathrm{X}$ & $\mathrm{X}$ & \\
\hline $\begin{array}{l}\text { Mediaciones pedagógicas } \\
\text { como los objetos virtuales de } \\
\text { aprendizaje y los simuladores. }\end{array}$ & $\mathrm{X}$ & $\mathrm{X}$ & $\mathrm{X}$ \\
\hline
\end{tabular}




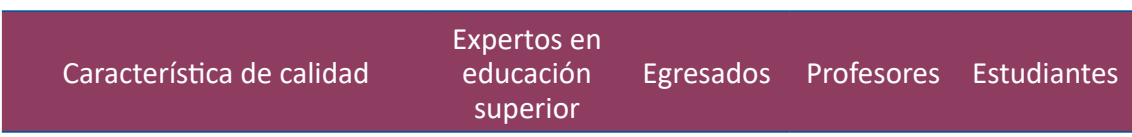

Estructura de los procesos de enseñanza-aprendizaje.

$x \quad x$

Existencia de métricas para análisis y seguimiento a las actividades de aprendizaje.

Currículos basados en competencias.

$\mathrm{X}$

Construcción de procesos pedagógicos con base en el trabajo colaborativo.

\begin{tabular}{llll}
\hline Construcción del conocimiento & $\mathrm{X}$ & $\mathrm{X}$ & \\
\hline $\begin{array}{l}\text { Titulaciones de los docentes } \\
\text { con maestrías y doctorados, y } \\
\text { divulgación científica. }\end{array}$ & $\mathrm{X}$ & & \\
\hline $\begin{array}{l}\text { Idoneidad y suficiencia } \\
\text { de profesorado, así como } \\
\text { racionalidad en la asignación de } \\
\text { número de estudiantes. }\end{array}$ & $\mathrm{X}$ & $\mathrm{X}$ & $\mathrm{X}$ \\
\hline $\begin{array}{l}\text { Procesos de investigación. } \\
\text { Impacto de los egresados. }\end{array}$ & $\mathrm{X}$ & $\mathrm{X}$ & \\
\hline $\begin{array}{l}\text { Acompañamiento docente } \\
\text { e interacciones con los } \\
\text { estudiantes. }\end{array}$ & $\mathrm{X}$ & $\mathrm{X}$ & $\mathrm{X}$ \\
\hline $\begin{array}{l}\text { Plataforma tecnológica LMS. } \\
\text { Estrategias para el trabajo de } \\
\text { campo, prácticas y aprendizaje } \\
\text { en contextos reales. }\end{array}$ & & $\mathrm{X}$ & $\mathrm{X}$ \\
\hline $\begin{array}{l}\text { Calendarios académicos } \\
\text { flexibles y personalizados. }\end{array}$ & & $\mathrm{X}$ & \\
\hline $\begin{array}{l}\text { Procesos de inducción para los } \\
\text { estudiantes nuevos. }\end{array}$ & & $\mathrm{X}$ & \\
\hline $\begin{array}{l}\text { Conectividad y acceso a } \\
\text { internet. }\end{array}$ & & & \\
\hline $\begin{array}{l}\text { Niveles académicos altos con } \\
\text { mínima deserción. }\end{array}$ & & & \\
\hline
\end{tabular}


De las anteriores sobresalen dos características por sus frecuencias de aparición: las mediaciones pedagógicas como los objetivos virtuales de aprendizaje y los simuladores y la idoneidad y suficiencia del profesorado, así como racionalidad en la asignación del número de estudiantes. Dicho de otra manera, la calidad queda resaltada por la razón de ser propia del ambiente educativo, que es al aprendizaje. Es claro, según ese cruce de percepciones, que, para las circunstancias especiales de los estudiantes alejados de las aulas físicas, es prioritario la calidad del acompañamiento docente y de las mediaciones pedagógicas, como se reconoce a los recursos tecnológicos dotados de intencionalidad pedagógica.

\section{Categoría 3: comportamientos éticos en la educación virtual}

Estudiantes y egresados afirmaron que sí existe riesgo para el fraude en la educación virtual y que ellos no sintieron controles institucionales para para la mitigación, aparte de esfuerzos aislados de los profesores para establecer mecanismos de validación de las actividades a partir de sustentaciones en las reuniones sincrónicas o en los foros o con la utilización de presentaciones en videoconferencia por parte de los estudiantes.

Todos los grupos de informantes coincidieron en tres aspectos: los problemas relacionados con la validación, autenticación y riesgo al fraude no son exclusivos de la educación virtual, también en la modalidad presencial se observan actos dolosos. Segundo, el problema de la ética es de la individualidad de la persona, los estudiantes llegan con formaciones previas y por eso la deshonestidad es un asunto de la actitud del estudiante y no de la responsabilidad de la institución. Y tercero, por lo anterior es casi imposible que los mecanismos implementados reduzcan totalmente el riesgo al fraude.

Expertos y profesores afirmaron que la ética no implica únicamente a los estudiantes. Los directivos incurren también en actos deshonestos, por ejemplo, cuando no se comprometen con los aprendizajes de los estudiantes y priorizan otros procesos institucionales, y los profesores tampoco tienen buen actuar, cuando no atienden a sus estudiantes 0 cuando lo hacen sin sentido y fondo.

Como alternativas para mitigar el riesgo del fraude en la educación virtual, en los grupos de informantes se plantearon las acciones mostradas en la tabla 7. 
Tabla 7. Propuestas para reducir el riesgo de fraude en la educación virtual

\begin{tabular}{|c|c|c|c|c|}
\hline $\begin{array}{l}\text { Propuestas para reducir } \\
\text { el riesgo al fraude }\end{array}$ & $\begin{array}{l}\text { Expertos en } \\
\text { educación } \\
\text { superior }\end{array}$ & Egresados & Profesores & Estudiantes \\
\hline $\begin{array}{l}\text { Brindar confianza y empatía a } \\
\text { los estudiantes. }\end{array}$ & & $x$ & & \\
\hline $\begin{array}{l}\text { Trabajar continuamente } \\
\text { en la concientización del } \\
\text { estudiante acerca de su } \\
\text { responsabilidad consigo } \\
\text { mismo. }\end{array}$ & & $x$ & $x$ & \\
\hline $\begin{array}{l}\text { Implementación de } \\
\text { tecnologías y sistemas para } \\
\text { validación de identidades y } \\
\text { detección de fraudes. }\end{array}$ & $x$ & $x$ & & $\mathrm{x}$ \\
\hline $\begin{array}{l}\text { Proponer actividades de } \\
\text { evaluación y formación } \\
\text { por competencias para } \\
\text { la aplicación de los } \\
\text { conocimientos por parte de } \\
\text { los estudiantes. }\end{array}$ & $x$ & $x$ & $\mathrm{x}$ & \\
\hline $\begin{array}{l}\text { Trabajar la formación integral } \\
\text { de los estudiantes. }\end{array}$ & & & $\mathrm{x}$ & \\
\hline $\begin{array}{l}\text { Evitar preguntas directas y los } \\
\text { exámenes tipo cuestionario. }\end{array}$ & & & $x$ & \\
\hline Utilizar rúbricas y portafolios. & & & $x$ & \\
\hline $\begin{array}{l}\text { Fomentar la formación } \\
\text { humanística e investigativa. }\end{array}$ & & & $x$ & \\
\hline $\begin{array}{l}\text { Planear las sustentaciones de } \\
\text { los exámenes y trabajos que } \\
\text { entregan los estudiantes a } \\
\text { través de videoconferencias } \\
\text { o foros }\end{array}$ & $x$ & $x$ & & $\mathrm{x}$ \\
\hline $\begin{array}{l}\text { Motivar a los estudiantes } \\
\text { para que se convenzan de sus } \\
\text { éxitos, logros y compromiso } \\
\text { responsable con las } \\
\text { actividades formativas. }\end{array}$ & $x$ & & $\mathrm{x}$ & \\
\hline
\end{tabular}

Los mecanismos usados con mayor frecuencia para intentar la reducción de riesgo al fraude o las situaciones dolosas son: la implementación de tecnología y sistemas para validar identidades y verificar autenticidades; 
el desarrollo de la evaluación con actividades prácticas en la formación y evaluación con enfoque en competencias; la planeación de sustentaciones de cada trabajo que presenten los estudiantes. No obstante, estas herramientas no restan importancia a las propuestas que hicieron expertos en educación y profesores con respecto a la motivación de los estudiantes sobre sus logros, a la estimulación para actuar responsablemente. En el mismo sentido se pronunciaron los egresados y los profesores cuando afirman que deben trabajar continuamente en la concientización del estudiante acerca de su responsabilidad consigo mismo.

Otro elemento que merece resaltarse surge no solo en esta categoría, sino en las demás relacionadas con la calidad y el aprendizaje: es el relacionado con el aprendizaje basado en problemas o proyectos en contextos significativos para el estudiante. Esta parece ser la estrategia metodológica más adecuada para la educación virtual y conduce a la formación de competencias y al fortalecimiento actitudinal de los estudiantes.

En relación con un código de ética para la educación virtual, los egresados afirmaron que sería inconveniente porque se estaría creando un reglamento de actos y conductas, cuando este actuar debe surgir desde el interior de cada persona. Los profesores no resaltaron ni desestimaron ese código, afirmando que exista o no, la convivencia y la armonía deben prevalecer en los ambientes virtuales, pues son escenarios educativos.

En el grupo de expertos se consideró innecesario e inadecuado un código de ética por las siguientes razones:

- Se estaría creando un mecanismo para instrumentalizar la ética o reglamentarla.

- Se traerían a la educación conceptos empresariales que entienden el código como listados de normas.

- Se configuraría un recetario de mandatos o de buenos comportamientos fundados en camisas de fuerza y no en la libertad de las personas.

- Si se hace para la educación virtual, se tendría que definir un código de ética para las otras modalidades educativas: virtual, a distancia y presencial.

- Se estarían codificando comportamientos que ya todos conocen en la educación como aceptables. 


\section{Categoría 4: el aprendizaje en la educación virtual}

Una percepción de egresados y profesores es que el aprendizaje es muy dinámico en la virtualidad, tiene distintas fuentes de información y recursos tecnológicos y abre posibilidades para competencias en materia de investigación y exploración. Según los profesores, los estudiantes en la modalidad virtual son muy proactivos y crean ambientes personales de aprendizaje con recursos y estrategias que cada uno elige, en tanto que egresados enfatizan en la importancia del trabajo colaborativo. Los estudiantes afirmaron que la metodología virtual determina que ellos sean constructoreseinvestigadoresytomencon determinación lasactividadesque deben desarrollar. En esto coincidieron también en el grupo de los expertos.

Los profesores hicieron críticas a las rúbricas y los foros porque pierden su esencia por asuntos de forma. En ocasiones, los formatos de las rúbricas son difíciles de gestionar y los foros no siempre despiertan el interés del estudiante.

Profesores y expertos afirmaron que el aprendizaje contextualizado, basado en problemas reales o al menos con significado para el estudiante, es una opción ventajosa para la educación virtual, pues despierta el interés en ellos.

Para el grupo de los estudiantes, el punto de partida en sus estudios son las actividades, ya que no exploran directamente los contenidos, sino luego de detectar necesidades en el planteamiento de las tareas, entran a escrudiñar los contenidos.

Un asunto que llama la atención en los argumentos de los estudiantes es el relacionado con la monotonía de la plataforma tecnológica. Las plataformas LMS y las estructuras de las aulas virtuales son desplegadas con formatos específicos para la funcionalidad, navegabilidad y visibilidad. Esos formatos son únicos para todos los cursos y a veces permanecen indefinidamente.

Para el grupo de expertos, más que los contenidos, es más importante el acompañamiento permanente de los profesores y la creación de posibilidades para la interacción formativa.

\section{Categoría 5: tendencias y retos de la educación virtual}

En la tabla 8 se resumen las apreciaciones de los informantes sobre tendencias y retos de la educación virtual: 
Tabla 8. Propuestas para reducir el riesgo de fraude (b)

\begin{tabular}{|c|c|c|c|c|c|c|}
\hline Descripción & Retos & Tendencias & $\begin{array}{l}\text { Expertos en } \\
\text { educación } \\
\text { superior }\end{array}$ & Egresados & Profesores & Estudiantes \\
\hline $\begin{array}{l}\text { Transformación del } \\
\text { ambiente educativo } \\
\text { para que sea más } \\
\text { acogedor y se } \\
\text { diezme la sensación } \\
\text { de aislamiento. }\end{array}$ & $x$ & & & $\mathrm{X}$ & & \\
\hline $\begin{array}{l}\text { Superación de } \\
\text { la monotonía } \\
\text { de la plataforma } \\
\text { tecnológica. }\end{array}$ & $\mathrm{X}$ & & & & & \\
\hline $\begin{array}{l}\text { Protagonismo } \\
\text { pedagógico los } \\
\text { profesores y } \\
\text { compromiso con los } \\
\text { estudiantes. }\end{array}$ & & $x$ & & $x$ & & \\
\hline $\begin{array}{l}\text { Metodología } \\
\text { constructivista }\end{array}$ & & $x$ & & $x$ & & \\
\hline $\begin{array}{l}\text { Introducción de } \\
\text { tecnologías de } \\
\text { inteligencia artificial. }\end{array}$ & $x$ & & $\mathrm{X}$ & & $\mathrm{x}$ & $\mathrm{X}$ \\
\hline $\begin{array}{l}\text { Introducción } \\
\text { de currículos } \\
\text { disruptivos. }\end{array}$ & $\mathrm{X}$ & & & & $x$ & \\
\hline $\begin{array}{l}\text { Integración de } \\
\text { plataformas LMS con } \\
\text { tecnologías Web 2.0. }\end{array}$ & $\mathrm{X}$ & $\mathrm{X}$ & & & $x$ & \\
\hline $\begin{array}{l}\text { Introducción de la } \\
\text { computación móvil. }\end{array}$ & $x$ & $x$ & & & $x$ & \\
\hline $\begin{array}{l}\text { Tecnologías } \\
\text { disruptivas para los } \\
\text { contenidos. }\end{array}$ & $x$ & & $\mathrm{X}$ & & $\mathrm{x}$ & \\
\hline $\begin{array}{l}\text { Cambio de } \\
\text { paradigma de los } \\
\text { docentes. }\end{array}$ & & $\mathrm{X}$ & & & & $\mathrm{X}$ \\
\hline $\begin{array}{l}\text { Interés de los } \\
\text { docentes por la } \\
\text { educación virtual. }\end{array}$ & & $x$ & $\mathrm{X}$ & & & \\
\hline $\begin{array}{l}\text { Incremento de la } \\
\text { confianza en la } \\
\text { gente a partir de } \\
\text { las evidencias de } \\
\text { la calidad de los } \\
\text { programas virtuales. }\end{array}$ & $x$ & & $x$ & & & \\
\hline
\end{tabular}


Aunque puede resultar discutible o muy subjetivo interpretar y clasificar la afirmación de una fuente como un reto o una tendencia, de todas formas, se hizo el intento. El tema de tecnologías disruptivas e inteligencia artificial son los que mayor frecuencia tienen en las narraciones de los informantes. Sin embargo, estos no son los únicos temas para resaltar. El listado completo debería analizarse por líderes de la educación virtual en el momento de las planeaciones, ya que se encarnan temas trascendentes como la confianza de la gente en la educación virtual, los currículos disruptivos, la transformación de los ambientes educativos y la superación de la monotonía de la plataforma tecnológica (LMS).

\section{Categoría 6: perfiles de estudiantes y docentes}

En la tabla 9 se resumen los perfiles que plantearon los informantes para los profesores.

Tabla 9. Percepciones sobre perfiles del profesor

\begin{tabular}{|c|c|c|c|c|}
\hline Perfiles del profesor & $\begin{array}{l}\text { Expertos en } \\
\text { educación } \\
\text { superior }\end{array}$ & Egresados & Profesores & Estudiantes \\
\hline $\begin{array}{l}\text { Tener la capacidad y entusiasmo para } \\
\text { que sus estudiantes lo sientan, acepten, } \\
\text { valoren y comprendan. }\end{array}$ & & $x$ & & \\
\hline $\begin{array}{l}\text { Demostrar recursividad y creatividad } \\
\text { para comunicarse y hacerse entender } \\
\text { de los estudiantes. }\end{array}$ & & $x$ & $x$ & \\
\hline $\begin{array}{l}\text { Mantener en los estudiantes niveles } \\
\text { incrementales de motivación. }\end{array}$ & & $x$ & & \\
\hline $\begin{array}{l}\text { Demostrar ética en el acompañamiento } \\
\text { y retroalimentación al trabajo de los } \\
\text { estudiantes. }\end{array}$ & & & $\mathrm{x}$ & \\
\hline $\begin{array}{l}\text { Deben ser estratégicos para la } \\
\text { preparación de los ambientes de } \\
\text { aprendizaje y el control de las } \\
\text { actividades. }\end{array}$ & & & $X$ & \\
\hline $\begin{array}{l}\text { Demostrar creatividad con la } \\
\text { tecnología, la pedagogía y las formas de } \\
\text { comunicación. }\end{array}$ & & & $x$ & \\
\hline $\begin{array}{l}\text { Manifestar interés en la mediación } \\
\text { pedagógica de la tecnología. }\end{array}$ & & & & $x$ \\
\hline
\end{tabular}


Comprender las plataformas

tecnológicas como centros de

aprendizaje.

Tener apertura a la capacitación

permanentemente.

$\mathrm{X}$

Conocer tendencias globales con

respecto al diseño de cursos.

Tener actitud para la innovación

educativa aplicando pedagogías y

$\mathrm{X}$

tecnologías disruptivas.

Planear estratégicamente las

actividades de aprendizaje con base en

la solución de problemas en contextos

$\mathrm{X}$

reales.

Aunque el perfil con mayor aparición es el de recursividad y creatividad para comunicarse y hacerse entender de los estudiantes, los demás son significativos para la modalidad virtual. Cada grupo de informantes planteó perfiles o actuaciones esperadas de los profesores, sin que pueda resaltarse o quitársele importancia a alguno, pues son visiones distintas, pero con experiencias educativas comunes.

Con respecto a los perfiles de los estudiantes, los informantes no fueron tan prolíferos. La información que merece resaltarse es la siguiente:

a). Según egresados y profesores, los estudiantes de la modalidad virtual se caracterizan por ser personas con capacidad para el trabajo individual, autodisciplina, autogestión, convencimiento, dinamismo y decisión para formarse profesionalmente.

b). En la visión de profesores, los estudiantes deben ser muy creativos para construir sus ambientes personales de aprendizaje.

c). Son personas que comparten responsabilidades académicas con otras sociales, laborales o familiares (este perfil lo plantearon en el grupo de los estudiantes).

d). Demuestran capacidades para interacciones productivas con la información puesta en internet (así lo afirmaron en el grupo de expertos). 


\section{Hallazgos en el abordaje cuantitativo}

La tabla 10 muestra los resultados del abordaje cuantitativo, con respecto a las seis indagaciones planteadas.

Tabla 10. Indagaciones y estratos de las encuestas

\begin{tabular}{|c|c|c|c|}
\hline Instrumento & Variables & Estratos & $\begin{array}{l}\text { Percepciones } \\
\text { encontradas }\end{array}$ \\
\hline \multirow{4}{*}{ Encuesta n. ${ }^{\circ} 1$} & $\begin{array}{l}\text { Comparación } \\
\text { entre educación } \\
\text { virtual y } \\
\text { presencial, } \\
\text { en cuanto a } \\
\text { presencia y } \\
\text { preferencia. }\end{array}$ & $\begin{array}{l}\text { Estudiantes de pregrado } \\
\text { de universidad } \\
\text { privada en modalidad } \\
\text { presencial. }\end{array}$ & $\begin{array}{l}\text { La educación virtual } \\
\text { no ha logrado } \\
\text { presencia y preferencia } \\
\text { en la sociedad en } \\
\text { proporción igual a la } \\
\text { educación presencial. }\end{array}$ \\
\hline & \multirow[t]{3}{*}{$\begin{array}{l}\text { Confianza en el } \\
\text { comportamien- } \\
\text { to ético de los } \\
\text { actores. }\end{array}$} & $\begin{array}{l}\text { Estudiantes de } \\
\text { posgrado de } \\
\text { universidad privada en } \\
\text { modalidad presencial. }\end{array}$ & $\begin{array}{l}\text { La educación virtual } \\
\text { no genera confianza } \\
\text { con respecto al actuar } \\
\text { ético de los actores } \\
\text { en los ambientes de } \\
\text { aprendizaje. }\end{array}$ \\
\hline & & $\begin{array}{l}\text { Estudiantes de pregrado } \\
\text { de universidad } \\
\text { pública en modalidad } \\
\text { presencial. }\end{array}$ & \\
\hline & & $\begin{array}{l}\text { Estudiantes de } \\
\text { educación básica en } \\
\text { modalidad presencial. }\end{array}$ & \\
\hline \multirow[t]{2}{*}{ Encuesta $n .^{\circ} 2$} & $\begin{array}{l}\text { Presencia de los } \\
\text { egresados de la } \\
\text { educación virtual } \\
\text { en el sector } \\
\text { empresarial. }\end{array}$ & \multirow{2}{*}{$\begin{array}{l}\text { Personas vinculadas con } \\
\text { el sector empresarial. }\end{array}$} & $\begin{array}{l}\text { Los egresados de la } \\
\text { educación virtual han } \\
\text { logrado presencia en } \\
\text { el sector empresarial, } \\
\text { en igual proporción } \\
\text { que egresados de la } \\
\text { educación presencial, } \\
\text { pero no de manera } \\
\text { significativa. }\end{array}$ \\
\hline & $\begin{array}{l}\text { Confianza en los } \\
\text { egresados de la } \\
\text { educación virtual } \\
\text { en el sector } \\
\text { empresarial. }\end{array}$ & & $\begin{array}{l}\text { En el sector } \\
\text { empresarial hay } \\
\text { confianza en la } \\
\text { formación profesional } \\
\text { de la educación virtual, } \\
\text { pero consideran que } \\
\text { hay riesgo de fraude } \\
\text { en su formación. }\end{array}$ \\
\hline
\end{tabular}




\begin{tabular}{|c|c|c|c|}
\hline Instrumento & Variables & Estratos & $\begin{array}{l}\text { Percepciones } \\
\text { encontradas }\end{array}$ \\
\hline \multirow[t]{2}{*}{ Encuesta $n .^{\circ} 2$} & $\begin{array}{l}\text { Confianza en los } \\
\text { hogares sobre } \\
\text { la educación } \\
\text { virtual. }\end{array}$ & \multirow{2}{*}{$\begin{array}{l}\text { Personas del común con } \\
\text { capacidad de decisión y } \\
\text { responsabilidad en los } \\
\text { hogares. }\end{array}$} & $\begin{array}{l}\text { La educación virtual no } \\
\text { genera confianza en } \\
\text { los hogares. }\end{array}$ \\
\hline & $\begin{array}{l}\text { Preferencia en } \\
\text { los hogares entre } \\
\text { educación virtual } \\
\text { y educación } \\
\text { presencial. }\end{array}$ & & $\begin{array}{l}\text { En los hogares las } \\
\text { personas prefieren a la } \\
\text { educación presencial } \\
\text { sobre la educación } \\
\text { virtual. }\end{array}$ \\
\hline
\end{tabular}

\section{Resultados de la encuesta 1}

Se aplicó un muestreo por conveniencia en los siguientes estratos:

- Estudiantes de pregrado de universidad privada en modalidad presencial.

- Estudiantes de posgrado de universidad privada en modalidad presencial.

- Estudiantes de pregrado de universidad pública en modalidad presencial.

- Estudiantes de educación básica en modalidad presencial.

En los instrumentos se consideraron los siguientes ítems:

a). Edad: los estudiantes de todos los estratos se escogieron con edades entre 15 y 40 años, de manera intencional. Esta preferencia se hizo porque hay homogeneidad en cuanto al uso que hacen de las tecnologías de la información y la comunicación en la cotidianidad, las relaciones sociales que experimentan en la globalidad del mundo, el sentido de sociedad que viven, las alteraciones culturales que los identifican o su visión frente a las movilidades de la sociedad.

b). Otros ítems: imaginario sobre educación virtual, experiencias con educación virtual, ética en la educación virtual, calidad en la educación virtual, preferencias por la educación virtual. 


\section{Estrato 1: estudiantes de pregrado de universidad privada}

Encuestados: 264 estudiantes de los programas de Derecho, Ingeniería Informática, Administración de Empresas y Negocios Internacionales.

Tabla 11. Datos obtenidos sobre ética y calidad de la educación virtual (a)

\begin{tabular}{|c|c|c|c|}
\hline Afirmación & Sí & No & NS/NR \\
\hline $\begin{array}{l}\text { Es mejor la enseñanza de profesor en el aula presencial } \\
\text { física que en el aula virtual. }\end{array}$ & $67,7 \%$ & $20,3 \%$ & $12 \%$ \\
\hline La calidad de la educación virtual es buena. & $65,4 \%$ & $12,8 \%$ & $21,8 \%$ \\
\hline La calidad de la educación virtual es mala. & $11,3 \%$ & $67,7 \%$ & $21,1 \%$ \\
\hline $\begin{array}{l}\text { La educación virtual facilita la suplantación de identidad } \\
\text { de los estudiantes. }\end{array}$ & $61,7 \%$ & $22,6 \%$ & $15,8 \%$ \\
\hline $\begin{array}{l}\text { En la educación virtual es mayor el riesgo para el fraude } \\
\text { en las evaluaciones. }\end{array}$ & $63,2 \%$ & $24,1 \%$ & $12,8 \%$ \\
\hline $\begin{array}{l}\text { El buen actuar de los estudiantes es independiente de la } \\
\text { modalidad de su carrera (virtual o presencial). }\end{array}$ & $76,7 \%$ & $15,8 \%$ & $7,5 \%$ \\
\hline $\begin{array}{l}\text { En la educación virtual los profesores pueden engañar o } \\
\text { mentir más fácilmente a sus estudiantes. }\end{array}$ & $27,1 \%$ & $48,1 \%$ & $24,8 \%$ \\
\hline $\begin{array}{l}\text { En la educación virtual los estudiantes tienen mayor } \\
\text { facilidad para entregar tareas o trabajos copiados. }\end{array}$ & $56,4 \%$ & $34,6 \%$ & $9 \%$ \\
\hline $\begin{array}{l}\text { En la educación virtual los profesores tienen mayor } \\
\text { posibilidad para ocultar sus carencias o sus problemas. }\end{array}$ & $55,6 \%$ & $26,3 \%$ & $18 \%$ \\
\hline $\begin{array}{l}\text { La calidad de una carrera universitaria es independiente } \\
\text { de la modalidad de su carrera (virtual o presencial). }\end{array}$ & $62,4 \%$ & $21,8 \%$ & $15,8 \%$ \\
\hline
\end{tabular}

\section{Estrato 2: estudiantes de pregrado de universidad privada}

Encuestados: 197 estudiantes de programas de Especialización en Gerencia Social, Gerencia de Proyectos y Especialización en Familia y Adolescencia.

Tabla 12. Datos obtenidos sobre ética y calidad de la educación virtual (b)

\begin{tabular}{lccc}
\multicolumn{1}{c}{ Afirmación } & Sí & No & NS/NR \\
$\begin{array}{lccc}\text { Es mejor la enseñanza de profesor en el aula presencial } \\
\text { física que en el aula virtual. }\end{array}$ & $73,3 \%$ & $14,7 \%$ & $12,1 \%$ \\
\hline La calidad de la educación virtual es buena. & $66,4 \%$ & $23,3 \%$ & $10,3 \%$ \\
\hline La calidad de la educación virtual es mala. & $8,6 \%$ & $68,1 \%$ & $23,3 \%$ \\
\hline
\end{tabular}




\begin{tabular}{|c|c|c|c|}
\hline Afirmación & Sí & No & NS/NR \\
\hline $\begin{array}{l}\text { La educación virtual facilita la suplantación de identidad } \\
\text { de los estudiantes. }\end{array}$ & $60,9 \%$ & $23,5 \%$ & $15,7 \%$ \\
\hline $\begin{array}{l}\text { En la educación virtual es mayor el riesgo para el fraude } \\
\text { en las evaluaciones. }\end{array}$ & $63,8 \%$ & $22,4 \%$ & $13,8 \%$ \\
\hline $\begin{array}{l}\text { El buen actuar de los estudiantes es independiente de la } \\
\text { modalidad de su carrera (virtual o presencial). }\end{array}$ & $77,6 \%$ & $13,8 \%$ & $8,6 \%$ \\
\hline $\begin{array}{l}\text { En la educación virtual los profesores pueden engañar o } \\
\text { mentir más fácilmente a sus estudiantes. }\end{array}$ & $26,1 \%$ & $47,8 \%$ & $26,1 \%$ \\
\hline $\begin{array}{l}\text { En la educación virtual los estudiantes tienen mayor } \\
\text { facilidad para entregar tareas o trabajos copiados. }\end{array}$ & $58,6 \%$ & $33,6 \%$ & $7,8 \%$ \\
\hline $\begin{array}{l}\text { En la educación virtual los profesores tienen mayor } \\
\text { posibilidad para ocultar sus carencias o sus problemas. }\end{array}$ & $57,8 \%$ & $24,1 \%$ & $18,1 \%$ \\
\hline $\begin{array}{l}\text { La calidad de una carrera universitaria es independiente } \\
\text { de la modalidad de su carrera (virtual o presencial). }\end{array}$ & $62,1 \%$ & $21,6 \%$ & $16,4 \%$ \\
\hline
\end{tabular}

\section{Estrato 3: estudiantes de pregrado de universidad pública}

Encuestados: 40 estudiantes del primer semestre de Ingeniería Informática.

Tabla 13. Datos obtenidos sobre ética y calidad de la educación virtual (c)

\begin{tabular}{lccc}
\multicolumn{1}{c}{ Afirmación } & Sí & No & NS/NR \\
\hline $\begin{array}{lcc}\text { Es mejor la enseñanza de profesor en el aula presencial } \\
\text { física que en el aula virtual. }\end{array}$ & $90 \%$ & $0 \%$ & $10 \%$ \\
\hline $\begin{array}{l}\text { La calidad de la educación virtual es buena. } \\
\text { La calidad de la educación virtual es mala. }\end{array}$ & $42,5 \%$ & $10 \%$ & $47,5 \%$ \\
\hline $\begin{array}{l}\text { La educación virtual facilita la suplantación de identidad } \\
\text { de los estudiantes. }\end{array}$ & $60 \%$ & $15 \%$ & $25 \%$ \\
\hline $\begin{array}{l}\text { En la educación virtual es mayor el riesgo para el fraude } \\
\text { en las evaluaciones. }\end{array}$ & $77,5 \%$ & $7,5 \%$ & $15 \%$ \\
\hline $\begin{array}{l}\text { El buen actuar de los estudiantes es independiente de la } \\
\text { modalidad de su carrera (virtual o presencial). }\end{array}$ & $85 \%$ & $7,5 \%$ & $7,5 \%$ \\
\hline $\begin{array}{l}\text { En la educación virtual los profesores pueden engañar o } \\
\text { mentir más fácilmente a sus estudiantes. }\end{array}$ & $12,5 \%$ & $35 \%$ & $52,5 \%$ \\
\hline $\begin{array}{l}\text { En la educación virtual los estudiantes tienen mayor } \\
\text { facilidad para entregar tareas o trabajos copiados. }\end{array}$ & $52,5 \%$ & $22,5 \%$ & $25 \%$ \\
\hline $\begin{array}{l}\text { En la educación virtual los profesores tienen mayor } \\
\text { posibilidad para ocultar sus carencias o sus problemas. }\end{array}$ & $57,5 \%$ & $17,5 \%$ & $25 \%$ \\
\hline $\begin{array}{l}\text { La calidad de una carrera universitaria es independiente } \\
\text { de la modalidad de su carrera (virtual o presencial). }\end{array}$ & $50 \%$ & $35 \%$ & $15 \%$ \\
\hline
\end{tabular}




\section{Estrato 4: estudiantes de educación básica}

Encuestados: 88 estudiantes del grado $11^{\circ}$

Tabla 14. Datos obtenidos sobre ética y calidad de la educación virtual (d)

\begin{tabular}{|c|c|c|c|}
\hline Afirmación & Sí & No & NS/NR \\
\hline $\begin{array}{l}\text { Es mejor la enseñanza de profesor en el aula presencial } \\
\text { física que en el aula virtual. }\end{array}$ & $72,7 \%$ & $17 \%$ & $10,2 \%$ \\
\hline La calidad de la educación virtual es buena. & $54,5 \%$ & $22,7 \%$ & $22,7 \%$ \\
\hline La calidad de la educación virtual es mala. & $17 \%$ & $56,8 \%$ & $26,1 \%$ \\
\hline $\begin{array}{l}\text { La educación virtual facilita la suplantación de identidad } \\
\text { de los estudiantes. }\end{array}$ & $60,2 \%$ & $15,9 \%$ & $23,9 \%$ \\
\hline $\begin{array}{l}\text { En la educación virtual es mayor el riesgo para el fraude } \\
\text { en las evaluaciones. }\end{array}$ & $71,6 \%$ & $17 \%$ & $11,4 \%$ \\
\hline $\begin{array}{l}\text { El buen actuar de los estudiantes es independiente de la } \\
\text { modalidad de su carrera (virtual o presencial). }\end{array}$ & $68,2 \%$ & $19,3 \%$ & $12,5 \%$ \\
\hline $\begin{array}{l}\text { En la educación virtual los profesores pueden engañar o } \\
\text { mentir más fácilmente a sus estudiantes. }\end{array}$ & $45,5 \%$ & $33 \%$ & $21,6 \%$ \\
\hline $\begin{array}{l}\text { En la educación virtual los estudiantes tienen mayor } \\
\text { facilidad para entregar tareas o trabajos copiados. }\end{array}$ & $71,7 \%$ & $14,8 \%$ & $13,6 \%$ \\
\hline $\begin{array}{l}\text { En la educación virtual los profesores tienen mayor } \\
\text { posibilidad para ocultar sus carencias o sus problemas. }\end{array}$ & $70,5 \%$ & $10,2 \%$ & $19,3 \%$ \\
\hline $\begin{array}{l}\text { La calidad de una carrera universitaria es independiente } \\
\text { de la modalidad de su carrera (virtual o presencial). }\end{array}$ & $53,4 \%$ & $23,9 \%$ & $22,7 \%$ \\
\hline
\end{tabular}

\section{Conclusiones de la encuesta 1}

Los estudiantes de educación básica del grado 11 o son quienes están próximos a elegir universidad para sus proyectos de vida y formación profesional. Ellos tienen una baja preferencia por la educación virtual, cercana al $6 \%$. Los estudiantes de pregrado de universidad pública son quienes menos prefieren a la educación virtual $(2,5 \%)$, lo que puede explicarse en el hecho que estas son personas que permanecen buena parte del tiempo en las aulas presenciales y en los campus físicos de las universidades, donde han logrado empatías y arraigos con los distintos grupos de interés y escenarios (aparentemente podrían verse tentados por la educación virtual precisamente para ahorrar tiempo y no tener que pasar la mayor parte del día en la universidad). Los estudiantes de pregrado y posgrado de universidad privada son quienes más prefieren a la educación presencial, pero con unos porcentajes que no son muy significativos (entre el $15 \%$ y el $21 \%$ ). 
Los datos además expresan que la modalidad presencial supera en diferencias a la modalidad virtual. En el caso de los estudiantes de pregrado y posgrado de universidad privada, las diferencias entre las dos modalidades son mucho menores que lo que ocurre en los estratos de estudiantes de universidad pública y de educación básica.

Son muy superiores los porcentajes de quienes expresan que la calidad de la educación presencial es mayor que la virtual. Esta percepción es preocupante si se tiene en cuenta que entre el $60 \%$ y $70 \%$ han tenido experiencias con estudios virtuales. Podría inferirse que, aun sin haber interactuado con la modalidad virtual, hay un preconcepto desfavorable, no por desconocimiento, pues se sabe que entre el $90 \%$ y $95 \%$ conocen en qué consiste la educación virtual.

En este punto no se está analizando la percepción de calidad de la educación virtual en comparación la presencial en forma directa. Entre el $42 \%$ y el $65 \%$ afirman que la calidad de la educación virtual es buena, pero entre el $68 \%$ y el $90 \%$ dicen que es mejor la enseñanza en el aula física. Por consiguiente, las personas prefieren la enseñanza tradicional, sin desconocer absolutamente que la calidad en la educación virtual puede ser buena. Entre el $50 \%$ y el $65 \%$ respondieron que la calidad es independiente de la modalidad educativa, lo que explica que se reconoce a la educación virtual como una opción educativa de buena calidad.

En el rango aproximado entre el $62 \%$ y el $78 \%$ opinan que en la educación virtual hay riesgos para el fraude y la suplantación. Además, entre el $57 \%$ y el $72 \%$ afirmaron que el estudiante tiene mayor facilidad para copiar tareas o trabajos. No obstante, en una mayoría significativa entre el $75 \%$ y el $85 \%$ dicen que el buen actuar de los estudiantes es independiente de la modalidad de estudios.

El estrato de estudiantes de educación básica es el que mayoritariamente expresa desconfianza con respecto a la ética de los profesores de la educación virtual. El $45 \%$ dice que ellos pueden engañar más fácilmente a sus estudiantes, mientras que el $70 \%$ afirma que esos profesores tienen posibilidades para esconder sus carencias o problemas. En este último aspecto, un poco más de la mitad de estudiantes de los estratos de universidad privada y universidad pública expresan también sus temores. Entre el $13 \%$ y el $27 \%$ afirman que los profesores virtuales tienen mayor posibilidad de mentir a sus estudiantes, cifra que es en cierto sentido favorable con respecto a la credibilidad sobre el comportamiento ético de ellos (favorable en el sentido de la magnitud del dato, pero preocupante en cuanto a que la opinión sobre esa posibilidad debiera de tener tendencias a cero). 
En los cuatro estratos es menor el porcentaje de quienes afirman que los profesores pueden engañar o falsear a los estudiantes, que quienes afirman que tienen posibilidad de ocultar sus carencias. Comparando, aunque ambas conductas son dañinas, puede ser más dolosa y grave la primera. Por consiguiente, puede inferirse que para los estudiantes en la virtualidad la mala fe en el engaño de los profesores (conducta lesiva para el estudiante) tiene menos probabilidad que su mala fe expresada en su conveniencia (conducta mañosa para el bien del profesor).

Para verificar las indagaciones que se plantearon, se prefirió no utilizar las herramientas y conceptos estadísticos sobre contrastación, con fundamento en variables paramétricas o no paramétricas. Pero sí se considera que las indagaciones deben ser compatibles con unos datos de una muestra que debe ser representativa para una población. Se ha establecido como estrategia un análisis de los datos con unos procedimientos empíricos y comparativos, no exhaustivos, pero sí fundamentados en los porcentajes logrados. Esta decisión se tomó porque la forma como se formularon las indagaciones no expresan una exactitud en cuanto a la cuantificación o la relación causa-efecto entre variables, sino que denotan cierta consideración a la manera de conjetura o de indagaciones generales. La encuesta logro los siguientes resultados concretos:

- La mayoría de las estudiantes (65\% promediado) entre 15 y 40 años han tenido experiencia en la modalidad virtual, la reconocen y saben que se imparte a través de internet. Pero la mayoría de las personas $(47,7 \%)$ dicen preferir la educación presencial en el caso de tener que tomar una decisión entre varias alternativas, mientras que la minoría $(11,1 \%)$ se inclina por la educación virtual. Es decir, las personas saben qué es la educación virtual, han tenido experiencias con esa virtualidad, pero, aun así, no la prefieren.

- El $76 \%$ de los estudiantes dice que es mejor la enseñanza en el aula física, en tanto que el $43 \%$ afirma que la calidad de la educación virtual es menor que la de educación presencial y el $6,6 \%$ afirma que es mayor. Obsérvese que la diferencia entre esos dos últimos números es significativa.

- El 65 \% de las personas ha tenido experiencias con la educación virtual y el $93 \%$ sabe en qué consiste esa modalidad. No obstante, en los cuatro estratos se prefiere a la educación presencial.

- Las edades de los entrevistados estén entre 15 y 20 años (porcentaje promediado del $81 \%$ ) y entre 21 y 40 años (19\%). 
Son personas jóvenes que han vivido en la era del conocimiento y la tecnología. Sin embargo, las preferencias son por la educación presencial. Es decir, ser usuarios cotidianos de la tecnología no es suficiente para preferir la educación virtual como una opción educativa.

- El 57 \% de las personas dice que la calidad de la educación virtual es buena, cuando el $93 \%$ dice saber en qué consiste esa modalidad. Es decir, hay un marcado nivel de desconfianza sobre la calidad de los ambientes virtuales.

- El $61 \%$ de los encuestados dice que la educación virtual facilita la suplantación de identidad de los estudiantes.

- El 69 \% afirma que en la educación virtual es mayor el riesgo para el fraude en las evaluaciones.

- El 59,7 \% afirma que en la educación virtual los estudiantes tienen mayor facilidad para entregar tareas o trabajos copiados.

- El 76,8 \% dice que el buen actuar de los estudiantes es independiente de la modalidad (virtual o presencial). Esto quiere decir que, según la encuesta, el riesgo del fraude es igual en las modalidades presencial y virtual y en cierta medida, aunque no explica los tres datos anteriores, sí los justifica.

- El 28 \% de los estudiantes dicen que en la educación virtual los profesores pueden engañar o mentir más fácilmente a sus estudiantes, en tanto que el $60 \%$ afirma que en esta modalidad los profesores tienen mayor posibilidad para ocultar sus carencias o sus problemas. Podría interpretarse el $28 \%$ como una cifra que no es significativa en la comparación porcentual, pero con respecto a la sensibilidad que representa (la ética de los profesores), puede considerarse que es alta. Esto es, la conducta del profesor para mentir a sus estudiantes, debe tender tendencia a cero, de lo contario es una manifestación de proceso irregulares.

\section{Resultados de la encuesta 2}

Se aplicó un muestreo por conveniencia en los siguientes estratos:

- Personas vinculadas con el sector empresarial.

- Personas comunes con capacidad de decisión y responsabilidad en los hogares.

En los instrumentos se consideraron los siguientes ítems: 
Ocupación: son distintas las opiniones sobre educación virtual que pueden dar personas dedicadas a la academia, las personas de hogar o quienes están en ambientes empresariales. Estos últimos tienen más argumentos para hablar del impacto de la modalidad educativa y desde su experiencia pueden tener una mirada externa más directa acerca de receptividad que tienen sus egresados y de las diferencias, si existen, con la metodología presencial de estudios.

Sector empresarial: empíricamente puede deducirse que posiblemente no hay homogeneidad conceptual sobre la educación virtual en todos los sectores empresariales. En los sectores agropecuario, servicios, industrial, de transporte, de comercio, financiero, de construcción o mineroyenergético, se manejan ciertas interrelaciones sociales y culturales surgidas de las tipologías de los negocios, que conducen a interpretaciones distintas del mundo.

\section{Estrato 1: personas vinculadas con el sector empresarial}

Encuestados: 192

La encuesta se aplicó con un muestreo por conveniencia a personas vinculadas a empresas públicas y privadas.

\section{Conclusiones}

La encuesta muestra que hayun porcentaje significativo de encuestados que desconocen el tipo de educación que tienen los profesionales de la empresa en la cual laboran. Tan solo el 28,6 \% manifiesta claramente que en su empresa hay profesionales graduados de la educación virtual, mientras que el $43,2 \%$ manifiesta que no hay profesionales graduados en esta modalidad de educación superior. Hay que tener en cuenta que en Colombia priman las estructuras jerarquizadas, llamadas también estructuras funcionales: "Son las más comunes en nuestro medio y, además, eficaces en la relación jerárquica porque es muy claro quién es el jefe" (Gómez Osorio, 2017, s.p.), lo que hace que las escalas inferiores de la estructura de la empresa no conozcan por menores de la profesión de su jefe o de los empleados de una escala jerárquica superior.

El desconocimiento de los encuestados sobre la presencia de profesionales egresados de la educación virtual, (el 53,1 \% de los encuestados no respondió o manifestó no saber) evidencia que generalmente los empleados colombianos no conocen las políticas de recursos humano de sus empresas, sea por falta de información o porque la empresa no las ha establecido. 
A pesar del desconocimiento que ha manifestado la mayoría de los encuestados, hay confianza por la educación virtual, con el 61,5\%, aunque hay que tener en cuenta que estos no conocen los pormenores de este tipo de educación. De acuerdo a una encuesta adelantada por el Centro Nacional de Consultoría, los empleadores: "Encuentran similitudes cuando les piden comparar las capacidades de los egresados virtuales con los presenciales" ("La educación virtual del país", 2018, s.p.), lo que confirma la aseveración de los encuestados en la investigación que nos ocupa. Como corolario a la pregunta anterior, aunque los encuestados no conocen los pormenores de la educación y confían en ella, manifiestan que hay riesgo de fraude en este tipo de educación, lo que al final hace pensar que el profesional de la educación virtual no es confiable, siendo una respuesta contradictoria, lo que refuerza la idea de que los encuestados no conocen los pormenores de este tipo de educación profesional.

El $28,6 \%$ de las personas dice que en su empresa sí hay profesionales graduados de la educación virtual, mientras que el 43,2 \% afirma que no. Pero debe considerarse que cerca del $30 \%$ manifestaron no conocer si hay o no graduados de esa modalidad. Este porcentaje es significativo con respecto a los otros dos y en consecuencia queda algún nivel de incertidumbre en el contraste de la indagación.

El 21,9\% dice que en la empresa prefieren más a los egresados de la educación tradicional presencial, en comparación con los egresados de la educación virtual, en tanto que el $25 \%$ dice que no. Es de anotar que la incertidumbre es alta, ya que el $53 \%$ de los egresados expresaron lo contrario. El $61,5 \%$ afirma que la educación en modalidad virtual sí puede garantizar la calidad formativa que se requiere para el desempeño profesional. Solo el 2,1\% manifiesta incertidumbre. El 57,3\% asevera que en la educación virtual el riesgo para el fraude y la suplantación es alta. Aunque es mayoría, puede decirse que la cifra no es absolutamente significativa y aún más, cuando el 33,3 \% declaró que no hay riesgo.

\section{Estrato 2: personas del común con capacidad de decisión y responsabilidad en los hogares}

\section{Encuestados: 133}

La encuesta se aplicó con un muestreo por conveniencia a personas de hogar, básicamente a padres de familia o hermanos que podían tomar decisiones sobre los estudios futuros de quienes aspirarían a ingresar a la educación superior. 


\section{Conclusiones}

La encuesta se orientó a personas mayores de 25 años, ya que de acuerdo con el informe del diario colombiano El Tiempo, en Colombia los estudiantes universitarios adquieren un título a los 25 años, siendo líderes en Latinoamérica ("En universitarios graduados", 2018), por lo que se puede inferir que el $75,9 \%$ de los encuestados no eran estudiantes en ese momento, o bien, no habían emprendido un programa de educación superior, o ya lo habían terminado. Por ello las respuestas que siguen han de mirarse desde la perspectiva de personas que no están en el proceso de educarse en un programa de pregrado.

La percepción de la educación virtual está asociada al internet como lo sugiere la pregunta. Hay que destacar que, de acuerdo de un estudio del Centro Nacional de Consultoría, hay "más de seis millones de colombianos están aprendiendo algo en Internet" ("¿Qué tanto y cómo usan internet los colombianos?", 2016, s.p.), Aunque con respecto al total de la población (48 millones) no es algo que impresione (12,5\%). Se puede inferir que un porcentaje importante de la población asocia palabras como virtualidad con internet, seis millones, por experiencia propia, y otros tanto por extensión del contacto social con estos seis millones de colombianos. Tambien cabe destacar que de acuerdo al informe que presentó el de Ministerio de Tecnologías de la Información y las Comunicaciones, MinTIC, en el Congreso TIC Andicom 2017, en Colombia "el $64 \%$ de los hogares tiene acceso a internet, cifra que por primera vez supera la suscripción a telefonía fija en todas las regiones" (“¿Colombia vive digital?”, 2017, s.p.).

La presencialidad sigue siendo la modalidad tradicional y deseable de la educación superior, ya que el $51 \%$ de los encuestados la prefiere. Sumado al estudio en el extranjero este porcentaje aumenta al 64,7\%, aunque hay que aclarar que, en conjunción con la primera pregunta, la respuesta es la precepción de personas que no están enfrentando la decisión de qué modalidad de educación adoptar para sí mismos. También vale la pena resaltar que sorprende que la preferencia por la educación virtual esté por encima de la educación a distancia ( $18 \%$ a favor de la virtualidad contra $15 \%$ a favor de la educación a distancia), a pesar de que esta última lleva en el país cerca de 50 años: "A nivel superior universitario la educación a distancia se inicia a mediados de la década de 1970 en varias universidades: Antioquia, Javeriana, Santo Tomás, La Sabana, San Buenaventura, a las que muy pronto se unen otras" (González et al., 2000, p. 22).

Con respecto a la posibilidad de fraude, el 59,4 \% responde que sí hay posibilidad de que se presente fraude o suplantación; aunque 
es significativo el porcentaje que no lo cree ( $32 \%$ ante la facilidad de que por lo menos la suplantación se presente. A pesar de las dudas que la educación virtual genera en los encuestados es llamativo que casi la mitad -49,6\% - cree en su efectividad en cuanto a formar profesionales idóneos. Aunque hay que pensar que las personas que contestaron la encuesta no están familiarizadas con los pormenores de la educación virtual y mucho menos con las dudas que arrojan los sistemas de evaluación, respecto a la posibilidad de la suplantación al momento de evaluar el conocimiento adquirido y poder certificar la idoneidad del profesional.

\section{Análisis convergente final del estudio mixto}

Esta es una investigación con enfoque mixto convergente. Luego de las rutas de recolección-análisis-resultados de datos cualitativos y cuantitativos por separado, de acuerdo con el proceso mostrado en la figura 4, se hará un análisis acorde con los siguientes procesos:

a). Se elige como punto de inicio el despliegue de las indagaciones contrastadas de acuerdo con los datos cuantitativos.

b). Se toma la información cualitativa con la intención de confirmar o rechazar la contratación de la indagación.

c). La interpretación final de los hallazgos se determina considerando el enfoque cualitativo de la investigación, con base en los dos pasos anteriores.

En la tabla 10 se presenta un compendio de los resultados de la investigación cuantitativa, luego del análisis de las encuestas aplicadas. A continuación, se presentarán los resultados de acuerdo con la contratación de las indagaciones.

Indagación 1: ¿la educación virtual ha logrado presencia y preferencia en la sociedad en proporción igual a la educación presencial?

Los datos en la investigación cuantitativa responden negativamente a esta indagación. En la categoría de la investigación cualitativa sobre encuentros y rupturas entre la educación virtual y la educación presencial, se corrobora el resultado cuantitativo. Es claro que, según los informantes (profesores, egresados, estudiantes y expertos), la preferencia por la educación presencial radica en que históricamente ha prevalecido la metodología tradicional y los padres de familia difícilmente aceptan 
una metodología que rompe la estructura tradicional de escolarización. Aparte de esto, dicen los informantes que las interacciones directas en las aulas físicas entre profesores y estudiantes son irremplazables y que los ambientes virtuales no tienen la capacidad para suplir las necesidades de socialización de los estudiantes, es decir, sus demandas por conocer y hacer parte de círculos sociales que son naturales en los campus presenciales. Se afirmó también que en la virtualidad existen dificultades para que los estudiantes interactúen con programas culturales, procesos de investigación, integración de semilleros o actividades para la formación integral o la extensión académica.

Se dijo que la educación virtual supera a la educación presencial en cuanto a los recursos disponibles para los estudiantes y además porque determina autorregulación, compromiso, autodisciplina, es decir, conduce a competencias complejas altamente favorables para los profesionales. Pero las personas no consideran estas ventajas en el momento de optar por esta modalidad y la prefieren porque se evitan desplazamientos, hay más flexibilidad para la gestión de horarios de estudios y tiempos para acceder a las actividades formativas. Por eso, predominantemente el público que acude a la educación virtual son personas cuya prioridad está en actividades del hogar o trabajo o porque tienen limitaciones físicas para desplazarse.

Otra justificación para la confirmación de la indagación 1 es que, en la construcción de la categoría sobre retos y tendencias de la educación virtual, una de los desafíos expuestos en los grupos focales y en las entrevistas es que debe incrementase la confianza en la gente a partir de las evidencias de la calidad de los programas virtuales.

Agréguese también que estadísticamente los estudiantes de educación básica de pregrado o de posgrado que están en instituciones presenciales manifestaron ampliamente que no prefieren a la educación virtual, no les es atractiva. Esto se confirmó en las entrevistas y grupos focales, especialmente en el caso de los estudiantes de educación básica, pues dijeron en las encuestas y grupos focales que son personas que están ávidas por pertenecer a grupos sociales y el campus presencial los llena de motivación para hacer parte de sus comunidades formales o informales.

Indagación 2: ¿la educación virtual genera confianza sobre el actuar ético de los actores en los ambientes de aprendizaje?

Según los datos estadísticos, la educación virtual no genera confianza sobre el actuar ético de los actores en los ambientes de aprendizaje. En las categorías cualitativas de calidad de la educación virtual y de comportamientos éticos 
en la educación virtual se revela parcialmente información que corrobora el resultado cuantitativo. Aunque debe reconocerse que las percepciones en ambas son amplias y variadas. Se consideran estas dos categorías, ya que hablar de confianza en la educación virtual conlleva considerar los temas de la ética y la calidad. Es decir, la confianza en sus procesos formativos se deriva a partir de las actuaciones en el ambiente educativo, de la forma cómo estas se comprometen con las actividades académicas y con la convivencia y por otro lado, en general la calidad educativa es garante de reconocimiento social. Pero merece aclararse que otras circunstancias o variables pueden incidir en la confianza social de las organizaciones educativas.

Se concluye que, parcialmente el estudio cualitativo corrobora la contratación de la indagación, porque los informantes afirmaron que sí se presentan actos deshonestos y los estudiantes y egresados sostuvieron que no se evidencian controles por parte de las instituciones educativas, pero a su vez manifestaban sentimientos de confianza y gratitud hacia la modalidad virtual. Estos argumentos son reveladores pues fueron emitidos por quienes son los actores centrales, al ser ellos la razón de ser de los programas educativos.

Asimismo, no puede desconocerse la opinión de los profesores, quienes explicaron que implementan acciones de tipo pedagógico para la validación y autenticación de las actividades. Debe considerarse también que expertos, profesores y egresados reiteradamente afirmaron que los actos de corrupción no son exclusividad de la educación virtual, pues también en la educación presencial y la educación a distancia se presentan irregularidades, ya que la ética es un asunto de la individualidad de cada persona. Pero lo preocupante de estas aseveraciones es que, desde su perspectiva, ellos quisieran justificar mirando hacia otros lados, ciertas realidades develadas. Sería como sustentar lo inaceptable en un contexto específico, porque ocurre también en otros escenarios.

En lo concerniente a la calidad, para los informantes, una modalidad virtual no es por sí misma deficiente. Lo que entra en juego es que haya correspondencia entre sus procesos, recursos y conceptos, con las demandas formativas de sus estudiantes.

La contratación y compromiso de los profesores y la capacidad de las mediaciones pedagógicas fueron los dos factores que los encuestados resaltaron como garantía de calidad. Estos asuntos no son explícitos en la formulación de las encuestas y por eso las respuestas, probablemente, atienden a conceptos o experiencias específicas de educación virtual, 
tomando como referencia casos concretos donde no se evidencia calidad de los profesores ni de las mediaciones pedagógicas. Sin embargo, no puede desconocerse que los informantes expusieron un listado de asuntos que deben valorar la calidad, lo cual quiere decir que subrepticiamente están exponiendo sensaciones sobre experiencias vividas o sobre necesidades no correspondidas en los procesos académicos.

Otro punto de divergencia es que, en los grupos focales y las entrevistas, los informantes señalaron que el ambiente virtual de aprendizaje es un escenario educativo y por eso valoran las interrelaciones, las actuaciones éticas, los roles humanos de profesores y estudiantes, en tanto que los encuestados posiblemente tienen una visión distinta, pues, aunque ellos saben qué es educación virtual, sus estudios los realizan en instituciones presenciales y allí están sus vivencias académicas. Por lo general, ellos conciben un ambiente virtual de aprendizaje o un aula virtual, como una sumatorio de dispositivos informáticos y sistemas de comunicación a través de internet para facilitar aprendizajes o para adquirir informaciones.

Indagación 3: ¿̇los egresados de la educación virtual han logrado presencia en el sector empresarial en igual proporción que egresados de la educación presencial?

Según los datos cuantitativos, los egresados de la educación virtual sí han logrado presencia en el sector empresarial en igual proporción que egresados de la educación presencial. No obstante, los resultados no son significativos. En los grupos focales y en las entrevistas con los distintos informantes se reafirmó dicha conclusión sobre la indagación. Es decir, en el sector empresarial los egresados de la virtualidad sí han logrado presencia en proporciones iguales a los de la prespecialidad. En particular los egresados que fueron informantes no manifestaron exclusiones de tipo laboral, ni preferencias. En la construcción de las distintas categorías los informantes tuvieron la oportunidad de revelar tensiones, inconformidades, denuncias o exclusiones de tipo laboral, pero no fue así.

En esta dirección apuntan también las opiniones de los expertos en educación virtual, ya que por sus experiencias y conocimientos tienen argumentos acerca del impacto de los programas educativos y las modalidades de educación en las empresas y en la sociedad y de existir exclusiones para los egresados de la modalidad virtual, seguramente lo hubieran dicho.

Relacionado con el impacto de los egresados, está también lo opinado en la construcción de las categorías sobre aprendizaje en la 
educación virtual y sobre perfiles de estudiantes y profesores. Antes que preocupaciones o angustias, se observaron realidades y proposiciones sobre formación por competencias y sobre formación de actitudes como la disciplina, la autogestión, la responsabilidad, que están alineadas con los perfiles que solicitan las empresas.

Indagación 4: ¿ ¿en el sector empresarial confían en la educación virtual y se considera que el riesgo de fraude en su formación es alto?

De acuerdo con las estadísticas, la mayoría de las personas confían en la educación virtual, pero consideran que el riesgo de fraude en su formación es alto. La investigación cualitativa confirmó esta conclusión. Es decir, en el sector empresarial sí confían en la educación virtual y no se considera que el riesgo de fraude en su formación sea alto. Una razón fundamental es que los entrevistados y que participantes de los grupos focales son personas adultas que conocen el sector empresarial y allí tienen convivencias y compromisos.

A pesar de toda la oportunidad para expresarlo, en ningún momento se expuso desconfianza en las empresas hacia el profesionalismo de los egresados de la educación virtual. Los informantes reconocieron que sí hay dificultades con actos deshonestos o con el riesgo para el fraude y tienen sus explicaciones y sus propuestas al respecto. Pero estas dificultades son internas, en el entorno empresarial no se manifiestan tales temores.

No obstante, es justo aclarar algo con respecto a la investigación cuantitativa: la percepción no es favorable en un $100 \%$, esto es, hay un alto porcentaje de entrevistados que manifiestan que hay desconfianza en las empresas y riesgo para el fraude, pero no es significativamente mayoritario y siendo fieles a la conceptualización estadística, el análisis de los datos determina que lo que se generaliza es lo contrario.

Indagación 5: ¿la educación virtual genera confianza y preferencia en las personas con vinculación empresarial?

De acuerdo con los datos cuantitativos, la mayoría de las veces la educación virtual no genera confianza y preferencia en las personas. Desde los hallazgos obtenidos en las entrevistas y los grupos focales no se confirma la conclusión del resultado estadístico. Si así fuera, en los discursos, los estudiantes y los egresados hubieran expuesto sus argumentos. Se sabe que cuando una persona tiene espacios para manifestar sus sentimientos, aprovecha y habla de sus dificultades o temores. 
En términos generales, lo que se observó en los informantes es una credibilidad certera en la modalidad virtual y satisfacción sobre sus dinámicas. Claro está, cuando se especifican detalles vienen críticas, comparaciones, insatisfacciones y también, voces de aliento y conformidad. Pero los informantes no sienten rechazo o incertidumbres sobre la modalidad virtual en la cotidianeidad.

Es de anotar que las personas de la vida cotidiana tienen sus arraigos en la educación presencial, entendida como la relación directa entre un profesor que enseña y un grupo que aprende en un escenario cerrado físicamente. Ese paradigma puede haber incidido en la consignación de las opiniones en las encuestas, pero distinta es la visión de quienes son actores de la educación virtual como los estudiantes, los egresados y los profesores que tienen convivencia con las personas que no son de vida académica. Aparte de esto, dentro de su sabiduría, si los expertos en educación superior entendieran que en la vida cotidiana no se confía en la educación virtual, lo hubieran manifestado en las entrevistas.

Indagación 6: ¿cuál es el nivel de preferencia en los hogares de modalidad virtual con respecto a la modalidad presencial?

Según los datos de las encuestas, las personas de hogar no prefieren en mayor proporción los estudios en modalidad virtual que en la presencial. Los hallazgos de la investigación cualitativa reafirman estos datos. Esto es, en la vida cotidiana no se prefiere a la educación virtual. En la percepción de estudiantes, egresados y profesores de la modalidad virtual, se observa que encuentran en la educación virtual ciertas características que la hacen más ventajosa que la educación presencial, muy al contrario de la percepción de las demás personas. En estas hay más dudas que certezas con respecto a la viabilidad de la educación virtual. Un elemento fundamental es que la gente de la vida cotidiana no entiende las ventajas formativas que puede tener la educación virtual, por ejemplo, el acceso permanente a múltiples recursos didácticos y mediaciones pedagógicas. Para ellos es difícil comprender que el aprendizaje en el ambiente virtual requiere del acompañamiento docente y que se forman comunidades de aprendizaje, pues su paradigma está marcado por la enseñanza de contenidos. Por eso la educación virtual no es de su preferencia. 


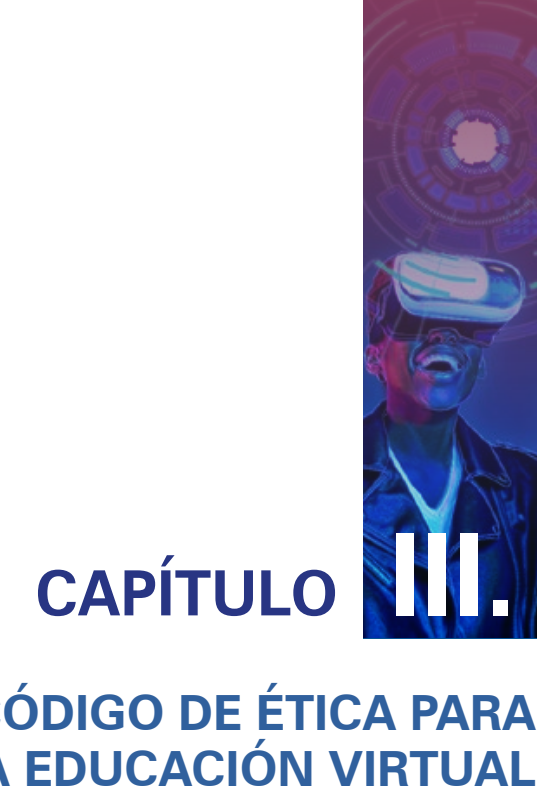

Los ambientes virtuales de aprendizaje son puntos donde se encuentran subjetividades de profesores y estudiantes, con sus propias expectativas, pero con homogeneidad en sus intereses. Los estudiantes tienen el propósito común de lograr peldaños para sus proyectos de vida y los profesores tienen la misión de contribuir directamente a esas consecuciones y, además, aspiran a encontrar en esos ambientes satisfactores profesionales y personales. Directivos y gestores asumen el compromiso de crear recursos y vínculos para que se puedan concretar las aspiraciones de estudiantes y profesores. Es decir, hay una maraña de intereses y responsabilidades que comprometen las decisiones y posturas de todos.

Pensando en lo anterior, se encuentran razones para la existencia y promulgación de un código de ética. No para reglamentar intereses, pero sí para fomentar reflexiones, autodeterminaciones, alteridades y cuidados por la virtud y la armonía en los procesos formativos virtuales. El código exhorta a los integrantes de los ambientes virtuales a que, con sentido de autodeterminación y principios éticos, como lo definen Aranda et al. (2015), emprendan las actividades propias de su rol, buscando que de verdad se realice el propósito de formación de los estudiantes.

\section{Responsabilidad y libertad}

La apuesta por un código de ética para la educación virtual abre un debate donde básicamente se plantean varios argumentos: sería intentar instrumentalizar la ética o reglamentarla; sería traer a la educación conceptos de las empresas que entienden el código como listados de normas; sería configurar un recetario de mandatos o de buenas 
comportamientos fundados en "camisas de fuerza" y no en la libertad de las personas; sería definir un código de ética para cada modalidad educativa (virtual, a distancia, presencial); sería codificar los comportamientos que ya todos conocen en la educación; sería crear otro reglamente para las conductas de las personas. Así se expresaron quienes participaron en el proyecto de investigación como informantes en los grupos focales y en las entrevistas.

En general, los informantes en los grupos focales y las entrevistas no vieron viable la introducción de un código de ética para a educación virtual. Aunque sus argumentos son razonables, pues imaginan que es un compendio de normas sobre la conducta, el establecimiento de unos impedimentos que deben cumplirse para poder permanecer y no un marco conceptual para que las personas en su individualidad opten y se responsabilicen de sus actos.

Es cierto también que, en el mismo proyecto, aunque sin reclamar directamente un código de ética, las personas en las entrevistas y grupos focales lo justificaron, desde relatos acerca de comportamientos mañosos o dolosos y desde la consideración del ambiente virtual como una concentración de seres humanos que eligieron aprender ahí y que, por la condición y la naturaleza de ese ambiente, pueden incurrir en actos deshonestos. Más aun, cuando se consideró repetidamente que la deshonestidad en el ambiente virtual es un asunto de la individualidad, que aun con muchos controles, habría unas decisiones y actitudes venidas desde la educación familiar o desde la estructura misma de la persona, que lo haría ineficiente, se estaba abriendo la necesidad de un fundamento institucional mucho más profundo que un libro de sanciones.

Los informantes plantean que el riesgo del fraude puede mitigarse de tres formas, en general: con dispositivos tecnológicos, con estrategias docentes para enfocar aprendizajes y evaluación y con la reflexión intensa y motivada de los estudiantes acerca de su proyecto de vida. Cualquiera de estas tres estrategias requiere de un marco conceptual que permita verificar o validar los actos que libremente decidan los actores. Desde este punto de vista adquiere también sentido un código de ética para la educación virtual.

Otro hallazgo significativo en los grupos focales y las entrevistas en profundidad, es que la ética en el ambiente virtual debe expresarse también en las determinaciones y actuaciones de empleados, directivos y profesores. La evaluación y calificación de los comportamientos no debe 
limitarse a los estudiantes, pues los otros actores son también sujetos y, debido a la naturaleza del ambiente virtual, también pueden incurrir en actos deshonestos, que, además, pueden desencadenar en decisiones indecorosas de otras personas. Además, el aula virtual, más que un sistema tecnológico, es un ambiente educativo en el que coinciden grupos de personas con el fin de aprender y convivir.

La médula de la ética, según Savater (citado por Camperos, 2002), está relacionada con la libertad de elección racionalmente. El ser humano no solo actúa a causa de la realidad, sino que es constructor de esta, de acuerdo con la convicción sobre posibles futuros.

Vivir bien implica llegar a saber qué es lo que realmente se quiere y, de igual forma, conocer, por sí mismo, lo que de verdad nos satisface como seres humanos que habitamos este planeta. La ética es aprender a vivir bien. La ética es hacer lo que de verdad queremos (no las satisfacciones inmediatas), sin olvidar que todas nuestras acciones y todos nuestros comportamientos siempre tendrán influencia fundamental en nuestra vida individual, y no en la vida de los demás (como muchas veces creemos). Cuando tratamos de dañar al prójimo, muchas veces nos causaremos peores daños nosotros. Hay que recordar (y tratar de hacer de ellos un principio de vida) que debemos tratar a los seres humanos como tales, y que, al no hacerlo de este modo, seremos nosotros mismo los que no vamos a conseguir ser tratados en estas condiciones. De igual forma, si no hacemos a otros lo que no queremos que nos hagan, tampoco debemos permitir que nos hagan lo que nosotros seríamos incapaces de hacer a otros, ya que no sería justo ni de razón (Camperos, 2002, p. 277).

La ética es general. No es preciso buscar la ética en busca de recomendaciones exactas para actuar en situaciones específicas, a la manera de recetario de comportamientos. Sería inútil entenderla como cánones que digan qué se debe hacer en determinados momentos, ya que, aunque es incidente en los comportamientos de las personas y en sus decisiones, cada uno tiene su propia condición moral. Además, la ética dentro de la convivencia social se encuentra en continuo movimiento (Aranda, Jaimes y Caballero, 2015).

Para entender la ética, es oportuno enlazar tres significantes que se relacionan: responsabilidad, corresponsabilidad y libertad. Este entrelazado surge cuando se van a tomar decisiones, en vez de las contraposiciones del pasado: optar entre lo bueno o lo malo o entre el bien y el mal. La persona es libre de optar frente a varias disyuntivas y se hace responsable de sus actos 
y es una condición suya, únicamente. Asimismo, se hace responsable de las consecuencias que esos actos traen para otras personas o instituciones. La corresponsabilidad se obstruye cuando las acciones se examinan de acuerdo con el beneficio propio y no con las secuelas ocasionadas en los otros. La libertad se refiere a la conducta de razonar por sí mismo, racional y autónomamente (Jiménez, 2016).

Según lo anterior, autónomamente el individuo tomará sus decisiones o actuará por sí mismo, pero con criterios de responsabilidad y corresponsabilidad. Por supuesto, para asumir responsabilidades y consecuencias de sus decisiones, debe conocer el estado de cosas. En efecto, debe existir un establecimiento de relaciones que den señales sobre el actuar, entendido como el desenvolvimiento autónomo y razonable para el beneficio propio, pero que no desencadene lesiones para otros individuos o instituciones.

¿Qué es un código de ética? Es un compendio de principios y valores que constituyen el establecimiento para el actuar con autonomía, responsabilidad y corresponsabilidad y que deben ser reconocidos por los integrantes. No debe interpretarse como una lista de códigos buenos antepuestos a otros que son malos, ni como un despliegue de deberes o derechos. Un código es una declaración formal de principios que orientan los comportamientos y decisiones de una organización (Fernández, 2011).

Según Trapero et al. (2015), la introducción de un código de ética debe surgir de la convicción colectiva y no desde la determinación vertical de los directivos, teniéndose claro cuál es la importancia de la ética y cuáles son los lineamientos que sustentan las decisiones en las organizaciones. En estas las personas proceden convenientemente no de acuerdo a normas estrictas, sino por cánones que hacen parte de sus convicciones y que asumen como tal.

\section{Referentes sobre códigos de ética}

Es común que las instituciones educativas y las empresas tengan declaraciones sobre su código de ética, distinto a sus reglamentos laborales o estudiantiles. Surgen varios interrogantes: ¿será que los reglamentos son de cumplimiento obligatorio, pero no los códigos de ética? ¿Cuál es la línea divisoria para comprender la función del uno y del otro? ¿Sancionar a quien transgrede con sus actuaciones o decisiones al orden establecido y la armonía es un asunto de la legalidad, pero no de la ética? Un código de ética es un instrumento orientador y, según Trapero et al. (2015), 
debiera de ser un acuerdo entre los grupos de interés. Estos códigos, aunque no son reglas, a veces se socializan con el rótulo de "obligatorio cumplimiento" (Vatia, 2018, p. 2).

Un código de ética se concibe como el documento institucional que permite evidenciar y proteger los valores éticos compartidos en la organización y funda el referente general para la conducta de las personas y su comportamiento probo (Gobierno Regional del Maule, 2018). Un reglamento, en cambio, es un dispositivo regulador riguroso. Es decir, es una estructura rígida cuya función es determinar límites de las conductas. Los reglamentos constituyen la normatividad de las organizaciones, y, por eso, explícitamente, definen su configuración jurídica. Los reglamentos contemplan sanciones a quienes incumplen o quebrantan sus normas, en tanto que los códigos de ética promulgan unas conductas esperadas, pero no castigos, y quien no actué en sincronía con ellas quedará expuesto o al señalamiento social y o al hostigamiento de su propio yo.

Como antecedentes conceptuales, merecen atención los códigos de ética de empresas y de instituciones educativas. Esto para contrastar argumentos en los grupos focales y en las entrevistas que se mostraron contrarios a un código de ética para la educación virtual, porque sería llevar al entorno educativo prácticas que son propias del mundo empresarial. Además, para verificar si el contenido de esos códigos en las empresas tiene un carácter normativo, al contrario de lo que debe ser un código formativo en el ámbito de la educación. A continuación, se presentan algunos códigos de ética de organizaciones empresariales y educativas.

El Grupo Aval (2019) entiende el código de ética como una incorporación de pautas éticas y de conductas que deberán seguir todos los funcionarios para que en "cumplimiento de sus deberes, observen los principios establecidos para promover transparencia y confianza en las relaciones internas de la Compañía" (s.p.).

Por su parte, el Grupo Bancolombia (2019) define el código de ética como principios y reglas de conducta para guiar la actitud y el comportamiento del personal de la empresa para mantener excelentes relaciones y compromiso con el crecimiento y desarrollo institucional, mediante la promoción de principios y exaltación de valores.

Asimismo, el Grupo Éxito (2019) concibe este código como "como un conjunto de lineamientos de actuación" de su recurso humano, de manera que, "su operación y su cadena de suministro sean transparentes, económica, social y ambientalmente responsables" (s.p.). 
El Consejo Nacional de Ingeniería (COPNIA, 2019) define su código de ética así: "Constituye el catálogo de conductas profesionales que se exigen, se prohíben o que inhabilitan a los ingenieros en general y a sus profesionales afines o auxiliares. Dicho catálogo es el marco legal del comportamiento profesional del ingeniero, por lo que el ejercicio profesional debe estar ajustado a sus disposiciones" (s.p.).

En los anteriores códigos aparece cierta homogeneidad en las siguientes definiciones: pautas éticas y de conductas, principios y reglas de conducta, lineamientos de actuación y catálogo de conductas profesionales. Puede entenderse esto como la especificidad para el buen actuar de los funcionarios de estas compañías expuesto el listado de conductas o comportamientos aceptables. En la misma dirección se define el código de ética de la empresa ESCO Technologies INC. (2019), orientado en términos de normas mínimas de conducta y prácticas comerciales que deberán cumplir los vendedores, proveedores, representantes, agentes, subcontratistas y socios comerciales.

A diferencia de estos, la siguiente es la definición del código ética del Ministerio de Protección Social (2019), concebido como un compromiso esencial y construido en colectivo:

El Código de Ética del Ministerio de la Protección Social, construido con la participación de buena parte de los funcionarios, se constituye en el compromiso esencial de todos los que hacen parte de la entidad de desarrollar las tareas cotidianas dentro de parámetros éticos y conductas íntegras que contribuyan al mejoramiento continuo de nuestra gestión con lo cual se verá beneficiada la ciudadanía en general.

El objetivo de este es establecer las pautas de comportamiento que debe observar toda persona que preste sus servicios, bajo cualquier modalidad de vínculo laboral o contractual en el Ministerio de la Protección Social.

Dar las orientaciones éticas que marquen el camino de cómo debe relacionarse la Entidad y los servidores públicos con un sistema o grupo de interés, promoviendo un activo compromiso con la puesta en práctica de los principios y valores, en procura del cumplimiento de la misión institucional. Este código está orientado a los que participan en el funcionamiento en general del Ministerio. (s.p.).

La Alcaldía de Fonseca, Guajira, (2019) concreta su código de ética en términos de un referente que debe tenerse en cuenta por parte de 
los funcionarios en sus actuaciones y decisiones, en consideración de los siguientes principios y valores: libertad, pertenencia, responsabilidad, aptitud, honestidad, disciplina, respeto y tolerancia.

El código de ética de la Policía Nacional (2019) no se exhibe como un compendio de conductas. En vez de esto, se despliega como un compromiso general de los policías:

Como policía tengo la obligación fundamental de servir a la sociedad, proteger vidas y bienes; defender al inocente del engaño, a los débiles de la opresión y la intimidación; emplear la paz contra la violencia y el desorden y respetar los derechos constitucionales de libertad, igualdad y justicia de todos los hombres.

Llevaré una vida irreprochable como ejemplo para todos; mostraré valor y calma frente al peligro, al desprecio, al abuso o al oprobio; practicaré la moderación en todo y tendré constantemente presente el bienestar de los demás. Seré honesto en mi pensamiento y en mis acciones; tanto en mi vida personal como profesional, seré un ejemplo en el cumplimiento de las leyes y de los reglamentos de mi institución. Todo lo que observe de naturaleza confidencial o que se me confíe en el ejercicio de mis funciones oficiales, lo guardaré en secreto a menos que su revelación sea necesaria en cumplimiento de mi deber.

Nunca actuaré ilegalmente ni permitiré que los sentimientos, prejuicios, animosidades o amistades personales lleguen a influir sobre mis decisiones. Seré inflexible pero justo con los delincuentes y haré observar las leyes en forma cortés y adecuada, sin temores ni favores, sin malicia o mala voluntad, sin emplear violencia o fuerza innecesaria y sin aceptar jamás recompensas. (s.p.).

El Instituto de Consejeros Administradores (2019) parte de una definición amplia de lo que constituye su código y la responsabilidad que implica a sus distintos estamentos, configurándose así un marco conceptual, luego hace un listado de deberes que deben cumplirse en las funciones de dirección, en las relaciones con proveedores y clientes, competidores, empleados y sociedad civil.

La Dirección de Impuestos y Aduanas Nacionales (DIAN, 2019), despliega su código de ética en términos de unas políticas de buen gobierno y expone diferenciaciones en el ámbito de la persona, en los equipos de trabajo y en el nivel institucional. 
El Grupo EPM (2019) define el código de ética identificándose como una organización que es sujeto ético, que actúa en reconocimiento de la universalidad de derechos humanos, laborales, medio ambiente, y lucha contra la corrupción y que articula sus objetivos empresariales con los sociales, para lograr desarrollo humano.

El Consejo de Normas Internacionales de Ética para Contadores (2019) plantea su código de ética en términos de normatividad internacional, bajo el marco de Normas Internacionales de Ética para Contadores (International Ethics Standards Board of Accountants, IESBA). Por eso más que un marco conceptual sobre la ética, está enfocado es una reglamentación para el buen actuar.

El Ministerio de Educación Nacional (2019) presenta un código de ética entrecruzado con orientaciones estratégicas y políticas de buen gobierno. Por esta razón aparece impal pable, sin fundamento ético y configurado como un documento para la gestión institucional, pero no para la determinación de la subjetividad responsable con corresponsabilidad. En este mismo sentido está planteado el código de ética de la Dirección de Impuestos y Aduanas Nacionales (DIAN, 2019). Incluso, presenta un contenido más amplio que configura elementos de buen gobierno, código de ética, orientaciones estratégicas y una amplia gama de políticas de gestión.

Interconexión Eléctrica S.A. (ISA, s.f.) define un código de ética y conducta. Llama la atención que diferencian estos dos conceptos en la declaración, pero en su fondo no diferencian cuáles actuaciones se direccionan hacia uno u otro concepto. Este código es amplio y parte de los siguientes principios éticos: transparencia (actuar de manera confiable, accesible, clara y honesta); reciprocidad (respeto a la dignidad del otro con quien la empresa se relaciona, en un ambiente de reconocimiento mutuo de las obligaciones y derechos de las partes involucradas); cumplimiento (compromiso de realizar lo prometido y de observar los parámetros, políticas, estándares y en general la normatividad aplicable a las empresas); pluralismo (reconocimiento de la diversidad de las personas que contribuye, en un ambiente de respeto, a enriquecer a la organización en los lugares y culturas donde opera; laboriosidad (deber de los administradores, directivos y trabajadores de cumplir con las responsabilidades orientadas al logro de los objetivos misionales de la empresa. Implica realizar con cuidado y esmero las labores y deberes que le son propios dentro de la empresa).

Para el Departamento Nacional de Planeación (DNP, 2019), la denominación tomada es la de código de integridad. Se referencia como 
un instrumento técnico de la Política de Integridad del Modelo Integrado de Planeación y Gestión (MIPG). Se plantea que:

No basta con adoptar normas e instrumentos técnicos, también es necesario que los ciudadanos, los servidores y las organizaciones públicas se comprometan activamente con la integridad en sus actuaciones diarias. Lo anterior significa que para avanzar en el fomento de la integridad pública es indispensable acompañar y respaldar las políticas públicas formales, técnicas y normativas con un ejercicio comunicativo y pedagógico alternativo que propenda por efectuar cambios concretos en las percepciones y las actitudes de las entidades públicas de la Rama Ejecutiva colombiana. (DNP, 2019, s.p.).

Finalmente, el código de ética del Ministerio del Interior (2019) se define desde unos planteamientos de integralidad para unos propósitos relacionados con generación de una cultura de comportamiento en los funcionarios, fomentos de principios, valores, y creencias institucionales, creación y mantenimiento de un ambiente de cordialidad y apoyo y colaboración para garantizar que la gestión laboral satisfaga plenamente a los clientes.

Una definición de código de ética que la entiende como un concepto general es la siguiente:

No pretende ser un manual exhaustivo que cubra diferentes situaciones particulares de los integrantes de la organización. Es una relación comprensiva de estándares de conducta que genera información acerca de principios, normas y regulaciones que aplica la Uniremington, y constituye una herramienta que ayuda a tomar decisiones dentro de un marco ético, propiciando una interacción armónica entre sus diferentes estamentos. (Corporación Universitaria Remington, 2019, s.p.).

El código de ética de UNIMINUTO (2019) se expone en conexión con principios organizacionales, comunidad educativa, autonomía universitaria y otras declaraciones de tipo institucional y por eso parece no estar delimitado como un documento rector. Su esencia no es evidente ya que su composición es difusa y por eso, ni se presenta como un listado de conductas especificas ni como una conceptualización general.

El código de ética del SENA (2019) se formula de manera pedagógica, no como grupos de normas para el buen actuar, sino como la especificidad de conceptos orientadores de las acciones y decisiones de las personas. 
Plantea los siguientes principios éticos (creencias básicas internas): primero la vida, la dignidad del ser humano, la libertad con responsabilidad, el bien común prevalece sobre intereses particulares y formación para la vida y el trabajo. Define unos valores y compromisos y especifica los comportamientos esperados en torno a cada uno de los principios éticos.

El código de ética de la Institución Universitaria de Envigado (2019) se advierte etéreo y escueto, orientado por los siguientes principios éticos: la vida (como fundamento de toda posibilidad para la condición humana), la libertad, la equidad y la recta intención (como fundamento para obrar con idoneidad).

El código de ética de la Universidad Nacional Autónoma de México (UNAM) se configura de la siguiente manera: un preámbulo donde se define el código; un conjunto de valores agrupados en las categorías de formación de profesionales e investigadores, contribución a la generación del conocimiento y divulgación de los beneficios del conocimiento; doce principios éticos relacionados con convivencia pacífica, igualdad, libertad de pensamiento y de expresión, respeto y tolerancia, laicidad en los dinamismos universitarios, honestidad académica, respeto a los derechos de autor, responsabilidad social y ambiental, objetividad académica y honestidad, uso responsable de los recursos de la institución, trasparencia de la información y resguardo de la información personal (Código de ética de la Universidad Nacional Autónoma de México, 2015).

Analizados los códigos de ética de 30 organizaciones distintas, algunos expuestos muy resumidamente en los párrafos anteriores, se concluye lo siguiente acerca de los contenidos:

1). Algunos se definen como un conjunto de normas de conducta que deben cumplir las personas de los grupos de interés y señalan qué es considerado una buena o una mala actuación.

2). Otros se presentan como un conjunto de valores y principios que constituyen un marco de referencia para las actuaciones de las personas dentro del contexto especifico de la organización.

3). Un tercer grupo lo constituyen códigos formulados con sentido pedagógico, ya que exponen lo que se considera en la organización, debe ser la actuación coherente de las personas con la naturaleza del contexto y su formulación se acentúa de manera formativa. 


\section{Constitución de un código de ética para la educación virtual}

Este código ha surgido desde el proyecto de investigación presentado en los capítulos anteriores, pero su puesta en escena en alguna organización de educación virtual debe ser sometida al horizonte compartido de los distintos grupos de interés bajo criterios de contratos consensuados y participativos. La propuesta de código de ética está dirigida a organizaciones de educación que, aunque independientes y con sus propios contextos, comparten o advierten homogeneidades en cuanto a los siguientes elementos:

a). Se asume educación totalmente virtual, esto es, sin momentos para encuentros presenciales en recintos físicos.

b). Se asume la existencia de profesores con la responsabilidad de orientar a los estudiantes en sus cursos y con funciones relacionadas con gestiones pedagógicas y curriculares.

c). Se asume que el espacio formativo es una plataforma tipo LMS gestionado por un grupo de colaboradores que deben garantizar su continuo funcionamiento.

d). Se asume la existencia de una estructura organizacional para atender a profesores y estudiantes, dentro de la cual existen procesos estratégicos, operativos y de apoyo.

e). Se entiende que la comunidad de estudiantes está compuesta por personas mayores de quince años que han decidido estudios de educación técnica, tecnológica, profesional o de posgrado.

Con los anteriores supuestos se sugiere un código de ética cuya estructura se muestra en la figura 5. 
Figura 5. Estructura del código de ética

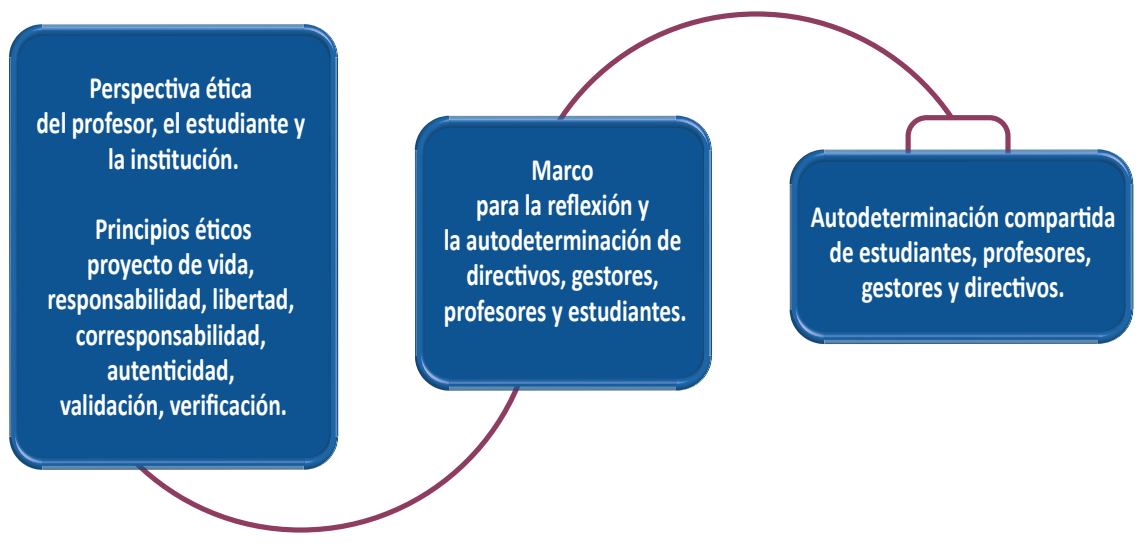

Se concibe el código de ética no como reglas de conducta, sino marco para la reflexión y la autodeterminación de los distintos actores. Según Martínez Negrete (2014), la educación virtual es aquella que tiene como espacio académico el ciberespacio, dicho de otra manera, no es necesario que el estudiante esté en cuerpo presente para lograr un diálogo de aprendizaje. Los principios básicos de la educación virtual, como toda actividad humana son la honestidad, responsabilidad, el respeto, la justicia, el trabajo colaborativo, la disciplina, la autorregulación, el compromiso y la solidaridad. Estos principios están acordes con criterios universales de la educación: ser neutral en los ámbitos político y religioso; ser garante del respeto a la libertad ideológica de los miembros de su comunidad; ser participativa y crítica, en la que, partiendo de una actividad docente centrada en la excelencia, el estudiante sea un sujeto activo dentro del proceso educativo (Universidad Nacional de Educación a Distancia [UNED], 2009).

Los estudiantes y sus necesidades formativas son el centro de la actividad universitaria $y$, por tanto, objeto de su atención preferente, orientada a obtener las máximas aportaciones al conocimiento y a su desarrollo personal. Una relación generadora de confianza, pero basada en el rigor y la exigencia recíprocos (UNED, 2009, art. 5).

En relación con los estudiantes, la honestidad académica se presume como la piedra angular para logar una formación profesional adecuada, especialmente bajo la premisa de que los estudios son procesos acumulativos y exigen secuencias y logros intermedios (Athabasca University, 2019). Así 
pues, se exige que se reconozca la contribución de los demás. Reclamar contribuciones e ideas de otro como propias, o adueñarse de ellas, es privarse de la oportunidad y el desafío de aprender y participar en el proceso académico de adquisición y desarrollo de conocimiento.

La atención a las conductas deshonestas comienza con el reconocimiento individual de las responsabilidades personales y académicas. Algunas actitudes indecentes son: el fraude y el plagio de información, el uso inadecuado de los recursos académicos, la violación de derechos informáticos, la negación de los derechos de autor, la realización de declaraciones falsas en la recopilación y presentación de información (Martínez Negrete, 2014). El estudiante deberá desarrollar las capacidades cognoscitivas para enfrentar los retos que presenta el siglo XXI: mente disciplinada, mente sintética o sintetizadora, mente creativa, mente respetuosa y mente ética (Martínez Negrete, 2014).

\section{Perspectivas de los involucrados}

\section{Perspectiva ética institucional}

La ética institucional está inspierada en el cultivo y cuidado de las determinaciones responsables de estudiantes y profesores para apropiarse de: la cooperación, la disciplina con el compromiso académico, la honestidad consigo mismo y con los otros y el respeto por la institucionalidad. Es responsabilidad de direcivos y gestores velar por la independencia política, religiosa e ideológica y respetar las posturas individuales de los actores, promover la participacion sincera y dinámica de los estudiantes y los profesores.

El fin úlitmo de un curso virtual es la formación del estudiante y la razón de ser institucional es garantizar formación integral para el desarrollo humano y para el bienestar social.

\section{Perspectiva ética del estudiante}

Las conductas de los estudiantes deben ser examinadas por su autocrítica. Las actitudes indecentes y las decisiones indecorosas deben autoevaluarse teniendo en mente sus retos personales relacionados con la disciplina académica, la creatividad con el conocimiento, el respeto hacia los demás, el cuidado de su proyecto de vida y el respeto por el trabajo de los demás. 


\section{Perspectiva ética del profesor}

El profesor debe comprometerse e involucrarse directamente con el ambiente virtual, a través de la comparecencia oportuna de las actividades programadas, el seguimiento de la participación estudiantil, el fomento del aprendizaje autocontrolado, la asistencia oportuna y, sobre todo, el compartimiento con el estudiante del aprendizaje significativo. El docente, en su rol multiplicador, promueve la responsabilidad, cuando exhorta a sus estudiantes al cumplimiento oportuno de las tareas, a la realización de las actividades formativas, y a desplegar los comportamientos en sintonía con aquel que es el protagonista de su propio aprendizaje.

La probidad es un valor para fomentar por parte de los profesores. Ellos promueven la honestidad cuando estimulan a los estudiantes y los motivan para participar activamente en la interacción formativa y dentro de los entornos virtuales de aprendizaje. Igualmente, la solidaridad hace parte de la agenda de los profesores y su promulgación es de su responsabilidad. La solidaridad debe ser promovida a través de la integración de los participantes en actividades colaborativas, donde a partir de la alteridad se obtengan mejores resultados. A partir de la aportación sinérgica de los intervinientes dentro del proceso virtual de aprendizaje, se debe promover la construcción colectiva e individual del aprendizaje.

Los entornos virtuales de aprendizaje se sustentan en el construccionismo y esto también está dentro de la agenda del docente virtual. Por ello, es relevante el concepto del aprendizaje significativo, toda vez que mientras el estudiante participa y aprende, va tejiendo su propia red de conocimientos, a partir de lo que es verdaderamente trascendente para ellos.

Tomando como base el reconocimiento del otro, de su sentir, de su individualidad, de su existencia, el profesor debe cuidar la rectitud y fomentar los valores personales. Dentro de los entornos virtuales de aprendizaje, el respeto es un valor fundamental, si el propósito es propender por el aprendizaje colaborativo. Un ambiente hostil es incompatible en entornos virtuales de aprendizaje, de allí que sea deseable que el profesor modele y promueva la sujeción a las normas de clase, la promoción y el acatamiento de la convivencia armónica dentro y fuera de los espacios virtuales, fomentando el aprecio por las ideas, sentir y perspectivas de los estudiantes, así como la toma de decisiones de manera consensuada. 
Elprofesordebefomentarlaequidad,yaqueestapromuevelaaccesibilidad igualitaria, partiendo de las diferencias personales, cognitivas y sociales, que caracterizan a los participantes que forman parte de la experiencia virtual de aprendizaje. La equidad se manifiesta a través de la igualdad en la asistencia o soporte al estudiante, el tiempo dedicado y en el acceso a las mediaciones pedagógicas, actividades y recursos (Chirinos Campos, 2016).

\section{Propósito del código de ética}

Integrar un marco conceptual que sirva de fundamento para las actuaciones y decisiones con criterios de responsabilidad, corresponsabilidad y libertad de estudiantes, profesores, empleados y directivos de la educación virtual.

\section{Principios éticos}

a). Proyecto de vida: la razón de ser del ambiente virtual es el proyecto de vida del estudiante y su construcción es responsabilidad de sí mismo y de profesores e institución. Todo lo que se haga o no, se evalúa desde tal motivación.

b). Responsabilidad: los estudiantes virtuales toman con obligación moral su compromiso académico y de convivencia. Intrínsecamente se empoderan de sus retos para ir configurando sus aprendizajes y sus relaciones legítimas de pertenencia al ambiente virtual. Los profesores con determinación enfilan sus esfuerzos pedagógicos hacia los estudiantes, mientras que directivos y empleados toman decisiones entendiendo la coyuntura de una comunidad académica dispersa.

c). Libertad: en la modalidad virtual, la autonomía es una característica especial. El estudiante decide cuándo y cómo estudiar, el profesor elije en qué momento acompaña a sus estudiantes, el empleado prioriza según su criterio y el directivo planea y ejecuta según la conveniencia institucional.

d). Corresponsabilidad: las decisiones que libremente tomen estudiantes, profesores, empleados y directivos estarán en armonía con sus criterios y gustos, pero asumiendo las secuelas que dejen sobre otros y sobre la institución.

e). Autenticidad: cada uno interiorizara su rol decididamente en la virtualidad, aun con la ausencia de concentraciones físicas, de 
encuentros cara a cara. Ser auténtico es ser veraz en la identidad y en las actuaciones en el aula virtual. Esto es innegociable e inalterable. Contra esa veracidad nada es justificable.

f). Validación: la institución virtual define y divulga estrategias y mecanismos de aceptación de la actividad y determinaciones de sus integrantes. Todo acto será susceptible de comprobación y su reconocimiento estará determinado por otros actos externos.

g). Verificación: la institución virtual establece formas de confrontación de los actos y decisiones de todos los actores, para evaluar que sus decisiones autónomas no lesionen las de los otros ni afecten el establecimiento.

\section{Enfoque compartido de la autodeterminación de los actores}

Estudiantes, profesores, gestores y directivos comparten entusiasmo, responsabilidad, credibilidad, esfuerzos y creencias para que efectivamente se desarrollen las actividades para el propósito formativo de la educación virtual. Por lo anterior, estos actores deben comprender las autodeterminaciones de los otros y cuidar que sus actitudes, conductas, procederes y toma de decisiones, estén en sincronía y armoniosamente apunten a las dimensiones significativas de la educación.

\section{Autodeterminación de los estudiantes}

- Como estudiantes, reconocen que su responsabilidad primordial es con su proyecto de vida. Consideran que sus actividades académicas e investigativas las comparten con otros compromisos familiares, sociales o laborales, que hacen también parte de tal proyecto. En torno a esas dos circunstancias evalúan sus determinaciones.

- Saben de su autonomía para optar entre diversas alternativas para sus logros académicos, pero con cuidado de sí mismo y de sus compañeros. Cuidan que sus decisiones se correspondan con la legitimidad institucional, con el entorno virtual, con sus compañeros, y asumen responsabilidades sobre sus actos y las derivaciones de estos.

- Entienden que hacen parte de un ambiente virtual de aprendizaje donde las comunicaciones los unen a otros y donde libremente pueden actuar. No obstante, entienden que sus determinaciones deben ser armónicas con el compromiso de sus profesores y con la integridad de sus compañeros. 
- Comprenden que en la virtualidad hay convivencia, aunque no haya encuentros físicos y que las decisiones deben ser armónicas con esta.

\section{Autodeterminación de los profesores}

- Como profesores entienden que sus estudiantes están dispersos en distintos territorios y que cada uno está ávido de información e instrucción. Comprenden que puede haber contingencias particulares en la tecnología de los estudiantes o en sus ambientes personales de aprendizaje.

- Comprenden que sus estudiantes esperan respuestas en el menor tiempo posible para continuar con sus procesos de aprendizaje. Saben que su asesoría debe ser oportuna y que cada estudiante tiene su agenda de estudio.

- Reconocen la autonomía de los estudiantes. Su autodeterminación para gestionar los compromisos académicos, su disposición para investigar, pero no los identifican como autodidactas absolutos que emprenden indagaciones sin rutas fijas.

- Deciden libremente sobre las formas de su docencia y evaluación de sus estudiantes. Pero son conscientes de su responsabilidad con ellos y la asumen, como también las consecuencias para la institucionalidad, el proyecto de vida de los estudiantes y la integralidad de sí mismos.

- Deciden libremente sobre los contenidos en el aula virtual y saben de las implicaciones en el aprendizaje de sus estudiantes y en la responsabilidad institucional.

- Comprenden que los comportamientos de sus estudiantes son de la decisión y responsabilidad de ellos, aunque saben, además, que ambas partes conforman un ambiente formativo virtual. Por eso los comportamientos de sus estudiantes ameritan motivaciones, validaciones, verificaciones, consensos y momentos de reinicio.

- Entienden que la ética de los estudiantes en los ambientes virtuales puede partir a veces de la de las decisiones de los profesores y por eso deben también asumirla responsablemente. Es decir, la armonía, la estética, el compromiso son asuntos de su libertad, pero saben que puede incidir en el compromiso de sus estudiantes. 


\section{Autodeterminación de los empleados}

- Saben que su misión fundamental es apoyar a los estudiantes y profesores en el ambiente virtual y que las decisiones que libremente tomen incidirán en ellos.

- Interpretan el ambiente virtual como comunidad de personas conectadas por la tecnología y por fines de aprendizaje, aunque dispersas en territorios distintos. Cada uno con afanes propios, ávidos de soluciones, angustiados porque tienen que cumplir sus compromisos.

- Reconocen dilemas y optan con autonomía y responsabilidad, sopesando su satisfacción, el bienestar de la institución y los intereses de estudiantes o profesores. Entienden las consecuencias de las decisiones en esos casos, no obstante, actúan armónicamente.

- Se identifican con la modalidad virtual. Saben que se configura con redes tecnológicas y grupos humanos y que las situaciones problemáticas pueden alterar la integridad y la continuidad en uno u otro sentido.

\section{Autodeterminación de los directivos}

- Reconocen que el profesor es un elemento esencial en la modalidad virtual. Por eso toman decisiones pensando en su bienestar. Saben que las determinaciones sobre los profesores inciden en los estudiantes.

- Responsablemente, entienden que el trabajo del profesor en el ámbito virtual demanda atención personalizada a los estudiantes, planeación de las aulas virtuales, evaluación formativa, exploración de mediaciones pedagógicas y que su tiempo y capacidad son finitos. Con esto en mente, ejecutan racionalmente las demandas de contratación y la asignación de responsabilidades.

- Asumen con responsabilidad la formación de los estudiantes. Saben que el conocimiento es el propósito central de la institución $y$, en consecuencia, asumen con criterio y determinación los compromisos sobre pedagogía virtual, mediaciones pedagógicas, estructuras de comunicación, procesos de investigación y docencia.

- Comprenden que el dilema entre masificación de la oferta académica, aprovechando a internet y la calidad educativa, debe tomarse responsablemente, balanceando los intereses de uno y otrolado y evaluando realmente los efectos de las determinaciones para los estudiantes y los profesores. 
- Comprenden que la educación virtual implica tecnología, currículo y pedagogías disruptivas y aceptan su responsabilidad en tal sentido. Además, son conscientes de las consecuencias que traen las decisiones sobre estos aspectos, para los propósitos formativos.

- Saben sopesar intereses financieros y de mercadeo, con la responsabilidad institucional de educación con calidad. Entienden que la virtualidad es una opción educativa incluyente para personas que encontraron ahí posibilidades para su futuro. Saben que nada es óbice para el compromiso con la calidad.

- Interpretan la calidad como el aseguramiento en la consecución y sostenimiento de profesores, tecnología, pedagogía, contenidos y sistemas de comunicación, para la formación de los estudiantes, y deciden pensando en tal sentido.

\section{Metodología}

¿Cómo desarrollar la iniciativa de un código de ética para la educación virtual?

Lo trascendental es considerar el código de ética no como un documento o un reglamento, sino como un concepto cuyo afinamiento requiere de la formalización de determinados procesos institucionales.

Aunque todas las instituciones de educación virtual son diferentes, con sus propias declaraciones filosóficas y direccionamientos estratégicos, tienen homogeneidades por las formas que adquieren sus procesos formativos. Los elementos afines que las identifican son: ausencia de encuentros presenciales, ambientes virtuales en plataformas LMS, existencia de profesores remotos que gestionan aprendizajes y comunicaciones, existencia de estudiantes remotos que aprenden y se comunican, currículos de educación técnica, tecnológica, profesional o de posgrado, estudiantes con libertad de decisión y existencia de una estructura organizacional para los procesos administrativos y académicos virtuales. Desde este ángulo, es viable el trazado de una ruta dentro, sin conspirar contra las diferencias institucionales, tal como se muestra en la figura 6 . 
Figura 6. Ruta metodológica para el código de ética

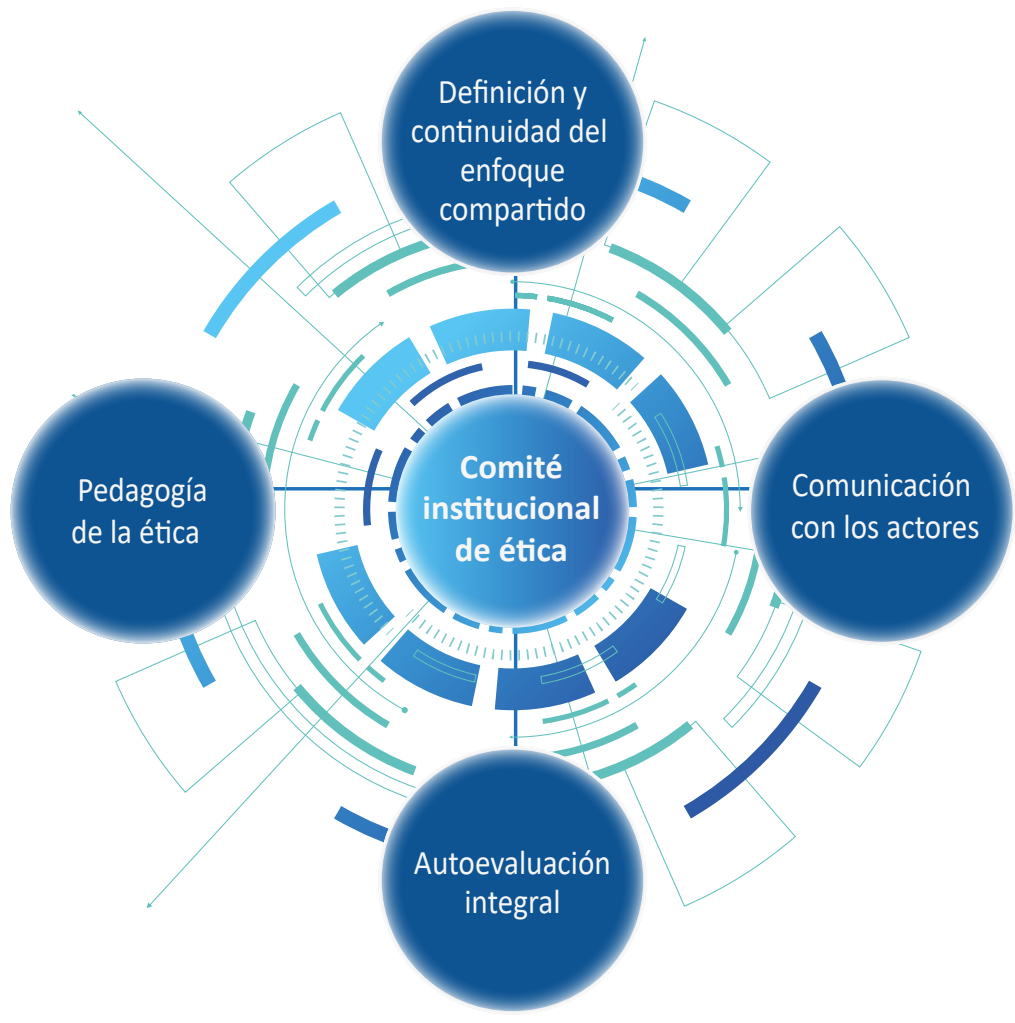

\section{Comité institucional de ética}

Este comité debe tener representantes de distintos grupos de interesados en la autenticidad, validación y verificación de los procesos institucionales, que de alguna manera inciden en los procesos formativos de los estudiantes. Sus integrantes internos y externos deben participar en la cocreación de programas, proyectos y actividades para fortalecer el marco conceptual que es fundamento para las actuaciones y decisiones de estudiantes, profesores, empleados y directivos. La agenda debe orientarse para dar curso a desarrollos en las siguientes direcciones:

1). Definición y continuidad del enfoque compartido

El propósito, los principios, las perspectivas éticas y las líneas de autodeterminación de estudiantes, profesores, empleados y directivos 
deben ser compartidos. Esto es, deben estar dentro del corazón y las prácticas de los integrantes, deben hacer parte de su convicción y reconocerse como un marco conceptual común. Todos deben convencerse de su parte en el contrato integral para la formación de los estudiantes. Este es el fin último y como tal el que concentra las responsabilidades y los esfuerzos. La autodeterminación de todos constituye el enfoque compartido y este necesariamente debe tener continuidad en todos los periodos académicos y en la vida institucional. Es un desafío para el comité de ética, lograr el compartimiento y continuidad del marco conceptual para la toma de decisiones y comportamientos en el ambiente de educación virtual.

\section{2). Comunicación con los actores}

El comité debe establecer vínculos como los consejos directivos y académicos, los comités y grupos investigaciones, mercadeo, planeación, proyección social e incluso, con las agremiaciones de estudiantes, egresados y profesores. Es decir, debe tener puesto en las reuniones cuyas temáticas en relación con la formación y atención de los estudiantes. Asimismo, debe crear canales para hacer llegar su voz a todos los actores y para escucharlos. El reto consiste en lograr credibilidad y reconocimiento en todos los órganos institucionales, de manera diáfana, transparente, objetiva, sin asumir posiciones de fiscalización o auditoria.

\section{3). Autoevaluación integral}

Periódicamente el comité de ética debe planear, desarrollar y sistematizar procesos de autoevaluación integral que comprendan lecciones aprendidas y compromisos reales con las líneas de autodeterminación de directivos, empleados, profesores y estudiantes. Al iniciar cada ciclo, en el intermedio y al finalizar, deben establecerse procesos e instrumentos para autoevaluación de las actividades incluidas en la agenda del comité y en forma concienzuda debe evaluarse cuál es el nivel e intensidad de los distintos grupos de interés internos y externos, en la dinámica del comité.

Aparte de lo anterior, objetivamente la autoevaluación debe estudiar cuál ha sido la incidencia del marco conceptual para los comportamientos éticos, en la calidad institucional y cuál ha sido la corresponsabilidad con la formación de los estudiantes. Igualmente, debe analizarse cómo el marco del código de ética ha permeado el currículo, entendido como los procesos y el ambiente institucional que son incidentes en los resultados de los aprendizajes. 
4). Pedagogía de la ética

El comité debe programar actividades formativas para que profesores, estudiantes, directivos y empleados, nuevos y antiguos, comprendan y se apropien de la necesidad institucional de autenticación, validación y verificación en las actuaciones y toma de decisiones. Se debe motivar el código de ética no como un documento más o como un reglamento, sino como el marco conceptual acordado para las actuaciones y toma de decisiones con cuidado de sí mismo, del otro y de la institución. Es función de comité abrir espacios formativos para la ética en investigación, proyección social, mercadeo, planeación y en todos los procesos académicos y administrativos que estén relacionados con la formación de los estudiantes. Aparte de esto, deben abrirse foros para que todos reflexionen sobre la enseñanza con el ejemplo personal, el compromiso ético con la alteridad, la conducta humana como esencia en los actos educativos y en temas que, como estos, constituyen la formación con orientación humana en la virtualidad.

Un asunto de fondo, y que es un desafío para el comité, es el de la ética digital. Ni internet, ni la tecnología en general tienen inclinaciones. Las decisiones sobre su aplicación dependen de la ética y moralidad de los usuarios. Siendo así, el comité de ética tiene el desafío de cultivar en los estudiantes y profesores el uso constructivo de la tecnología evitando transgredir la integridad del otro, actuando con respecto por el establecimiento sociocultural. 


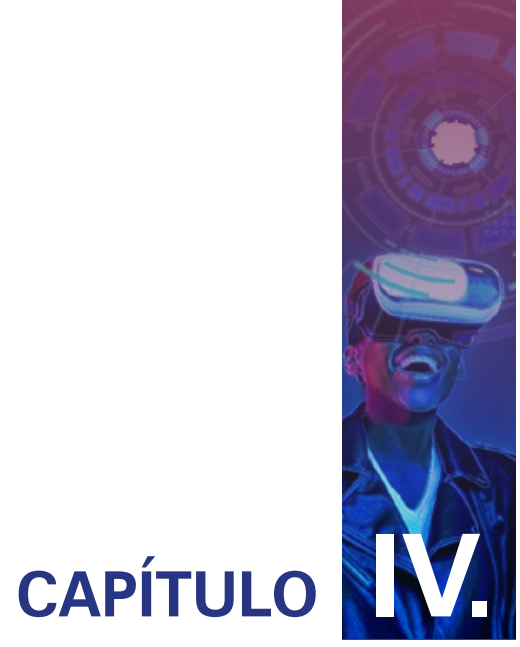

\section{EDUCACIÓN VIRTUAL EN LA CRISIS DE LA COVID-19}

La educación virtual, desde que surgió en Colombia en la última década del siglo XX, se ha considerado como una opción atractiva, con propósitos como ampliación de cobertura o una solución a la crisis al interior de los centros educativos. Sustentados en que se requieren mínima infraestructura física para su implementación, los imaginarios apuntan a su viabilidad como proyecto. Las iniciativas son aún más optimistas cuando se piensa que los esfuerzos de mayor dimensión son la conectividad y la plataforma tecnológica. No obstante el desarrollo mismo va dejando lecciones aprendidas entendiéndose que la organización de los ambientes virtuales es compleja, pues además de infraestructura de redes, dispositivos, sistemas e internet, se requieren, entre otros asuntos, definiciones en materia de contenidos, interacciones, comunicaciones, diseño instruccional, pedagogía de la virtualidad y modelos tecnopedagógicos para enfocar las mediaciones de aprendizaje.

A veces la educación virtual se instala por alguna coyuntura, pero esto no puede ser óbice para no enfocar su complejidad con asuntos como los relacionados en el párrafo anterior. Es el caso de la imposición en Colombia de esa modalidad de estudio, debido a la pandemia de la COVID-19. Para ubicar el análisis y las reflexiones en torno a las condiciones de equidad, ética y calidad de esa educación virtual obligada, merece plantearse el marco conceptual que se expone en la tabla 15. 
Tabla 15. Referentes teóricos sobre educación virtual

El énfasis de esta definición

"Educación virtual significa que se genere un proceso educativo, una acción comunicativa con intenciones de formación, en un lugar distinto al salón de clases; en una temporalidad que puede ser sincrónica o asincrónica y sin la necesidad de que los cuerpos de maestros y alumnos estén presentes" (Unigarro, 2004, p. 46). está puesto en la comunicación intensa de los participantes como condición para los aprendizajes. Deja entrever que no interesa la naturaleza de los medios sino la interactividad entre estudiantes y profesor.

"La formación virtual es un escenario alternativo de educación que utiliza las TIC como canales efectivos y asertivos para el propósito de llevar aprendizajes significativos, pese a la distancia y al tiempo de los discentes. En esta modalidad convergen disciplinas como la tecnología, la pedagogía, la comunicación, el diseño gráfico, entre otras. La educación virtual precisa un cambio de paradigma en el rol del docente; ya no se trata de enseñar dentro de las paredes de un aula, sino de facilitar aprendizajes a discentes que se encuentran a kilómetros de distancia" (Roldan, 2005, p. 92).

"En un estudio de IESALC se encontró que uno de los principales problemas de los estudiantes de América Latina es su incapacidad para autorregular su aprendizaje, en cuanto a horarios, por ejemplo. En cambio en Europa y Asia el estudiante a través del sistema escolar ha aprendido a aprender, ha aprendido a regular sus aprendizajes. En cambio en América Latina los sistemas escolares han creado un perfil de estudiante que es muy dependiente de lo que sucede en el aula. Se necesita que las instituciones vayan más allá" (Pedró, 2020).

El punto esencial en el ámbito educativo virtual es la actitud del estudiante para autogestionar sus aprendizajes. Naturalmente, el estudiante en ambientes virtuales tiene iniciativas propias para emprender rutas de aprendizaje y de búsqueda de información.

Se da importancia a la tecnología como mediadora, se exhorta hacia los logros de aprendizaje significativo. El docente asume funciones de facilitador de aprendizaje, no es la persona que enseña.

\section{Marco situacional}

Entre finales de 2019 e inicios de 2020 la pandemia del a COVID-19 sorprendió al mundo y ocurrió lo inimaginable: grandes ciudades cerradas, miles de muertos diarios, ciencia médica impotente, industria farmacéutica sin respuestas, la economía amenazada y en general, una crisis mundial sin precedentes, comparable con la desventura del mundo en la Segunda Guerra Mundial. El pánico y cierta desolación se fueron incrementando en las ciudades, encontrándose en pocas semanas que países, como Colombia, estaban frente a una problemática compleja, 
entretejida por dilemas, paradojas, visiones encontradas sobre lo fundamental del mundo. Más aún: el transcurrir normal se estremeció poniendo de manifiesto cambios acelerados en las agendas de medios de comunicación, alto Gobierno nacional, gobiernos locales, bancos y líderes de los sectores económicos. Con este panorama emergieron situaciones como las siguientes:

1). Dificultades en los sistemas de salud debido a la rápida propagación y contagio del virus, y porque no existían medicamentos ni vacunas para contrarrestarlo. Por eso las cifras exponencialmente mostraban incrementos de contagiados, muertos y riesgos por incapacidad e insuficiencia de los sistemas de salud.

2). Crisis económica y desempleo originado por el cierre masivo de empresas. Al inicio de la cuarentena periodistas, políticos, dirigentes y sociedad en general admitieron el cierre de los mercados y las empresas, pero al paso de las semanas vieron encima el derrumbe de la economía. Los pronósticos expertos señalaban que serían inevitables fenómenos de recesión y depresión económica. En Colombia se multiplicaron los casos de personas desempleadas y de empresas colapsándose, acrecentándose así los temores porque el virus devastador no solo estaba poniendo en aprietos la salud pública, sino que además estaba incrementando la pobreza. Según la cifra oficial, el desempleo en este país llego al $20 \%$ y 5,4 millones de personas perdieron el empleo en solo dos meses (un año atrás el desempleo estaba en el 10,3 \%) ("Dramático aumento del desempleo en Colombia", 2020).

3). Restricción de libertades y pérdida de derechos como la movilidad y la libre elección. De un momento a otro la sociedad se vio impedida para el desplazamiento libre, debido al rigor de gobiernos autoritarios de orden local y nacional. La gente quedó maniatada por los gobiernos que asumieron posiciones totalitarias que franquearon las libertades constitucionales. En Colombia fue visible la carrera entre presidente, ministros, gobernadores y alcaldes por imponer la prohibición más efectiva. En pocos días, la sociedad perdió sus libertades y el acceso a sus satisfactores cotidianos quedó prohibido. Se pasó de unas escenas de neoliberalismo, entendido como la ideología que promueve preceptos sociales con base en mercados libres y libertad individual (Zamora, 2019), a una sociedad controlada, sin libertad de ir y venir y con mercados a merced de las órdenes de 
los gobernantes. Ocurrió lo que era imposible para la ortodoxa económica e inclusive, lo inaudito para la vida social y la cultura de las comunidades, cuando por ejemplo, se cerraron masivamente centros comerciales, construcciones de infraestructura, sitios de diversión y en entretenimiento, transporte público. Llanamente se le prohibió a la gente la libre movilidad.

4). Desenfoques en la ayuda humanitaria y el asistencialismo social. Desde la misma semana del inicio de la cuarentena, en las ciudades colombianas proliferaron las ayudas alimenticias para la comunidad. El presidente inició una cascada de ayudas humanitarias para los pobres, en las ciudades la gente se desenfrenó en busca de alimentos gratis, en los barrios se abrió un abanico de expectativas por la llegada de los auxilios. Aunque, obviamente, el clamor por la gente por no padecer hambre en la pandemia tenía la aprobación social, paralelamente se extendió un ambiente trágico que influyó en la psicología de las personas. Sí, el ambiente se enrareció, pues en medio de las colectas de alimentos y las filas de la comunidad por las dadivas, la población oscilaba entre el temor, la pesadumbre y la tristeza. Pero lo singular es que decretada la pandemia de inmediato brotó el manantial de ayudas alimenticias, como si la crisis viniera desde meses atrás. Tal vez hubo apresamiento del Gobierno o, a lo mejor, se aprovechó la situación con propósitos políticos o quizá esa cascada de decretos humanitarios y de iniciativas sociales era la mejor opción.

5). Corrupción de los líderes y gobernantes. La cuarentena puso de manifiesto la enfermedad colombiana de la corrupción de la dirigencia pública. La Procuraduría, la Fiscalía y la Contraloría encontraron casos en grandes ciudades y pequeños municipios, sobre extralimitación en las contrataciones y demostraron que los gobernantes aprovecharon la tragedia de la pandemia para satisfacer intereses particulares. Es decir, se demostró que no hay escrúpulos cuando el objetivo es lucrarse de los recursos públicos, aunque sea de manera dolosa. Los siguientes testimonios documentales son reveladores por sí mismos.

Las contundentes cifras indignan. En los últimos dos meses ya van más de 500 procesos disciplinarios que comprometen a 26 gobernadores y 272 alcaldes del país por temas relacionados con actos de corrupción con las ayudas destinadas a atender a la población afectada por cuenta la pandemia. A diez alcaldes la Fiscalía les dictó medida de aseguramiento por estos hechos y la Contraloría 
inició procesos de responsabilidad fiscal por sobrecostos y abusos en la contratación por la emergencia, que rondan el medio billón de pesos. ("La pandemia disparó el virus de la corrupción", 2020).

Cuanto más alarguen el confinamiento social, más se frotan las manos los corruptos que nos dirigen en varios lugares, casi todos, del territorio colombiano, puesto que sobrevaloran costos en los contratos con la excusa de que todo se encareció por las circunstancias, excusa no válida pues el presidente solicitó por cadena nacional denunciar a los especuladores que aumenten los precios de los productos. Hasta el momento no hay una sola denuncia contra los proveedores que aumentaron costos. Haciendo el ejercicio de recuperar los dineros extraviados por contratos mal habidos desde iniciada la pandemia, tengan la seguridad de que el valor final alcanzaría para comprar pruebas de detección del COVID-19 para cada uno de los colombianos, dotación hospitalaria y mecanismos de protección para los héroes del sector médico y policial, que ofrendan sus vidas en aras del bienestar de sus connacionales. (Velandia, 2020).

Un oscuro diagnóstico sobre la corrupción en tiempos de pandemia hicieron esta noche en la Plenaria del Senado, la Fiscalía, la Contraloría y la Procuraduría. Pocos departamentos se salvan de investigaciones penales, fiscales o disciplinarias. Lo revelado por los tres entes de control debería producir escalofrío, sin embargo, la corrupción es pan de cada en Colombia, incluida esta etapa de emergencia social y económica que tiene aguantando hambre a millares de personas. Los corruptos no dan tregua. El fiscal reveló que su entidad tiene 125 líneas investigativas, dentro de las cuales hay 14 procesos que adelanta la delegada ante Corte Suprema de Justicia, que incluyen a un ministro y a 11 gobernadores. (Aristizábal, 2020).

6). Estado controlador y asistencialista. Con la justificación de evitar el hambre en el encierro, en cuestión de horas después de decretada la cuarentena, brotaron desde los gobiernos central y locales, decisiones y presupuestos para los más necesitados. Se notó cierta transformación del Estado Colombiano sobre los criterios para la inversión social, pues se rompió la ortodoxia económica para poder sacar recursos de fondos reservados y afanosamente se olvidó que el desarrollo duradero contra la pobreza se enfoca en la promoción de la persona humana, evitando la dependencia 
del asistencialismo gubernamental. Con el inicio del aislamiento social surgieron las escenas del Estado auxiliador, en contravía de conceptos como los de Gómez et al. (2017), quienes afirman que conceder recursos sin acompañamiento determina fracasos y detrimentos en las familias y comunidades receptoras. El Estado tradicionalmente escéptico con la inversión social y sobre todo, con la tendencia a la privatización de servicios básicos y reducción del gasto público, cambió su política económica y el país vio un Gobierno benefactor. Indudablemente, no fue una transformación del pensamiento del Estado y de su política económica, sino una salida a la coyuntura ocasionada por la COVID-19. No obstante, lo ocurrido, aunque muy fugazmente, demostró que es posible dentro de la economía de mercado y capitalista y dentro de las estrategias para la viabilidad económica del país, incrementar sostenidamente la inversión social para el bienestar de las comunidades pobres.

7). Crisis educativa. En Colombia, sin ninguna planeación, la educación en todos los niveles se convirtió a modalidad virtual. El 25 de marzo de 2020 inició la cuarentena obligatoria (Decreto 457), pero desde el 21 de dicho mes había encierro general, por disposición de alcaldías y gobiernos locales. Antes, el 13 de marzo, el presidente había ordenado la suspensión de clases presenciales en todos los niveles de la educación y, posteriormente, el Ministerio de Educación Nacional ordenó que todas las instituciones de educación en Colombia tendría que desarrollar sus actividades académicas en forma virtual. Una Directiva del Ministerio de Educación Nacional ( $N^{\circ} .04$ de 2020) autorizó a los programas académicos de educación superior con registro calificado en modalidad presencial, a desarrollar sus actividades académicas en modalidad virtual. Luego, en mayo se determinó que la educación en Colombia sería virtual hasta agosto de ese año.

8). Auge del teletrabajo. Aunque ya en Colombia había empresas que tenían organizado el teletrabajo, a raíz de la cuarentena esta práctica se volvió cotidiana. Muchas empresas, en el afán y sin planear, mandaron a sus empleados a trabajar desde sus casas. En el país, al inicio de la pandemia el 11,2 \% de las empresas venían desarrollando teletrabajo antes de la pandemia, esta cifra pasó al $98 \%$, y el 76,2 \% afirma que seguirá incorporándolo después de que pase la crisis, según un estudio divulgado por la revista Dinero ("El 50\% de empresas del país no estaba preparado", 2020). 
Como puede verse, en un episodio muy breve se vivieron unas escenas inverosímiles. Por sí misma, la COVID-19 era una novedad, pero inimaginablemente los ciudadanos sintieron un Estado lanzado por la asistencia social, la libertad impedida, las iglesias cerradas, la gente acorralada y muchos derechos humanos violados. Pasado un mes desde el encierro y luego de la euforia por las donaciones masivas, se fue erigiendo un dilema: la vida o la economía. En el centro de críticas, reflexiones y decisiones, había una disputa por la atención prioritaria entre la salud de la gente y el desplome de la economía. La desbandada de empleos perdidos y empresas quebradas fue demostrando que inclinar la balanza en favor de lo primero (la vida) no era tan absolutamente razonable, pues implicaba, debido a la prolongación del aislamiento social, la explosión de la pobreza (la vida indigna) causada por la parálisis empresarial. Por tanto, la sociedad fue advirtiendo que el desastre ocasionado por el virus tenía unas dimensiones mayúsculas. Además, la incertidumbre fue creciendo porque desde distintos ámbitos fue haciéndose penetrante cierta sentencia apocalíptica, que advirtió que la pandemia sería un hito histórico que cambiaría el mundo:

- "Economía global no volverá a ser la misma de antes" (López, 2020).

- "Parece que después de la pandemia nada será como antes" (Salazar, 2020).

- 'Después de la cuarentena llega la 'nueva normalidad': ya nada será como antes" (Lagos, 2020).

- "La vida después del COVID-19" (Arauz, 2020).

Solo la historia - muy prontamente- dirá hasta dónde el mundo cambiará por causa de la pandemia, tal como lo han afirmado expertos en distintas áreas. Al respecto cabe preguntarse: ¿después de superada la crisis, el Estado colombiano tendrá en su agenda la apuesta por el desarrollo social como prioridad real? ¿Los gobiernos venideros acelerarán políticas, recursos, normativas, para que los sistemas de salud sean equitativos para toda la población? ¿La vida social y la recreación serán protocolizadas indistintamente sin preconceptos culturales? ¿La educación de la gente y su cultura serán impedimentos para que los virus no se propaguen? ¿Los poderosos entenderán que, aunque las tragedias no distinguen posiciones socioeconómicas, son más letales con los más desvalidos? 


\section{La educación virtual obligada}

Estupefactos, los expertos en educación y pedagogos vieron cómo debido a la pandemia, sin planeación alguna, la educación pasó a ser virtual. En los medios de comunicación aparecieron imágenes y noticias sobre niños en los árboles conquistando la señal de internet -así se vio en la televisión colombiana-, padres de familia denunciando falta de conectividad, profesores preocupados porque no todos sus estudiantes contaban con computador y paradójicamente, los ministros de las TIC y de educación anunciando soluciones rápidas como radio educativa y entrega física de contenidos en cartillas. Además, se prometieron soluciones exprés para que más de diez millones de estudiantes y profesores no tuvieran dificultades en los procesos formativos (Pérez, 2020).

Obviamente, en medio de las crisis los gobiernos deben dar mensajes esperanzadores $y$, sobre todo, con soluciones precisas para que en la sociedad quedara la imagen sobre su capacidad y suficiencia. No obstante, surgieron las siguientes inquietudes: ¿en intervalo de días es probable llevar conectividad a un territorio de 1.142 kilómetros cuadrados y 1.096 municipios? ¿En contadas semanas es posible diseñar y desarrollar programas educativos utilizando la radiodifusora nacional o emisoras locales? ¿En días se puede dotar de recursos, contenidos, pedagogía para el desarrollo de cartillas didácticas? ¿Existen metodologías para la implementación instantánea de ambientes pedagógicos virtuales?

Lo cierto es que sorpresivamente el problema de salubridad desocupó las instituciones educativas, desde el nivel de preescolar hasta los posgrados. Varias realidades como las siguientes se evidenciaron con esta transformación no planificada ni diseñada, o dicho de otra forma, fueron revelaciones puestas al descubierto por la cuarentena.

\section{Las brechas entre niveles educativos}

Lasinstitucionesdeeducaciónsuperiorseacomodaronmáscoherentemente a la educación virtual que los otros niveles de educación, porque atributos como inteligencia organizacional, capital humano, capacidades tecnológicas y organización curricular constituyen ambientes favorables para cambios de tal trascendencia. En la educación básica y media, en cambio, la situación fue más compleja, pues el sistema escolar depende fundamentalmente de la vida social en la planta física y los propósitos pedagógicos se realizan en el aula de clase, aparte de ser organizaciones con arraigo en modelos tradicionales y con menor potencial de recursos humanos y tecnológicos. 
En tanto que las instituciones de educación superior tienen unas estructuras más dinámicas y flexibles, mayor diversidad constitutiva, orientaciones más abiertas y sistémicas y, por su naturaleza, asumen funciones de proyección social como un factor de su calidad. Pero ante la sorpresa y arremetida de la pandemia, ni en unos ni otros niveles educativos había planes trazados para responder a la educación virtual. No obstante, la contingencia fue menos drástica con la educación superior y rápidamente allí los profesores esgrimieron iniciativas para atender a sus estudiantes. En cambio, en los niveles de educación preescolar, primaria, secundaria y medía, profesores y estudiantes quedaron atrapados en la incertidumbre del "sálvese quien pueda".

Pero aún más: en las instituciones públicas que imparten esos cuatro niveles de educación, debido factores como su masificación interna, carencias de recursos, menor autonomía y condiciones socioeconómicas de los estudiantes, se sintió en mayor dimensión la crisis, que en las instituciones privadas. Pues en estas se advierten fortalezas organizacionales y mayores recursos para instalar con prontitud y eficiencia los medios requeridos para el sostenimiento de los procesos curriculares. Agréguese que en la educación privada los estudiantes cuentan con mejores facilidades para el estudio en casa, pueden acceder más fácilmente a recursos tecnológicos y en general, las condiciones ergonómicas y logísticas son superiores a las posibilidades de los estudiantes de la educación pública. Y a su vez, las condiciones para los estudiantes de las instituciones públicas rurales son todavía más desfavorables, pues están al margen de las infraestructuras tecnológicas y físicas de las ciudades.

La urgencia ocasionada por la pandemia demostró la profundidad de las brechas entre los niveles del sistema educativo colombiano, conformado por educación inicial, preescolar, básica primaria, básica secundaria, media y superior, en cuanto a la capacidad y organización para adaptarse a cambios del entorno. No en todos los niveles hay la idoneidad ni la filosofía institucional para comprender las implicaciones de la educación virtual como opción formativa y no en todas es posible implementar esa metodología.

En las instituciones de educación superior hay mayores posibilidades, ya que sus recursos, perfil de profesores, estructura organizacional y compaginación con las tendencias del mundo generan visiones para la innovación educativa, en menor o mayor grado. En la educación preescolar los objetivos educativos se enfocan en la socialización de los niños para 
reconocer el mundo, interactuar con los otros, aprender de entornos diferentes a los de su hogar, desarrollar su inteligencia con los juegos de roles. El interés en este nivel por los contenidos puntuales es inapreciable y por eso es inaudito pretender reemplazar esas condiciones por un ambiente virtual. En el nivel de básica primaria, aunque los contenidos adquieren importancia, el centro de la formación lo constituyen las relaciones socioafectivas y por eso para los objetivos formativos los ambientes virtuales aportan en una proporción baja. En la educación básica y media, de manera progresiva, se va haciendo preponderante el aprendizaje de temáticas y la promoción competencias específicas, sin que pierdan vigencia las necesidades de la socialización y la convivencia como dimensiones formativas trascendentales. En estos dos niveles la educación virtual, sin que pueda llenar esas necesidades, tiene unas condiciones más favorables para su realización.

La organización virtual requiere de capacidades de conectividad, software educativo, plataformas tecnológicas, sistemas de videoconferencia, mediaciones pedagógicas, contenidos digitales, diseño instruccional, pedagogía de la virtualidad y docentes competentes para la enseñanza virtual. Estos elementos son asequibles con mayor probabilidad para las instituciones privadas por su autonomía y músculo financiero, pero difícilmente alcanzables por las instituciones públicas que dependen de las políticas y presupuestos del Estado. Además, sin que esto se interprete como estigmatización, sus estudiantes tienen condiciones socioeconómicas, familiares y logísticas que aventajan a quienes viven en barrios pobres de las ciudades, en pueblos humiles o en zonas rurales, que son atendidos por las instituciones del Estado.

Aunque la educación superior tiene ventajas sobre los demás niveles educativos para la implementación de educación virtual, no todas las instituciones tienen la orientación estratégica ni la identidad para transformarse hacia la educación virtual. No todas habían explorado seriamente la posibilidad de impulsar esta modalidad educativa como opción para brindarle a la sociedad. Por eso la decisión del Ministerio de Educación de Colombia de imponer educación virtual, sin excepciones, dejó en la perplejidad a sus estudiantes, y sin un rumbo lógicamente trazado quedaron a merced de sus profesores. Por ejemplo, en un comunicado de una institución del departamento de Antioquia, el rector afirmó que "todo queda en la creatividad de los decanos", y otra afirmó que "profesores y estudiantes deben buscar alternativas con el apoyo institucional". Pero es menester destacar que esa imposición urgente de ambientes virtuales como única opción en la pandemia, demostró el 
potencial y la suficiencia de instituciones como UNIMINUTO, Universidad de los Andes, EAFIT o Uniremington.

Los siguientes son testimonios que evidenciaron inequidad en esa coyuntura de la educación virtual generalizada:

Ocurrió en Piendamó (departamento del Cauca): “Él ha tomado sus clases virtuales con regularidad, pero para poder acceder a estas, tiene que salir de su asentamiento, montarse en una chiva en la que dura alrededor de media hora para llegar al pueblo más cercano y pedirle el favor a la única persona del pueblo que cuenta con computador y servicio de internet que se lo preste para poder tomar la lección de la asignatura" (Martínez Negrete, 2020).

Según un informe publicado por la Unesco, más de la mitad del total de los alumnos (unos 826 millones) que no asiste a clases por la COVID-19 no cuenta con una computadora en el hogar, y el $43 \%$ (706 millones) no tiene internet en sus casas, en un momento crucial en el que se utiliza la educación a distancia por medios digitales para garantizar la continuidad de la enseñanza del 91 \% de alumnos matriculados en 191 países (Otero, 2020). "Un mes después de haber iniciado las clases virtuales, aún hay niños sin computador o internet. El Gobierno ha acudido a emisoras y canales de TV para intentar suplir esta falencia y algunos colegios trabajan para brindarles acceso a equipos" ("Un mes después de haber iniciado las clases virtuales", 2020).

La pandemia motivó soluciones urgentes por parte del Estado. Debido a lo inesperado de la crisis y a la magnitud de sus consecuencias, esas soluciones se improvisaron, en realidad no había planeaciones pensadas para la COVID-19. Con este antecedente el Ministerio de Educación Nacional dispuso la educación virtual en todo el país, con varios intereses concurrentes: defender la sanidad de profesores y estudiantes, demostrar la eficiencia del Gobierno, tomar decisiones equitativas y defender la calidad de la educación. Estos intereses no son mutuamente excluyentes, y, por eso, las decisiones solamente pensadas en la salud de las comunidades educativas y en mostrar un Gobierno eficiente y comprometido, dejando en el limbo la calidad y la equidad, ameritan el enjuiciamiento ético. No entender u olvidarse de las enormes diferencias socioeconómicas de las comunidades escolares o decidir cómo si todo todas las instituciones educativas tuvieran las mismas ventajas, no es ético ni político.

Es inconcebible que la alta dirigencia pública del país desconozca que en la educación hay extremos absolutos: centros educativos en barrios 
pobres y zonas urbanas privadas de recursos y otras, al contrario, con los medios suficientes para garantizar calidad educativa y ventajas patentes como el ámbito social y familiar de los estudiantes. La siguiente cita muestra escuetamente la situación planteada:

Desde que comenzó la cuarentena a raíz de la pandemia por la COVID-19, estos casi dos millones de menores de edad fueron enviados a sus hogares que, en muchos casos, se encuentran ubicados en zonas rurales dispersas, o más lejos de los centros poblados de sus municipios. "Tengo estudiantes que viven al borde del cañón del Chicamocha. Hay lugares en los que no hay luz ni internet", dice Ana Sierra, profesora de una escuela en el municipio de Málaga, Santander. Mientras tanto, en la vereda Mesones del municipio de Ortega, Tolima, Julián Totena cursa el noveno semestre de administración pública territorial en la Escuela Superior de Administración Pública. La finca en la que vive con su familia no tiene computador, sin embargo, cuenta con un smartphone que se convierte en su única posibilidad para acceder a internet: "En la vereda en la que yo vivo hay una zona wifi abierta, pero realmente esa zona no presta un buen servicio porque la señal es muy mala", dice (Duque, 2020).

\section{Los profesores fueron los héroes}

En la cuarentena las profesoras de educación preescolar reinventaron los espacios formativos con sus niños. Intentaron llevar a los hogares por intermedio de internet la socialización y el esparcimiento que se vive en las instituciones educativas. Es decir, afanosamente tuvieron que imaginarse escenarios educativos para cumplir con los siguientes objetivos específicos:

a) El conocimiento del propio cuerpo y de sus posibilidades de acción, así como la adquisición de su identidad y autonomía; b) El crecimiento armónico y equilibrado del niño, de tal manera que facilite la motricidad, el aprestamiento y la motivación para la lectoescritura y para las soluciones de problemas que impliquen relaciones y operaciones matemáticas; c) El desarrollo de la creatividad, las habilidades y destrezas propias de la edad, como también de su capacidad de aprendizaje; d) La ubicación espacio-temporal y el ejercicio de la memoria; e) El desarrollo de la capacidad para adquirir formas de expresión, relación y comunicación y para establecer relaciones de reciprocidad y participación, de acuerdo con normas de respeto, solidaridad y convivencia; f) La participación en actividades lúdicas con otros niños y adultos; g) El estímulo a la curiosidad 
para observar y explorar el medio natural, familiar y social; h) El reconocimiento de su dimensión espiritual para fundamentar criterios de comportamiento; i) La vinculación de la familia y la comunidad al proceso educativo para mejorar la calidad de vida de los niños en su medio, y j) La formación de hábitos de alimentación, higiene personal, aseo y orden que generen conciencia sobre el valor y la necesidad de la salud. (Artículo 16, Ley 115 de 1994).

Obviamente, estos objetivos son un desafío demasiado grande para la creatividad de las profesoras en la virtualidad. Ciertamente, ellas hacen parte de un centro educativo y la responsabilidad tendría que recaer sobre este, pero esas organizaciones escolares no están pensadas para la educación virtual y, por eso, el reto era para el cuerpo docente, pues son los interlocutores directos con los padres de familia. Es probable que con la participación directa de los padres de familia y con adaptaciones especiales en los hogares se puedan lograr algunos de esos objetivos, pero empíricamente puede concluirse que el ambiente preescolar tiene unas dimensiones socioafectivas, psicológicas y cognitivas para los niños, que no encajan dentro de la teorización de los ambientes virtuales. Aunque no se disponga de evaluacionesestrictas acerca de losresultados de los intentos de virtualidad con niños del nivel preescolar, es indudable la incompatibilidad entre el ambiente virtual y el que se naturaliza en los espacios lúdicos, aulas multicolor o miniparques de los centros físicos para infantes.

No obstante, a pesar de las inconveniencias, las profesoras se merecen todo el honor, pues tuvieron que asumir la tarea de mantener activamente la motivación de las familias y los niños. Pero esto no es óbice para interrogantes como los siguientes: ¿si las profesoras saben, desde la teoría y sus vivencias, que hay incompatibilidades para hacer virtual la educación preescolar, porque incursionan en esa aventura que además compromete a los padres de familia? ¿Las instituciones y las profesoras, al ser artífices de la transformación hacia lo virtual, comprenden el sentido de la calidad educativa? ¿Las instituciones y las profesoras están asumiendo sus funciones con criterios éticos y con responsabilidad educativa? ¿Los padres de familia conocen los alcances, filosofía, objetivos de la educación preescolar?, y, si así es, ¿por qué permiten esa propuesta de virtualidad?

Con respecto a la educación básica primaria, se observó cierta resaca en los niños y padres de familia. Fenomenológicamente, desde el discurso de la gente se percibe la imposibilidad del ambiente virtual para las necesidades de socialización y recreación de los niños. En este nivel también los profesores fueron héroes, ya que tuvieron que inventarse 
estrategias para las clases, cuando entre otros factores, sus instituciones no tenían concebida la virtualidad, la vida de los niños en gran parte está en función de escuela, la recreación virtual es aburrida finalmente, y el aprender haciendo con cosas tangibles es distante del aprender con software para simulación en la virtualidad.

El desafío para la educación virtual en el nivel de básica primaria fue la creación de ambientes para lograr objetivos como los siguientes:

a) El desarrollo de las habilidades comunicativas básicas para leer, comprender, escribir, escuchar, hablar y expresarse correctamente en lengua castellana y también en la lengua materna, en el caso de los grupos étnicos con tradición lingüística propia, así como el fomento de la afición por la lectura; b) El desarrollo de los conocimientos matemáticos necesarios para manejar y utilizar operaciones simples de cálculo y procedimientos lógicos elementales en diferentes situaciones, así como la capacidad para solucionar problemas que impliquen estos conocimientos. (Ley 115 de 1994, artículo 21).

Sin embargo, la práctica educativa demuestra que los siguientes objetivos son posibles verdaderamente en escenarios físicos para experiencia social:

a) La formación de los valores fundamentales para la convivencia en una sociedad democrática, participativa y pluralista; b) La formación para la participación y organización infantil y la utilización adecuada del tiempo libre; c) La adquisición de habilidades para desempeñarse con autonomía en la sociedad. (Ley 115 de 1994, artículo 21).

Como puede deducirse, sin planeaciones ni diseños de ambientes virtuales, corresponder con estos objetivos era un compromiso exigente para los profesores, pues ellos venían desarrollando su docencia en los ambientes físicos de las instituciones.

En la educación básica secundaria y media se observaron asuntos críticos como los siguientes: hay profesores que por el tipo de asignatura y para cumplir con la asignación académica reglamentada, tienen a su cargo clases hasta en diez u once grupos de 45 estudiantes (caso de los profesores de inglés, cuando la intensidad es de dos horas semanales). Esto quiere decir que en la plataforma virtual tienen que atender una cifra probable entre 400 y 500 estudiantes. Quedan las siguientes dudas: ¿el cansancio físico y mental, la finitud del tiempo, la logística del profesor en su casa son convenientes para que haya calidad en la atención a sus estudiantes? 
¿Hasta dónde las actuaciones de rectores y coordinadores son éticas, cuando no relacionan la capacidad real de los profesores con sus funciones pedagógicas? ¿Hasta dónde los profesores son éticos al improvisar ambientes de aprendizaje virtuales, a pesar de que conocen las teorías pedagógicas y que su vida profesional en la experiencia educativa le dicen que hay imposibilidades objetivas para procesos formativos con calidad? ¿Será que profesores, padres de familia e instituciones no comprenden las dimensiones de la educación formal y no relacionan los efectos de procesos educativos fallidos en la vida futura de los estudiantes?

Otro asunto que también cabe dentro de varias de los interrogantes anteriores está relacionado con los recursos pedagógicos. Como es lógico, las instituciones de educación secundaria y media no tenían enfocadas las mediaciones pedagógicas, los medios de comunicación y los contenidos para la educación virtual. Se observó que los profesores urgentemente implementaron canales libres de videoconferencia como Meet de Google, o Zoom (con restricciones), utilizaron portales gratuitos como Khan Academy o acudieron a plataformas públicas como Colombia Aprende. Se conocieron casos de profesores que llevaron recursos a hogares de sus estudiantes, otros que utilizaron sus correos electrónicos y sus dispositivos móviles y otros más que gestionaron computadores y conectividad para evitar la exclusión de hogares pobres.

Para ilustrar el desafío que tuvieron que enfrentar los profesores, se expone lo siguiente:

Se debe reconocer, con el personal sanitario en el COVID-19, la enorme heroicidad que están demostrando los profesores de educación superior y educación básica. Sin tiempo de preparación han sabido estar a la altura de las circunstancias, nadie habla de ellos, nadie reconoce que eso es heroico, ese enorme compromiso, esa enorme resiliencia y en el fondo esto es un capital de nuestros sistemas de educación. (Pedró, 2020).

Recientemente se dio a conocer que una maestra de primaria decidió imprimir el material educativo de sus alumnos con sus propios recursos. Esto lo hizo porque sabía que no todos ellos tenían acceso a las clases virtuales que difundió la Secretaría de Educación Pública (SEP) durante la Jornada Nacional de Sana Distancia (2020). Según esa información, la maestra por su propia iniciativa asumió el compromiso de imprimir el material de las clases virtuales y lo llevo a los hogares de los niños con carencias de internet. 
Profesores en cuarentena: no salen de casa, no usan mascarillas, no tienen especial contacto con el virus y no se les aplaude por las tardes, pero son también parte de la primera línea de batalla en esta guerra que estamos librando entre todos. (Núñez, 2020).

\section{Dudas sobre ética y calidad de la educación virtual}

Las noticias en la televisión colombiana y los anuncios del Ministerio de Comunicaciones y el Ministerio de Tecnologías de la Información y Comunicaciones dejaron en evidencia el desconocimiento de los funcionarios sobre la educación virtual. Es probable que sus discursos tuvieran más una intencionalidad política que educativa, lo que es normal, pues hacían parte de un equipo de Gobierno obligado a soluciones para la sociedad en épocas de crisis. Sin embargo, desconocer la inequidad entre estudiantes y entre instituciones educativas, olvidar que las iniciativas educativas deben ser planeadas y diseñadas, excluir a académicos y expertos en educación virtual a la hora de tomar las decisiones y echar de menos las diferencias territoriales y socioeconómicas reveló ser incapacidad en esos ministerios para responderle efectivamente a la sociedad y al Estado. Además, la forma como se impuso la solución de educación virtual para atender a los estudiantes en la cuarentena dejó dudas con respecto al conocimiento que tienen los funcionaros sobre esa modalidad. Hay varias posibilidades: la desactualización tecnopedagógica es evidente en el Ministerio Nacional, o se ignoró a los equipos que de ese ministerio que son expertos en el tema, o faltaron estrategias para convocar a los académicos, investigadores e instituciones que en Colombia vienen desarrollando educación virtual desde 1998. En cuanto a MinTIC, aunque su responsabilidad con la teoría de la educación virtual es menor que la del otro ministerio, el desconocimiento no se justifica totalmente, pues la conectividad hace parte del engranaje de los ambientes virtuales.

Lógicamente, se ve que hubo improvisación. Sin planear, diseñar, modelar, un ministerio arrojó a las instituciones a la educación virtual y el otro prometió conectividad y cobertura. Los compromisos por la calidad de la educación, la equidad, la inclusión quedaron relegados; la función pedagógica, según los discursos y disposiciones, se dejó en el olvido. Se enfatizó en la conectividad como problema central y por eso fue coprotagonista MinTIC, que sin temores garantizó cubrimiento para todo el país. Es decir, según los dos ministerios en todas las instituciones la educación era ya una realidad indetenible y viable. Lo paradójico fue que estas ligerezas estaban desentonadas con lineamientos de expertos 
de los ministerios y de grupos académicos que conciben la viabilidad de los ambientes virtuales, pero con la condición de su adecuado diseño tecnopedagógico.

Cabe entonces preguntarse: ¿si el Estado les apuesta a las soluciones con un doble criterio político y humanitario, no debiera el Ministerio de Educación Nacional poner en tal escenario una tercera condición de intervenciones con equidad y calidad en la implementación de a educación virtual? ¿La situación de emergencia manifiesta justifica que se implementen soluciones educativas como la educación virtual, sin planeación y diseño o dentro de la misma urgencia se hubieran podido tener estrategias más democráticas para mayores consensos? ¿La educación virtual es tan fácil de implementar que se puede reducir al aseguramiento de la conectividad o las conceptualizaciones sobre tecnopedagogía se han extralimitado en las condiciones?

Pero las carencias conceptuales y la despreocupación por la calidad de la educación virtual no se patentizaron exclusivamente en los ministerios. En una entrevista en la emisora W Radio (Colombia), el 9 de junio de 2020, una dirigente de un centro preescolar aseveró: "Los niños están recibiendo las clases en una plataforma virtual y todos están estudiando, es prácticamente como si estuvieran en la institución", en tanto que un padre de familia afirmó que "los niños no soportan estar cinco horas frente a la pantalla de un computador, como mi hija de cuatro años" ("Cobros exagerados en colegios", 2020). Al escuchar los argumentos y las respuestas a las preguntas de los periodistas, quedó sobre la mesa la desinformación y desactualización de la dirigente, cuando justificaba la aplicación de ambientes virtuales ignorando factores como la edad, la cognición, la psicología y le emotividad de los niños. Además, fue constante la justificación de continuar con los ambientes virtuales para infantes, arguyendo no clausurar para poder ejecutar los recaudos y cumplir con las obligaciones laborales. Por supuesto, se presentó un dilema ético: la apuesta por la educación sincera de los niños o por preservar el bienestar económico de los empleados. Tal vez se podrían buscar otras fórmulas, pero no desvirtuar y desnaturalizar la educación escolar de los infantes de cinco años o menos.

Quedan varas dudas: ¿sí puede ser tan normal la estadía de los niños en el ambiente virtual de la plataforma tecnológica como en el ambiente físico del preescolar? ¿Sí está preparado psicológica y biológicamente un infante de cuatro o menos años para permanecer motivado, alegre, creativo frente a un computador? ¿Cómo será la tensión psicológica, 
el arrojo pedagógico, el esfuerzo tecnológico de los profesores, para mantener la atención y la motivación de los niños en la virtualidad, sabiendo que están preparadas es para los ambientes físicos?

Otro caso que reflejó inconsistencias conceptuales sobre la educación virtual que aplicaron, ocurrió en una institución de educación superior de Medellín, cuando en la cuarentena esta institución emitió una normativa señalando que los docentes debían continuar el desarrollo de los contenidos de las asignaturas, a través del uso del uso de herramientas digitales, pero sin realizar las evaluaciones planeadas en cada asignatura.

En esta normativa es notable la inverosimilitud, pues avanzar en el desarrollo temático sin procesos de evaluación es no comprender la pedagogía de la virtualidad que, según los teóricos y quienes han tenido experiencias en sus ámbitos, debe sustentarse en el construccionismo de los estudiantes. Para esto es necesaria la propuesta de actividades de evaluación continua durante el proceso, tanto para retroalimentar los aprendizajes, como para motivar la actitud de los estudiantes.

Ahondando en los dos casos presentados, es claro que son dilemas éticos para los dirigentes. Por un lado, la disyuntiva entre educación virtual sin calidad para los infantes y contra la continuidad de las condiciones económicas de profesores y empleados, y por el otro, el cumplimiento con unos contenidos curriculares en un tiempo predefinido, contra unos ambientes virtuales carentes de fundamentos pedagógicos. El estado de emergencia sustentó situaciones sobre toma de decisiones entre pares de imperativos éticos, como el dilema entre priorizar sanidad o sostener desarrollo económico. No obstante, aceptando la dificultad para elegir entre un interés y otro, queda en tela de juicio la ética en las decisiones para imponer educación virtual sin calidad ni conceptualización en centros preescolares e igualmente, merecen un cuestionamiento ético las disposiciones en las universidades para remitir contenidos virtualmente, sin un método pedagógico, en detrimento de la docencia con calidad.

Otra decisión no planeada en la pandemia fue la de aplicar virtualmente las pruebas de Estado o Pruebas Saber, que aplica el Instituto Colombiano para la Evaluación de la Educación (Icfes).

Para el Icfes es prioridad la salud de los inscritos a las Pruebas de Estado y, teniendo en cuenta las condiciones de prevención y distanciamiento social establecidas por el Gobierno nacional, aplicará por primera vez un examen completamente electrónico a toda la población inscrita. [...] Además, en esta ocasión, el Instituto ofrecerá la posibilidad de presentarlo en la 
casa. [...] La aplicación de la prueba contará con un servicio tecnológico de supervisión y vigilancia para garantizar la seguridad necesaria en este tipo de exámenes, los cuales también sirven para evaluar la calidad de la educación en el país ("Icfes realizará por primera vez una prueba”, 2020).

Esta decisión expone problemas relacionados con equidad, ética y calidad. El asunto critico es que los sistemas informáticos para el control y supervisión remota de exámenes requiere de conectividad y computadores con una capacidad mínima que no la tienen todos los estudiantes en las ciudades, los municipios o las zonas rurales. Estos sistemas, además de la gestión de los exámenes cumplen funciones de vigilancia para evitar fraudes y deben detectar, por ejemplo, el ambiente cercano al estudiante y las interacciones de este con su computador.

En el caso de otras alternativas con menores exigencias tecnológicas, probablemente, se pueda incurrir en debilidades para asegurar validación y verificación en la aplicación de las pruebas. Parece que los dirigentes no evaluaron la inequidad de los estudiantes, e incluso, se olvidaron que muchos en sus hogares no tienen las condiciones mínimas de logística y confort para presentar unos exámenes tan significativos como los del Icfes. No tuvieron en cuenta que en los exámenes tipo Pruebas Saber entran en juego además de conocimientos y competencias, elementos como ambientación, ergonomía, disponibilidad o tranquilidad.

Programar esos exámenes en línea, con todos esos olvidos es un comportamiento anti-ético, aunque sea justificable por la crisis del virus, pues además, se pone en duda el criterio por la calidad, ya que si no hay igualdad de condiciones, técnicamente, no es posible la interpretación coherente de resultados. Es entendible que prevaleció la protección de la salud como elemento fundamental, pero faltó creatividad o voluntad política para tomar una decisión con más ética y preocupación por la calidad.

\section{Desconexión con la comunidad escolar}

Para demostrar la eficiencia del Estado, era menester tomar medidas urgentes y, además, porque en medio del caos había que llevar tranquilidad a la gente. En esa dirección dos medidas fueron tomadas por el Ministerio de Educación: una semana después de decretada la cuarentena, se determinó "permitir que el Programa de Alimentación Escolar se brinde a los niños, niñas y adolescentes matriculados en el sector oficial para su consumo en casa, durante la vigencia del estado de Emergencia Económica, Social y Ecológica" (Decreto 470 de 2020), y dos meses después se 
determinó que los estudiantes regresarían en modalidad de alternancia. "El concepto implica una combinación del trabajo académico en casa, complementado con encuentros periódicos presenciales e integración de diversos recursos pedagógicos, así como la asistencia al establecimiento educativo debidamente organizada" (Directiva Ministerial №. 011 de 2020). Estas disposiciones demostraron que las formas como interpretan en la alta dirigencia del Estado las dinámicas educativas y las vivencias de las comunidades escolares se alejan de la realidad escolar.

Los resultados de estas disposiciones revelaron la desconexión de la alta dirigencia con el entorno, pues el programa de alimentación escolar llegó con otra dirección (alimentos para el hogar, no especial para los niños como si ocurre en las instituciones) o llegó solo unas pocas veces o llegó en forma de bono como ingreso familiar del hogar (Alcaldía Distrital de Santa Marta, 2020; Gutiérrez, 2020). En el Ministerio de Educación no comprendieron que era complicado e incoherente replicar en el hogar el servicio de alimentación de las instituciones escolares, cuyo objetivo central y específico es el bienestar integral de los aprendices. El ministerio, por defender la eficiencia del Estado, asumió la función de alimentación para los hogares, que le es ajena. Pero, paradójicamente, no se advirtieron lineamientos ni recursos para la pedagogía de la virtualidad, la asistencia a los profesoresolas mediaciones pedagógicas que con urgenciase requerían.

Por otra parte, aunque fuera con modalidad de alternancia, no todas las instituciones educativas estaban en capacidad de preservar la salud de los estudiantes en los momentos de prespecialidad y ni siguiera con dos meses de anticipación podrían lograrlo, ya que sus condiciones de insuficiencia son estructurales, la autonomía es limitada y los presupuestos son insuficientes y, por esto, problemas como el hacinamiento, la higiene - la reducción de espacios libres impiden distanciamientos sociales o instalación de dispositivos para el aseo continuo de estudiantes y profesores. Es llamativo que el ministerio haya olvidado las condiciones físicas y la sobrepoblación de muchas instituciones del país para imaginar soluciones como si todas las plantas físicas y organización escolar fueran como la de los grandes centros educativos de las ciudades y demuestra la desconexión con la comunidad académica real.

El 12 de junio de 2020 se divulgaron unos lineamientos para la alternancia del trabajo combinado casa y en la virtualidad (Ministerio de Educación, 2020). Al mismo tiempo que rectores, padres de familia, sindicatos de profesores y expertos elevaban voces por la inconveniencia del retorno a las instituciones. Mientras tanto el 16 de junio, la 
Confederación Nacional de Rectores y Colegios Privados (Andercop), en un comunicado expresó que en 2020 los estudiantes no regresaran a las actividades presenciales.

Probablemente el Ministerio de Educación haya tenido que desistir de la iniciativa de alternancia, ante la presión de la comunidad académica. Pero esto no desvirtúa el análisis sobre la incoherencia de las decisiones con la realidad, el alejamiento con la comunidad académica real, el ambiente educativo y las desigualdades institucionales. Haya o no modalidad de alternancia, las justificaciones iniciales y la forma como se propuso, dejó en evidencia el obscurantismo educativo de la dirigencia. En vez de alimentos para los hogares o de modalidades de alternancia para el trabajo académico en casa y en la institución, probablemente sería más conveniente multiplicar esfuerzos, generar estrategias, crear mecanismos para que la educación virtual se desarrollara con mayor calidad y equidad. Es también obscurantismo no entender la complejidad tecnopedagógica, informacional, motivacional y de los ambientes virtuales y dejar que cada profesor implemente lo que le permitan sus conocimientos y su creatividad. Es preocupante que la situación problemática de la educación virtual impuesta, con respecto a su alcance y estrategia, haya quedado relegada.

Estas situaciones llevan a interrogantes como estos: ¿son éticas las posturas de los funcionarios cuando priorizan políticamente la defensa de la eficiencia del Estado, en deterioro de la calidad de la educación y cuando desconocen las realidades de las comunidades educativas? ¿Por qué no aceptar que el impacto del virus lleva a la interrupción de la escolarización normal y se asume éticamente la situación, en vez de improvisar educación virtual para niños, sin equidad ni calidad? ¿Son éticos los comportamientos de los funcionarios cuando no advierten que sus decisiones no consideran el principio de la equidad, pues no es lo mismo la modalidad de alternancia educativa en instituciones con bajos recursos que en otras con mayor capacidad instalada? ¿Es ético ignorar conceptualizaciones, justificaciones, alcances y condiciones de la educación virtual, por querer continuar calendarios académicos y organización escolar, cuando las condiciones objetivas no lo permiten?

\section{Efectos en la educación superior}

Un informe del Instituto Internacional de la Unesco para la Educación Superior en América Latina y el Caribe (IESALC, 2020) sobre los efectos de la pandemia de la COVID-19 advierte sobre sus impactos en estudiantes, profesores y personal no docente y en fenómenos como funcionamiento 
de las instituciones, demanda y oferta de la educación superior. En la tabla 16 se exponen las ideas centrales de ese informe:

Tabla 16. Impactos en la educación superior

Incertidumbres sobre la continuidad de los aprendizajes y la movilidad internacional para quienes la tenían planeada a

Estudiantes corto plazo. Incidencias y modificaciones en la vida cotidiana.

Dificultades para adaptarse a la educación virtual (e-learning).

\begin{tabular}{|c|c|}
\hline Profesores & $\begin{array}{l}\text { Imposición de continuidad de la docencia bajo la modalidad } \\
\text { de educación virtual. } \\
\text { Cancelación o modificación de contratos. }\end{array}$ \\
\hline Personal no docente & $\begin{array}{l}\text { Reducción de puestos de trabajo e inestabilidad laboral debido } \\
\text { a crisis en la matrícula de estudiantes o a posibles apretones } \\
\text { financieros. }\end{array}$ \\
\hline Disrupción funcional & $\begin{array}{l}\text { El cese de actividades presenciales puede ocasionar } \\
\text { perturbaciones en el funcionamiento institucional que } \\
\text { dependen de la capacidad para la continuidad de las } \\
\text { actividades y su fortaleza financiera. }\end{array}$ \\
\hline \multirow{2}{*}{$\begin{array}{l}\text { Alteración de } \\
\text { la demanda }\end{array}$} & $\begin{array}{l}\text { Se prevé que la matricula se reducirá significativamente en el } \\
\text { siguiente periodo académico a la pandemia y se espera que } \\
\text { repunte progresivamente en periodos posteriores. }\end{array}$ \\
\hline & $\begin{array}{l}\text { Las instituciones privadas se afectarán por la disminución } \\
\text { de la demanda de matrículas como consecuencia de la crisis } \\
\text { financiera. }\end{array}$ \\
\hline \multirow{2}{*}{ Alteración de la oferta } & $\begin{array}{l}\text { Las instituciones públicas sufrirán por la recesión económica } \\
\text { y se esperan recortes importantes en la inversión pública del } \\
\text { Estado en educación superior. Esto probablemente impactará } \\
\text { en su oferta a la sociedad. }\end{array}$ \\
\hline & $\begin{array}{l}\text { Las instituciones privadas, afectadas por la crisis financiera } \\
\text { tendrán que hacer replanteamientos sobre la tipología de } \\
\text { programas académicos, para que sean pertinentes con el } \\
\text { estado de situaciones socioeconómicas }\end{array}$ \\
\hline
\end{tabular}

Fuente: elaboración propia a partir de IESALC (2020).

El informe (IESALC, 2020) hace las siguientes recomendaciones que deben ser tenidas en cuenta por las instituciones de educación superior:

1). Prepararse para asegurar la continuidad formativa, con equidad, gestión, monitoreo y apoyo eficientes. 
2). Crear mecanismos pedagógicos, evaluar y apoyar el aprendizaje de los estudiantes en situación de desventaja con la educación virtual.

3). Documentar las experiencias vividas, las estrategias pedagógicas introducidas y los impactos observados. Sistematizar los cambios pedagógicos que se crearon.

4). Convocar a la reflexión y la investigación sobre transformación de los modelos de aprendizaje.

5). Sistematizar lecciones aprendidas y fomentar la educación virtual con base en los conceptos de hibridación y aprendizaje ubicuo. "Cada IES y probablemente cada disciplina, deben encontrar la combinación de tecnologías y recursos más apropiadas para mejorar el impacto pedagógico" (IESALC, 2020, p. 32). "No es necesario pensar en posibles crisis futuras para tener una aproximación diversificada al uso de tecnologías en la educación superior" (IESALC, 2020, p. 34). Se debe invertir más en tecnologías, recursos didácticos y dispositivos para mejorar la calidad de la docencia.

En el informe no se enfatiza en el impacto sobre la calidad de la educación debido a la forma improvisada y urgente como se impuso el estudio en casa con ambientes virtuales. Sorprende esa omisión, pues provienen de la Unesco que es el órgano que a nivel mundial promueve el fortalecimiento de la educación a todos los niveles. No obstante, se exponen las dificultades para los estudiantes debido a la sustitución de las clases presenciales por modalidad virtual (llamada e-learning en el informe). Para los estudiantes es un esfuerzo significativo la adaptación a nuevas formas de enseñanzaaprendizaje que tuvieron que crear sus profesores. Además, la exigencia de conectividad a internet se tropieza con la realidad de la baja conectividad en los hogares de América Latina, donde se alcanza el $45 \%$, mientras que en Estados Unidos es casi del 90 \% y en Europa el $83 \%$.

Aunque cabe suponer que los hogares donde hay un estudiante de educación superior las probabilidades de tener conectividad son mayores, sería muy aventurado suponer que todos los estudiantes cuando vuelven a sus hogares están efectivamente conectados. Existe todavía una enorme brecha digital entre países y dentro de cada país, tanto es así que la adopción del e-learning como medio para garantizar la continuidad pedagógica ha sido rechazada por varias organizaciones estudiantiles en distintos países africanos. (IESALC, 2020, p. 20). 
El informe es realista y sobre todo, está basado en la información de la Unesco a nivel mundial. Por eso las expectativas sobre educación virtual que posiblemente han crecido debido a su aplicación obligada por la COVID-19 deben considerarlas con recelo y reflexión. Se escuchó varias veces en los noticieros de televisión y en programas matutinos de las emisoras colombianas a periodistas, pensadores, dirigentes, e incluso, a expertos en política educativa, que después del virus las dinámicas en las universidades y escuelas cambiarían definitivamente. Las predicciones y los análisis proféticos tal vez exageraron o tal vez se erigieron sobre el desconocimiento. Si se tuvieran en cuenta los siguientes argumentos del informe, es probable que hubieran sido más cautelosas.

En general, lo dice el informe, la percepción es que el cambio de modalidad presencial a virtual haya tenido un recibimiento positivo. La animadversión inicia porque los cursos no fueron diseñados para la educación virtual ni se habían preparado contenidos para ese fin, sino que surgieron como paliativos por la suspensión de las clases presenciales.

En segundo lugar, las expectativas de los estudiantes son diferentes si deciden desde el principio matricularse en educación virtual o si lo hacen en programas de educación presencial, pues en este último caso esperan elementos sociales y experienciales para sus vivencias personales.

Tercero: la experiencia en el campus físico es especialmente importante para estudiantes vulnerables por circunstancias sociales o personales, pues allí pueden encontrar oportunidades socioafectivas y habilidades sociales y comunicacionales que no tienen en su hogar o en sus barrios y esto difícilmente lo puede suplir la modalidad de ambientes virtuales.

Y cuarto, se espera que se reproduzcan por medios tecnológicos las dinámicas normales de enseñanza-aprendizaje y la evaluación continua en línea, pero la duda es si los estudiantes lograrán totalmente los objetivos de aprendizaje planeados. Se espera que los resultados no cambien al haber cambiado la modalidad, pero las variables incidentes son múltiples y el contexto de cada estudiante tiene sus particularidades (IESALC, 2020).

\section{Lecciones aprendidas}

\section{¿Cómo capitalizar la experiencia adquirida en la crisis?}

La crisis ocasionada por la COVID-19 ha dejado lecciones aprendidas sobre la experiencia de enseñanza-aprendizaje por fuera del campus 
físico. Lo primero es reconocer que el desarrollo curricular puede extenderse con organizaciones duales o metodologías híbridas, aprovechando las oportunidades de internet. Antesque ensayar otras formas de docencia debidoa coyunturas como la COVID-19, estas deben planearse y diseñarse. Ciertamente, la experiencia demostró que sí es posible aplicar otras formas y medios.

De acuerdo con el IESALC, las instituciones de educación superior deben abrir espacios de reflexión con estudiantes y profesores acerca de las experiencias en la crisis. Además, deben aprovecharse esos conocimientos para proponer el rediseño de procesos curriculares y pedagógicos que permita maximizar las ventajas de la presencialidad, con la complementariedad, apoyo de la tecnología y el e-learning. Asimismo, deben fomentarse procesos efectivos de innovación tecnopedagógica y desarrollar estrategias para ampliar las competencias transversales de los docentes (comunicativas, pedagógicas, tecnológicas).

La crisis de la COVID-19 debe ser una oportunidad realmente asumida por las instituciones de educación superior para que se inicien investigaciones, rediseños, programas relacionados con innovaciones pedagógicas. Es claro que sobre la marcha y masivamente los profesores tuvieron que implementar formas nuevas de enseñanza. Se demostró que sí es posible romper paradigmas. Entonces, queda abierto el camino para emprender innovaciones pedagógicas en las instituciones, de manera planeada, controlada y organizada.

Debe reconocerse que la educación online garantiza continuidad en el aprendizaje y el desarrollo curricular, solo si los estudiantes tienen buenos artefactos y suficiente conectividad a internet. Este es un desafío para poblaciones vulnerables, pero asequible para otros grupos sociales. Esta inequidad debe ser reconocida, no para esquivar las alternativas de educación virtual, sino para planear programas de acompañamiento especial para esos estudiantes o para desarrollar con ellos actividades diferenciadoras.

Algo que se vivió en la experiencia del confinamiento obligado, y lo confirmó el informe del IESALC, es que los estudiantes y profesores utilizan distintos medios para conectarse a las clases y diversidad de recursos para el aprendizaje. Es por esto que las instituciones deben reconocer el uso de dispositivos móviles, redes sociales, aplicaciones y facilitar su accesibilidad. Es decir, debe ser función de las instituciones la producción planeada y sistematizada de contenidos digitales, mediaciones pedagógicas y aplicaciones para apoyar los aprendizajes ademas; debe proporcionarse conectividad para los estudiantes y profesores. 


\section{REFERENCIAS BIBLIOGRÁFICAS}

Acevedo, A., Linares, C. y Cachay, O. (2013). Investigación en la acción. Un ejemplo de estudio experimental en el mercadeo de servicios. Industrial Data, 16(2), 79-85. https://doi.org/10.15381/idata.v16i2.11925

Athabasca University. (2019). Student Code of Conduct and Right to Appeals Regulations. http://calendar.athabascau.ca/undergrad/ current/student-code/academic-misconduct-intellectual-honesty.php

Alcaldía de Fonseca. (2019). Resolución No. 556. Por el cual se adopta la actualización del Código de Ética de la Alcaldía de Fonseca, Guajira. http://www.fonseca-guajira.gov.co/transparencia/gestionhumana/ codigo\%20de\%20\%c3\%89tica.pdf

Alcaldía Distrital de Santa Marta.(2020, mayo 6). Programa de Alimentación Escolar (PAE) sigue llegando a los hogares de los estudiantes de las Instituciones Educativas del Distrito de Santa Marta. https://www. santamarta.gov.co/sala-prensa/noticias/programa-de-alimentacionescolar-pae-sigue-llegando-los-hogares-de-los

Aranda, R., Jaimes, I. y Caballero, M. (2015). Los principios éticos y las obligaciones civiles. Boletín mexicano de derecho comparado, 48(142), 313-337. https://www.redalyc.org/pdf/427/42737102009.pdf

Aristizábal, G. (2020, mayo 6). Corrupción en cuarentena: investigan a 26 gobernaciones. Noticias Canal 1. https://noticias.canal1.com.co/ nacional/corrupcion-cuarentena-investigan-gobernaciones/

Arauz, M. (2020, mayo 10). La vida después del COVID-19. El Comercio. https://www.elcomercio.com/opinion/columnista-elcomercioopinion-vida-covid19.html

Astudillo, G., Sanz, C., y Santacruz Valencia, L. (2016, junio). Sistemas ensambladores de objetos de aprendizaje. En: Red de Universidades con Carreras en Informática 2014. IX Congreso sobre Tecnología en Educación \& Educación en Tecnología. Universidad Nacional de Chilecito.

Arras A., Gutiérrez M. y Bordas, J. (2018). Escenarios de aprendizaje y satisfacción estudiantil en posgrado virtual 2010, 2014 y 2015. Apertura, 9(1), 110-125. 
Báez, C. y Clunie, C. (2019). Una mirada a la educación ubicua. RIED. Revista Iberoamericana de Educación a Distancia, 22(1), 325-344.

Baldomero, M. y Salmerón, J. (2015). EduToo $\left.\right|^{\circledR}$ : un instrumento para la evaluación y acreditación de la calidad de los MOOCs. Educación XX1: Revista de la Facultad de Educación, 18(2), 97-123. https://doi. org/10.5944/educxx1.13233

Basso-Musso, L. (2012). Enfermería y la resolución de los dilemas éticos. Investigación y Educación en Enfermería, 30(2), 260-268.

Benítez, C. y Gómez, H. (2015). Educador para la educación virtual: operario de la sociedad de la información y el conocimiento. [Tesis de maestría, Universidad Pedagógica Nacional]. http://repository. pedagogica.edu.co/bitstream/handle/20.500.12209/774/TO-18950. pdf? sequence $=1$ \&isAllowed $=y$

Bernal, M. (2015, junio 22-25). El abandono de los estudiantes en los MOOC. [sesión de conferencia]. Ubicuo y social: aprendizaje con TIC. Jornadas Virtuales de Colaboración y Formación. Murcia. https:// www.researchgate.net/publication/283205614_Abandono_de_los_ estudiantes_en_los_MOOC

Barrón, M., Zatarain, R., y Beltrán, R. (2015). Diseño y desarrollo de una red social de aprendizaje colaborativo para dispositivos móviles. Pistas Educativas, (112), 464-485.

Bautista, G. (2011). El acompañamiento del estudiante: profesorado para una nueva forma de aprender. En: B. Gros (Ed.), Evolución y retos de la educación virtual. Construyendo el e-learning de Siglo XXI (pp. 51-71). Editorial UOC.

Cabezas, M., Casillas, S. y Acuña, S. (2016). Entorno personal de aprendizaje (PLE): una propuesta para desarrollar las competencias digital e informacional en la enseñanza universitaria del derecho en Colombia. Aula, 22, 271-287. http://dx.doi.org/10.14201/ aula201622271287

Calle, D. y Posada, M. (2020, abril 20). Universidades paisas prestan computadores para clases virtuales. El Tiempo. https://www.eltiempo. $\mathrm{com} / \mathrm{colombia/medellin/universidades-de-medellin-prestan-}$ computadores-para-clases-virtuales-486192 
Camperos, K. (2002). Reseña de "Ética para Amador" de Fernando Savater. Revista de Teoría y Didáctica de las Ciencias Sociales, (7), 276-278.

Cando, A., Alcoser, F., Villa, H. y Ramos, R. (2017). Los entornos virtuales un plus en la docencia universitaria de la Escuela Superior Politécnica de Chimborazo. 3C TIC, 6(3), 26-42. https://doi.org/10.17993/ 3ctic.2017.63.26-42

Cantú-Cervantes, D., Amaya-Amaya, A. y Baca-Pumarejo, J. (2019). Modelo para el reforzamiento del aprendizaje con dispositivos móviles. CienciaUAT, 13(2), 56-70. 10.29059/cienciauat.v13i2.1161

Cardona, G. (2002). Tendencias educativas para el siglo XXI. Educación virtual, online y @learning. Elementos para la discusión. Edutec. Revista Electrónica de Tecnología Educativa, (15), 1-27. https://doi. org/10.21556/edutec.2002.15.542

Castañeda, D., Cañas, P. y Castillo, J. (2015). Factores asociados al proceso de autogestión del aprendizaje y la permanencia del estudiante virtualen el curso de convivencia de las redes sociales educativas de Cundinamarca. [Tesis de maestría, Universidad Pedagógica Nacional]. https:// repository.cinde.org.co/bitstream/handle/20.500.11907/1534/ CanasCruzCastanedaGuerreroCastilloGutierrez2015.pdf?sequence $=1 \&$ isAllowed=y

Chaves-Barboza, E. y Sola-Martínez, T. (2018). Entornos personales de aprendizaje (PLE) en el Grado de Educación Primaria de la Universidad de Granada. Revista Electrónica Educare (Educare Electronic Journal) EISSN, 22(1), 1-18. doi: http://dx.doi.org/10.15359/ree.22-1.12

Chirinos Campos, L. I. (2016). Ética del docente en los entornos virtuales de aprendizaje. REDINE, 8(2), 136-140.

Código de ética de la Universidad Nacional Autónoma de México. (2015, julio 30). Gazeta, 27-29.

¿Colombia vive digital? El uso de internet en el país va en aumento. (2017, agosto 24). Enter.co. https://www.enter.co/cultura-digital/colombiadigital/uso-de-internet-el-ultimo-ano/.

Consejo de Normas Internacionales de Ética para Contadores. (2019). Código de Ética para Profesionales de la Contabilidad. https:// www.ifac.org/system/files/publications/files/codigo-de-etica-paraprofesionales-de-la-contabilidad.pdf 
Consejo Nacional de Profesionales de Ingeniería. (2019). Código de Ética. https://copnia.gov.co/tribunal-de-etica/codigo-de-etica

Corporación Universitaria Minuto de Dios - UNIMINUTO. (2019). Código de Ética. http://www.uniminuto.edu/documents

Corporación Universitaria Minuto de Dios- UNIMINUTO. (2014). Proyecto Educativo Institucional. http://www.uniminuto.edu/documents.

Corporación Universitaria Remington. (2019). Código de Ética. https:// www.uniremington.edu.co/normatividad/reglamentos/codigo-deetica-y-buen-gobierno.html

Correa, M. (2009). Comunicación y educación. Especialidad en Competencias docentes, UPN-COSDAC [Documento]. Universidad Pedagógica Nacional. https://upncosdacg8.wordpress.com/

Creswell, J. (2003). Qualitive inquiry and research design: among five approaches, (2‥ Ed.). SAGE.

Creswell, J. (2014). Research design: Qualitative, quantitative, and mixed methods approaches. SAGE.

Day, M. (2018). De la identidad a la autonomía: los movimientos sociales en red en la obra de Manuel Castells. Millcayac-Revista Digital de Ciencias Sociales, 5(8), 187-194.

Decreto 1295 de 1994. Por el cual se determina la organización y administración del Sistema General de Riesgos Profesionales. D. O. 41.405, del 24 de junio de 1994. http://www.secretariasenado.gov.co/senado/basedoc/ decreto_1295_1994.html

Decreto 2566 de 2003. Por el cual se establecen las condiciones mínimas de calidadydemás requisitos parael ofrecimientoydesarrollodeprogramas académicosdeeducaciónsuperiorysedictanotras disposiciones.https:// www.mineducacion.gov.co/1621/articles-86425_Archivo_pdf.

Decreto 1330. Por el cual se sustituye el Capítulo 2 y se suprime el Capítulo 7 del Título 3 de la Parte 5 del Libro 2 del Decreto 1075 de 2015 -Único Reglamentario del Sector Educación. https://www.mineducacion.gov. co/1759/w3-article-387348.html?_noredirect=1

Decreto 457. (2020, abril 23). Mediante el cual se imparten instrucciones para el cumplimiento del Aislamiento Preventivo Obligatorio. https://www. mineducacion.gov.co/1759/w3-article-394357.html?_noredirect=1 
Delors, J. (1996). La educación encierra un tesoro. Santillana.

Decreto 470. (2020, marzo 24). Por el cual se dictan medidas que brindan herramientas a las entidades a las entidades territoriales para garantizar la ejecución del Programa de Alimentación Escolar y la prestación del servicio público de preescolar, básica y media, dentro del estado de Emergencia Económica, Social y Ecológica. https://www. mineducacion.gov.co/1759/w3-article-394502.html?_noredirect=1

Departamento Nacional de Planeación. (2019). Código de Integridad. https://www.dnp.gov.co/DNP/acerca-de-la-entidad/Paginas/codigode-etica.aspx

Díaz, J. (2007). Rutas de reflexión y acción pedagógica. Fundación Universitaria Luis Amigó.

Díaz, S. (2014). Los métodos mixtos de investigación: presupuestos generales y aportes a la evaluación educativa. Revista portuguesa de pedagogía, 48(1), 7-23.

Dirección de Impuestos y Aduanas Nacionales. (2019). Código de Ética. https://www.dian.gov.co/dian/entidad/CodigoBuenGobierno/ Codigo_Buen_Gobierno_Etica.pdf

Domínguez, J. y Rama, C. (Eds.). (2011). Aseguramiento de la calidad en la educación virtual. Editorial Gráfica Real.

Dramático aumento del desempleo en Colombia. (2020, mayo 29). Portafolio. https://www.portafolio.co/economia/empleo/noticiascoronavirus-desempleo-colombia-abril-2020-541240

Duque, N. (2020). Menos del $10 \%$ de los niños en el campo tienen computador para recibir clases durante la cuarentena. Cerosetenta. https://cerosetenta.uniandes.edu.co/por-alla-no-Ilega-ni-dios-laeducacion-rural-en-tiempos-de-pandemia/.

Durán, E. y Costaguta R. (2008). Experiencia de enseñanza adaptada al estilo de aprendizaje de los estudiantes en un curso de simulación. Formación Universitaria, 1(1), 19-28. http://dx.doi.org/10.4067/ S0718-50062008000100004

Durán, R., Estay-Niculcar, C. y Álvarez, H. (2015). Adopción de buenas prácticas en la educación virtual en la educación superior. Aula Abierta, 43(2), 77-86. https://doi.org/10.1016/j.aula.2015.01.001 
El $50 \%$ de empresas del país no estaba preparado para el teletrabajo. (2020, junio 14). Dinero. https://www.dinero.com/empresas/ articulo/empresas-de-colombia-no-estaban-preparadas-para-elteletrabajo/289260

En universitarios graduados, Colombia es un líder en la región. (2018, noviembre 15). El Tiempo.

ESCO Technologies INC. (2019). Código de conducta para vendedores. https://www.escotechnologies.com/wp-content/uploads/2016/04/ Vendor-Code-of-Conduct-Spanish.pdf

Esteban, F. y Fuentes, J. (2015). la educación universitaria virtual: una reflexión en torno al cultivo de las virtudes. Teoría de la Educación. Revista Interuniversitaria, 27(1), 103-118. https://doi.org/10.14201/ teoredu2015271103118

Facundo, A. (2003). Digital observatory for higher education in Latin America and the Caribbean. IESALC. https://unesdoc.unesco.org/ ark:/48223/pf0000139922

Fernández-Ferrer, M. (2019). Revisión crítica de los MOOC: pistas para su futuro en el marco de la educación en línea. Revista de Educación a Distancia, 17(1), 73-88.

Fernández, R. (2011, septiembre 18). Códigos éticos o de conducta. Su concepto. Su necesidad. Diario_responsable. La RSE Global. https://diarioresponsable.com/opinion/14404-codigos-eticos-o-deconducta-su-concepto-su-necesidad

Fuster, D. (2019). Investigación cualitativa: método fenomenológico hermenéutico. Propósitos y Representaciones, 7(1), 201-229. http:// dx.doi.org/10.20511/pyr2019.v7n1.267

Fundación Universitaria Católica del Norte. (2015). Proyecto Educativo Institucional.https://www.ucn.edu.co/institucion/Documents/pei.pdf

Galeano, M. (2004). Diseño de proyectos de investigación cualitativa. Fondo Editorial Universidad EAFIT.

Gallar, Y., Rodríguez, I. y Barrios, E. (2015). La mediación con las TIC en la enseñanza-aprendizaje de la educación superior. Didasc@lia: Didáctica y Educación. 6(6), 155-164. 
Gallego-Arrufat, M. y Chaves-Barboza, E. (2014). Tendencias en estudios sobre entornos personales de aprendizaje (Personal Learning Environments-PLE-). EDUTEC. Revista Electrónica de Tecnología Educativa, (49), 281-296. https://doi.org/10.21556/edutec.2014.49.89

García, A., Guerrero, R. y Granados, J. (2015). Buenas prácticas en los entornos virtuales de enseñanza-aprendizaje. Revista Cubana de Educación Superior, 34(3), 76-88.

García, L. (2017). Educación a distancia y virtual: calidad, disrupción, aprendizajes adaptativo y móvil. Revista Iberoamericana de Educación a Distancia, 20(2), 9-25. https://doi.org/10.5944/ried.20.2.18737

Gimeno, S. (2002). Educar y convivir en la cultura global. Morata.

Giraldo, B. y Villa, C. (2006). Percepciones de los docentes universitarios sobre el uso de las nuevas tecnologías de información y comunicación en sus prácticas pedagógicas. Proyecto de grado para obtener el título de Maestría en Educación y Desarrollo Humano. CINDE.

Gobierno Regional del Maule. (2018). Código de Ética. http://www. goremaule.cl/goremaulenuevo/images/2018/CODIGOETICA.pdf.

Gómez, B. (2006). Recomendaciones de políticas sobre educación virtual en Antioquia. Politécnico Lugaza.

González,L.J.,Sfer,A.L.yMalagón.L.A.(2000).Laeducaciónsuperioradistancia en Colombia, Bogotá: Instituto Colombiano para la Educación Superior.

Gómez Osorio, J. (2017, marzo 30). ¿Cuál es la estructura organizacional que más le conviene? Dinero. https://www.dinero.com/opinion/ columnistas/articulo/estrctura-organizacional-que-mas-convienepor-jorge-gomez/243414

Gómez, J. , Machado, D. , Pizarro, L. , y Betancur, M. (2017). Acción con daño: del asistencialismo a la construcción social de la víctima. Mirada a procesos de reparación e intervención psicosocial en Colombia. Universitas Psychologica, 16(3). https://www.redalyc.org/ pdf/647/64753516012.pdf.

Gozálvez, V., García-Ruiz, R. y Aguaded-Gómez, I. (2014). La formación en competencias mediáticas: una cuestión de responsabilidad ética en educación superior. Revista Interuniversitaria de Formación del Profesorado, 79 (28), 17-28. 
Grupo Aval. (2019). Código de Ética y Conducta. https://www.grupoaval. com/wps/wcm/connect/grupo-aval/8800652c-9f1d-48e6-a71190ca8d62f9f7/Codigo-etica-Conducta.pdf?MOD=AJPERES

Grupo Bancolombia. (2019). Código de Ética. https://www. grupobancolombia.com/wps/portal/acerca-de/informacioncorporativa/sostenibilidad/reporte-de-sostenibilidad/banco-etico

Grupo EPM. (2019). Código de Ética del Grupo EPM. https://www.epm. com.co/site/Portals/4/descargables/codigo_etica.pdf

Grupo Éxito. (2019). Código de Ética. https://www.grupoexito.com.co/es/ codigo_de_etica_grupo_exito_2019.pdf

Guaña-Moya, E., Llumiquinga-Quispe, S. y Ortiz-Remache, K. (2015). Caracterización de entornos virtuales de enseñanza aprendizaje (EVEA) en la educación virtual. Ciencias Holguín, 21(4), 1-16.

Guedez, M. (2005). El aprendizaje de funciones reales con el uso de un software educativo: una experiencia didáctica con estudiantes de educación de la ULA-Táchira. Acción pedagógica, 14(1), 38-49.

Gutiérrez, E. (2020, abril 10 ). Sec. Educación ya está entregando bonos para alimentación escolar. El Tiempo. https://www.eltiempo.com/ bogota/sec-educacion-ya-esta-entregando-bonos-para-alimentacionescolar-479778

Heredia, M. (2020). Pedagogía e historia. La educación como tiempo de la historia. Pedagogía y Saberes, (52), 9-22. https://doi.org/10.17227/ pys.num52-10628

Hernández, C. (2001). Hacia la construcción colectiva del conocimiento. La investigación en la enseñanza de las ciencias a finales del siglo XX. Instituto Tecnológico Metropolitano. Escuela de Pedagogía.

Honey, P. y Mumford A. (1992). The manual of learning styles. Ardingly House.

Icfes realizara por primera vez una prueba de estado de manera virtual. (2020, mayo 26). El Tiempo. https://www.eltiempo.com/vida/ educacion/icfes-realizara-por-primera-vez-una-prueba-de-estadodemanera-virtual-499606 
Insuasty, E., Martín, A.e Insuasti,J.(2014).Comparación de tresmetodologías de evaluación de objetos de aprendizaje virtuales. Teoría de la Educación. Educación y Cultura en la Sociedad de la Información, 15(2), 69-85.

Interconexión Eléctrica, S.A. (ISA). (s.f). Código de ética. http://www. isa.co/es/sala-de-prensa/Documents/nuestra-compania/codigo-deetica/CodigodeEticayConducta.pdf

Instituto de Consejeros Administradores. (2019). Código de Ética.https:// master2.teenvio.com/v4/public/ficheros/fichero. $p h p$ ?file=a2ada20d380a79103ad55d45911b5 aea\&plan=iconsejeros\&mode=view

Internacional de la UNESCO para la Educación Superior en América Latina y el Caribe. (2020). COVID-19 y educación superior: de los efectos inmediatos al día después. Análisis de impactos, respuestas políticas y recomendaciones. https://portal.acta.org.co/covid-19-y-educacionsuperior-de-los-efectos-inmediatos-al-dia-despues/

Institución Universitaria de Envigado. (2019). Resolución 1434. Por la cual se adopta el Código de Ética con los principios, valores y el pacto de convivencia de la Institución Universitaria de Envigado. http:// www.iue.edu.co/portal/documentos/resoluciones/2002-2011/ Resolucion1434-2010-ComiteEtica.pdf

Islas, C. y Carranza, M. (2011). Uso de las redes sociales como estrategias de aprendizaje. ¿Transformación educativa? Apertura, 3(2), 6-15.

Jiménez, G. (2016). La ética y la moral: paradojas del ser humano. CES Psicología, 9(1), 109-121.

Jaramillo, E. (2005). Sobre didáctica y clase virtual. En: A. Sánchez (ed.). Educación virtual: reflexiones y experiencias, (pp. 3-18). Coimpresos.

Leiva, J., Cabero, J. y Meza, L. (2018). Entornos personales de aprendizaje (PLE) en estudiantes universitarios de Pedagogía. Revista Latinoamericana de Tecnología Educativa, 17(1), 25-39.

La W Radio. (2020, junio 1). Cobros exagerados en colegios, otra pesadilla de los padres de familia en la pandemia. https://www. wradio.com.co/noticias/actualidad/cobros-exagerados-en-colegiosotra-pesadilla-de-los-padres-de-familia-en-la-pandemia/20200609/ nota/4045467.aspx 
La educación virtual del país mejora su calificación. (2018, enero 26). Portafolio. https://www.portafolio.co/tendencias/la-educacion-virtual-del-paismejora-su-calificacion-513667

La pandemia disparó el virus de la corrupción en los contratos. (2020, mayo 23). Semana. https://www.semana.com/nacion/articulo/ coronavuris-en-colombia-crece-la-corrupcion-en-contratos-encuarentena/673562

Lagos, A. (2020, abril 30). Después de la cuarentena llega la "nueva normalidad": ya nada será como antes. El Mundo. https://www. elespectador.com/coronavirus/despues-de-la-cuarentena-Ilega-lanueva-normalidad-ya-nada-sera-como-antes-articulo-917312/

Loaiza, R. (2003). La universidad virtual en Latinoamérica. Etic@net, 1(2), 1-12.

Ley 115 de 1994. Por la cual se expide la ley general de educación. D.O. No. 41.214 de 8 de febrero de 1994.

López, R. (2020, junio 1). Economía global no volverá a ser la misma de antes. Portafolio. https://www.portafolio.co/economia/global-novolvera-a-ser-la-misma-que-antes-541354

Llorente, M. (2005). La tutoría virtual: técnicas, herramientas y estrategias. En: Eduweb 2005, Valencia, Venezuela). http://tecnologiaedu.us.es. Universidad de Sevilla, España.

Machado, L. y Ramos, F. (2005). ITIC una propuesta metodológica de integración tecnológica al currículo. Universidad Pedagógica Nacional.

Maestra imprime material de clases virtuales y las lleva a niños sin internet. (2020, abril 22). Municipios. https://municipiospuebla.mx/nota/202004-22/naci\%C3\%B3n/maestra-imprime-material-de-clases-virtualesy-las-Ileva-ni\%C3\%B1os-sin-internet

Marañón, F., Muñiz, C. y Sardinera, A. R. (2017). La persuasión política en campañas electorales: cuasi-experimento sobre el efecto del uso de rutas persuasivas de los spots políticos. Daena: International Journal of Good Conscience, 12(2), 148-158.

Marciniak, R. y Gairin, J. (2018). Dimensiones de evaluación de calidad de educación virtual: revisión de modelos referentes. RIED. Revista Iberoamericana de Educación a Distancia, 21(1), 217-238. https://doi. org/10.5944/ried.21.1.16182 
Marciniak, R. (2015). Propuesta metodológica para la aplicación del benchmarking internacional en la evaluación de la calidad de la educación superior virtual. RUSC. Universities and Knowledge Society Journal, 12(3), 46-6. http://dx.doi.org/10.7238/rusc.v12i3.2163

Martínez Negrete, E. (2014). Hacia un código de ética para la educación virtual, basado en las cinco mentes del futuro. Revista mexicana de bachillerato a distancia, 6(11), 127-134. http://dx.doi.org/10.22201/ cuaed.20074751e.2014.11.65017

Martínez, G. (2020, marzo 28). La realidad de las clases virtuales. El Diario. https://periodicoeldiario.com/la-realidad-de-las-clases-virtuales/

Martínez, O., Steffens, E., Ojeda, D. C. y Hernández, H. (2018). Estrategias pedagógicas aplicadas a la educación con mediación virtual para la generación del conocimiento global. Formación universitaria, 11(5), 11-18. http://dx.doi.org/10.4067/S0718-50062018000500011

Martínez, X. (2015). Educación virtual: consideraciones éticas y semánticas desde la infoesfera. Innovación Educativa, 15 (68), 9-14.

Martínez, X. (2017). Onlife manifesto y la ética digital. Revista Mexicana de Bachillerato a Distancia, 9(18), 15-22.

Massa, S. y Rodríguez, D. (2014). Objetos de aprendizaje: propuesta de evaluación de calidad pedagógica y tecnológica. En: OEI. Congreso Iberoamericano de Ciencia, Tecnología, Innovación y Educación. OEI.

Méndez, A., Arias, E. y Vives, J. (2018). Estimación de calidad de objetos de aprendizaje en repositorios de recursos educativos abiertos basada en las interacciones de los estudiantes. Educación XX1, 21(1). 285-302. 10.5944/educXX1.20196

Mercado, M., Fernández, K., Lavigne, G. y Ramírez, M. (2018). Enseñanza y difusión sobre el uso de recursos educativos abiertos con MOOC: un estudio de caso. CPU-e. Revista de Investigación Educativa, (26), 3-19.

Ministerio de Educación Nacional (2019). Código de Ética y Buen Gobierno. https://www.mineducacion.gov.co/1621/articles-265914_archivo_ pdf_codigo_etica.pdf.

Ministerio de Educación Nacional (2020). Lineamientos para la prestación del servicio de educación en casa y en prespecialidad bajo el esquema de alternancia y la implementación de prácticas de bioseguridad en la 
comunidad educativa. https://www.mineducacion.gov.co/1759/w3article-399094.html?_noredirect=1

Ministerio de Educación Nacional (2020). Directiva 011 de 2020. https:// www.mineducacion.gov.co/1759/articles-398622_recurso_1.pdf

Ministerio de Educación Nacional (2020). Nivel. https://www. mineducacion.gov.co/1621/article-80330.html.

Ministerio del Interior. (2019). Código de Ética. https://www.mininterior. gov.co/sites/default/files/codigo_de_etica3993.pdf

Ministerio de Protección Social (2019). Código de Ética. https://www. minsalud.gov.co/Ministerio/Paginas/codigoEtica.aspx

Molano, M. (2018). Educación disruptiva en el contexto lasallista: glosas para la discusión. Revista de la Universidad de La Salle, (75), 55-68.

Montoya, J., Sánchez, L. y Torres, P. (2011). Diseños experimentales ¿qué son y cómo se utilizan en las ciencias acuáticas? Ciencia y Mar, 15(43), 61-70.

Mora, D. y Bejarano, C. (2013). Buenas prácticas educativas en Ambientes Virtuales de Aprendizaje (AVA) de la Educación Superior. [Tesis de maestría, Fundación Centro Internacional de Educación y Desarrollo Humano]. https://repository.cinde.org.co/handle/20.500.11907/1426

Narváez-Romo, Y., Luna, G., Leonel, H. , y Ruiz, J. (2017). Evaluación del Software Educativo Mundo Agroforestal con Jóvenes Rurales de Nariño, Colombia. Información tecnológica, 28(2), 135-140. 10.4067/ S0718-07642017000200015

Núñez, J. M. (2020, abril 30). Profesores en cuarentena. Santillana. https:// santillana.com/es/articulo-completo-profesores-en-cuarentena/

Organista-Sandoval, J., Domínguez, C. y López, M. (2019). Desarrollo y aplicación de contenidos educativos digitales desde un teléfono inteligente para un tema de Estadística en un curso universitario. Actualidades Investigativas en Educación, 19(1), 1-22. 10.15517/aie.v19i1.35711

Orozco, G., Tejedor, F. y Calvo, M. (2017). Meta-análisis sobre el efecto del software educativo en alumnos con necesidades educativas especiales. Revista de Investigación Educativa, 35(1), 35-52. https:// doi.org/10.6018/rie.35.1.240351 
Otero, M. (2020, abril 21). La mitad de los alumnos sin clases en el mundo no tiene PC y no accede a los contenidos. La voz. https://www.lavoz. com.ar/ciudadanos/mitad-de-alumnos-sin-clases-en-mundo-notiene-pc-y-no-accede-a-contenidos

Páez,M.S. (2019).Launiversidadenelcontextodelasociedadred:percepción del diseño instruccional en las instituciones educativas superiores. En: Jornada Académica por los XXXIV años de vida institucional de la Universidad Tecnológica Indoamericana - Quito, Ecuador.

Parra, E. (2005). Aproximación a la virtualidad desde la propuesta educativa de la Fundación Universitaria Católica del Norte. En: A. Sánchez (ed.), Educación virtual: reflexiones y experiencias (pp. 3-18). Coimpresos.

Parra, E. (2010). Teletrabajo y e-learning: reflexiones desde una perspectiva interaccional. Revista Virtual Universidad Católica del Norte, (31), 25-59.

Parra, E. (2011). Propuesta de metodología de desarrollo de software para objetos virtuales de aprendizaje-MESOVA. Revista Virtual Universidad Católica del Norte, 1(34), 113-137.

Parra, E. (2017). Evaluación experimental de software desarrollado con fines didácticos. En F. Vargas, D. Soto y C. Giraldo (Eds.), Investigación e innovación en ingeniería de software (pp. 21-30), Publicar T, Sello Editorial TdeA.

Parra E., Londoño E. y Ángel, M. B. (2007). Educación virtual: escenarios para la afectividad y la convivencia. Teoría del Color.

Pedró, F. (2020, junio 3). Perspectiva internacional del aseguramiento de la calidad [ponencia]. II Foro Internacional Sobre el Aseguramiento de la Calidad de la Educación Superior. http://unired.edu.co/index.php/ calendario/896-ii-foro-internacional-sobre-el-aseguramiento-de-lacalidad-de-la-educacion-superior.

Peña, J. (2010). La concepción filosófica de lo virtual en la educación virtual. Revista Colombiana de Educación, (58), 118-138. 10.17227/01203916.639

Peralta, R. y Mora, J. (2016, noviembre). El abandono en la educación virtual y a distancia: el caso de la Universidad Nacional Abierta y a DistanciaUNAD, Colombia. [Conferencia]. Sexta conferencia latinoamericana sobre el abandono en la educación superior, CLABES. https://ridda2. utp.ac.pa/handle/123456789/6121?show=full 
Pérez, A. (2020, mayo 4). La educación básica y media en la era del coronavirus. Razón Pública. https://razonpublica.com/la-educacionbasica-media-la-del-coronavirus/

Ponce, H., López, M., Labra, J., Brugerolles, J. y Tirado, C. (2007). Evaluación experimental de un programa virtual de entrenamiento en lectura significativa (E-PELS), Revista electrónica de investigación psicoeducativa, 5(2), 399-432.

Policía Nacional (2019). Código de Ética Policial y Código de Buen Gobierno. https://www. policia.gov.co/control-interno-anticorrupcion/codigoetica-codigo-buen-gobierno

Programa de las Naciones Unidas para el Desarrollo, (1999). Educación. La agenda del siglo XXI. Hacia un desarrollo humano. TM Editores.

¿Qué tanto y cómo usan internet los colombianos? (2016, noviembre 25). EI Tiempo.https://www.eltiempo.com/archivo/documento/CMS-16759068

Rama, C. (2011). Evaluación en la educación no presencial: Desde el paradigma tradicional de evaluar procesos de enseñanza (indicadores educativos) a modelos emergentes de evaluación del aprendizaje (competencias adquiridas). https://www.academia.edu/5279215/

Raposo-Rivas, M. y Salgado-Rodríguez, A. (2017). Estudio sobre la intervención con software educativo en un caso de TDAH. Revista de Educación Inclusiva, 8(2), 121-138.

Ramírez, D., Giraldo, L. y Henao, O. (2015). Diseño y experimentación de una propuesta didáctica apoyada en tecnología multimedial para el desarrollo de habilidades comunicativas en niños con síndrome de Down. Revista Educación y Pedagogía, 11(23-24), 245-261.

Ramírez, J. (2016). La educación transformadora: un camino hacia la ciudadanía. Educare, 20(3), 115-128.

Ramos, C. (2015). Los paradigmas de la investigación científica. Avances en Psicología, 23(1), 9-17. https://doi.org/10.33539/avpsicol.2015. v23n1.167

Reidl L. (2012). El diseño de investigación en educación: conceptos actuales. Investigación en educación médica, 1(1), 35-39.

Riestra, J. (2013). Estadística en la experimentación y evaluación educativas. Ediciones Díaz de Santos. 
Rivera, J. Minelli, J. (2017). El problema ético de la identidad digital en la educación virtual. Revista Iberoamericana de Educación, 75(2), 41-58. https://doi.org/10.35362/rie7522633

Roldán O. e Hincapié C. (1999). Ambientes educativos que favorecen el desarrollo humano. En: Roldán, O., Alvarado, S. V., Hincapié, C. M., Ocampo, E., Ramírez, J. E., Mejía Jiménez, M. R., Ospina, H. F. Educar el desafío de hoy. Editorial Mesa Redonda Magisterio.

Roig, R., Mengual, S. y Suárez, C. (2014). Profesorado, revista de currículo y formación del profesorado, 18(1), 28-41.

Roldan, N. (2005). Comunicación y pedagogía para el arte de aprender. En: A. Sánchez (ed.), Educación virtual: reflexiones y experiencias, (pp. 72-94). FUCN.

Romero, A. (2016). Software matemático en el aprendizaje de cálculo para estudiantes de la Universidad Nacional Intercultural de la Amazonía. Repositorio de Revistas de la Universidad Privada de Pucallpa, 1(3), 46-49. https://doi.org/10.37292/riccva.v1i03.38

Romero, A. y Garay, U. (2017). Aprendizaje colaborativo a través de redes sociales en contextos universitarios. Edutec. Revista Electrónica de Tecnología Educativa, (62), 62-72. https://doi.org/10.21556/ edutec.2017.62.999

Rosanigo, Z., Bramati, P., López de Munain, C., Bramati, S. y Cotti, L. (2016, abril). TIC y Objetos de Aprendizaje en el Ámbito Educativo [Ponencia]. XVIII Workshop de Investigadores en Ciencias de la Computación (WICC 2016, Entre Ríos, Argentina). http://sedici.unlp.edu.ar/ handle/10915/53321

Rueda, R. (2011). De los nuevos entramados tecnosociales: emergencias políticas y educativas. Folios, (33), 7-23.

Rúgeles, P., Mora, B. y Metaute, P. (2015). El rol del estudiante en los ambientes educativos mediados por las TIC. Revista Lasallista de Investigación, 12(2), 132-138.

Sabariego-Puig, M., Vilà-Baños, R. y Sandin-Esteban, P. (2014). El análisis cualitativo de datos con ATLAS TI. REIRE. Revista d'Innovació $i$ Recerca en Educació, 7(2), 119-133. 
Salazar, H. (2020, marzo 25). Parece que después de la pandemia nada será como antes. El Colombiano. https://www.elcolombiano.com/ opinion/columnistas/parece-que-despues-de-la-pandemia-nadasera-como-antes-KN12685593

Sánchez, J. (2019). Currículo y vivencia. Aporía. Revista Internacional de Investigaciones Filosóficas, (16), 51-61. https://doi.org/10.7764/ aporia.16.663

Sánchez, J. (2011). Ingeniería pedagógica, nuevo desafío para los objetos de aprendizaje. Ciencia e Ingeniería, 32(1), 105-114.

Sánchez, R., Costa, O., Mañoso, L. Novillo, M. y Pericaho, F. (2019). Orígenes del conectivismo como nuevo paradigma del aprendizaje en la era digital. Educación y Humanismo, 21(36), 121-142.

Sancho, T. y Borges, F. (2011). El aprendizaje en un entorno virtual y su protagonista, el estudiante virtual. En: B. Gros (Ed.), Evolución y retos de la educación virtual. Construyendo el e-learning de Siglo XXI (pp. 27-49). Editorial UOC.

Santaella, S. (2018). El docente universitario como promotor de la educación mediada por las tecnologías de información y comunicación libre. In Crescendo, 9(3), 399-415.

Savater, F. (2008). El valor de educar. Ariel.

Servicio Nacional de Aprendizaje. (2019). Código de Ética. http://cepefsena. org/index.php/formacion/pedagogia/134-codigo-de-etica-del-sena

Silva, J. y Romero, M. (2014). La virtualidad una oportunidad para innovar en educación: un modelo para el diseño de entornos virtuales de aprendizaje.Didasc@lia: Didáctica y Educación, 5(1), 1-23.

Sistema Nacional de Información de la Educación Superior. (2016). https:// hecaa.mineducacion.gov.co/consultaspublicas/programas

Sistema Nacional de Información de la Educación Superior. (2018). https:// hecaa.mineducacion.gov.co/consultaspublicas/programas

Sistema Nacional de Información de la Educación Superior. (2020) https:// hecaa.mineducacion.gov.co/consultaspublicas/programas

Suárez, O. (2016). Aproximación al origen de la noción de objeto de aprendizaje: revisión histórico-bibliográfica. INGE CUC, 12(2), 26-40. https://doi.org/10.17981/ingecuc.12.2.2016.03 
Tabares, V., Duque, N. D., y Ovalle, D. (2017). Modelo por capas para evaluación de la calidad de Objetos de Aprendizaje en repositorios. Revista Electrónica de Investigación Educativa, 19(3), 33-48. https://doi.org/10.24320/ redie.2017.19.3.1128

Toll, Y. y Ril, Y. (2013). Aspectos e indicadores para evaluar la calidad de los objetos de aprendizaje creados en la Universidad de las Ciencias Informáticas. RUSC. Universities and Knowledge Society Journal, 10(2), 149-162. http://dx.doi.org/10.7238/rusc.v10i2.1470

Trapero, F., De la Garza García, J. y Castaño, L. (2015). Propuesta para el diseño de un código de ética empresarial basado en la ética kantiana. Cuadernos de Administración, 30(52), 9-19.

Un mes después de haber iniciado las clases virtuales, aún hay niños sin computador o internet. (2020, abril 24). Noticias Caracol. https:// noticias.caracoltv.com/colombia/un-mes-despues-de-haber-iniciadolas-clases-virtuales-aun-hay-ninos-sin-computador-o-internet.

Unigarro, M. (2004). Educación virtual: encuentro formativo en el ciberespacio. Editorial UNAB.

Universidad de Colima (s.f.). El Portal de la tesis. Glosario de términos de uso frecuente en la investigación. https://recursos.ucol.mx/tesis/ glosario_terminos_investigacion.php

Universidad Nacinal de Educación a Distancia. (2009). Código de Conducta de la UNED. https://descargas.uned.es/publico/pdf/respsoc/Codigo_ conducta_UNED.pdf

Vatia. (2018). Código de Ética. https://www.vatia.com.co/Portals/0/pdfs/ codigo-de-etica.pdf

Velandia, H. (2020, abril 20). Cuarentena, festival de corrupción. El Espectador. https://www.elespectador.com/opinion/cuarentena-festival-decorrupcion-columna-915432

Vera, C., Llarena, M., Díaz, M. (2017). Entornos personales como apoyo para el aprendizaje y desarrollo de competencias: experiencia con alumnos de informática. En: Red de Universidades con Carreras en Informática (RedUNCI) (Ed.). XII Congreso de Tecnología en Educación y Educación en Tecnología (TE\&ET, La Matanza 2017). http://sedici. unlp.edu.ar/handle/10915/63431 
Villalonga, C., y Marta, C. (2015). Modelo de integración educomunicativa de'apps' móviles para la enseñanza y aprendizaje. Pixel-Bit. Revista de Medios y Educación, 46, 137-153. 10.12795/pixelbit.2015.i46.09

Villalobos, O., Cornejo, M., Quintana, P., Torres, C. , Ramos, E. (2017). Impacto del uso de software Geogebra en la enseñanza del cálculo diferencial en dos institutos tecnológicos. Pistas Educativas, 39(126), 352-368.

Zamora, D. (2019). Cómo el neoliberalismo reinventó la democracia. Nueva Sociedad, (282), 148-155. 
Esta obra ofrece una reflexión sobre la educación virtual tecnológica, profesional y de posgrado basada en una juiciosa investigación que, con datos cualitativos y cuantitativos, entrega panorama y perspectivas sobre la ética y la calidad. Asimismo, expone retos, dificultades y fortalezas que surgieron debido a la pandemia causada por la COVID-19, que generó que muchas universidades impartieran clases virtuales sin ninguna preparación.

En los capítulos que componen este libro, el lector encontrará temas como antecedentes y tendencias tecnopedagógicas, referentes sobre códigos de ética, perspectivas de los involucrados y lecciones aprendidas.
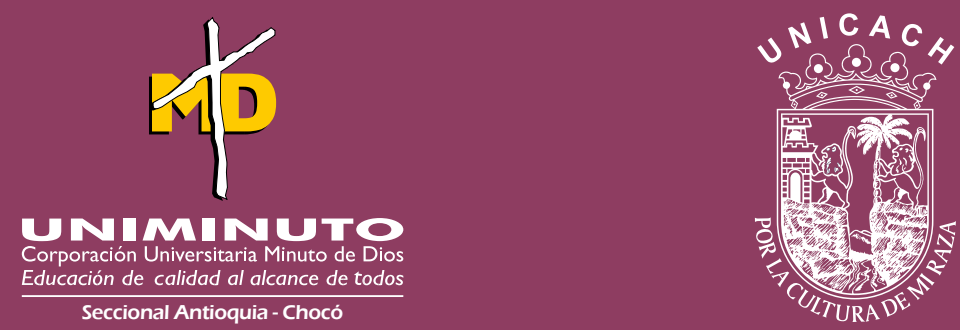

Bogotá, D. C. Calle 81B №.72B - 70

Teléfono $+(57) 1-2916520$

www.uniminuto.edu 